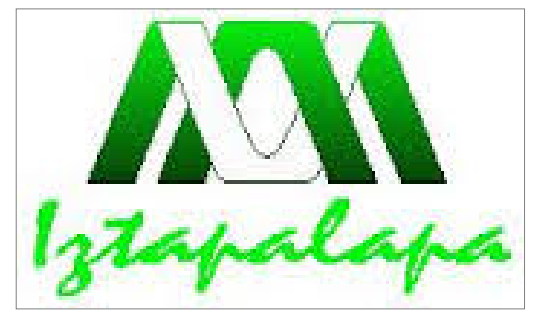

\title{
Consideraciones teóricas y metodológicas de las escrituras académicas y la reflexividad en estudiantes de nivel superior
}

Tesis que para obtener el grado de Doctor en Humanidades en la línea de Lingüística en la Universidad Autónoma Metropolitana Iztapalapa presenta el

\section{M. en C. Ernesto Hernández Rodríguez}

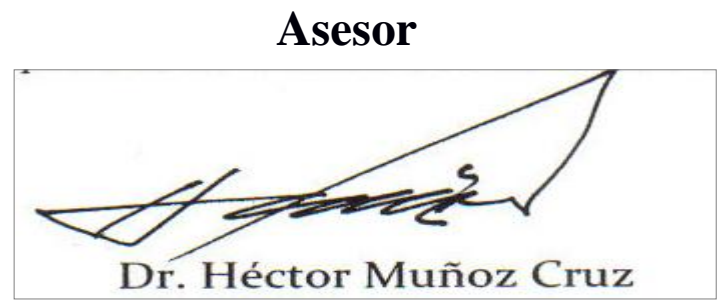

Posgrado en Humanidades Línea de Língüística

Universidad Autónoma Metropolitana Iztapalapa

México, D.F. 22 de febrero de 2013. 


\section{Consideraciones teóricas y metodológicas de las escrituras académicas y la reflexividad en estudiantes de nivel superior}

\section{Tesis para obtener el grado de Doctor en Humanidades en la línea de Lingüística en la Universidad Autónoma Metropolitana Iztapalapa}

Capítulo I

Ernesto Hernández Rodríguez

Introducción, propósitos y alcances de la investigación

1.1 Introducción a la situación de escritura académica en nivel superior 4

1.2 Propósitos y alcances contemplados en esta investigación $\quad 8$

Capítulo II

Enfoque de la escritura académica en la educación superior

2.1 Revisión y algunas reflexiones sobre estudios de escritura en ambiente académico 13

2.2 Algunos antecedentes sobre los conceptos de reflexividad e intencionalidad. 17

2.3 Propuesta de construcción conceptual sobre la reflexividad e intencionalidad 23 en la escritura académica

2.3.1. Textualizar 24

2.3.2 Intencionalidad $\quad 25$

2.3.3 Reflexividad 30

2.4 Enfoque y propuesta de estándares de textualidad 39

2.4.1 El posicionamiento de enunciación y las relaciones de referencia textual 43

2.5 Hacia la aplicación de una propuesta de modelo de caracterización y análisis textual 47

Capítulo III

Propuesta metodológica para la elicitación y la caracterización de los textos

3.1 Sobre el enfoque y perspectivas de la elicitación. 51

3.2 Primeros criterios para la toma de decisiones en la fase de elicitación 53

3.3 Fase de elicitación 1: Universidad Autónoma Metropolitana Iztapalapa 54

3.4 Fase de elicitación 2: Universidad Pedagógica Nacional en Ixtepec, Oaxaca 65

3.5 Fase de elicitación 3: Universidad Pedagógica Nacional en Tehuantepec, Oaxaca 69

3.6 Fase de elicitación 4: Universidad Intercultural de Chiapas 73

3.7 Sobre los alcances y limitaciones del diseño de la interacción para la elicitación. $\quad 83$

3.8 Criterios metodológicos para la identificación de los textos y la transcripción $\quad 87$ 
3.8.1 Criterios de identificación: folios $\quad 87$

3.8.2 Criterios de transcripción textual 88

3.9 Decisiones sobre la restricción de la muestra para la construcción del corpus $\quad 90$

3.10 Caracterización general de los textos 91

3.10.1 Sobre los comentarios como autores, jueces y decisiones de edición $\quad 92$

3.11 Consideraciones sobre la aplicación de los criterios metodológicos 97 de la propuesta de elicitación y caracterización textual.

\section{Capítulo IV}

Criterios metodológicos para la clasificación de los textos

4.1 Pertinencia de crear criterios metodológicos de clasificación textual

4.2 Primeros criterios de clasificación: el género textual y el tema abordado en la interacción y el instrumento empleado

4.3 Clasificación conforme al criterio de tipo de comentario y reflexividad 113

4.4 Clasificación conforme al criterio de temáticas de reflexividad 138

4.4.1 Clasificación de las temáticas predominantes en los textos 139

4.5 Enfoque integral en los criterios de clasificación textual 144

Capítulo V

Reflexividad del alumno como autor y luego como juez

5.1 Tipo de reflexividad como autor y luego como juez

5.2 Temática de reflexividad como autor y luego como juez 152

5.3 Elementos de reflexividad en las reacciones de los autores ante los comentarios recibidos

5.4 Caracterización del tipo y temática de reflexividad como autor y luego como juez

5.4.1 Comentarios generales y prescriptivos a reflexividad parcial sobre la actividad desarrollada

5.4.2 Comentarios generales y prescriptivos a reflexividad compuesta sobre la actividad desarrollada

5.4.3 Reflexividad parcial a reflexividad parcial sobre la actividad desarrollada

5.4.4 Reflexividad parcial a reflexividad compuesta sobre la actividad desarrollada

5.4.5 Reflexividad compuesta a generalidades sobre la actividad desarrollada

5.4.6 Reflexividad compuesta a parcial sobre la actividad desarrollada

5.4.7 Reflexividad compuesta a reflexividad compuesta sobre la actividad desarrollada 


\title{
Consideraciones teóricas y metodológicas de las escrituras académicas y la reflexividad en estudiantes de nivel superior
}

\author{
Tesis para obtener el grado de Doctor en Humanidades en la línea de \\ Lingüística en la Universidad Autónoma Metropolitana Iztapalapa
}

Ernesto Hernández Rodríguez ${ }^{1}$

\section{Capítulo I \\ Introducción, propósitos y alcances de la investigación}

\subsection{Introducción a la situación de escritura académica en nivel superior}

La escritura académica en el nivel superior involucra una multiplicidad de aspectos, situaciones comunicativas y actores que implican un reto de estudio para la investigación educativa en México, precisamente porque la variedad en las distintas realidades institucionales y las prácticas son complejas en su caracterización. De hecho, sería imposible establecer la existencia de criterios uniformes sobre los programas de estudio, el papel de la redacción y la interacción académica por escrito en las diversas instituciones públicas y privadas, enfoques, modalidades, perfiles $\mathrm{y}$, principalmente, sobre las actividades involucradas en la expresión escrita. Establecer un diagnóstico general sobre las prácticas académicas escritas en la educación superior es un reto mayor que implica un esfuerzo complejo que requeriría una inversión gubernamental con una propuesta educativa y un presupuesto considerable, evidentemente esto está lejos del alcance de esta

\footnotetext{
${ }^{1}$ Ernesto HeRo. correo electrónico: ernestotem@live.com.mx
} 
investigación. A pesar de esta imposibilidad actual de tener una caracterización documentada sobre la realidad de la expresión escrita en México, en las prácticas cotidianas podemos advertir que uno de los problemas a los que nos enfrentamos todos los actores del nivel superior es la expresión escrita que posibilite plasmar el pensamiento mediante la redacción y la comunicación en un ambiente académico que permita la interacción. De esta manera, la escritura académica involucra a los actores, incluidos los alumnos, los docentes, las autoridades, la institución, y también, las diversas modalidades de géneros textuales, el tipo de comunicación, las prácticas y la interacción. No basta el desarrollo de habilidades lingüísticas encaminado a escribir con propiedad en la universidad, además, los actores requerimos construir las relaciones de interacción para el establecimiento de la comunicación en la multiplicidad de prácticas académicas. El punto es considerar de qué manera esta realidad está conformada en cada una de nuestras instituciones.

Otro aspecto que de manera general podemos advertir es que en la mayoría de nuestros ambientes académicos en la educación superior la redacción no se concibe como un elemento fundamental para la construcción gradual de conocimiento en las distintas disciplinas. Esta situación sobre el papel de la redacción en el nivel superior se presenta en la mayoría de los contextos, en instituciones públicas, privadas, en universidades con alumnos bilingües o monolingües, indígenas o no indígenas. Es una realidad que caracteriza al sistema educativo actual en México. En muchos casos, se considera que los alumnos que llegan a la licenciatura ya saben redactar y el docente se dedica exclusivamente a su disciplina, de manera tal que el alumno se las arregla como puede para resolver las problemáticas que implica responder a las exigencias académicas de redacción. Asimismo, una gran mayoría de docentes también tiene dificultades en la expresión escrita y son escasos los programas de capacitación sobre este punto, ya que se da prioridad a la actualización disciplinar sobre la materia. Ante esta realidad el docente se centra en la enseñanza de los contenidos de la materia.

En México existen distintas modalidades de universidades. En una clasificación general distinguimos las públicas y las privadas y, por otra parte, las que tienen población monolingüe hablante del español o bien bilingüe, principalmente, con hablantes de una lengua indígena y el español. En general en cualquiera de las modalidades de 
universidades en México, los productos de los estudiantes presentan múltiples problemáticas sobre la redacción, mismas que incluyen el manejo de los recursos para plasmar por escrito las ideas en la toma de decisiones, por ejemplo, sobre la estructuración, el lenguaje empleado, el contenido, la distribución de las ideas, la construcción de interlocutores, la coherencia, la cohesión, así como las valoraciones comunicativas y sociales sobre la pertinencia, la aceptabilidad y la eficiencia en el contexto del escrito. Los alumnos se enfrentan a la dificultad para concebir a sus interlocutores y para el reconocimiento de la diversidad de géneros textuales. Tienen que identificar el contexto de uso de los textos en ambientes académicos e interactuar en una comunicación escrita que en gran parte les es ajena. El alumno se enfrenta a un conjunto de dificultades y retos sobre los complejos procesos de textualización e interacción que implica la redacción de textos académicos.

En el caso concreto de la situación de las universidades con población bilingüe indígena en México podemos apreciar diversos contextos y realidades, por una parte, las instituciones donde asisten alumnos bilingües indígenas que se incorporan a la dinámica e interacción monolingüe, donde tienen que interactuar y escribir en español, resolviendo sus dificultades de expresión escrita para poder incorporarse satisfactoriamente al tipo de interacción que demanda la comunicación académica. La institución no tiene un proyecto sobre este tipo de alumnos, y en muchas ocasiones el indígena bilingüe pasa desapercibido y está asimilado o incorporado a la interacción predominante, en el caso más desfavorable este alumno fracasa por las dificultades comunicativas relacionadas, principalmente, con el manejo del español en ambiente académico. Por otra parte, existen universidades con población bilingüe indígena de uno o varios grupos étnicos que interactúan y emplean sus lenguas originarias en la comunicación cotidiana, y que en la comunicación académica oral y escrita emplean el español. De reciente creación, tenemos en México el modelo de universidad intercultural, que incluye en sus programas la interacción académica en las lenguas indígenas en los programas de enseñanza de lenguas originarias, el español y, además, otras lenguas en el entorno de comunicación intercultural, como las lenguas extranjeras. La interculturalidad es una propuesta en construcción que involucra la interacción cultural y lingüística en el marco de la comunicación y la globalización con 
énfasis en el rescate del aspecto regional.

Existe la necesidad de hacer investigación sobre las prácticas de escritura de los alumnos, tanto monolingües como de los bilingües indígenas, y de esta manera caracterizar, por ejemplo, el tipo de recursos empleados y las prácticas por escrito en el entorno académico, y, en el marco contextual de las instituciones, el tipo de interacciones, las problemáticas enfrentadas y las formas en que los alumnos dan soluciones a su desempeño en la interacción cotidiana. No basta simplemente hacer una caracterización de los recursos formales del desempeño, además, es necesario contemplar la manera en que los alumnos, por ejemplo, interactúan y reflexionan por escrito sobre su experiencia de redacción en situaciones cooperativas, en este caso, en las prácticas de revisión y edición de textos entre compañeros al asumir los roles de autores y jueces con la idea de mejorar sus escritos.

Esta perspectiva permite considerar la reflexión de los actores sobre diversos aspectos relacionados con su desempeño en el contexto académico, de esta forma es posible plantear el reto de construir el concepto de reflexividad sobre los procesos de redacción en el marco de un enfoque del estudio de la textualidad, para lograr la caracterización de la intencionalidad de los alumnos en su expresión escrita, en la textualización como un proceso integral que involucra no sólo los recursos formales, sino también los contextuales, culturales, de identidad y construcción de géneros textuales y de conocimiento, identidad interacción y comunicación. Este tipo de enfoque puede cobrar relevancia cuando se lleva a cabo a partir de muestras concretas de escritura académica, porque de este modo es posible crear categorías de análisis y criterios de interpretación sobre las prácticas concretas de escritura. Este tipo de mirada hacia los textos constituye una visión del estudio de la textualidad. Esto implica crear situaciones y diseños de interacción para la elicitación desde una perspectiva de la etnografía de la comunicación, en este caso, de las prácticas que favorezcan la reflexión de la escritura sobre el desempeño propio y el de los compañeros en ambiente académico.

En este panorama es fundamental desarrollar una propuesta de estudio del enfoque de escrituras académicas con un énfasis en los elementos de reflexividad y la intencionalidad presentes en la interacción comunicativa, así como una atención especial en los criterios metodológicos para la elicitación, la clasificación de los textos para la 
construcción de un corpus de trabajo y la interpretación de las muestras de escritura académica.

\subsection{Propósitos y alcances contemplados en esta investigación}

En este trabajo presento un estudio teórico de un enfoque de los elementos de la escritura académica en nivel superior, y, por otra parte, contemplo aspectos metodológicos de acceso a la producción de muestras de escritura académica, la clasificación y la interpretación de los textos. A partir de estos intereses me planteo como objetivos

Desarrollar una propuesta teórica de enfoque de la escritura académica desde la perspectiva de los aspectos de la reflexividad y la intencionalidad en la interacción comunicativa en torno a las prácticas de revisión y edición de textos de alumnos universitarios en la línea de análisis de textos académicos, desde una perspectiva del estudio de la textualidad.

Y por otra parte me propongo presentar una discusión y propuesta de criterios metodológicos de elicitación, clasificación textual y los primeros acercamientos a la interpretación de las muestras de escritura académica, como parte de un diseño construido con la idea de estudiar las evidencias de reflexividad, presentes en los escritos de alumnos de distintas universidades que participaron en prácticas de revisión y edición de textos ${ }^{2}$. Asimismo presento de manera panorámica evidencias ejemplares de textos representativos que manifiestan algún tipo de reflexividad. La reflexividad y la intencionalidad están siempre relacionadas y son elementos fundamentales de la comunicación.

Contemplo así un interés conceptual dual con interrelaciones fundamentales teóricas y metodológicas. La construcción teórica conceptual para un enfoque de la escritura académica desde la perspectiva de la reflexividad y la intencionalidad involucra

\footnotetext{
${ }^{2}$ Realicé este diseño como parte del trabajo conjunto que desarrollamos los integrantes del Proyecto Conacyt 99274. "Dominio lingüístico y académico de estudiantes bilingües indígenas en universidades de México: habilidades comunicativas y académicas, reflexividad, sociolingüística y políticas interculturales del lenguaje" a cargo del Dr. Héctor Muñoz Cruz, investigador del Doctorado en Linguiística de la Universidad Autónoma Metropolitana Iztapalapa. Desarrollamos las sesiones con alumnos de la Universidad Pedagógica Nacional, Planteles Ixtepec y Tehuantepec, de la Universidad Intercultural de Chiapas y de la UAM Iztapalapa.
} 
una mirada integral de los diversos elementos contextuales de la comunicación escrita, que indudablemente son fundamentales en una propuesta de discusión metodológica sobre la elicitación, la clasificación textual y la interpretación

En este trabajo presento muestras ejemplares de textos de distintos tipos de poblaciones de alumnos, y por ende, de las evidencias textuales, ya que por un parte contemplé una universidad monolingüe (Universidad Autónoma Metropolitana Iztapalapa), dos bilingües indígenas de Oaxaca (Universidad Pedagógica Nacional, Planteles Ixtepec y Tehuantepec) y una institución bilingüe intercultural (Universidad Intercultural de Chiapas). Ocupo las muestras de escritura académica como evidencias ejemplares que me ayudan a caracterizar algunos elementos de reflexividad y para la discusión de los procedimientos de elicitación e interpretación. Tan solo muestro evidencias ejemplares de cada universidad y no me centro en hacer estudios de caso, ya que el centro de mi investigación es la discusión sobre un enfoque teórico de la reflexividad y los criterios metodológicos de elicitación, clasificación e interpretación.

En el diseño metodológico de elicitación que fui construyendo a lo largo de la investigación en las interacciones desarrolladas en las universidades mencionadas, los alumnos asumieron el rol de jueces que revisarían el texto de uno de sus compañeros e hicieron comentarios y sugerencias por escrito, con el fin de que el autor modificara su texto con la idea de mejorarlo. Destaco a partir de los escritos de los alumnos, experiencias de revisión, comentarios, sugerencias, decisiones de textualización, y las valoraciones expresadas por los alumnos al asumir el papel de jueces, y, por otra parte, la manera en que el autor reacciona y valora los comentarios recibidos para editar su texto, con la intención de mejorarlo.

En mi revisión teórica y de discusión metodológica me apoyo en las evidencias ejemplares de muestras de escritura académica desde una perspectiva panorámica a partir de la interacción en el aula. Sobre la discusión metodológica relacionada con la elicitación, no pretendo hacer un seguimiento o secuencia didáctica, ni tampoco centrarme en determinado aspecto concreto del análisis de la reflexividad, el interés es mostrar y caracterizar las diversas manifestaciones reflexivas sobre los aspectos de la experiencia de redacción en la interacción de revisión y edición de los textos a partir de lo que los alumnos 
desearon expresar en sus escritos. Así, la propuesta de elicitación se basa en generar interacciones que permitan que los alumnos se expresen sin imposiciones ni condicionamientos arbitrarios. De hecho, los temas de la interacción contemplados en las sesiones de interacción están centrados, en la medida de lo posible, en las prácticas comunicativas de reflexión sobre la lengua, y, en el caso del diseño de elicitación en la Universidad Intercultural de Chiapas, el tema corresponde a las escrituras propias y las de otros alumnos, precisamente para motivar la reflexión sobre las experiencias de redacción académica. Este diseño final fue el resultado de las revisiones y adaptaciones en un proceso que comenzamos en las interacciones de elicitación con alumnos de la Universidad Autónoma Metropolitana Iztapalapa, mismo que continuamos en la Universidad Pedagógica Nacional en Oaxaca.

Para llevar a cabo esta investigación es necesario contemplar una reflexión teórica y una construcción conceptual sobre la reflexividad en el ámbito del enfoque de la textualidad. Por ello, realizo una propuesta integral para caracterizar, en primer plano, el concepto de reflexividad, y además los conceptos fundamentales asociados a ella: la textualización y la intencionalidad, en el marco de las prácticas de escritura académica. Contemplo la perspectiva del estudio de la textualidad, misma que involucra el conjunto de relaciones presentes en la construcción de un texto y, además, las decisiones en el manejo de recursos de expresión escrita que los autores ponen en juego al plasmar sus ideas por escrito, por ejemplo, aspectos intra y extratextuales, la construcción de interlocutores, el contexto y los principios constitutivos y regulativos del proceso de escritura. Considero, como referentes teóricos de partida y discusión, los enfoques de la textualidad iniciados en las perspectivas de Beugrande \& Dressler (1997) y Adam (2005) debido a que contemplan la mayor parte de las consideraciones arriba mencionadas sobre la conformación y funciones de un texto, el autor y los interlocutores.

Propongo hacer una caracterización de los conceptos de textualización e intencionalidad en el marco de las prácticas de escritura como enfoque para estudiar los textos. Considero que la reflexividad y la intencionalidad son aspectos fundamentales de la comunicación, y están presentes en la toma de decisiones, en las regulaciones y las valoraciones de los autores y los jueces sobre el desempeño escrito en ambiente académico 
en distintas modalidades y facetas de reflexión.

Estos aspectos de reflexividad involucran, además de los elementos constitutivos de un texto, por ejemplo, coherencia y cohesión, los elementos contextuales, personales, sobre las percepciones del conocimiento y la construcción de significados e identidad en relación a lo que cada alumno expresa sobre lo que le implica, significa o representa la práctica de redacción, revisión y edición de un texto al asumir los roles de autor y juez.

La reflexividad sobre la textualización puede incluir otros aspectos diversos, tales como lo cognitivo, lo afectivo, la inseguridad, el prestigio, criterios sobre el desempeño lingüístico y las actitudes ante dificultades enfrentadas en la redacción. En este estudio tan solo presento evidencias ejemplares de reflexividad que manifiestan los alumnos sobre el ejercicio de revisión y edición desarrollados en el aula, como parte de las consideraciones teóricas y de metodología de elicitación a partir de una propuesta de categorías temáticas y de intencionalidad presentes exclusivamente en los textos de los alumnos, sin pretender imponer modelos o que el alumno deba expresar la múltiple gama de aspectos de posibles reflexividades determinadas. En esto radica el análisis de la textualidad con una propuesta etnográfica desde la perspectiva de Lea \& Street (1998).

Presento el desarrollo metodológico para el diseño de la interacción en la fase de elicitación para obtener los escritos de los alumnos en la Universidad Intercultural de Chiapas. Además, expongo el proceso gradual que me llevó a la construcción de este diseño de elicitación durante los sondeos realizados en la Universidad Autónoma Metropolitana Iztapalapa y la Universidad Pedagógica Nacional Ixtepec y Tehuantepec, Oaxaca como primeros intentos en una fase de elicitación exploratoria para tener los primeros acercamientos con alumnos y comenzar la construcción y toma de decisiones metodológicas. Además, presento el proceso de la construcción de los criterios teóricos y metodológicos a partir de los datos observados en los textos obtenidos en las fases de elicitación.

Como criterio metodológico para la elicitación, la clasificación textual y la interpretación, evito hacer valoraciones normativas y prescriptivas sobre los recursos de redacción de los alumnos, tampoco pretendo hacer interpretaciones o explicaciones sobre 
las diversas causas del nivel de desempeño o dominio de los recursos de escritura. Por ello, ante las dificultades de redacción afrontadas por los estudiantes y las decisiones de textualización para intentar resolver las problemáticas al redactar y comentar sus propios textos y los de sus compañeros, destaco las evidencias de intencionalidad para caracterizar aquello que el alumno desea, pretende o intenta expresar y la manera en que lo expresa por escrito y la reflexividad manifestada por los mismos estudiantes sobre la experiencia de redacción en la revisión y edición.

Independientemente de la lengua materna del estudiante, la escritura académica requiere de una práctica cotidiana en situaciones comunicativas contextualizadas en un ambiente académico ${ }^{3}$. Por esto evito centrarme en hacer caracterizaciones sobre el nivel de desempeño escrito en español de los alumnos indígenas por su condición de bilingüismo. De esta forma, mi estudio sobre consideraciones teóricas de la escritura académica y metodología de elicitación e interpretación corresponde a muestras representativas ejemplares de la educación superior.

\footnotetext{
${ }^{3}$ En mi trabajo sobre redacción argumentativa de alumnos monolingües hablantes del español de nivel medio superior, muestro que ante las dificultades enfrentadas para organizar un texto argumentativo y abordar el tema, los alumnos por momentos presentan problemáticas en la estructuración gramatical, por ejemplo, en las relaciones de referencia y concordancia de género y número. (Hernández Rodríguez 2003 y 2010). Esto pone de manifiesto que estas problemáticas no son exclusivas de los indígenas, en realidad es un asunto que corresponde al complejo proceso del desarrollo de la práctica escrita en ambientes académicos.
} 


\section{Capítulo II}

\section{Enfoque de la escritura académica en la educación superior}

\section{2.|1 Revisión y algunas reflexiones sobre estudios de escritura en ambiente académico}

El interés por las investigaciones sobre la escritura se consolida con el surgimiento de los estudios de la textualidad como objeto de estudio de la lingüística, en medio de un fuerte debate y polémica sobre la consideración de la escritura como parte de la lingüística. La unidad textual y el complejo conjunto de relaciones involucradas se conforman como objeto de estudio, ya no desde la filosofía del lenguaje, ni desde el análisis del discurso oral. Así nace la línea del análisis de la lingüística textual y con ello un enfoque característico para estudiar las categorías de análisis propias de la textualidad, así como el conjunto de relaciones del texto en su contexto comunicativo y en las prácticas en que cobra vida. En este punto, el trabajo de Beugrande \& Dressler (1997), además de ser el texto clásico fundamental precursor sobre la línea de la textualidad, nos es de utilidad debido al establecimiento de los siguientes estándares de textualidad: cohesión, coherencia, intencionalidad, informatividad, situacionalidad, aceptabilidad, efectividad y propiedad. La mirada a los textos mediante estos principios revolucionó el estudio de la escritura y en particular el conjunto de elementos involucrados por el autor y los interlocutores en la construcción de un texto.

En el área de la descripción y el análisis de los textos el trabajo de Halliday \& Hassan (1976) es un referente fundamental que influyó en el estudio de la cohesión y la coherencia, que ha sido contemplado posteriormente en la caracterización de los recursos de textualización. Los aportes de Adam (1990 y 2005) sobre la lingüística textual nos permiten contemplar la unidad del texto y las relaciones intra y extratextuales en un enfoque que va más allá de un nivel oracional, así, por ejemplo, las relaciones de referencia 
y concordancia pueden ser caracterizadas mediante categorías y unidades de análisis en la complejidad de unidades textuales que conforman un escrito, por ejemplo, en diversos bloques o párrafos, incluyendo las referencias externas al texto. Además, es posible establecer las relaciones de intertextualidad como parte de los análisis a partir de nuevas categorías para estudiar los textos. Sobre la descripción y creación de categorías construidas para el análisis textual encontramos los trabajos de C. Blanche-Benveniste (1998) y Béguelin, M-J (2000).

El estudio de la redacción en ambientes académicos en la educación superior desde una perspectiva de la etnografía en las prácticas cotidianas es un campo que comenzó a desarrollarse en los trabajos de Johns (1997), Lea (1999), Lea \& Street (1998), Scott (1999), Lillis (2001) Street (2009 y 2009b) y Zavala (2009). El enfoque etnográfico proporciona una herramienta metodológica fundamental para interactuar en situaciones que dan relevancia al contexto y la práctica, por ejemplo, en los trabajos de Brice-Heath (1983) y Brice-Heath \& Street (2008). Estos autores proponen metodologías de análisis etnográfico, centradas en los recursos y funciones comunicativas e interactivas mediante el uso de la lengua, tanto en las comunidades de habla como en los entornos escolares desde una perspectiva etnográfica de la literacidad. De esta manera incursionan en la metodología de la etnografía de la comunicación mediante el manejo de la lengua como objeto de estudio en concreto.

Sobre el conjunto de prácticas y los actores involucrados en los contextos y enfoques institucionales Lea \& Street (1998) consideran tres modelos básicos. El primero es el enfoque del desarrollo de habilidades lingüísticas, en el cual se considera que el alumno debe desarrollar un conjunto de destrezas o habilidades diferenciadas, mismas que pueden ser aplicadas y transferidas a distintos contextos, y cuando un alumno no ha desarrollado determinada habilidad deberá ser habilitado para resolver, de manera remedial, ese problema, es decir, la instrucción está diseñada para "arreglar" problemáticas específicas y se hace énfasis en el desempeño no satisfactorio como problemas del individuo que hay que "reparar" en las distintas áreas o habilidades. La crítica a este enfoque se centra en la conceptualización aislada, descontextualizada y normativa del desempeño del estudiante como un problema para resolver y no como un proceso de 
desarrollo gradual en contextos integrales. El segundo modelo corresponde a la socialización académica, en el cual se pretende transmitir a los alumnos un determinado conocimiento de interacción a la cultura de la comunicación académica como elemento fundamental para el desenvolvimiento y socialización en las prácticas e interacciones en la universidad, es decir, la cultura académica. La crítica a este enfoque es que dicha socialización cultural se presenta como un modelo preestablecido, homogéneo y que contempla contextos muchas veces alejados de las perspectivas, por ejemplo, interculturales y de las relaciones sociales e institucionales en las múltiples realidades y áreas de conocimiento. El tercer nivel corresponde a la propuesta de literacidad académica, con un centro de interés en las prácticas sociales y las relaciones establecidas entre los diversos actores involucrados, alumnos, docentes, instituciones, autoridades y las relaciones de poder e interacción, así como las fuerzas sociales y culturales en la comunicación escrita. Enfatiza, además, las prácticas de escritura en el nivel epistemológico y de la construcción de significados e identidad mediante la variedad de modalidades comunicativas, géneros textuales, contextos, repertorios lingüísticos, situaciones y dominios comunicativos.

Los enfoques sobre el análisis de la textualidad y literacidad académica en el conjunto de prácticas de redacción han llevado a cuestionar, principalmente, el modelo de habilidades lingüísticas y el concepto de textualización. De manera general textualizar ha sido considerado como el proceso de plasmar las ideas en el código del texto escrito, mediante la toma de decisiones sobre el manejo de recursos formales, semánticos, morfosintácticos y en la conformación de la coherencia y la cohesión manifestada en la representación gráfica lineal del texto. En otras perspectivas la textualización ha sido vinculada a procesos cognitivos y psicolingüísticos involucrados en la construcción de habilidades de redacción y en las fases del proceso de conformación de la unidad textual, que proponen, principalmente, por Flower \& Hayes (1980 y 1981). En el plano de la didáctica, la textualización ha sido contemplada como el proceso de planificación de la unidad y estructura textual, principalmente, en la línea de las teorías procesuales con aplicación en las secuencias didácticas propuestas, por ejemplo, por Camps (1990 y 1995). En este campo surge la discusión sobre la no linealidad del proceso de composición y textualización y su naturaleza recursiva, y el desarrollo de secuencias didácticas lineales en 
los procedimientos y contenidos en las distintas etapas del proceso para resolver problemáticas de redacción. Además, estos enfoques de la textualización enfrentan la crítica sobre la prescripción de procedimientos y fases didácticas, que en determinadas situaciones no funcionan por los distintos modos de aprendizaje de los individuos en diversos contextos, además del impacto de las recientes propuestas de regulación del autoaprendizaje, las realidades interculturales de la comunicación y las distintas formas de aprender.

En general, podemos advertir que en estos diversos enfoques de textualización el énfasis está puesto en el manejo de recursos y habilidades correspondientes a la redacción y a la construcción formal de la unidad textual. Es necesario construir un enfoque integral sobre el concepto de textualización, que, además, ponga en juego el conjunto de elementos contextuales, interactivos y las prácticas.

Por otra parte, Ivanič (1998) incorpora el estudio de la construcción de identidad, fundamentalmente en las relaciones que establece el autor del texto con su propia representación formal o textual, personal y vivencial sobre su postura y actitud al posicionarse ante su propio escrito, la representación y construcción de sus interlocutores, los recursos expresivos y la anticipación de múltiples posibilidades de recepción de su texto en un ambiente contextualizado que le permite construir significados e identidad en la comunicación.

Sobre estudios relacionados con la caracterización y descripción de actividades de escritura escolar predominan los enfoques sobre aplicaciones didácticas en los niveles básicos escolares, por ejemplo, en los trabajos de Bilguer (1995), Perelman (2001), Zammuner (1991), Rubio y Arias (2002) y en el caso de alumnos de bachillerato el trabajo de Dellerman, Coirier y Merchand (1996) sobre secuencias didácticas para argumentar. En concreto sobre estudios de prácticas de revisión de textos en ambientes escolares a partir de secuencias didácticas y del análisis de interacciones orales y muestras de escritura de adolescentes aparecen los trabajos de Camps (1992), Camps \& Milian (2000), quienes abordan una perspectiva de conocimiento del proceso de aprendizaje y actividad metalingüística. En esta misma línea Ribas Seix (2001) incorporó el estudio de pautas de regulación en la revisión y edición textual. 
Un terreno aún poco explorado en los distintos niveles educativos y, principalmente, en el nivel superior, corresponde a la investigación sobre el análisis de los recursos de escritura, la textualidad y las prácticas de revisión y edición textual con un centro de interés en las decisiones y en la intencionalidad manifestada en las versiones de los escritos de los alumnos. Podemos apreciar una propuesta de caracterización de recursos de escritura académica a partir del análisis de la intencionalidad argumentativa en los textos de alumnos de bachillerato en Hernández Rodríguez (2003 y 2010). En nivel superior aparecen trabajos sobre caracterizaciones diagnósticas de la escritura de alumnos, por ejemplo, los trabajos de Carlino (2004 y 2006), Fragoso Peralta (2007), Desinano (2009) y Serrano de Moreno et al (2012) y, por otra parte, Patiño Garzón (2006) hace este tipo de diagnóstico para estudiar la escritura de los profesores.

En el nivel básico y en una metodología de la observación y reflexión docente sobre la escritura en actividades escolares, Galaburri (2000) estudió las prácticas de revisión y edición textual en las tomas de decisiones interactivas de los alumnos para escribir un texto y reelaborarlo en las distintas versiones requeridas para cumplir con el objetivo comunicativo correspondiente a la tarea asignada ${ }^{4}$, y en la misma línea en nivel medio superior Camps Melgar (2009) estudia las prácticas de regulación, revisión y edición de textos en cursos de inglés como lengua extranjera al analizar la interacción oral y muestras representativas de los textos.

\subsection{Algunos antecedentes sobre los conceptos de reflexividad e intencionalidad.}

Los conceptos de reflexividad e intencionalidad se encuentran en construcción en el campo de la lingüística, son motivo de polémica en los años recientes debido a su vinculación con diversos campos de estudio, por ejemplo, la filosofía del lenguaje, el análisis del discurso, la psicología y la didáctica. Indudablemente la reflexividad y la

\footnotetext{
${ }^{4}$ En este estudio, Galaburri (2000) analizó la actividad de una profesora que motivó a sus alumnos de primaria a participar en las actividades del día del niño, representando una obra de títeres, para ello les propuso transformar un breve cuento, inventado y escrito por los alumnos, a un texto dialógico correspondiente a una obra de teatro para ser representada con títeres. En este caso el diseño elaborado no se focaliza en la aplicación didáctica sino en la observación y análisis textual de las prácticas de edición y revisión.
} 
intencionalidad son elementos entrelazados fundamentales de la comunicación. En virtud de que la construcción de estos conceptos inicialmente se vincula a disciplinas distintas a la lingüística, principalmente la filosofía del lenguaje, considero necesario hacer una revisión sobre los referentes teóricos y conceptuales de las distintas áreas del conocimiento relacionadas con el tema, en las que me apoyo para la construcción conceptual de la reflexividad sobre los procesos de textualización en esta investigación.

El concepto de intencionalidad ha sido abordado desde diversas perspectivas en distintas épocas y enfoques teóricos y filosóficos desde la Antigüedad hasta nuestros días. La distinción entre intención e intencionalidad tiene una frontera difícil de establecer en distintas propuestas y de acuerdo al objeto de estudio o análisis y la disciplina en cuestión, fundamentalmente, la filosofía, la hermenéutica, la retórica, el derecho, el análisis del discurso y, para el interés de este trabajo, la lingüística textual. Además del significado práctico y cotidiano de la palabra intención, como el propósito de hacer algo, han existido diversas acepciones y matices, por ejemplo, la intención o intentio, en tiempos de la Grecia clásica y hasta la Edad Media con las acepciones, por ejemplo, de deseo, voluntad, conocimiento y percepción. Además, la intención o lo intencional ha estado asociado a diversos temas como la relación entre el objeto y la consciencia, las interpretaciones, las subjetividades, la verdad, lo psíquico, las motivaciones, lo psicológico y los usos del lenguaje.

Sobre la complicada distinción entre la intención y la intencionalidad, en la filosofía desde los trabajos de Husserl (1901 \& 1913), Brentano (1960) y Anscombre (1965) y, en el campo de la filosofía del lenguaje, por ejemplo, Peirce (1868) y Wittgenstein (1953), el debate sobre la intención se ha centrado, principalmente, en el ámbito de lo mental, lo que en épocas posteriores se ha denominado como la consciencia del objeto, con sus múltiples posibles interpretaciones, por ejemplo, intuición, conocimiento, voluntad y deseo. ${ }^{5}$ Por otra parte, el término técnico filosófico de la intencionalidad ha sido asociado a la representación del objeto mental o de conocimiento y por ello está situado en el nivel de la conducta o el lenguaje. De esta manera, la intención como acto mental es anterior a la

\footnotetext{
${ }^{5}$ Para ampliar el estudio detallado sobre la historia y evolución del concepto de la intención y la intencionalidad en las distintas áreas del conocimiento desde la Antigüedad hasta nuestros días consultar Paredes Martín (2007).
} 
intencionalidad, por ello no existe intencionalidad sin intención previa ${ }^{6}$. Desde esta perspectiva la intencionalidad podría contemplarse como la manifestación o realización de una intención, es decir, de una toma de consciencia determinada. A principios del Siglo XX, Husserl (1901 y 1913) incorpora los conceptos de noesis y noema en la conciencia intencional, así la conciencia no es una entidad vacía, es en el acto intencional (noesis) o intencionalidad una relación con el objeto intencional (noema) o intención.

La toma de consciencia de una intención, como un aspecto mental, ha sido tema de debate por tratarse de un conocimiento que puede estar conformado como una intuición. Peirce (1868) abordó este tema sobre la relación entre intuición, conocimiento y consciencia al contemplar que no siempre podemos estar seguros de que alguien tome consciencia de sus intenciones conformadas por intuiciones, es decir, pensamientos o conocimientos que no son aún claros o no están del todo construidos o conformados en la mente de un individuo. Finalmente, la intención individual y personal conformada por una intuición puede no llegar a la conciencia plena, precisamente porque la intuición es un conocimiento en etapa de gestación. Esta discusión es relevante para proponer una de las caracterizaciones de la reflexividad, precisamente porque ésta puede estar conformada por intenciones o motivaciones en una faceta de intuiciones como una reflexividad inferencial o bien concepciones o conocimientos consolidados, internalizados y conscientes. Así, la reflexividad es la manifestación de los diversos tipos, modalidades y facetas del pensamiento y conocimiento reflexivo.

La intención, como acto mental complejo, puede exteriorizarse, representarse o expresarse en una acción determinada, pero el hecho de que exista una intención no lleva a la existencia de una acción externa o acto de lenguaje concreto y observable. Asimismo, la manifestación o acto intencional puede, en determinados casos, no corresponder a la intención mental del individuo, de manera que alguien puede decir que lo que hizo no era su intención o que no se siente mal por lo que hizo, pero sí por la intención que tenía o bien decir que "la intención es lo que cuenta" cuando algún interlocutor le manifiesta que no comprende, por ejemplo, lo que desea expresar en su escritura. Es aquí donde la

\footnotetext{
${ }^{6}$ García Elskamp (1986: 47) desarrolla la distinción clásica de la dualidad de la intención como acto interno mental e intencionalidad como representación del objeto en la conducta observable y en el lenguaje.
} 
intencionalidad cobra relevancia como la representación concreta de lo intencional en el lenguaje. Son múltiples y complejos los factores que motivan una intención y su posible manifestación en la intencionalidad comunicativa, por ejemplo, las razones, las causas, las justificaciones, los deseos y la necesidad expresiva ${ }^{7}$.

Así, a partir de las concepciones de Anscombre (1965) y Brentano (1960) la intención es una cuestión de nivel mental, privada, personal y que podríamos tener acceso a ella, por ejemplo, al preguntarle directamente al individuo cuál es o era su intención, en el supuesto de que éste desee o pueda explicitar el acto mental intencional. Entonces, la manifestación de la intención mediante una conducta o lenguaje da vida a la acción, misma que posee determinada intencionalidad. En principio, tal como apuntan Anscombre (1965) y Brentano (1960) la intención como acto mental es personal, individual y no observable, es decir, no podemos conocer cuáles son las intenciones de las personas por ser actos mentales, pero podemos llegar a percibir y apreciar la intencionalidad en determinadas facetas en lo externo, la conducta, las acciones y, principalmente, en el lenguaje.

El tema de la intención o lo intencional y la intencionalidad, merece un estudio especial extenso que escapa a los alcances de esta investigación. Por ello ahora centro mi interés en los aportes de la intencionalidad como criterio de representación del objeto mediante el lenguaje, en concreto desde las perspectivas de los estudios del lenguaje y la textualidad. Es necesario contemplar la intencionalidad y la interpretación desde la postura del autor y del lector, puesto que esta investigación involucra la práctica de redacción y revisión, es decir, del autor y lector que asume el papel de juez y además, comenta por escrito.

En el área de los estudios del lenguaje con aproximación a la linguística, la reflexividad ha sido asociada, por ejemplo, a los estudios sobre representaciones mentales, creencias y actitudes, conceptos que han evolucionado en distintas vertientes desde sus

\footnotetext{
${ }^{7}$ Para García Elskamp (1986: 150) la intención es 1) “el último estadio de un proceso de formación en el que intervienen motivos, deseos, obligaciones; 2) un acto de la mente y, como tal, es interno; 3) puede ser conocido sin observación, aun cuando la intención se puede desplegar en las acciones que en tal caso se llaman "acciones intencionales" y 4) la expresión de una intención queda incluida dentro del grupo de las predicciones en las acciones.”
} 
inicios $^{8}$ y, por otra parte, la intencionalidad sobre la escritura se ha asociado, principalmente, a los enfoques de la interpretación del lector en diversas propuestas teóricas y modelos de análisis ${ }^{9}$. La discusión que ha surgido es el asunto de tener que distinguir, por lo tanto, entre la interpretación de un lector o interlocutor que deja, en muchas ocasiones, de lado la intención sobre aquello que el autor pretendía expresar, por ejemplo, en escrituras con dificultades o ambigüedades debidas al tipo de desempeño de autores no expertos. Así, estudiar la intencionalidad no se limita a contemplar la interpretación del lector, puesto que es necesario el estudio de las relaciones diversas sobre el proceso de construcción textual que experimenta quien escribe en su contexto. Sobre este punto Beuchot (2002) plantea la visión de una interpretación pragmática contextual para intentar recuperar la voz y la intencionalidad del autor ${ }^{10}$.

Recanati (1979 y 2004) y Perry (2001) desarrollan el concepto de reflexividad como la construcción de significados, el primero a partir de la enunciación en torno a la dualidad de opacidad y transparencia del signo lingüístico, y el segundo mediante el estudio de la relación entre referencia y la reflexividad. En el campo de la sociolinguística en contextos de bilingüismo Muñoz Cruz (2010) aporta el estudio de la reflexividad de hablantes indígenas. En una perspectiva de las prácticas del lenguaje en ambiente académico Turner (2012) incorpora la reflexividad cultural en el marco de las dinámicas interculturales.

\footnotetext{
${ }^{8}$ En el campo de la enseñanza de la lengua Horwitz (1987) acuñó el término creencia (beliefs) en un instrumento o batería denominado BALLI (Belief's About Language Learning Inventory), desde una perspectiva que combina aspectos cognitivos y sociolingüísticos. A partir de este trabajo, y predominantemente para la enseñanza de lengua extranjera, se desarrolla la propuesta de la metacognición, donde se considera que quien aprende se cuestiona y reflexiona sobre el funcionamiento lingüístico, el desempeño y la manera en que aprende la lengua, de manera tal que crea representaciones mentales. Este enfoque combina aspectos interactivos y de contexto, pero se centra en su mayoría en aspectos cognitivos y sobre el aprendizaje. Como representantes de esta propuesta podemos mencionar a Nikitina \& Furuoka (2006), quienes reexaminan y critican a Horwitz sobre la necesidad de un trabajo estadístico y la incorporación de los elementos multilingües y contextuales. Otros representantes de este tipo de propuestas son Wenden (1986), Cotteral (1995), Gardner \& Miller (1999), Groult \& Mercau (2002) y Bernat \& Gvozdenko (2005).

${ }^{9}$ Sobre la tradición clásica de la hermenéutica posterior a Heidegger (1988), las propuestas de Gadamer (1973), Derrida (1976), Ricoeur (2003), Rorty (1991), y Ferraris (1998) nos permiten apreciar el enfoque donde el lector interpreta a partir del intento sistemático de reconstruir los aspectos del contexto y del entorno histórico, es decir, en la medida de lo posible poner el texto en su contexto, principalmente cuando dicho texto corresponde a una realidad histórica difícil de reconstruir. Halliday (1978) consideró la interpretación social de la lengua y el significado. Por otra parte, Eco (1979) y Camps (1995) contemplan la posibilidad de analizar aspectos vinculados con cuestiones pragmáticas contextuales donde se rescatan elementos de textualidad, naturaleza dialógica e intertextualidad en situaciones interactivas donde es posible, en algunos casos, contemplar el punto de vista de los autores de los textos.

${ }^{10}$ Beuchot (2002) propone un comportamiento dual en una interpretación analógica en un punto medio entre un nivel subjetivo que permite ir más allá de los límites interpretativos y otro objetivo que impide la dispersión en la multiplicidad de posibilidades interpretativas subjetivas del lector.
} 
Beugrande \& Dressler (1997) no plantean la reflexividad de manera explícita, de hecho, no es el motivo de su estudio, sin embargo, en la consideración de los estándares de textualidad ponen en juego el conjunto de valoraciones sobre el manejo de recursos lingüísticos y comunicativos, así como las regulaciones de los desempeños del autor y el lector presentes en la construcción del texto en un contexto específico. Esto involucra de algún modo un tipo de toma de consciencia o reflexión sobre la construcción del texto.

La consideración de la intencionalidad como estándar de textualidad, considerada por Beugrande \& Dressler (1997) implica un nivel de reflexión tanto del autor como del lector que va más allá de una simple interpretación, puesto que involucra la reflexión sobre la valoración de aquello que está plasmado por escrito y sobre lo que el autor intenta expresar, independientemente del nivel de desempeño, es decir, contemplar el manejo de recursos y la intención expresiva. De esta manera, la intencionalidad cobra fuerza en el análisis textual, por ejemplo, en los textos de los no expertos en la redacción. De hecho, se esperaría que toda interpretación rescate los elementos de intencionalidad, por ejemplo, sobre lo no expresado de manera explícita o bien aquello expresado de manera ambigua debido a complejidades por el enfrentamiento a problemáticas de textualización y las soluciones a las que llegan los autores para expresarse.

Hyland (2005) incorpora los conceptos de reflexividad e intencionalidad a los procesos de redacción como prácticas interactivas donde el autor del texto construye las relaciones intertextuales así como las relaciones con los interlocutores. Hyland desarrolla su concepto de reflexividad a partir de experiencias de textualización desde una perspectiva de la relación entre el autor y la representación que éste hace de sus interlocutores desde las prácticas concretas y Oxford (1990) considera el desarrollo de estrategias compensatorias que desarrollan los alumnos para enfrentar determinadas problemáticas comunicativas. Desde esta perspectiva asumir, adoptar o construir determinadas estrategias compensatorias para autorregular el desempeño propio implica la consideración de la intencionalidad en aquello que el alumno pretende expresar, la manera en que lo hace y la reflexividad en las decisiones involucradas en las autorregulaciones en este proceso.

Esta revisión panorámica de estudios relacionados con la intencionalidad, la reflexividad y las prácticas de escritura en ambientes académicos nos permite percatarnos 
de la escasez de investigaciones sobre el área, especialmente en el nivel universitario. El estudio de la reflexividad en el ámbito de la textualidad, sobre las prácticas de revisión y edición de textos de alumnos en nivel superior es un tema novedoso que impone el reto de hacer una construcción conceptual sobre la relación entre reflexividad e intencionalidad en el terreno de la textualidad y presentar evidencias ejemplares a partir de los textos de los alumnos.

Es fundamental hacer un estudio con esta perspectiva, pues considero que los enfoques centrados exclusivamente en la psicolingüística y la didáctica no logran contemplar los aspectos fundamentales de reflexividad sobre lo que vive, siente y considera el autor de un texto en los diversos planos involucrados en la redacción, precisamente porque mediante estos enfoques corremos el riesgo de basarnos en modelos centrados en el análisis y la interpretación textual del investigador y en prescripciones a partir de diseños preestablecidos que no siempre se pueden aplicar en diversos contextos. Por ello, en relación a los alcances de esta investigación, me interesa hacer una propuesta centrada en la discusión teórica y metodológica de elicitación e interpretación en situaciones de escritura académica para estudiar evidencias escritas de reflexividad de los individuos sobre sus prácticas de escritura en ambiente académico. De esta manera es posible contemplar la discusión teórica y metodológica de elicitación que sustenta la creación de criterios de clasificación, sistematización, caracterización y análisis de las categorías propuestas para el trabajo de investigación con los textos, por ejemplo, sobre la temática y el tipo de reflexividad a partir de la intencionalidad manifestada por los alumnos en diversos aspectos de la experiencia de escritura, por ejemplo, la estructuración textual, lo contextual, la identidad, las prácticas, la resolución de dificultades y las actitudes ante la experiencia de revisión y edición textual en ambiente cooperativo.

\subsection{Propuesta de construcción conceptual sobre la reflexividad e intencionalidad en la escritura académica}

Para realizar una propuesta conceptual en este trabajo, el punto de interés es crear una discusión sobre un enfoque teórico de la escritura académica desde la perspectiva de la 
textualidad, con centro de interés en la relación existente entre la reflexividad y la intencionalidad en la interacción comunicativa en torno a las prácticas de revisión y edición de textos de alumnos universitarios. Para lograr este propósito, en primer plano es de relevancia fundamental hacer una revisión, reflexión y una propuesta sobre los conceptos asociados y manejados teórica y metodológicamente en el trabajo. Por lo anterior, presento una propuesta de conceptualización sobre la textualización, por su impacto en el estudio de la textualidad, como enfoque integral sobre la práctica de escritura y como herramienta metodológica para la creación de categorías de análisis. Además, considero una conceptualización de la intencionalidad ligada a la reflexividad en el marco de los estudios de la textualidad.

\subsubsection{Textualizar}

En la sección anterior contemplé la necesidad de construir un enfoque integral sobre el concepto de textualización desde una perspectiva que contenga los diversos elementos contextuales, interactivos, la construcción de identidad y las prácticas, mismas que involucran la intencionalidad en la escritura. Al redactar ponemos en juego un conjunto complejo de recursos de textualización. Redactar involucra el manejo de los recursos para la conformación de la coherencia y cohesión en la unidad textual, además de los procesos regulatorios y contextuales involucrados, incluida la intencionalidad del autor.

Para caracterizar la textualización es necesario contemplar la intencionalidad en las tomas de decisiones en el proceso de construcción del texto, manifestadas en las prácticas de escritura, en el manejo de los aspectos constitutivos formales, semánticos y morfosintácticos para la conformación de la cohesión y la coherencia. Además, este enfoque requiere contemplar la función y los diversos aspectos contextuales y las decisiones y prácticas regulativas. En el nivel de cohesión y coherencia, contemplo en el área de la textualidad, además del trabajo de Beugrande \& Dressler (1997), la propuesta de Adam (1990 y 2005) como referentes fundamentales metodológicos para la descripción textual y la creación de categorías de análisis de los textos analizados, como herramientas 
de apoyo en el estudio de la reflexividad ${ }^{11}$.

Concibo la textualización como un proceso complejo e integral en el manejo y desarrollo de habilidades en la toma de decisiones al plasmar las ideas por escrito y para la conformación de la unidad textual como medio comunicativo que involucra, además de la articulación y estructuración formal, el conjunto de funciones del lenguaje en la expresión escrita y de la información contextual, cultural, de construcción de conocimiento e identidad, manifestada en la intencionalidad comunicativa en los diversos géneros textuales. Desde esta perspectiva la textualización es mucho más que el exclusivo manejo de recursos formales de la lengua escrita.

Las decisiones de textualización implican que quien escribe puede poner en juego el conjunto de consideraciones sobre el desempeño lingüístico y comunicativo mediante la valoración, por ejemplo, de los estándares textuales de cohesión, coherencia, intencionalidad, informatividad, situacionalidad, aceptabilidad, efectividad y propiedad (Beugrande \& Dressler 1997). Estos elementos son fundamentales para el manejo de recursos de articulación y estructuración, el conocimiento del tipo de lenguaje y géneros textuales, así como las consideraciones sociales, individuales y contextuales que posibilitan la construcción de significados e identidad al asumir una representación o posicionamiento textual del autor, así como de los interlocutores o lectores potenciales.

\subsubsection{Intencionalidad}

En esta investigación contemplo la relación de la dualidad entre intención como acto mental personal, privado e inaccesible a la observación y la intencionalidad como la posible manifestación de lo intencional en lo externo, en las acciones, mediante determinadas representaciones de conducta, en este caso, del manejo del lenguaje en la escritura. De hecho, para los efectos de esta investigación en adelante consideraré la

\footnotetext{
${ }^{11}$ En este punto un referente teórico obligado es el trabajo precursor de Halliday \& Hassan (1976) por la incorporación del estudio de la cohesión y la creación de categorías de análisis oracionales y extraoracionales, por ejemplo, anáfora, elipsis y referente. Este trabajo contempla una noción de texto constituido en la oralidad o en la escritura como un pasaje de cualquier longitud que forme una totalidad unificada. El punto de interés es que esta propuesta no es parte de los estudios de textualidad en tanto no se centra exclusivamente en lo escrito, pero es un punto de partida innovador en el manejo de categorías que después desarrollaron, por ejemplo, Beugrande \& Dressler (1997) en los estándares de textualidad y Adam (1990 y 2005) en sus categorías de análisis, al consolidarse los estudios de la lingüística textual.
} 
manifestación de la "conducta observable" como "determinada práctica de escritura o textualización". Propongo, en el caso de la comunicación escrita, que la intención, como el conjunto de conocimiento formal y contextual conformado en las estructuras mentales de cada individuo, se consolida en una diversidad multifacética de posibilidades de representación escrita en las manifestaciones de intencionalidades presentes en distintos contextos de interacción comunicativa.

Además, en esta investigación destaco que la existencia de una intención no implica necesariamente que el individuo lleve a cabo una determinada acción de escritura observable, por ejemplo, alguien que decide no escribir porque se reprime o no maneja los recursos necesarios para expresarse. Asimismo, destaco que la manifestación de intencionalidad, es decir, las posibles representaciones escritas contextualizadas de la intención personal, en determinados casos pueden no corresponder a la intención mental y personal del individuo. En este caso, el estudio de la intencionalidad y su relación con la interpretación y la reflexividad cobra relevancia en la comunicación, por ejemplo, cuando el autor escribe algo, que él mismo reconoce que no corresponde a la intención sobre lo que deseaba expresar, o bien los interlocutores percibimos que enfrenta dificultades de expresión en la textualización, existen ambigüedades o percibimos una multiplicidad de interpretaciones. Es en este punto donde, principalmente, contemplo la reflexividad sobre las prácticas de escritura y la valoración sobre el desempeño y la manifestación de la intencionalidad propia y la de otros, en este caso, los compañeros que participan en una práctica de revisión y edición textual. En la medida en que un alumno revisa un texto sin tener al autor presente para hacerle comentarios y retroalimentación sobre lo escrito, el revisor realiza prácticas de reflexividad sobre la manifestación de la intencionalidad de su compañero y también tiene cierta intención y manifiesta determinada intencionalidad al hacer comentarios por escrito. Así, la intencionalidad, la interpretación y la reflexividad son elementos que dan vida a la comunicación.

En esta investigación el centro de interés es el conjunto de comentarios que realizan los alumnos sobre sus propios textos y los de sus compañeros, es decir, los desempeños en las prácticas de escritura. Es posible estudiar comentarios sobre las intencionalidades y las interpretaciones de los alumnos en sus roles de autores y revisores con la oportunidad de 
recibir retroalimentación y comentar por escrito sobre las observaciones recibidas, así podemos tener distintas situaciones comunicativas que posibilitan la manifestación de la reflexividad sobre la práctica de escritura. De esta manera, el aspecto prioritario es la manifestación de interpretación y valoración de los alumnos. Así, la creación de las categorías de análisis de los datos, su interpretación y el estudio de los textos se puede hacer a partir de evidencias escritas de reflexividad sobre la intencionalidad.

Además de la propuesta dual de la relación entre lo intencional (mental) y la intencionalidad (acción y representación de lenguaje) en una posible multiplicidad de situaciones comunicativas, contemplo en mi enfoque la propuesta de intencionalidad implícita o difusa desarrollada en los trabajos de Copi \& Burges-Jackson (1986) y en la perspectiva de la interpretación analógica el trabajo de Beuchot (2002). Propongo que en la lectura e interpretación de un texto se entrecruzan las diversas intencionalidades manifiestas, por una parte, aquella intencionalidad que podemos advertir, recuperar o interpretar sobre las posibles manifestaciones de la intención del autor presentes en el acto o representación de la escritura, la intencionalidad surgida por la interpretación del lector, pero principalmente por las posibles interpretaciones cuando el lector contempla aquello que el autor intenta expresar, en lo implícito, lo ambiguo, lo problemático, y tal como expresa Beuchot (2002), la flexibilidad en la oscilación unívoca (literal y objetiva) y equívoca (subjetiva y más allá de lo literal) de la interpretación y de lo que consideramos que el autor intentó expresar.

En la línea de los estudios de la argumentación en la lógica, Copi \& Burges-Jackson (1986) examinan los argumentos y los intentos de argumentación en el contexto de uso de los usuarios, valorando la intención de argumentar, de tal manera que la descripción de la lógica no se centra exclusivamente en ubicar las premisas y la conclusión, puesto que se plantea que aun cuando éstas no estén manifiestas, pueden estar implícitas en el contexto argumentativo, de manera tal que es necesario analizar aquello que hace y cómo lo hace, quien argumenta para defender o sustentar una postura ${ }^{12}$.

\footnotetext{
12 Esta discusión ya había sido contemplada en el debate Austín (1962) versus Searle (1969) en el campo de la filosofía del lenguaje. En contraste con Searle (1969), Austin (1962) propone que los actos de habla no son acervos o repertorios preestablecidos como actos de habla asociados a determinadas prácticas ritualizadas en actos específicos, por el contrario,
} 
Por su parte, Beuchot (2002) destaca que la intencionalidad en los ambientes cotidianos debe ser caracterizada de manera cuidadosa, puesto que en muchas ocasiones aquello que aparece de manera clara en un texto puede tener una intencionalidad totalmente diferente, tal vez como un acto consciente o bien como algo que quien escribe no pretendía expresar.

Aun la intencionalidad puede ser de muchas clases. Pero podemos hablar de cuatro principales, atendiendo a su captabilidad. Hay una intencionalidad consciente y explícita, esto es, que capta tanto el autor como el lector. Hay otra consciente y tácita, que sólo capta el autor y difícilmente accede a ella el lector. Otra es inconsciente y explícita, la que se escapa al propio autor, pero el lector la encuentra con ciertos instrumentos sutiles ad hoc, por ejemplo, aplicando el psicoanálisis. Y hay otra que es inconsciente y tácita, la que se oculta tanto al autor como al lector, y permanece escondida, tal vez por siempre ${ }^{13}$. (Beuchot 2002: 18)

Esta caracterización de la intencionalidad es relevante para la diversidad de posibilidades de expresión en la interpretación y en la reflexividad en distintos tipos y facetas, en este caso de los textos de los alumnos en sus roles de autores y jueces. Esto permite caracterizar, de acuerdo a la posibilidad de toma de consciencia de autores y jueces o lectores, múltiples manifestaciones de tipos, modalidades y facetas de reflexividad. Las intenciones pueden estar conformadas por distintos tipos de pensamiento, ya sea como intuición o conocimiento inacabado en gestación, muchas veces inconsciente, es decir, intenciones conformadas como intuiciones $\mathrm{y}$, por otra parte, intenciones plenamente conscientes. Ambas son susceptibles de manifestarse en el lenguaje en diversas posibilidades de intencionalidad y así reflejar evidencia de reflexividad.

Sobre la identificación de la intencionalidad y la interpretación, Beuchot (2002) considera que

hay que mediar, y sabiendo que siempre se va a inmiscuir la intención del intérprete, tratar de conseguir, lo más que se pueda, la intención del autor. Podríamos, así, hablar de una "intención del texto", pero tenemos que situarla en el entrecruce de las dos intencionalidades anteriores. Por una parte, hay que respetar la intención del autor (pues el texto todavía le pertenece, al menos en parte); pero, por otra, tenemos que darnos cuenta de que el texto ya no dice exactamente lo que quiso decir el autor: ha

\footnotetext{
plantea que existen diversas intencionalidades, algunas de las cuales son complejas y no siempre corresponden a lo expresado por quien crea cosas con palabras. Es decir, puede existir una intención distinta al contenido literal expresado.

${ }^{13}$ De hecho Beuchot (2012) no hace la distinción dual intencional - intencionalidad correspondiente a la tradición de Anscombre y Brentano.
} 
rebasado su intencionalidad al encontrarse con la nuestra (Beuchot 2002: 17)

Desde una propuesta analógica Beuchot (2002) propone un comportamiento dual en la interpretación que mantiene un punto medio de una oscilación entre dos polos extremos interpretativos; por una parte, la interpretación equívoca que permite ir más allá de los límites interpretativos $\mathrm{y}$, por otra parte, lo unívoco, que impide la dispersión en la multiplicidad de posibilidades interpretativas subjetivas del lector. Así, Beuchot plantea la visión de una interpretación contextual para intentar recuperar la voz del autor, donde toda interpretación conlleva una autointerpretación.

También considero fundamental para esta investigación contemplar el aspecto regulatorio sobre el desempeño lingüístico propio y el de otros, en este caso, que manifiestan el autor y el juez en las prácticas de revisión y edición textual, como manifestación de la intencionalidad en el marco de los estudios de la lingüística textual. Anteriormente comenté que Beugrande \& Dressler (1997) consideran como sustento de la lingüística textual los estándares de cohesión, coherencia, intencionalidad, informatividad, situacionalidad, aceptabilidad, efectividad y propiedad, que autores y lectores ponen en juego en la construcción contextualizada e interactiva de un texto. En este aspecto el autor y el lector evalúan la intencionalidad manifestada en el texto, en el desempeño y en las prácticas de escritura para la toma de decisiones de textualización e interpretación para lograr la comunicación que responda a las necesidades de determinados contextos. Asimismo, también considero como referente, el trabajo de Oxford (1990), quien aborda el desarrollo de estrategias compensatorias sobre el desempeño lingüístico en ambientes académicos. Mediante la construcción de estrategias compensatorias para tratar de modificar y, en su caso, mejorar el desempeño lingüístico en determinada situación, quien participa en la práctica comunicativa puede valorar, evaluar y reflexionar sobre su propia intencionalidad manifestada en su desempeño y emplear recursos y estrategias alternas o compensatorias para tratar de que el texto responda a las necesidades requeridas en un contexto dado.

De esta manera propongo que el autor del texto hace la valoración, evaluación e interpretación de su propia intencionalidad presente en su desempeño lingüístico mediante 
el conjunto de decisiones y prácticas de textualización contextualizadas comunicativamente. En este proceso el autor, principalmente el no experto, puede enfrentar diversas problemáticas de textualización y toma decisiones sobre el manejo de los diversos recursos y aspectos involucrados en la escritura. La autoevaluación de su intencionalidad manifestada en su redacción, le permite evaluar su desempeño. Principalmente, aquí es cuando el autor se puede preguntar si lo que escribió corresponde a lo que deseaba expresar, es decir, si la intencionalidad manifestada corresponde a la intención o a parte de ella o bien si tenía clara su intención o idea de lo que deseaba escribir. La autoevaluación le permite al autor, si así lo determina, tomar decisiones para autorregular su propio desempeño durante la escritura, la revisión o la edición, y mediante la reflexión sobre su intencionalidad puede, en su caso, construir estrategias alternas o compensatorias para tratar de que su texto responda a las necesidades comunicativas. Así, la valoración, evaluación y reflexión sobre el desempeño se realiza sobre la intencionalidad comunicativa, de esta forma se puede manifestar la reflexividad. A continuación presento una propuesta de conceptualización de la reflexividad en la que contemplo, además, los conceptos de textualización, intencionalidad e interpretación que aquí he presentado, precisamente porque son elementos presentes en la manifestación de la reflexividad.

\subsubsection{Reflexividad}

En las secciones anteriores destaqué que la reflexividad es un concepto en construcción y ha sido motivo de polémica en el terreno de la lingüística, de hecho la construcción conceptual se ha venido haciendo desde diversas áreas del conocimiento y enfoques teóricos que incluyen, por ejemplo, los estudios de las representaciones mentales, aspectos cognitivos, discursivos, filosóficos, psicológicos y didácticos. Desarrollar cada una de estas propuestas escapa a los alcances de esta investigación, por lo que ahora me centraré en los estudios más relacionados o vinculados con el estudio del lenguaje, la textualización y la lingüística textual y, en concreto, haré referencia a las prácticas de lectura y escritura presentes en las prácticas de revisión y edición textual

En el campo de la sociolingüística Muñoz Cruz (2010) contempla, de manera 
general a la reflexividad como

un mecanismo constitutivo, intencional y regulativo de la comunicación lingüística, que se expresa a través de representaciones cognitivas, razonamientos, normatividades, evaluaciones, juicios y descripciones de los recursos lingüísticos y socioculturales de los hablantes ${ }^{14}$. (Muñoz Cruz 2010:18)

Entonces considero que en su conformación la reflexividad es un conjunto de concepciones, ideas, pensamientos, conocimientos y actitudes regulativas e intencionales que tenemos sobre la comunicación y, en este estudio, sobre el desempeño propio, de otros y en general, de la lengua. Estos pensamientos, conocimientos y actitudes son, al igual que las intenciones motivadas, objetos mentales construidos en procesos personales cognitivos, interactivos y contextuales, por ello no son observables, no podemos tener acceso a esta reflexividad sin que el individuo la manifieste de alguna manera. Además, las reflexividades son el conjunto de pensamientos y conocimientos en distintas modalidades y facetas, algunas son intuiciones y otras son conocimientos plenamente conformados y elaborados, algunas son conscientes y otras inconscientes. En la sección anterior comenté lo mismo sobre las intenciones: algunas están conformadas por intuiciones como conocimiento en gestación, y muchas veces inconscientes y otras son intenciones motivadas plenamente conscientes. Así, existe una relación sobre los tipos de intención y la reflexividad, como pensamientos o estructuras mentales construidas cultural y contextualmente, mismas que no son observables por ser internas y personales. Estas se expresan en las distintas manifestaciones y posibilidades de realización o representación de la intencionalidad mediante el lenguaje, en este caso, el escrito. De hecho, tal como apunta Turner (2011) es posible considerar de manera general que en una comunidad existen reflexividades colectivas construidas socialmente, cuando ciertos grupos comparten determinadas concepciones culturales, sin embargo, dicha reflexividad colectiva se origina a partir de la suma de las reflexividades individuales y personales de cada individuo, mismas que tienen características únicas debido a que cada quien construye en la colectividad sus propias concepciones, intencionalidades y reflexividades.

Contemplo que la reflexividad, entendida como esta conformación de concepciones

\footnotetext{
${ }^{14}$ Proyecto Conacyt 99274 (1999). Dominio lingüístico y académico de estudiantes bilingües indígenas en universidades de México: habilidades comunicativas y académicas, reflexividad, sociolingüística y políticas interculturales del lenguaje.
} 
y actitudes, involucra aspectos cognitivos, culturales, contextuales y la construcción de significado e identidad, por ello no se limita sólo al terreno de lo cognitivo. Propongo que la reflexividad es un proceso jerárquico, cíclico y recursivo en distintos tipos de construcción conceptual sobre la valoración de la lengua escrita y del desempeño propio y el de otros en términos de los múltiples factores que el individuo, concibe, considera y puede llegar a manifestar de manera consciente o inconsciente, explícita o implícita como relevantes para la comunicación, en concreto para su desempeño en ambiente académico. La reflexividad puede ser un conocimiento en gestación correspondiente a intuiciones o creencias, muchas de ellas inconscientes y difíciles de explicar o expresar de manera explícita, o bien puede ser una reflexividad conformada por concepciones y conocimientos consolidados y, en su mayoría, conscientes que llevan al individuo a reflexionar o creer sobre la creencia o la intuición, y que pueden llegar a ser manifestados de manera explícita. En el momento en que individuo establece representaciones reflexivas sobre sus propias creencias se lleva a cabo la conformación recursiva de la reflexividad ${ }^{15}$.

La recursividad reflexiva consiste en convertir creencias o proposiciones reflexivas en objetos de referencia de nuevas proposiciones (Muñoz Cruz 2010)

La reflexividad es la manifestación de los diversos tipos, modalidades y facetas del pensamiento intencional y conocimiento reflexivo. Sobre la naturaleza de reflexividad ya sea consciente o inconsciente, en un tipo de creencia o intuición como conocimiento en gestación o bien como concepciones y actitudes asumidas con plena consciencia e introspección, es necesario recalcar que éstas, al igual que las intenciones, pueden manifestarse en distintas facetas, generalmente de manera parcial y, en algunos casos, no manifestarse, por ejemplo, cuando el individuo simplemente se abstiene, por ejemplo, por timidez, a comentar o abordar temáticas o a profundizar, ya que sólo cuando el individuo se expresa, en este estudio, mediante la lengua escrita, existe la posibilidad de que manifieste evidencias de reflexividad. De hecho, como investigadores no es fácil tener acceso a la reflexividad, es necesario que el individuo interactúe en situaciones que favorezcan la

\footnotetext{
${ }^{15}$ Dennett (1996) establece la propuesta de posturas intencionales de primer y segundo órdenes. En la postura intencional de segundo orden el individuo manifiesta reflexiones y creencias sobre sus propias creencias, ideas o intuiciones. Esta manifestación de reflexividad corresponde a un tipo de pensamiento de mayor abstracción e introspección.
} 
expresión sobre temas que propicien el discurrir de temáticas reflexivas, esto impone un reto para el diseño de interacciones para las fases de elicitación encaminadas a obtener muestras significativas de textos con evidencias de reflexividad.

En el caso de la reflexividad sobre las prácticas de escritura y sobre el desempeño personal y el de otro, el alumno puede opinar y reflexionar sobre diversos aspectos relacionados con estos temas, $\mathrm{y}$, en este caso, tener dificultad para identificar los aspectos de sus concepciones y actitudes, o simplemente tenerlas en un modo intuitivo o inconsciente.

En estas diversas facetas, la focalización, identificación o referencia al objeto de reflexividad puede ser algunas veces clara y transparente y en otras ocasiones opaca o difusa, precisamente porque la construcción de la reflexividad involucra diversos aspectos en distintos niveles de complejidad y en ocasiones cuesta trabajo apreciar, focalizar o centrar la atención en los objetos de reflexividad de cada individuo, en este caso sobre el lenguaje. Respecto a esta discusión me apoyo en la propuesta de Recanati (1979 y 2004) en relación a la conformación de la reflexividad a partir de la construcción de significados expresados mediante la manifestación de la enunciación en el lenguaje. En este proceso el signo y el conocimiento tienen una naturaleza dual de transparencia y opacidad, de manera tal que en el acto de enunciación, como mecanismo de comunicación, los objetos de reflexividad en algunas ocasiones son opacos y otras veces transparentes, precisamente porque es difícil centrar la atención en una construcción reflexividad, misma que puede ser una intuición, una concepción o bien pensamientos interrelacionados múltiples.

La opacidad se debe, principalmente, a que al centrar la atención en el objeto o tema de reflexividad, es decir el signo o el conocimiento en cuestión, se complica por la mediación o interrelación con los diversos aspectos relacionados con el centro de interés que pretendemos focalizar o con el enfoque o instrumento con el cual deseamos reflexionar y referirnos sobre determinado aspecto que motiva la reflexividad. Por ejemplo, si nos expresamos sobre nuestro desempeño lingüístico en escritura académica podemos focalizar, identificar o referirnos al tema de interés que seleccionemos, pero podemos perderlo y desviarnos porque en torno a dicha temática existen muchas otras relacionadas que en realidad no corresponden a la temática concreta que pretendemos focalizar, en este caso, el 
desempeño personal y el de otros en escritura académica.

El enfoque, la mirada y la actitud pueden propiciar la opacidad en la apreciación del signo u objeto de reflexividad, de manera tal que en la enunciación o práctica comunicativa terminemos reflexionando sobre otros aspectos relacionados, por ejemplo, en lugar de reflexionar sobre el desempeño en ambiente académico terminemos reflexionando exclusivamente sobre aspectos sociolingüísticos, políticos o históricos, o bien el enfoque adoptado, entre otros, sin relacionarlos con las prácticas de escritura en el desempeño personal y el del compañero. Por ejemplo, el objeto de reflexividad puede volverse opaco debido al énfasis en la concepción o enfoque con el que miramos el tema de reflexión, tal como si al apreciar y describir un objeto con unos anteojos determinados, terminemos haciendo referencia y reflexión sobre los cristales de los anteojos.

Por otra parte, sobre la construcción de significado e identidad me apoyo, principalmente, en las propuestas de Ivanič (1998) sobre la manera en que el autor se representa ante el texto y el conjunto de relaciones interactivas, la construcción de interlocutores y el contexto que le permiten conformar identidad en las prácticas académicas de escritura. También contemplo que este tipo de construcción surge en el marco dinámico de relaciones interculturales, tal como lo propone Turner (2011), de manera tal que cada individuo puede manifestar, por ejemplo, un conjunto de aspectos vivenciales que reflejan reflexividad cultural e intercultural de su entorno. También, sobre el tema de la representación o posicionamiento de enunciación del autor y el establecimiento de relaciones intertextuales y con los interlocutores considero fundamental la propuesta de Hyland (2005) sobre la relación de la intencionalidad y la reflexividad como prácticas interactivas. Este tipo de concepción posibilita la conformación de una reflexividad cultural interactiva en el marco de las dinámicas interculturales. En ambos casos, Ivanič (1998) y Hyland (2005) contemplan la manera en que el autor se posiciona ante el texto, las motivaciones para hacerlo en determinada manera y la forma en que construye conocimiento e identidad al hacerlo, precisamente porque en los ambientes académicos ha sido un tema de polémica la manera en que el autor se posiciona y 
representa ante el texto, y por ende, ante sus interlocutores ${ }^{16}$.

De esta manera, considero que en las prácticas de escritura académica el alumno conforma conocimiento e identidad en el marco de relaciones culturales e interculturales múltiples. Esto sucede cuando el alumno toma decisiones para asumirse o representarse ante el texto y contempla el complejo entramado de relaciones que incluyen construir a los interlocutores, las interacciones, las valoraciones culturales y contextuales en que el texto en cuestión cobra vida comunicativa. También construye identidad y conocimiento cuando valora o evalúa la pertinencia y efectividad de su texto, así como las reacciones y el impacto de su interacción y producción textual en el ambiente académico. Estos aspectos pueden manifestarse en la reflexividad expresada en los textos y en las concepciones sobre la manera en que el alumno se asume como participante de dinámicas académicas.

Para establecer la propuesta de reflexividad, también me apoyo en el trabajo de Bateson (1972: 345-350) sobre los aspectos de regulación y recursividad en los sistemas cibernéticos y mentales del procesamiento de la información y, por otra parte, la propuesta de Dennett (1991), quien propone que el pensamiento procede de manera recursiva en distintas facetas, de manera cíclica en las fases en las que el individuo conforma el objeto de reflexión y conocimiento. Así, el individuo en determinados momentos experimenta y manifiesta modalidades reflexivas y como parte del proceso regresa, retoma o se retroalimenta de diversos tipos y facetas de pensamiento reflexivo para construir sus propias concepciones o reflexividades, en esto radica el aspecto cíclico y recursivo de la construcción de la reflexividad.

La reflexividad sobre el manejo de recursos de la redacción en prácticas de revisión y edición en ambiente académico, involucra que los alumnos se expresen por escrito, sobre su propia experiencia integral de redacción, contemplando, por ejemplo, los recursos y

\footnotetext{
${ }^{16}$ Existe un tipo de reflexividad sociocultural o socio-académica en la que es mal visto que el alumno se posicione de manera directa, ya sea en $1^{\mathrm{a}}$ persona del singular y plural, y es una exigencia hacerlo en impersonal por la consideración de que la ciencia o el texto académico es algo serio. Sin embargo, algunos alumnos manifiestan confusión al percatarse de que los investigadores que consideran de prestigio y autores reconocidos se atreven a posicionarse de manera directa. Entonces existe un nivel de reflexividad sobre lo considerado como "serio" en ambiente académico y los autores que tienen permitido romper ese tipo de "seriedad". En mi investigación sobre la redacción con intencionalidad argumentativa abordo un capítulo sobre la oscilación dubitativa entre posicionamiento directo e impersonal cuando los alumnos se representan ante el texto al tratar un tema polémico, y las consecuencias de esta oscilación reflejadas en el desempeño (Hernández Rodríguez 2010).
} 
repertorios lingüísticos empleados, las problemáticas enfrentadas, la resolución de dificultades, las decisiones tomadas durante la textualización o conformación de la unidad textual, lo que piensan sobre la práctica comunicativa escrita, así como lo que sienten, experimentan y les representa significativamente la revisión y edición de sus propios textos como parte de la construcción de identidad y de conocimiento en un contexto interactivo y cultural. La reflexividad sobre la textualización puede incluir aspectos diversos, tales como lo cognitivo, lo afectivo, la inseguridad, el prestigio, criterios sobre el desempeño lingüístico y las actitudes ante dificultades enfrentadas en la redacción.

Considero que la reflexividad sobre los procesos de textualización puede llegar a manifestarse en algunas facetas cuando el alumno se expresa, valora y, en algunos casos, hace la evaluación del desempeño propio en términos de los múltiples factores que el individuo considera y decide que son relevantes para apreciar sus textos y los de otros en las funciones comunicativas correspondientes.

La reflexividad es multifacética en la medida en que cada individuo construye sus tipos de reflexión conforme valora y regula su desempeño e intencionalidad desde perspectivas más generales, basadas en creencias o suposiciones que conforman una reflexividad inferencial sobre la textualización, y en algunos casos manifiesta reflexividad introspectiva sobre su desempeño escrito y académico en el marco de la interacción y el contexto sociocultural. Evidentemente, todos los alumnos construyen de manera personal sus objetos intencionales y de reflexividad en las prácticas escolares diarias, en contextos y situaciones culturales e interactivas determinadas, y es, precisamente, en el marco de un ambiente cooperativo y de retroalimentación interactiva de revisión y edición de sus propios textos y los de sus compañeros, donde los alumnos pueden manifestar algunas facetas de sus intencionalidades y de reflexividad. El reto es lograr esto en los diseños de elicitación.

Cada individuo conforma sus propios criterios y modalidades de reflexividad sobre las experiencias y repertorios de intencionalidad y expresión durante la práctica de escritura. En cada experiencia de revisión y edición, el alumno intenta resolver nuevas problemáticas y decisiones de textualización, también puede contemplar otros factores, por ejemplo, contextuales sociales, culturales, de función textual, y de construcción de 
identidad y de significados. Además contempla de manera personal, por ejemplo, otro tipo de conocimientos, actitudes y vivencias. Así conforma de manera integral nuevas valoraciones recursivamente al retomar y regular aspectos de su desempeño en determinado nivel, y puede manifestar diversas facetas de reflexividad y de construcción de repertorios y de recursos de escritura.

La reflexividad sobre el desempeño está directamente ligada a la valoración de la intencionalidad, de tal manera que al escribir, revisar y editar un texto, el alumno contempla reflexivamente lo que su compañero y él mismo intentan expresar, y el conjunto de decisiones integrales de textualización, con el fin de que dicha intencionalidad quede plasmada en el lenguaje escrito. En el caso de la escritura el objeto de referencia o reflexividad corresponde a los diversos recursos de textualización, principalmente, a aquellos que podemos caracterizar mediante los estándares de textualidad planteados por Beugrande y Dressler (1997).

Contemplo una modalidad o faceta de reflexividad basada fundamentalmente, en intuiciones, creencias, presuposiciones, actitudes, vivencias e ideas generales en las que el tema u objeto de la reflexividad, se manifiesta de manera ambigua, implícita, y, principalmente, no aterriza en la temática de las prácticas concretas de escritura personal y del compañero en ambiente académico. Así, en términos de Recanati (2004) el objeto de la reflexividad aparece, en su mayoría de manera opaca u opacado por otras temáticas de reflexividad relacionadas, pero no focalizadas en el tema en cuestión.

Resulta relevante contemplar la intencionalidad manifestada en las muestras de reflexividad y tomar en cuenta aquello que el alumno pretende expresar en la fase de retroalimentación escrita y en la revisión, al asumir el papel de juez y opinar sobre los comentarios recibidos. De esta manera es posible caracterizar la relación de intencionalidad y reflexividad a partir de los textos.

En otro tipo de modalidad o faceta de reflexividad el alumno logra construir y manifestar una reflexividad que le permite valorar y reflexionar introspectivamente, la mayor parte de las ocasiones de manera consciente y explícita, sobre sus propias creencias, regulaciones de intencionalidad y toma de conciencia sobre el manejo integral de recursos 
de textualización y desempeño de escritura, así como de aquellos aspectos formales y contextuales a los que da relevancia sobre su desempeño y el del compañero. Sobre el tipo de enunciación o manifestación escrita tanto de la intencionalidad y la reflexividad, el tipo de reflexividad corresponde, como dije antes, a un proceso cíclico que se manifiesta en distintas facetas, algunas de ellas de manera recursiva.

Además de la naturaleza cíclica y recursiva de la reflexividad como un conocimiento gradual y escalonado, que pasa por diversas facetas y modalidades, podemos destacar la naturaleza de la dualidad propia de la reflexividad, y que también caracteriza a los elementos que la conforman, tal como vemos a continuación en la tabla 1.

Tabla 1. Elementos de dualidad en la reflexividad

\begin{tabular}{|c|c|}
\hline Conformación de la reflexividad & Dualidad \\
\hline $\begin{array}{l}\text { Concepciones, conocimiento } \\
\text { y actitudes }\end{array}$ & \begin{tabular}{|cc} 
Pensamiento reflexivo - & $\begin{array}{c}\text { Reflexividad escrita } \\
\text { (Hyland 2005) }\end{array}$ \\
\end{tabular} \\
\hline Intención & $\begin{array}{c}\text { Lo intencional } \quad \text { - La intencionalidad } \\
\text { Filosofía: Ascombre (1965) Husserl (1913) } \\
\text { Textualidad: Beugrande y Dressler (1997) } \\
\text { Beuchot (2002) }\end{array}$ \\
\hline Objeto de reflexividad & $\begin{array}{r}\text { Opacidad - Transparencia } \\
\text { Recanati (1979 y 2004) }\end{array}$ \\
\hline Relaciones de referencia textual & Implícito - Explícito (Perry 2001) \\
\hline $\begin{array}{l}\text { Representación del autor } \\
\text { y de interlocutores en el texto }\end{array}$ & \begin{tabular}{|} 
Posicionamiento directo - $\quad$ Distanciamiento \\
Adam (2005), Eco (1979), Ivanič (1998)
\end{tabular} \\
\hline Interpretación & Equívoco - Unívoco \\
\hline
\end{tabular}

En cualquier interacción comunicativa que propicie la manifestación de la reflexividad estarán en juego siempre este conjunto de relaciones y oscilaciones en la dualidad característica de estos elementos constitutivos de la reflexividad. De esta manera podemos percatarnos de la naturaleza dinámica de la reflexividad en la escritura.

En virtud de que los alumnos pueden manifestar diversas facetas de intencionalidad y de reflexividad, el reto es hacer un diseño para la fase de elicitación que propicie que los alumnos manifiesten dicha intencionalidad y reflexividad. También es fundamental hacer una caracterización de las evidencias escritas presentes en los textos, crear las categorías que favorezcan la clasificación de los datos y presentar las evidencias ejemplares de los 
diversos tipos de reflexividad presentes en los textos.

\subsection{Enfoque y propuesta de estándares de textualidad}

Como punto de partida teórico sobre la caracterización de un objeto de estudio de escritura académica en el marco de la textualidad tomo como criterio inicial y referente fundamental, la propuesta de la lingüística textual de Beugrande \& Dressler (1997) sobre los estándares de textualidad que autores y lectores de un texto ponen en juego, de manera consciente o inconsciente, en la interacción contextualizada comunicativa de la escritura y en la interpretación textual. Beugrande \& Dressler (1997) consideran como sustento de la lingüística textual los estándares de cohesión, coherencia, intencionalidad, intertextualidad, informatividad, situacionalidad, aceptabilidad, propiedad y efectividad.

Los estándares de textualidad de Beugrande \& Dressler (1997) no son consideraciones normativas ni modelos preestablecidos didácticos de evaluación sobre el desempeño, por el contrario, estos estándares son el conjunto de información y conocimiento contextualizado en la comunicación que cada persona que interactúa en la construcción e interpretación textual maneja en distintos niveles de desarrollo.

La cohesión se relaciona con el manejo de recursos formales de construcción gramatical y de estructuración intra e intertextual, la coherencia permite que las ideas relacionadas en un texto puedan transmitir un mensaje con claridad, que sea entendible, es decir, coherente. Cuando un texto presenta determinado mensaje e información y es clara la relación entre un remitente y un receptor, se cumple el criterio de informatividad. Además, cuando esta comunicación escrita responde a determinada situación comunicativa o contextual decimos que el texto corresponde a cierta situacionalidad. El criterio de aceptabilidad refleja la pertinencia de aparición de un texto en determinado contexto y género textual que responde a una necesidad comunicativa, por ejemplo, una receta médica cumple el criterio de aceptabilidad en el contexto de un hospital y una oración religiosa en un ritual específico, por ejemplo, en una misa, su contexto de aparición en otra situación no cumple el criterio de aceptabilidad. Además, Beugrande \& Dressler (1997) contemplan la aceptabilidad como una actitud que manifiesta quien recibe el texto, sobre la idea de que lo 
expresado debe tener un sentido y uso relevante. La propiedad está relacionada principalmente con el tipo de léxico y registros de lenguaje que son apropiados en determinado uso y contexto. La intencionalidad corresponde a las actitudes manifestadas, encaminadas a lograr los propósitos comunicativos en el texto. La intertextualidad es el principio que contempla el uso de un texto y su dependencia de la referencia o conocimiento de otros textos en diversos contextos de uso, así como de las experiencias vivenciales, lo que el autor y lector sienten y la manera en que construyen conocimiento, significado e identidad, al relacionar el texto con este conjunto de referentes intertextuales.

En esta investigación propongo hacer una adaptación y ampliación de los estándares plantados por Beugrande y Dressler (1997). Considero en mi enfoque un modelo integral de textualidad conformado por estándares constitutivos, regulativos, contextuales y de prácticas o usos. En este modelo incorporo la reflexividad como un estándar estrechamente ligado a la intencionalidad, como elementos fundamentales para la comunicación.

\section{Tabla 2 Propuesta de modelo integral de estándares de la textualidad}

\begin{tabular}{|l|l|}
\hline Constitutivos & $\begin{array}{l}\text { cohesión, coherencia, informatividad, } \\
\text { aceptabilidad e intencionalidad }\end{array}$ \\
\hline Regulativos & efectividad, propiedad, estrategias, reflexividad \\
\hline Contextuales & $\begin{array}{l}\text { intertextualidad, temporalidad, situacionalidad, } \\
\text { significados, trayectoria textual, géneros }\end{array}$ \\
\hline $\begin{array}{l}\text { Prácticas } \\
\text { y usos }\end{array}$ & $\begin{array}{l}\text { actoracciones, funciones, interpretación, } \\
\text { acterlocutores, identidad }\end{array}$ \\
\hline
\end{tabular}

Sobre los estándares agregados al modelo de Beugrande \& Dressler (1997), en mi propuesta contemplo el grupo de estándares constitutivos como aquellos de conformación textual en el manejo de recursos fundamentales en el uso del lenguaje, en lo formal, los contenidos, la organización y la estructuración textual, es decir, la materia prima básica de un texto.

Considero que los estándares regulativos corresponden a aquellas valoraciones de regulación sobre el desempeño personal y de los interlocutores en la comunicación escrita, la construcción e interpretación textual. Mediante la regulación, por ejemplo, el autor de un texto valora su desempeño para determinar la efectividad y la propiedad, y, en su caso, tomar decisiones de textualización para adecuar o modificar su texto de acuerdo a los 
requerimientos comunicativos, en este caso, en ambiente académico, y, principalmente, mediante las decisiones y estrategias asumidas. Así el alumno puede crear estrategias mediante esa regulación y valoración sobre el desempeño propio y el de otros en la comunicación.

Tal como propone Oxford (1990), ante una valoración y regulación, por ejemplo, sobre el desempeño personal, el alumno puede buscar alternativas para modificar su desempeño creando estrategias compensatorias. Esto permite hacer una mirada introspectiva mediante la regulación que involucra la consideración de los estándares de intencionalidad y reflexividad. Así, podemos ver que los diversos estándares de la textualidad se interrelacionan en los comentarios sobre el desempeño en escritura académica. Este tipo de regulación aparece cuando el alumno contempla que un texto puede estar muy bien estructurado en cuanto a los principios constitutivos, por ejemplo, de coherencia, cohesión e informatividad, pero no tener propiedad en algunas partes o en su totalidad. Este es el caso de los textos académicos, en donde un tipo de lenguaje puede ser apropiado en determinado contexto o disciplina, pero inapropiado en otros casos, tal como sucede en las críticas sobre la escritura, por ejemplo, “como un mensaje de celular" en un contexto académico, como vemos en la siguiente observación del juez.

[...] Y otra de las cosas es que no escribas como un mensaje de celular ya que esto es

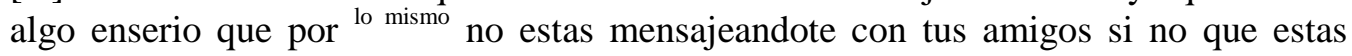
plasmando lo que piensa.

Checa bien lo que has escrito y veras que estas escribiendo como un celular por lo que antotaste " $\mathrm{x}$ " y eso no se ocupa en este tipo de redacciones. [f] (triom05juez)

En el caso de los estándares contextuales contemplo la relevancia de aparición de un texto en su temporalidad y trayectoria textual, puesto que en la reflexión sobre el desempeño un alumno puede incluir el momento y el entorno en que un texto cobra vida, así como las transformaciones contextuales de la función comunicativa para determinado escrito en diversas etapas o trayectorias textuales, por ejemplo, en distintos momentos de la formación académica en la universidad. También incluyo la construcción de significados y el tipo de género textual como estándares contextuales, puesto que en determinada situación de aparición de un texto el alumno de manera continua construye conocimiento y significado, tal como propone Ivanič (1998), al mismo tiempo que amplía su manejo de 
géneros y tipologías textuales. Este es un proceso de construcción y resignificación que involucra distintos tipos de reflexividad que el alumno puede manifestar por escrito, en una interacción favorable para la expresión de sus ideas.

Incorporo el estándar de prácticas y usos de la escritura. Me apoyo en el trabajo de Ivanič (1998), al destacar que en la interacción en un contexto el individuo, al construir conocimiento y significado, también construye identidad. Ésta se manifiesta, principalmente, en aquello que le representa y significa al alumno la práctica de escritura y cómo impacta en su desarrollo académico y personal en el ambiente académico, y también sobre la manera en que el autor y el juez que hace comentarios a su compañero se representa o posiciona ante el texto, así como las oscilaciones en el posicionamiento de enunciación, al abordar temáticas específicas que considera relevantes. Además, incorporo a la propuesta de estándares, los criterios sobre la interacción y la conformación de actores e interlocutores en la construcción de la interpretación en la comunicación escrita. Considero que estos aspectos están estrechamente relacionados, tal como proponen Eco (1979) y Beuchot (2002).

Considero que en los distintos comentarios y reflexiones de los alumnos sobre el tema del desempeño escrito y las experiencias compartidas sobre la escritura en ambientes académicos, estarán presentes algunos de los estándares de textualidad que aquí propongo, incluida la reflexividad y la intencionalidad. Evidentemente, en toda práctica de interacción escrita e interpretación textual, autores y lectores ponen en juego todos o algunos de estos principios. El individuo puede, por distintas cuestiones, simplemente no ponerlos de manifiesto en sus escritos, ya sea, por ejemplo, porque no maneja los recursos de lenguaje que le faciliten desarrollar sus ideas, por timidez, por abordar otras temáticas ajenas a la escritura o por evadir el tema. Aquí el punto relevante es crear las condiciones favorables para que el alumno se exprese y manifieste evidencias de estos aspectos y, principalmente, de la reflexividad sobre estos principios de textualidad. 


\subsubsection{El posicionamiento de enunciación y las relaciones de referencia textual}

La relación de opacidad y transparencia en la apreciación del signo y el conocimiento nos remite al establecimiento de relaciones de referencia vinculadas a la expresión de la reflexividad. Así, también me apoyo en la propuesta de Perry (2001) sobre la conformación de mecanismos de referencia hacia el objeto o motivación de la reflexividad y su manifestación en el lenguaje en el nivel de representación mental y discursiva, como un recurso de construcción, identificación y regulación de significados. Indudablemente este tema requiere de un desarrollo amplio que no contemplo en este trabajo. Únicamente considero las relaciones de referencia en el plano de los recursos formales de redacción, cuando los alumnos se remiten de manera implícita o explícita a determinados elementos de los textos en sus comentarios.

Las relaciones de referencia tienen una manifestación de textualización formal correspondiente a los principios constitutivos de coherencia y cohesión, en concreto cuando los alumnos establecen o intentan establecer las relaciones de referencia relacionadas con elementos de la estructura textual, al remitirse a diversos elementos presentes en los textos propios o en los de sus compañeros, así como en la información extratextual, por ejemplo, las referencias a elementos tomados de la interacción oral.

Las relaciones de referencia son recursos de enunciación y textualización que reflejan múltiples cuestiones en sus manifestaciones, relacionadas con el tipo de desempeño escrito de cada alumno, y también con la toma de decisiones de textualización que podemos relacionar, en algunos casos, con evidencias de intencionalidad y reflexividad, tal como presentaré más adelante en los ejemplos sobre la manera en que los alumnos hacen referencia a elementos textuales propios o del texto de sus compañeros.

Mediante los recursos de referencia textual establecemos una relación de correspondencia entre un objeto, idea, expresión o manifestación y los modos de mencionarlos o referirnos a ellos, ya sea, por ejemplo, mediante recursos pronominales o directamente mediante ejemplos concretos en el plano textual e intertextual. Este tipo de referencia corresponde al enfoque de la propuesta de la lingüística textual, tal como lo 
concibe, por ejemplo, Adam (2005). Estas relaciones de referencia pueden tener alcances extra oracionales y corresponder a elementos textuales diversos, por ejemplo, entre distintos párrafos y, en algunos casos, más allá del texto, cuando el alumno menciona aspectos que no escribió, pero que fueron parte de una interacción oral previa o corresponden a la lectura de otro texto, por ejemplo, el texto del compañero que leyeron. En este caso es relevante el enfoque de la intencionalidad, ya que muchas veces los alumnos tienen dificultad al establecer este tipo de relaciones de referencia. Cuando los alumnos parafrasean lo que ellos mismos o sus compañeros intentan expresar y cuando ejemplifican con muestras concretas de los textos o mencionan aspectos implícita o explícitamente, establecen o intentan establecer distintos tipos de relaciones referenciales con el objeto de reflexividad.

En este estudio contemplo los recursos de textualización de referencia inter y extratextual mediante los recursos de cohesión, desde el enfoque de la intencionalidad manifestada en el desempeño. Considero los casos en que los alumnos en algunas ocasiones no hacen o no logran establecer la relación de correspondencia en cuestión o bien la hacen de manera indirecta o implícita, refiriéndose tan solo a ideas, expresiones o elementos textuales asociados al objeto de referencialidad. Así contemplo en estos casos la caracterización de la intencionalidad en el manejo de recursos de textualización y, como veremos más adelante, su posible relación con elementos de reflexividad que relaciono con el tipo de comentarios, temáticas y con el posicionamiento de enunciación. Asimismo considero como criterio metodológico de referencia implícita aquellos casos en que el alumno aborda una temática sin remitirse de manera concreta a evidencias del texto, por ello contemplo la referencias implícitas y explícitas con o sin ejemplos de los textos en cuestión, como manifestaciones de intencionalidad y, en su caso, de reflexividad.

Hacer referencia implícita o explícita a determinada temática o elemento de textualidad implica un proceso regulativo y de reconocimiento de los objetos susceptibles de reflexividad, además del proceso de manifestación verbal de dichas relaciones de referencias, mismas que se van conformando en la medida en que el individuo expresa consciente o inconscientemente evidencias de intencionalidad y reflexividad. La práctica regulativa presente en el establecimiento de las relaciones de referencia y la construcción 
del signo o conocimiento, también son procesos que avanzan de manera cíclica en las diversas facetas de la reflexividad. Considero que un alumno manifiesta una reflexividad más conformada y consciente sobre la escritura cuando hace referencia explícita a aspectos concretos del desempeño propio o de otros, ejemplificando y estableciendo relaciones entre elementos de la unidad textual, en tanto que un alumno manifiesta una reflexividad incipiente o inferencial cuando simplemente expresa ideas generales al nivel de creencias o intuiciones sin hacer referencia a elementos concretos del texto.

A continuación presento un ejemplo en el que la alumna hace comentarios sobre la escritura de alumnos de nivel superior y además, comparte sus experiencias de escritura académica. Utiliza relaciones de referencia explícita con ejemplos concretos de reflexión sobre el texto que comentó y sobre el desempeño propio. Apreciamos en los comentarios de la alumna los estándares constitutivos de cohesión, con énfasis en la acentuación, además cuestiona la propiedad y la informatividad. Emplea la referencia explícita con ejemplos tomados del texto comentado.

[i] Con respecto a la reflexión que hace el compañero sobre su escritura, que empieza por una promesa, pues que no solamente debe de prometerse sino operar por mejorar sus fallas, asi como se dice "No solo hay que preocuparse sino hay que ocuparnos de eso".

El comentario que hace el alumno a su compañero, esta bien para mí ya que le sugiere poner los acentos, no hacer repeticiones y entre otras pero también que ponga los acentos, así como de la palabra "párrafo" pues es una palabra esdrújula....al igual que en otros puntos para cada línea.

En mi caso se me dificultan poner acentos o en dónde llevan acentos las palabras aunque sabiendo las reglas de las palabras graves, esdrújulas y sobreesdrújulas pues aún así se me presentan algunas dudas, al igual que saber de las letras que llevan hlazs palabras que se escuchan igual pero se escriben diferente, en fin son algunas cuestiones, ya que la escritura de esta lengua es diferente a la escritura de la lengua originaria porque estas son más notorias. [f] (trsicm36)

El posicionamiento de enunciación del autor es en una posible manifestación de un tipo de intencionalidad y, en su caso, de reflexividad. Los alumnos se representan a sí mismos en el texto, ya sea de manera directa ( $1^{\mathrm{a}}$ persona del singular) o inclusivamente $\left(1^{\mathrm{a}}\right.$ persona del plural) o bien con distanciamiento de manera prescriptiva o impersonal. Las oscilaciones en el posicionamiento de enunciación asociadas al tipo de reflexividad son muestras de que ante determinada temática y situación comunicativa el alumno decide en 
determinado tipo de consciencia o inconsciencia tomar distancia al representarse ante el texto. En el siguiente ejemplo vemos que la alumna comenta generalidades sin tratar el tema de la lectura y sin comentar el desempeño personal, asume un distanciamiento para representarse ante el texto al incluirse junto con otros en 1a persona del plural y posteriormente en $2^{a}$ persona singular (tú).

[i] Por mi parte considero que no es mi lengua natal sino que es nuestra segunda lengua por tal razon ${ }^{\text {tenemos }}$ esas dificultades de la ortografía, nos hace dificil escribir un texto tal como debe de ser por lo tanto, también algunos de nosotros como estudiantes no nos gusta leer; porque es una buena corrección de escritura si lees; además vas conociendo nuevas cosas en cuando vas leendo. conoces nuevos conceptos y te das cuenta de como se respetan los acentes, punto, coma etc. [...] (trsiscm41)

Este fragmento refleja el estándar de construcción de identidad, correspondiente a las temáticas de prácticas y usos, por ejemplo, al justificar los errores y la ausencia de gusto por la lectura debido a que el español no es la lengua nativa.

En el siguiente ejemplo, al tratar, sus propias dificultades, la alumna se representa en $1^{\mathrm{a}}$ persona del plural, es decir, incluyéndose junto con otros o bien de forma distanciada o en impersonal.

[...] Cinceramente, en mi opinión personal, e pasado por esas cituaciones en que senos dificulta ${ }^{\text {de }}$ realizar un texto, o la falta de compresión en la lectura, o que no le damos coheriencia a la redacion, o no sabemos como escribir la idea o ampliar el texto. [f] (triom06)

La manifestación de reflexividad puede ser consciente, inconsciente, implícita o explícita. En la reflexividad crítica e introspectiva sobre las propias creencias o conocimientos predomina la toma de conciencia de diversas facetas de intencionalidad y de reflexividad, con referencias explícitas al objeto o tema de reflexividad, con representación de interlocutores directa para referirse a los destinatarios de los textos, principalmente, en $2^{\mathrm{a}}$ persona singular (tú), en este caso, al hacer comentarios al compañero, también predomina el posicionamiento de enunciación del autor de manera directa en $1^{\mathrm{a}}$ persona del singular (yo).

En determinada fase podemos manifestar aspectos de reflexividad introspectiva y consciente sobre nuestras propias creencias y conocimientos y también podemos manifestar 
otros aspectos de reflexividad inferencial intuitiva y centrada en las creencias y las representaciones. Por ejemplo, al asumir el papel de autor podemos manifestar reflexividad inferencial e intuitiva, sin hacer referencias explícitas sobre nuestro desempeño, y, en contraste, manifestar una reflexividad distinta al comentar el texto de un compañero. Después en una siguiente fase, podríamos, por ejemplo, manifestar una faceta de reflexividad introspectiva y de autoevaluación al opinar sobre las observaciones realizadas por el juez en relación a nuestro propio desempeño, y, también, en contraste, una reflexividad intuitiva y centrada en nuestras creencias al opinar sobre el desempeño escrito del juez al hacer sus comentarios. En todos estos casos, está en juego la valoración y la reflexión sobre la intencionalidad, mismas que en la manifestación de las opiniones escritas pueden reflejar todas estas diversas fases en que se conforma la reflexividad como un juego cíclico de ida y venida sobre las valoraciones a partir de las regulaciones sobre las concepciones en torno a nuestro propio desempeño y el de los compañeros.

\subsection{Hacia la aplicación de una propuesta de modelo de caracterización y análisis textual}

Una vez que he realizado este conjunto de consideraciones teóricas sobre los conceptos de textualización, intencionalidad y reflexividad en el marco del enfoque de la textualidad en las escrituras académicas, considero que el aporte de la investigación radica en la aplicación de una propuesta de modelo para la caracterización y análisis de los objetos de intencionalidad y reflexividad en muestras de escritura académica. En el caso de este trabajo la aplicación concreta para la propuesta de caracterización y análisis de los elementos de intencionalidad y reflexividad en la escritura académica de los alumnos puede realizarse mediante el manejo de la herramienta conceptual de los estándares de textualidad de Beugrande \& Dressler (1997) para adoptar una enfoque y una metodología para el estudio de los textos. En la aplicación conceptual contemplo el manejo de estos criterios en una propuesta de modelo de textualidad conformado por estándares constitutivos, regulativos, contextuales y de prácticas o usos, tal como presenté en la tabla 2. Esta perspectiva me permite, también, establecer una propuesta integral del concepto de 
textualización que incluye aspectos constitutivos formales y contextuales. Además, considero, en sí misma, a la reflexividad como un estándar de textualidad estrechamente ligado a la intencionalidad, como elementos fundamentales para la comunicación. De esta manera establezco un sustento conceptual desde la perspectiva de la textualidad que me sirve para crear otros criterios y categorías para el estudio de los textos, y, por otra parte, los elementos de sustento para la construcción de una metodología de caracterización y clasificación textual mediante las herramientas idóneas para trabajar con los datos propios de la textualidad.

El tipo de categorías de clasificación y análisis textual a partir de la propuesta de estándares de textualidad también me sirve para proponer otras herramientas teóricas características de la textualidad con un enfoque para el estudio de algunos elementos de intencionalidad y reflexividad presentes en los textos. De esta manera tomo en cuenta los recursos de representación o posicionamiento del autor de manera directa en $1^{\mathrm{a}}$ persona singular o $1^{\mathrm{a}}$ persona del plural inclusiva o con distanciamiento impersonal o prescriptivo, así como el tipo de representación de los interlocutores, por ejemplo, de manera directa ( $2^{\mathrm{a}}$ persona singular) o distanciada ( $3^{\mathrm{a}}$ persona singular o plural). Éstos son elementos concretos de evidencia textual que nos permiten caracterizar distintos tipos de manifestaciones y facetas de intencionalidad y reflexividad. Estas manifestaciones están relacionadas con diversos tipos de razonamientos reflexivos sobre la textualización en los ámbitos formales y contextuales.

La propuesta de aplicación de un modelo de análisis textual contempla el énfasis en la caracterización de la naturaleza dual de las manifestaciones de evidencias de intencionalidad y reflexividad correspondientes, principalmente, a partes del pensamiento intencional y reflexivo. En la perspectiva del estudio de la textualidad es necesario reconocer la dificultad de tener acceso a algunas de estas evidencias, así como la necesidad de crear situaciones de elicitación que favorezcan la manifestación escrita de aspectos de intencionalidad y reflexividad. Además, en la propuesta contemplo la necesidad de caracterizar el objeto de reflexividad en términos de elementos de la textualidad en el contexto académico. Considero que el objeto de reflexividad sobre la textualización en algunos momentos puede ser transparente o claramente identificado o bien ser difuso, por 
ejemplo, cuando no es posible explicitarlo porque se encuentra en un modo de conocimiento incipiente o bien el alumno aborda temáticas relacionadas pero ajenas al tema de reflexión. Así contemplo que el objeto de reflexividad está continuamente en conformación, y por lo tanto es fundamental contemplar la intencionalidad en la manifestación de la reflexividad.

Sobre el concepto de intencionalidad aporto la propuesta de la caracterización de la multiplicidad de manifestaciones y recursos de escritura cuando los alumnos tratan de expresar diversas temáticas aún cuando no logren resolver diversas dificultades de textualización, de manera tal que lo que el alumno intenta expresar puede estar expresado de manera implícita, difusa o ambigua. En este punto propongo la caracterización de las evidencias de reflexividad sobre estas manifestaciones intencionales al abordar temáticas relacionadas con el desempeño académico. Además contemplo la necesidad de caracterizar en la multiplicidad de facetas de la reflexividad aspectos de reflexividad introspectiva y consciente sobre nuestras propias creencias y conocimientos y también otros aspectos de reflexividad inferencial intuitiva y centrada en las creencias y las representaciones. En la propuesta de enfoque conceptual contemplo que los alumnos manifiestan estas variedades multifacéticas de manifestaciones reflexivas al abordar diversas temáticas relacionadas con el desempeño académico. Por ello contemplo la necesidad de enfatizar en las fases de elicitación aquellos aspectos que los alumnos contemplan como relevantes en sus puntos de vista sobre el desempeño académico.

Considero que la reflexividad es la manifestación de diversos tipos, modalidades y facetas del pensamiento y conocimiento reflexivo, y está conformada por el conjunto de concepciones, ideas, pensamientos, conocimientos y actitudes regulativas e intencionales en distintas facetas, algunas como intuiciones y otras como conocimientos plenamente conformados y elaborados. El individuo puede manifestar reflexividad como conocimiento intuitivo o creencias sobre aspectos del desempeño escrito, y a su vez, en otra faceta puede reflejar un mayor número de elementos reflexivos cuando manifiesta reflexividad sobre dichas creencias relacionadas con el desempeño escrito. En este proceso las manifestaciones de intencionalidad siempre estarán presentes, principalmente, en el manejo de recursos de escritura y en las temáticas abordadas. 
La propuesta de modelo de aplicación de criterios conceptuales en el marco de la textualidad implica crear un enfoque dinámico sobre la reflexividad. Considero que la reflexividad es la manifestación consciente o inconsciente, implícita o explícita, generalmente, de parcialidades del pensamiento reflexivo. Propongo que la reflexividad sobre la escritura es un proceso jerárquico, cíclico, multifacético y recursivo en distintos tipos de conceptualizaciones y valoraciones de la escritura y del desempeño propio y el de otros, y los factores que el individuo, concibe, considera y puede llegar a manifestar como relevantes para la comunicación y para su desempeño académico. Para tener acceso a algunas evidencias de reflexividad los alumnos requieren manifestarse, en este caso por escrito, sobre la experiencia de textualización, los recursos empleados, las problemáticas enfrentadas, lo que les representa la escritura académica en términos del manejo de principios constitutivos y regulativos, así como lo que manifiestan sobre lo que sienten, experimentan y les significa la revisión y edición de sus propios textos como parte de la construcción de identidad y de conocimiento. Este tipo de reflexividad incluye lo cognitivo, lo afectivo, la inseguridad, el prestigio, criterios sobre el desempeño lingüístico y las actitudes ante dificultades enfrentadas en la redacción. El reto de investigación es crear situaciones e interacciones académicas en que los alumnos manifiesten este tipo de elementos de reflexividad por escrito. 


\section{Capítulo III}

\section{Propuesta metodológica para la elicitación y la caracterización de los textos}

\subsection{Sobre el enfoque y perspectivas de la elicitación.}

En las investigaciones realizadas a partir de muestras o evidencias orales o escritas correspondientes a los datos obtenidos para estudiar el objeto de estudio o de interés, la elicitación corresponde a lo manifestado o las respuestas de los individuos, por ejemplo, en la entrevista, el cuestionario, las instrucciones solicitadas o cualquier tipo de interacción contemplada. Así, la elicitación puede llevarse a cabo gracias al diseño de múltiples posibilidades de recursos metodológicos que el investigador diseña conforme a los intereses de estudio. En esta investigación, la expresión escrita de los estudiantes es fundamental para el diseño de la metodología para la elicitación.

La tarea de trabajar con muestras de escrituras de alumnos en ambientes académicos es un reto complejo, puesto que en los intentos para obtener evidencias de escritura para los intereses de esta investigación, nos vemos en la necesidad de construir un diseño de interacción que vamos armando a partir de las distintas fases de elicitación desde los primeros sondeos exploratorios. En este proceso es necesario tomar decisiones a partir de las experiencias en cada fase de elicitación conforme a los intereses y objetivos de la investigación, y, principalmente, la naturaleza del dato o información que buscamos, en este caso, en la escritura de los alumnos. Las metodologías de elicitacíón para obtener muestras de escritura sobre las concepciones o actitudes en contexto académico están en un proceso de construcción, como técnica general predomina la entrevista y el análisis de muestras de escritura de trabajos escolares sobre diseños preestablecidos, principalmente, sobre planeaciones didácticas.

Desde diversas perspectivas, existe la posibilidad de generar diseños guiados o 
modelos para la obtención del dato o bien hacer que los alumnos escriban libremente e intentar interpretar los datos obtenidos. En ambos casos considero que existe la problemática de asumir que el dato es algo que está disponible y accesible, listo para que el investigador prácticamente lo tome o lo solicite. Proceder de esta manera es, desde mi perspectiva, una ingenuidad metodológica que poco ayuda, particularmente, para el estudio de la reflexividad e intencionalidad sobre las prácticas de escritura. De hecho, en principio el dato no es una entidad empaquetada manipulable de fácil acceso, podemos trabajar con los datos, solamente en un complejo proceso de construcción metodológica para poder tener acceso a la información, en ese caso, de manera escrita y, posteriormente, a lo largo de un proceso de construcción de un corpus que nos permite poco a poco tener acceso a esos datos que se constituyen en los objetos de interés de nuestra investigación. En muchas ocasiones ese dato no corresponde al objeto en cuestión que deseamos focalizar, y en estas situaciones debemos contemplar la manera de obtener la información en la fase de elicitación y la construcción del corpus. Para poder ver nuestros objetos de investigación, manifestados en la escritura, es necesario llevar a cabo un proceso de toma de decisiones que nos facilite mejorar nuestros instrumentos e interacciones, es necesario, en suma, diseñar una metodología de elicitación.

En esta investigación un objetivo central era el desarrollo de una propuesta metodológica de elicitación, manejo de los datos y establecimiento de criterios para la interpretación del corpus de trabajo. En esta ocasión, presento el proceso de construcción de la elicitación que incluyó distintas fases de interacción que desarrollamos en la Universidad Autónoma Metropolitana Iztapalapa, los planteles de Ixtepec y Tehuantepec de la Universidad Pedagógica Nacional y los planteles de Oxchuc y San Cristóbal de las Casas en la Universidad Intercultural de Chiapas (UNICH).

Me propongo presentar y discutir las experiencias vividas, las modificaciones y las decisiones en cada experiencia de interacción para la construcción de una propuesta de diseño de elicitación para obtener muestras representativas de escritura académica. Además, considero los alcances y expectativas de los criterios metodológicos de elicitación e interpretación de las muestras de escritura académica, como parte de un diseño construido con la idea de estudiar las evidencias de reflexividad presentes en los escritos de alumnos 
de estas universidades que participaron en prácticas de revisión y edición de textos. En esta discusión y reflexión sobre el proceso de elicitación, el punto fundamental que permite el avance en el diseño de elicitación es contemplar aquellas decisiones para modificar los instrumentos, la interacción y el diseño a partir de los datos obtenidos en cada sesión de trabajo con los alumnos, con el propósito de mejorar o adaptar la metodología conforme a las necesidades requeridas e intereses de investigación.

En general en este trabajo tan solo presento los criterios metodológicos de elicitación y de clasificación, sistematización caracterización de los textos y criterios para crear categorías para el primer acercamiento a los textos y la interpretación.

\subsection{Primeros criterios para la toma de decisiones en la fase de elicitación}

En la sección anterior comenté que la reflexividad es una manifestación de la intencionalidad y de un conjunto de concepciones, ideas, creencias, intuiciones, conocimientos y actitudes, en este caso, sobre el desempeño de la escritura. Además, contemplé el hecho de que la reflexividad enunciada o manifestada en el lenguaje puede corresponder a determinados tipos y modalidades en las construcciones de reflexividad como un proceso cíclico y recursivo, ya sea consciente o inconsciente, implícito o explícito. El asunto sobre la existencia de la reflexividad es que ésta está presente en nuestras concepciones, pensamientos y conocimientos, pero no necesariamente la manifestamos, al igual que nuestras intenciones en la interacción mediante el lenguaje, en este caso el escrito. Esto puede deberse a múltiples causas, por ejemplo, por timidez, confusión, dificultad en el manejo de recursos expresivos o por encontrarse en el nivel de intuiciones o conocimiento en gestación. En suma, la reflexividad se puede manifestar cuando las condiciones interactivas favorecen que el individuo se exprese e intente reflexionar o manifestar consciente o inconscientemente sus concepciones. Aún así, nunca podemos tener certeza de que un alumno exprese todas sus concepciones de reflexividad sobre un tema determinado.

Por lo anterior, sería muy ingenuo pensar que los alumnos expresarán evidencias de reflexividad por instrucciones directas, del tipo "dime lo que piensas o reflexionas sobre el 
desempeño", "haz un comentario crítico del desempeño” o “¿qué opinas sobre el desempeño tuyo y el de tu compañero?”. En realidad tenemos que pensar en un diseño para la fase de elicitación que propicie lo más espontáneo y natural posible la interacción y la expresión, en este caso escrita, sobre el tema de la escritura y el desempeño personal y el de los compañeros. Considero que en este caso la práctica de revisión y edición de los textos al asumir el papel de jueces y autores, con interacción y retroalimentación escrita puede facilitar y propiciar que los alumnos se expresen sobre la temática de sus desempeños y manifestar así la reflexividad. Con esto en mente, me propuse diseñar una interacción con estas características. A continuación presento las fases de construcción del diseño de la fase de elicitación en los sondeos previos que me sirvieron para la toma de decisiones y modificaciones realizadas al diseño, primero en la Universidad Autónoma Metropolitana Iztapalapa (UAMI), después en la Universidad Pedagógica Nacional (UPN) de Ixtepec y Tehuantepec, Oaxaca y finalmente en la propuesta aplicada en la Universidad Intercultural de Chiapas (UNICH) en San Cristóbal de las Casas y Oxchuc, Chiapas. Presento más adelante ejemplos representativos de textos con algunas evidencias de reflexividad, sin embargo, en general obtuvimos las muestras de escrituras académicas en condiciones muy accidentadas, por ello los datos, o elementos empíricos son apenas muestras fragmentarias o indicios a modo de ejemplos no exhaustivos que no pueden ser tomados como un corpus para el análisis de estudios de casos. Sin embargo, estos textos son útiles para aplicar una metodología de sistematización, caracterización y aplicación de criterios para la clasificación textual.

\subsection{Fase de elicitación 1: Universidad Autónoma Metropolitana Iztapalapa}

Realizamos este primer ejercicio a manera de sondeo con un grupo de los alumnos de lingüística del Profesor Héctor Muñoz Cruz, en la materia de enseñanza de la lengua materna en la UAM Iztapalapa. En conjunto con el Dr. Muñoz Cruz realizamos el diseño y lo aplicamos con sus alumnos. En esta ocasión, los alumnos tendrían que revisar un texto 
de reflexión sobre las propuestas de temáticas y autores seleccionados como parte de su evaluación. En general la UAM Iztapalapa es una institución de instrucción monolingüe en español, la población es amplia y es difícil identificar a los alumnos bilingües indígenas.

\section{Descripción de las sesiones del ejercicio}

\section{Sesión 1:}

Primero el profesor nos presentó a sus alumnos del curso Introducción al lenguaje, antes del examen, con quienes haríamos el ejercicio de elicitación. En esta ocasión trabajé en el diseño de elicitación con los alumnos de la materia optativa de Enseñanza de la lengua, quienes participarían controlando las actividades del ejercicio. Como parte de su examen, los alumnos del curso Introducción al lenguaje tenían que redactar un comentario sobre un texto de interés que anteriormente seleccionaron como parte del curso del Dr. Muñoz. Consistió en desarrollar amplia y razonadamente cuatro preguntas referentes a las lecturas: El origen del lenguaje, Las lenguas minoritarias y La globalización a las lenguas minoritarias. A continuación presentamos las instrucciones del examen.

El examen consiste en desarrollar amplia y razonadamente una de las cuatro preguntas siguientes. Selecciona libremente una de ellas, respóndela en esta misma hoja. El tiempo máximo de contestación es una hora y media. Cumplido el tiempo asignado, se organizará en plenaria la segunda actividad del proceso de examen.

El texto del examen no tiene una extensión predeterminada. No dudes en ocupar todo el espacio necesario para redactar tus explicaciones.

Te solicitamos escribir de la forma más legible posible, debido a que tu texto será capturado por otro compañero.

Platón: Expresa tu preferencia por una de las dos teorías sobre el origen del lenguaje que se plantean en El Cratilo. Explica por qué.

Dortier: Siguiendo a los diversos autores que cita Dortier. ¿Cuáles son las principales hipótesis sobre la aparición del lenguaje? Comenta la importancia de estas explicaciones y establece las diferencias.

García: Desde tu punto de vista ¿en qué afecta la globalización a las lenguas minoritarias?

Boyer: ¿Qué opinas del fenómeno del hibridismo lingüístico contemporáneo? Comenta con base en las ideas de H. Boyer?

Después del examen, pedimos a los alumnos que lo intercambiaran con otro compañero, cada alumno sería crítico de su propio texto y actuaría como "juez" del texto de 
un compañero, con el propósito de hacerle comentarios y sugerencias críticas que le pudieran servir para mejorar la redacción. Los jueces tendrían que leer el texto y hacer las observaciones, comentarios y sugerencias por escrito. Al asumir el papel de jueces cada alumno tenía que seguir las indicaciones de las siguientes instrucciones y cuestionario:

Acabas de recibir una primera versión del examen de uno de tus compañeros. Te solicitamos desarrollar un importante papel de lector crítico y comentarista del escrito que has recibido. Sin importar el nombre o la persona, deberás actuar con honestidad y solidaridad, para que el texto de este examen pueda mejorar en varios sentidos.

Primero, te solicitamos que captures el texto en un archivo Word y contestes lo que se te pide a continuación en el archivo word:

¿Qué opinas de la organización del texto que recibiste?

¿Qué objetivos se propone el texto? ¿Se desarrollan claramente los objetivos?

Explica.

Comenta si en el texto se desarrollan de manera adecuada los conceptos que plantea el autor elegido. Explica.

¿Qué recomendaciones sugieres para mejorar este texto?

Sobre esta parte del diseño podemos destacar que en principio se ajusta a una práctica académica cotidiana y en particular sobre una manera de evaluar del profesor a partir de comentarios sobre alguna de las lecturas del curso. Esta actividad es favorable para contemplarla como una fase de elicitación porque los alumnos la consideran como un procedimiento normal del curso y no existe la sensación de que están participando en una interacción artificial o como parte de una investigación. Este tipo de interacciones basadas en situaciones incorporadas en prácticas cotidianas donde el investigador logra crear un diseño a partir de una actividad lo más espontánea en el contexto de la comunicación mediante la lengua aparece, por ejemplo, en los trabajos de Brice-Heath (2009) y BriceHeath \& Street (2008) desde una perspectiva de la etnografía de la comunicación.

De hecho, cuando los alumnos saben que están participando en un ejercicio para una investigación, en muchas ocasiones llegan a fingir o intentar expresarse de tal manera que den cierta impresión al investigador. En esta fase de elicitación fue una ventaja importante que los alumnos participaran libre y naturalmente como parte de una actividad cotidiana en la manera de resolver examen. El único aspecto diferente fue la petición de que opinaran sobre el texto de uno de los compañeros y que contestaran el cuestionario en 
Word en su casa. De esta manera podríamos propiciar que los alumnos hicieran un mayor esfuerzo al evitar las distracciones y la falta de tiempo en la clase.

El cuestionario está centrado en comentarios sobre el texto, su estructuración y los objetivos planteados, y no sobre una opinión acerca del estudiante o sobre su desempeño. De esta manera es posible propiciar una opinión basada en ideas relacionadas con la consideración de aspectos vinculados con estándares de textualidad a partir de la descripción y valoración de recursos lingüísticos. Además, la manera de opinar sobre la organización textual y hacer sugerencias para mejorar el texto, es una forma de evitar que el alumno simplemente haga evaluaciones normativas y prescriptivas, principalmente, para descalificar al compañero. Un aspecto fundamental en esta etapa es que los alumnos hacen esa actividad como parte de su calificación, por ello considero que en general se mostraron comprometidos a hacer comentarios cuidados. Otro aspecto fundamental en el diseño de las instrucciones es que los alumnos sabían que estaban revisando "una primera versión del examen" de uno de sus compañeros. Esta situación genera la expectativa de que en la práctica desarrollada los alumnos tendrían la oportunidad de hacer revisiones y modificaciones al examen y que los comentarios estaban encaminados a ayudar al compañero.

\section{Sesión 2:}

Ésta se dividió en diversas etapas: presentación de los alumnos de la materia optativa que nos ayudaron en esta fase de elicitación, el apoyo a los alumnos para la organización de ideas, fase de redacción del texto, fase de elaboración de comentarios sobre los textos de los compañeros, fase de retroalimentación, y finalmente la edición del texto.

\section{Fase 1: Interacción entre autores y jueces}

Después de la presentación de los participantes de la materia optativa, el profesor aclara que éstos ayudarían a resolver dudas sobre la organización de la actividad. Organizamos el grupo en parejas, conformadas cada una por un autor y un juez. Los jueces leerían los comentarios y sugerencias a los autores, además, mostrarían en el texto de su compañero aquellos puntos susceptibles de modificarse, apoyándose del cuestionario que les proporcionamos al final de la sesión 1 . Les dijimos que podían tomar notas en su propio escrito, de manera tal que recordaran aspectos comentados. 
Este tipo de retroalimentación directa por parte del juez a su compañero para discutir y, en su caso, reflexionar sobre los comentarios escritos que escribió al compañero, constituye un recurso para motivar la valoración, regulación y evaluación del desempeño de una manera crítica que propicia la comunicación y el intercambio de puntos de vista, principalmente, la reacción del autor al recibir los comentarios. Además, la interacción oral en este momento es un aspecto que permite aclarar puntos y puede favorecer la motivación para que el alumno tenga disposición para escribir e intentar mejorar su texto a partir de todos los elementos contemplados en este diseño de elicitación.

\section{Fase 2: Intercambio de roles y breves comentarios}

Ahora dimos la indicación de intercambiar roles, quienes fueron jueces buscaron al compañero que revisó su texto para escuchar los comentarios de alguien más sobre sus escritos, aquel que leyó su texto y lo comentó, tal como se pidió en el cuestionario.

Una vez terminada esta actividad, solicitamos, de manera grupal, que los alumnos comentaran acerca de las sugerencias que escucharon. En general, no hubo mucha participación, tres alumnos comentaron aspectos de ortografía y léxico.

La presentación que el profesor realizó de nosotros y la explicación de que participaríamos simplemente para ayudarlo a resolver dudas ayudó, en gran medida, a que los alumnos no se sintieran incomodados, vigilados o evaluados, además, considero que fue favorable el que supieran que también éramos estudiantes. La actividad estaba centrada en resolver de manera práctica las cuestiones de escritura porque los jueces tendrían que mostrar de manera concreta las partes del texto susceptibles de mejorarse para tener una retroalimentación con los compañeros. La sugerencia de que tomaran notas en su escrito sobre la interacción con los jueces era una manera de dar importancia a los comentarios recibidos y a establecer una postura y valoración sobre los comentarios y sugerencias para mejorar el texto. Esta breve interacción oral de retroalimentación es un recurso encaminado a motivar que los alumnos se animen posteriormente a plasmar por escrito sus planteamientos y lo que opinan sobre su propia escritura. Tomé en cuenta esta situación y la desarrollé posteriormente en el diseño aplicado en la Universidad Intercultural de 
Chiapas cuando los alumnos expresaron por escrito lo que opinaban sobre los comentarios recibidos.

\section{Fase 3: Experiencia y reflexión}

En esta fase pedimos a los alumnos que expresaran comentarios sobre la experiencia de ser 'criticados' por otro compañero y que expresaran lo que habían encontrado en los textos que pudiera mejorarse. Fue una actividad en la que destacaron las principales dificultades que encontraron en los textos de sus compañeros. Las sugerencias consistieron en aspectos superficiales del texto; esto es, expresaban sus sugerencias acerca de la ortografía, redundancia del léxico utilizado, esbozo de las ideas, etc. Esta interacción fue de manera oral y grupal, recuperamos lo expresado, en la medida de lo posible, en el pizarrón.

En esta parte, la interacción fue guiada, simplemente para propiciar una breve reflexión grupal sobre la experiencia vivida. La dinámica fue propiciar una manifestación sobre la experiencia de recibir comentarios por escrito. Considero que en este punto la poca participación de los alumnos en la dinámica grupal se debió a un aspecto del diseño que realmente no propició o favoreció la motivación para la posterior actividad de escritura. Me parece que no resulta motivante el que los alumnos se expresen grupalmente sobre la experiencia de recibir comentarios, puesto que es una cuestión que los puede desviar del tema de la escritura académica y además los puede intimidar porque no es una práctica común. En las siguientes fases de elicitación tomé en cuenta este aspecto y en lugar de hacer esta actividad grupalmente, contemplamos la reacción ante comentarios recibidos y lo que les representa participar en este tipo de actividades de manera escrita e individual y también como parte de una guía de apoyo sugerida, con el propósito de centrar la atención de manera personal en una reflexión escrita sobre el desempeño propio

\section{Fase 4: Evidencias de reflexividad por parte de los alumnos}

La importancia de la actividad anterior consistió en crear una reflexión sobre las ideas que pudieran ayudar a mejorar el texto redactado. Recordemos que en este momento ya todos fueron autores y jueces. En esta fase pedimos a los alumnos que comentaran sus ideas sobre aquello que consideran que debe tener un texto académico, con el fin de escribirlas en el pizarrón; esto facilitaría la recopilación de comentarios de los alumnos, 
para los posteriores análisis. Conforme iban participando hacíamos una síntesis en el pizarrón sobre lo que iban diciendo; en todo momento recuperamos lo que expresaban los alumnos, evitando condicionarlos, hacer juicios valorativos o precisiones normativas, simplemente, intentábamos escribir de manera sintetizada lo expresado. De esta manera podemos tener más elementos registrados para dar cuenta de los aspectos de reflexividad.

En un primer momento, los alumnos destacaron cuestiones sobre la textualización, fundamentalmente sobre aspectos relevantes para la corrección. Esto fue lo que acordó la mayoría y que apuntamos en el pizarrón.
Cuidar la ortografía
Repetición de palabras (usar sinónimos)
Carencia de cierre.
En cuanto a la organización del texto (cohesión): ideas sueltas;
Congruencia: no se llega al objetivo
Redundancia: hay demasiada información no importante.
Búsqueda de la estructura adecuada para llegar a concluir
la idea que se pretende.

En este punto, en general los alumnos destacaban aquellos aspectos en que notaron dificultades o fallas que veían en los textos. Durante la interacción insistimos en que sugirieran ideas para mejorar el texto, sin embargo, prevaleció en ellos una visión descriptiva en la que evaluaron el desempeño de sus compañeros. Solamente una alumna, destacó la necesidad de planificar conforme a una estructura para "concluir la idea que se pretende". Este comentario dio lugar a que algunos alumnos comentaron sobre la necesidad de organizar las ideas y contemplar la distinción entre los conceptos y los puntos de vista. Podemos apreciar que en este punto destacan de manera fundamental la coherencia textual, sin mencionarla como tal. A continuación los aspectos que sintetizamos sobre este punto en el pizarrón.

\footnotetext{
Mantener pautas

Balance entre conceptos y puntos de vista

Balance y diferencia

El problema de traer varios conceptos y al mismo tiempo
} 
Podemos percatarnos de que existe una clara reflexión sobre el texto, en concreto sobre procesos de textualización y la coherencia. Los alumnos reflexionaron sobre la forma de intentar organizar, clarificar y concluir sus ideas eficientemente. Sin embargo, notamos varias dificultades sobre estos puntos en los textos redactados, puesto que los alumnos se enfrentan a problemáticas complejas que deben resolver sobre pautas, balance entre conceptos y puntos de vista, así como la relación entre diferentes conceptos. En este punto la reflexividad manifestada se refiere a las propias dificultades sobre el desempeño personal y de otro al distinguir los planteamientos propios y los conceptos de las lecturas, así como de los procesos concretos de textualización, principalmente de coherencia y cohesión.

En esta parte del diseño de la interacción de elicitación prevaleció una visión descriptiva y evaluativa por parte de los jueces sobre el trabajo de los compañeros. Me parece que esto se debe a que la reflexión grupal se realizó una vez que todos los alumnos habían asumido el rol de jueces y, de esta manera, la actividad no había servido para propiciar la escritura y la reflexión al momento en que los alumnos asumieron el rol de jueces y escribieron comentarios. Es decir, la reflexión grupal no fue aprovechada para el propósito de que los alumnos comentaran por escrito sus apreciaciones en relación al texto revisado y que así pudieran llegar a manifestar evidencias de reflexividad. Por lo anterior, decidí que en el diseño final, la actividad de una lluvia de ideas sobre aquello que los alumnos consideran que debe contener un texto académico en la universidad se haría justo antes de que los jueces revisaran el texto y escribieran sus comentarios. Además, consideré que los autores escribirían su opinión acerca de los comentarios del juez una vez que hicieran una breve interacción oral que motivara la escritura.

Los ajustes en estos detalles sirvieron para construir gradualmente el diseño aplicado posteriormente en la Universidad Intercultural de Chiapas. De esta manera, podemos establecer una propuesta de construcción gradual de las decisiones elicitación aplicadas en cada experiencia de interacción para proponer modelos, diseños y materiales flexibles en cada contexto y situación correspondiente a cada universidad. En particular el diseño aplicado en la UAM Iztapalapa me permitió tomar en consideración el tipo de interacciones, los momentos y las temáticas propicias para hacer actividades que motivaran la expresión escrita en las actividades desarrolladas. 


\section{Fase 5: Comentarios sobre organización textual (coherencia y cohesión)}

Evitamos en todo momento hacer que los conceptos de coherencia y cohesión fueran motivo de una explicación tipo clase, puesto que nuestro interés era recuperar aquellos comentarios que reflejan la reflexividad sobre el desempeño, así como el funcionamiento de los recursos de la textualización.

Una vez que los alumnos expresaron sus ideas y que las fuimos sintetizando en el pizarrón, procedimos a comentar la importancia de organizar el texto. Para ello comentamos la necesidad de que el texto tenga armonía y que esté organizado en su estructura, y que sea claro y fácil de entender, es decir, que tuviera cohesión y coherencia. Inmediatamente, sin mayores explicaciones, apuntamos a manera de recomendación el siguiente cuadro en el pizarrón.

(Cohesión): procurar que el texto tenga armonía, que esté organizado en su estructura, en las concordancias entre pronombres, género, número y referencia, y que esté gramaticalmente bien armado.

(Coherencia): Intentar que el texto sea claro y fácil de entender. En el texto, aquello que vas a explicar o plantear, debe coincidir con lo que escribes en el desarrollo a lo largo del texto; por lo tanto, no ser incongruentes.

Comentamos la importancia de estos aspectos y que prestaran atención a estos puntos en la organización de su escrito. Entonces procedimos a proporcionarles la guía para la redacción de la versión final.

Tomamos la precaución de revisar que en este cuadro sobre la cohesión y la coherencia estuvieran presentes todos los aspectos que los alumnos habían considerado, solamente incorporamos la recomendación que una alumna planteo de que "no debemos ser incongruentes". También les dijimos que en caso de no estar de acuerdo nos dijeran para eliminar los puntos que consideraran. Los alumnos estuvieron de acuerdo en que en el cuadro proporcionado estaban contenidas todas las ideas que habían expresado. La decisión de proponerles un cuadro una vez que los alumnos expresaron sus puntos de vista nos sirvió para evitar la sensación de que nosotros les habíamos impuesto esta información, además nos ayudó a controlar la posible dispersión sobre el tema y que nos estancáramos en una discusión sobre la definición de coherencia y cohesión, puesto que no era el objetivo. Nuestro interés únicamente era propiciar la motivación para que escribieran. Como parte 
del diseño consideré que esta actividad no debería ser parte de la interacción grupal para evitar la posible dispersión y la sensación de imposición de los conceptos en cuestión. En el diseño final simplemente eliminé las palabras coherencia y cohesión y no realicé ninguna actividad de interacción grupal sobre este punto. Simplemente mantuve esta información como parte de la guía de apoyo en la que consideré que simplemente era necesario decirles a los alumnos que esta información les podría ser útil y que podrían emplearla si así lo deseaban.

\section{Fase 6: Entrega de guía o pre-texto}

En esta fase les indicamos a los alumnos que les entregaríamos un esquema que serviría para hacer la versión final de sus exámenes. Este texto no se realizó en clase, por evidente falta de tiempo. Sin embargo, sí se les pedimos que llenaran los rubros de la guía; para esto, los apoyamos resolviendo y aclarando dudas, o simplemente repitiendo lo que se pedía en la guía. Precisamos oralmente las indicaciones del ejercicio como sigue:

En el primer punto simplemente escriban el título; en el segundo punto respondan de manera breve y precisa las preguntas sobre qué quieren demostrar y con qué procedimientos demostrarás tus ideas. En el tercer punto, van a hacer una lista de las ideas principales que a ustedes les parecen más importantes. En el siguiente punto resumirás tus conclusiones en una oración. Y finalmente escribirás las fuentes consultadas.

Finalmente, veremos los puntos del esquema que les entregamos para poder llegar a una mejoría de sus textos:

-Título del escrito: incluyendo, nombre del autor, fecha y lugar

-Enmarque o contextualización del trabajo. ¿Qué quieres demostrar? ¿Con qué procedimientos demostrarás tus ideas?;

-Ideas principales que desarrollarás en el trabajo: Enlistalas en orden de importancia para ti, independientemente del autor seleccionado.

-Conclusiones: Resume en una oración cada una de las conclusiones a las que piensas llegar en tu escrito.

-Fuentes de consulta. Enumera las fuentes bibliográficas, hemerográficas que emplearás en tu trabajo.

Este esquema nos sirvió simplemente como un apoyo para que los alumnos tuvieran lineamientos sobre la estructura textual que el profesor solicitó para apoyarlos en la redacción de su examen. En el caso del diseño final no había examen de por medio, y por 
ello simplemente realizamos una guía temática reducida sugerida para que los alumnos se centraran en aquello que deseaban expresar. Tampoco hicimos una actividad relacionada, simplemente enfatizamos en que esa guía era sugerida y que les podía servir.

En general la experiencia de interacción con los alumnos de la Universidad Autónoma Metropolitana Iztapalapa en una situación académica correspondiente a la resolución de un examen sobre la asignatura nos permitió crear un diseño en un contexto que favoreció la manifestación de diversos elementos de intencionalidad y reflexividad en relación a temáticas de escritura académica. El aspecto de mayor aporte sobre el diseño y la aplicación de las actividades y materiales para la interacción con los alumnos fue el conjunto de decisiones metodológicas para corregir, adaptar y modificar el diseño en las siguientes fases de elicitación a partir de la evaluación del ejercicio desarrollado. De esta manera es posible hacer una propuesta metodológica concreta aplicada a la elicitación para obtener muestras representativas de escritura académica. Las decisiones metodológicas principales corresponden al diseño y la conformación de la guía de apoyo en interacciones encaminadas a la reflexión escrita sobre el desempeño académico, propiciar que las manifestaciones de intencionalidad y reflexividad quedaran expresadas por escrito y enriquecer los materiales y las dinámicas diseñadas con las ideas expresadas por los alumnos sobre la temática de escritura académica.

Mediante estas decisiones metodológicas para intentar mejorar el diseño de elicitación, establecí criterios con la idea de tener un impacto en el tipo de comentarios de los alumnos en los siguientes ejercicios realizados en las otras universidades. En el caso de la guía de apoyo, consideré fundamental para las siguientes fases de elicitación la reflexión sobre el desempeño escrito a partir de evidencias de escritura de alumnos de nivel superior y el énfasis en la coherencia y la cohesión para propiciar que los alumnos se centraran en esta temática para contemplar aspectos de intencionalidad y reflexividad en el ámbito de la escritura académica. De esta forma la guía permitió que los alumnos se centraran en estas temáticas. La decisión metodológica de dar prioridad a la reflexión escrita y no a la expresión oral, surge a partir de percatarnos de que la gran mayoría de elementos de reflexivivdad sobre la escritura se desarrolló en las interacciones grupales y en la retroalimentación oral, y esta situación no favorece a una propuesta de estudio de 
evidencias escritas de reflexividad en el marco de la textualidad. Por ello, en la propuesta aplicada en las siguientes sesiones veremos que todas las intervenciones orales están diseñadas para propiciar la reflexión escrita. El enriquecimiento de los materiales y dinámicas a partir de los puntos de vista de los estudiantes, por ejemplo, en las guías de apoyo, en las lecturas proporcionadas y en las lluvias de ideas nos permite crear diseños de elicitación con énfasis en temáticas concretas y reales que experimentan los estudiantes con el propósito de favorecer el comentario sobre el desempeño propio y el de los compañeros. En suma, la experiencia de interacción con los alumnos de la UAM Iztapalapa constituyó un punto de partida fundamental para las siguientes fases de elicitación a partir de la evaluación crítica del diseño desarrollado y, principalmente, las decisiones para modificarlo e intentar adaptarlo y mejorarlo en cada sesión.

\subsection{Fase de elicitación 2: Universidad Pedagógica Nacional en Ixtepec, Oaxaca}

En este acercamiento para obtener muestras de escritura en contexto académico hice un estudio exploratorio de las prácticas de revisión y edición de los textos redactados por 26 estudiantes universitarios bilingües indígenas, en la población de Ixtepec, correspondiente al distrito de Juchitán, región del Istmo de Tehuantepec en el estado mexicano de Oaxaca, al Sureste de México ${ }^{17}$.

En la educación primaria en Oaxaca se imparte de manera regional la enseñanza de la lengua indígena como lengua materna o segunda lengua como parte de la educación oficial bilingüe. Sin embargo, en general, a lo largo de la historia en Oaxaca ha prevalecido una fuerte política de castellanización y relaciones complejas de desplazamiento de las lenguas indígenas en las funciones cotidianas básicas, además, actualmente existe un

\footnotetext{
${ }^{17}$ Realicé este ejercicio en abril de 2011 como parte del trabajo conjunto que desarrollamos los integrantes en el Proyecto "Dominio lingüístico y académico de estudiantes bilingües indígenas en universidades de México: habilidades comunicativas y académicas, reflexividad, sociolingüística y políticas interculturales del lenguaje” a cargo del Dr. Héctor Muñoz Cruz, investigador del Doctorado en Lingüística de la Universidad Autónoma Metropolitana Iztapalapa. En la interacción desarrollada me apoyaron Jorge Soto, alumno de la licenciatura en Lingüística de la UAM Iztapalapa y Rodolfo Hernández, de la Maestría en Sociolingüística de la Universidad Pedagógica Nacional Oaxaca.
} 
complejo contacto de lenguas y relaciones lingüísticas en el marco del intercambio comunicativo en la globalización y las tecnologías. En los niveles medio y medio superior la educación se imparte predominantemente en español, aunque existen algunos sistemas educativos que incorporan la enseñanza de las lenguas indígenas y las recientes propuestas de formación intercultural en la educación superior que incorporan la presencia de las diversas lenguas de la región, incluido, por supuesto, el español y lenguas extranjeras. A grandes rasgos, Oaxaca es uno de los estados con mayor pobreza del país, y esto se ve reflejado en las precarias condiciones educativas en la educación bilingüe indígena, principalmente, por el reducido número de docentes bilingües indígenas con formación universitaria y la deserción de los alumnos por las condiciones económicas.

El estado de Oaxaca tiene una situación lingüística compleja, y existen diversos criterios para clasificar las lenguas indígenas y las familias lingüísticas, que incluyen la zapotecana, la oaxaqueña, la mixteca, la mazatecana, y diversas lenguas, por ejemplo, huave, triqui, zoque, serrano, chatino, chinanteco, chontal, amuzgo, triqui, mixe, cuicateco y popoluca. En el estado existen diversos niveles de bilingüismo y hablantes monolingües ${ }^{18}$. En Ciudad Ixtepec, correspondiente al Istmo de Tehuantepec, predominan el huave, una variante del zapoteco y el español, además, hay presencia del mixe y el zoque.

Los 26 estudiantes de la Universidad Pedagógica Nacional en la unidad Ixtepec asistían a un curso de formación de profesores bilingües indígenas de educación básica de distintas comunidades de Oaxaca ${ }^{19}$. Esta universidad imparte las licenciaturas en docencia indígena en nivel básico y ofrece capacitación docente. Actualmente estos alumnos, además de estudiar el nivel superior, desarrollan su trabajo docente en nivel primaria, en comunidades con población mayoritariamente bilingüe indígena. Ante la escasez de profesores bilingües indígenas, es común que los estudiantes de licenciatura en docencia comiencen a trabajar en sus comunidades al iniciar sus estudios. De hecho, muchos alumnos de nivel medio superior ya trabajan como instructores que son capacitados para el

\footnotetext{
${ }^{18}$ Para una revisión completa del panorama lingüístico y de los niveles de bilingüismo consultar Manrique Castañeda (1988) y Cifuentes (1998).

${ }^{19}$ Anteriormente, en México quienes deseaban ser profesores de nivel básico no requerían cursar licenciatura, y, de manera directa, al concluir la educación secundaria se incorporaban a la Escuela Normal Superior de Maestros, donde se formaban como docentes. Recientemente, se ha implantado e impulsado la licenciatura en docencia.
} 
trabajo docente en nivel básico y posteriormente tienen la opción de cursar el nivel superior en docencia.

Los alumnos universitarios manifestaron tener distintos niveles de bilingüismo, todos hablan español y alguna de las siguientes lenguas: zapoteco, zoque, mixe, chatino y huave. De los 12 alumnos cuya lengua materna es el español, ocho dijeron ser monolingües ${ }^{20}$ y los otros cuatro tienen como segunda lengua la indígena, en tanto que 14 dijeron tener la lengua indígena como materna.

El profesor del grupo nos permitió llevar a cabo la interacción con sus alumnos. Propuse como actividad la lectura de un texto expositivo de difusión informativa sobre la discusión de la teoría Sapir-Whorf, en torno al relativismo lingüístico, en el que se plantea que la gramática de la lengua determina el pensamiento y la forma de concebir el mundo de las personas ${ }^{21}$. Ver Anexo 1. El tema abordado en la lectura es polémico, pero seleccioné un texto expositivo breve, aparentemente sencillo, simplemente para despertar el interés sobre un asunto en torno al uso de la lengua, contemplando que los alumnos son también profesores que participan en interacciones y contextos de bilingüismo y ésta sería una oportunidad para reflexionar sobre aspectos vinculados con su práctica cotidiana.

En esta ocasión el diseño de la situación y la interacción fue muy sencilla, sin una conducción dirigida a determinados aspectos, simplemente les dijimos a los alumnos que leyeran atentamente el texto, y que hicieran un comentario crítico sobre el mismo, cuidando de hacerlo con sus propias palabras. Evitamos hacer valoraciones y comentarios que impactaran o influyeran los puntos de vista de los alumnos, y simplemente nuestras intervenciones orales estaban dirigidas a que se motivaran a escribir. Una vez que escribieron su texto, les pedimos que lo intercambiaran con un alumno que asumiría el papel de juez, éste tendría que hacer comentarios al texto del compañero para ayudarle a que mejorara su escrito. Posteriormente, los jueces regresaron los textos a sus autores y

\footnotetext{
${ }^{20}$ Tomé la decisión de considerar el bilingüismo incipiente y funcional para aquellos alumnos que manifestaban tener conocimientos de la lengua indígena y que podían entenderla en algunas interacciones y en algunos casos comunicarse de manera básica en su entorno cotidiano. Así contemplo que todos los alumnos son bilingües indígenas sin entrar en detalles sobre el tipo y nivel de su bilingüismo para los efectos de esta investigación.

${ }^{21}$ El texto expositivo es una adaptación para fines de divulgación que realizo a partir del texto de Whorf (1964) y de la reflexión de Manrique Castañeda (1988) sobre la importancia de las lenguas para el conocimiento de las formas culturales.
} 
entonces les indicamos que a partir de las observaciones realizadas, modificaran su redacción y que escribieran una segunda versión contemplando las sugerencias ${ }^{22}$.

Este primer sondeo me permitió tomar decisiones concretas sobre el tipo de instrucciones, la dinámica y el tema seleccionado para la discusión y reflexión, con la idea de propiciar interacciones que favorecieran la expresión escrita de evidencias de reflexividad sobre la escritura académica. En primer lugar, el tema seleccionado sobre la polémica de que la gramática de la lengua de un individuo determina su pensamiento y su forma de concebir el mundo, generó que los alumnos se desviaran o focalizaran su atención hacia temas ajenos al desempeño de la escritura. Los alumnos abordaron diversos temas, por ejemplo, la cultura, la etnia, la política, la historia, aspectos sociolingüísticos y en algunos casos la gramática, pero alejados del tema de la escritura, tanto en las versiones del autor como en los comentarios del juez. Esta situación me llevó a tomar la decisión de seleccionar en la siguiente fase un tema de reflexión de inicio sobre la escritura académica, para propiciar una discusión focalizada en el tema de interés. Además, el texto resultó complicado y los alumnos tuvieron dificultades para la comprensión. En segundo lugar, la instrucción dada fue tan abierta que los alumnos podían escribir prácticamente cualquier cosa, ya que al pedirles que hicieran un "comentario crítico", simplemente dejamos abierta la posibilidad de escribir lo que cada quien considere sobre cualquier idea. Además, con una instrucción de esta forma cualquier aspecto puede ser considerado como comentario crítico. Así tomé la decisión de modificar la instrucción y en la siguiente fase consideré motivar la escritura a partir de la discusión y la interacción de manera más espontánea al poner en juego la reflexión para comentar el texto de otros y compartir experiencias personales.

En general, este primer sondeo fue útil en la medida en que me permitió contemplar que es necesario focalizar el tema de reflexividad de manera práctica y espontánea. También me permitió contemplar algunas consideraciones para evitar interacciones normativas, reguladas y forzadas, así como cuidar las instrucciones e incorporar otras fases de retroalimentación entre los alumnos, que deberían quedar plasmadas por escrito, de tal

\footnotetext{
${ }^{22}$ Para revisar los resultados de manera detallada sobre este ejercicio de investigación consultar Hernández Rodríguez (2011).
} 
manera que la metodología de elicitación diera prioridad al dato escrito y no a la elicitación oral en entrevistas, puesto que la investigación se refiere a reflexividad en prácticas de revisión y edición de textos en ambiente académico.

\subsection{Fase de elicitación 3: Universidad Pedagógica Nacional en Tehuantepec, Oaxaca}

En esta sesión trabajamos con 36 alumnos bilingües indígenas de licenciatura que cursaban la formación de profesores en la Universidad Pedagógica Nacional, en el plantel de Tehuantepec, a 4 kms. de Ixtepec en el distrito de Juchitán, región del Istmo de Tehuantepec en el estado mexicano de Oaxaca, al Sureste de México. Estos alumnos de licenciatura desarrollan su práctica docente en ambientes indígenas ${ }^{23}$. En esta ocasión llevamos a cabo una actividad que incorporamos a la secuencia de dos clases, planteada por el profesor, quien nos permitió realizar la actividad con su grupo en la última hora de su clase sabatina de 9 a 15 horas. No teníamos pretensiones de aplicaciones didácticas ni de dar seguimiento temático a la clase previa realizada por el profesor, ya que nosotros no estuvimos en esa clase. Simplemente deseábamos propiciar que los alumnos asumieran el papel de jueces y que comentaran el texto de un compañero para que éste pudiera revisar y editar la redacción de su propio texto. El profesor nos presentó a los alumnos y les dijo simplemente que con nosotros harían un ejercicio. Nunca antes había visto a estos alumnos ni al profesor, por lo que desconozco la planeación del curso y la manera en que se desarrolló la clase previa. A continuación presento las actividades y temas que nos comentó el profesor sobre la clase anterior.

\section{Sesión 1.}

El profesor solicitó un reporte de clase en el que tenían que desarrollar cuatro temas en específico: 1) grupo étnico y antropología, 2) nacionalidad e identidad cultural, 3) Estado monoétnico y lenguas vernáculas y 4) marxismo.

Los temas enunciados son parte del temario a desarrollar en la asignatura, por lo

\footnotetext{
${ }^{23}$ En esta fase de elicitación me apoyó Karina Hernández, alumna de la maestría en Sociolingüística de la Universidad Pedagógica Nacional de Oaxaca.
} 
que al final de la clase, y después de haber realizado la exposición por parte de los alumnos y de llevar a cabo una plenaria, proceden a elaborar su texto (reporte de lectura). La segunda parte de este ejercicio es la revisión del escrito por parte del docente como primer borrador. El profesor primero nos dijo que era un reporte de clase y después que era un reporte de lectura.

En relación al reporte solicitado por el profesor, no tenemos mayor información sobre la instrucción dada ni sobre la naturaleza de ese reporte solicitado en la sesión anterior.

\section{Sesión 2.}

En esta fase nos tocó intervenir hacia la parte final de una clase sabatina. Hicimos que los alumnos revisaran el texto que escribieron en la sesión anterior, después hicimos que intercambiaran sus textos con algún compañero que designamos al azar, y les entregamos una hoja donde escribirían su nombre y el del alumno a quien revisarían su texto con la siguiente indicación.

Has recibido el escrito de uno de tus compañeros. Revísalo con atención y cuidado y escribe los aspectos que consideras que tu compañero debe tomar en cuenta para realizarlo de mejor manera ¿Qué sugerencias le harías para mejorar ese mismo texto?

En este momento, evitamos hacer cualquier tipo de comentarios que influyeran sobre las opiniones, simplemente nuestras intervenciones estaban encaminadas a resolver dudas de procedimiento y a motivar la redacción. Además, les dijimos que este trabajo sería considerado como parte de la evaluación, puesto que el profesor así nos lo indicó. Una vez que los alumnos terminaron de hacer sugerencias por escrito, les pedimos que buscaran al compañero del texto que revisaron y que le comentaran oralmente aquello que escribieron, de manera tal que preguntara posibles dudas sobre los comentarios y, en su caso, tomara notas que le sirvieran de apoyo. Una vez que terminaron de comentar, les pedimos que tomaran sus propios textos y la hoja de observaciones que realizó el juez, les entregamos otra hoja para que redactaran la versión final. La instrucción fue la siguiente.

A partir de las sugerencias que te han hecho, ahora tómalas en cuenta para hacer una versión final de tu texto. ¡Haz tu mejor esfuerzo para mejorarlo!

A partir de este momento los alumnos redactaron la versión final y nuestras 
intervenciones se limitaron a resolver dudas y a motivarlos para que hicieran su mejor esfuerzo.

Este segundo sondeo resultó un tanto accidentado y complicado, debido a que tuvimos que trabajar a partir de una actividad en curso, a la cual nos incorporamos hacia el final de la clase sabatina de 6 horas en un diseño que desconocíamos totalmente, establecido previamente por el profesor. No tuvimos control sobre los materiales ni las temáticas abordadas, tampoco información sobre el tipo de alumnos ni sus características de bilingüismo, tan solo pudimos platicar con el profesor breves minutos antes y durante la actividad. El profesor interrumpía la actividad e intervenía continuamente haciendo sugerencias y comentarios de diversa naturaleza, por lo que tuvimos que hacer lo posible para que se mantuviera al margen de distintas maneras a lo largo de la actividad, principalmente, haciéndole la plática o bien mostrándole unos materiales para que los revisara mientras hacíamos la actividad.

Un aspecto que indudablemente impactó en el desarrollo de la actividad es que a partir de la revisión de los textos me percaté de que el docente había solicitado en la instrucción un "reporte de lectura", cuando en realidad a lo que se refería era a un reporte de la clase previa, con información de apuntes previos. Unos alumnos escribieron un reporte de actividades, describiendo o narrando las actividades y otros, la minoría, agregaban a la descripción comentarios sobre los contenidos o lo aprendido. Otra cuestión que influyó en el tipo de comentarios y revisiones de los alumnos al asumir el papel de jueces es que el docente les entregó a los alumnos los trabajos de la clase previa aparentemente calificados, puesto que tenían las notas de MB o de B. Esto propició comentarios y reacciones diversas, por ejemplo, algunos jueces destacaron dificultades y problemáticas de redacción en textos que tenían asignada la calificación de MB.

Indudablemente este segundo sondeo me sirvió para tomar en consideración diversos aspectos sobre una interacción en situación muy improvisada, en la que no es posible controlar diversas variables, por mencionar una, en este caso la intervención del docente. El sondeo me permitió contemplar la problemática de centrarnos en temáticas tan diversas abordadas en una clase previa de tantas horas, y, por otra parte, la dificultad para construir un género textual que les resulta ajeno a los alumnos, en este caso el reporte de 
clase o bien el comentario crítico sobre lo aprendido, sin que los alumnos tuvieran claridad sobre el tipo de texto que tendrían que redactar. La participación de los alumnos como jueces de un texto con una calificación asignada hizo que sus comentarios se centraran, en su mayoría, en los recursos formales de redacción, destacando lo que consideraban correcto o incorrecto, sin hacer reflexiones sobre la naturaleza del desempeño o la intencionalidad para resolver las dificultades enfrentadas. Por otra parte, el hecho de que los alumnos comenzaran, en su rol de jueces, escribiendo los comentarios y sugerencias sobre textos escritos en una clase anterior, influyó en que los jueces centraran su atención inmediatamente, sin distracciones, enfocándose, principalmente, en los recursos formales de escritura. Esto me permitió contemplar la necesidad de que en el siguiente diseño los alumnos trabajaran con material e interacción accesible, sin complicaciones temáticas, para poder centrarse inmediatamente en la escritura ${ }^{24}$.

En general, este sondeo, al igual que el de Ixtepec, me llevó a tomar la decisión de proponer para el siguiente diseño una interacción basada en una lectura que abordara el tema del desempeño de la escritura académica y a partir de ella propiciar la discusión y la reflexión sobre el desempeño personal y el de los compañeros, con la idea de que los alumnos comentaran la lectura en cuestión y compartieran algunas experiencias previas. Además me percaté de la necesidad de incorporar al diseño un tipo de retroalimentación entre autores y jueces sobre el impacto de participar en este tipo de prácticas de revisión, edición y comentario sobre los textos propios y de los compañeros. Considero que la interacción debería incluir la manifestación escrita de la reacción de los autores sobre los comentarios recibidos así como una valoración propia sobre el texto redactado. Asimismo, era fundamental contemplar alguna actividad de reflexión sobre las temáticas relacionadas con el desempeño. Evidentemente era fundamental lograr trabajar con grupos donde nos permitieran la interacción plena con los alumnos, por lo menos en dos sesiones en las que pudiéramos controlar nosotros la actividad para cuidar los aspectos del diseño y que la interacción fuera lo más natural y espontánea.

\footnotetext{
${ }^{24}$ Para revisar los resultados de manera detallada sobre este ejercicio de investigación consultar Hernández Rodríguez (2012).
} 


\subsection{Fase de elicitación 4: Universidad Intercultural de Chiapas}

Históricamente el Estado de Chiapas, en el sur de la República Mexicana, ha presentado una realidad social, cultural y económica contrastante, ya que, por una parte, en la mayoría de poblaciones y comunidades rurales indígenas ha prevalecido la pobreza, misma que motivó el levantamiento del Ejército Zapatista de Liberación Nacional en 1994, y en otras regiones como San Cristóbal de las Casas, se aprecian distintas clases sociales y culturales indígenas, mestizas y extranjeras organizadas en torno a diversas actividades económicas, principalmente, el turismo.

En Chiapas ha prevalecido una fuerte política de castellanización, así como relaciones complejas de desplazamiento de las lenguas indígenas en las funciones cotidianas básicas, principalmente, ante la implantación del español como lengua oficial y los desplazamientos debidos a conflictos internos. Existe un complejo contacto de lenguas y relaciones lingüísticas en el marco del intercambio comunicativo en la globalización y las tecnologías, principalmente, en las zonas urbanas, sin embargo, existen comunidades rurales donde predominan las lenguas indígenas con hablantes monolingües y otros con distintos niveles de bilingüismo. Las lenguas indígenas de Chiapas pertenecen a la familia maya, e incluyen el tzeltal, el tzozil, el tojolabal, el chontal, el chol, el lacandón, el teco, el mam, el zoque, el quiché y el motozintleco. La lengua indígena predominante en San Cristóbal de las Casas y Oxchuc es el tzeltal, además existe presencia del tzotzil. Estas lenguas conviven con el español, mismo que tiene mayor presencia en San Cristóbal de las Casas, por su tradición histórica colonial y turística. Por ello podemos apreciar lenguas extranjeras en el marco del comercio, principalmente, el inglés.

En Chiapas se imparte de manera regional la enseñanza de los idiomas indígenas como lengua materna o segunda lengua, como parte de la educación oficial bilingüe en el nivel básico en primaria. Existen condiciones precarias en la educación bilingüe indígena, principalmente, por el reducido número de docentes bilingües indígenas con formación universitaria y la deserción de los alumnos por las condiciones económicas. En los niveles 
medio y medio superior la educación se imparte predominantemente en español. Recientemente en el nivel superior se ha creado la educación intercultural, misma que incorpora la presencia de las diversas lenguas de la región, incluido, el español y el inglés como lengua dominante extranjera en el comercio y turismo. Además, el enfoque intercultural ofrece una propuesta sobre desarrollo cultural, lingüístico y social en el marco de la interrelación de tradiciones y costumbres regionales, y, además, el contacto de diversas prácticas que confluyen en la globalidad. La Universidad Intercultural de Chiapas en San Cristóbal de las Casas y Oxchuc constituye el pilar educativo de esta propuesta.

En esta ocasión trabajé con 51 alumnos de esta universidad. Los alumnos manifestaron tener distintos niveles de bilingüismo, todos hablaban el español y mayoritariamente el tzeltal. ${ }^{25}$ Los alumnos que participaron en el ejercicio en la clase de lengua regional cursaban alguna de las siguientes licenciaturas: Lengua y cultura, Desarrollo sustentable, Comunicación intercultural y Turismo alternativo en los siguientes grupos: 5to semestre de Oxchuc (textos 01 al 19), y de San Cristóbal de las Casas 1er semestre (textos 20 al 33) y 5to semestre (textos 34 al 51).

Las principales decisiones tomadas a partir de las experiencias en los sondeos tenían que ver primero con el tema abordado y con el manejo de un género textual que no representara complicaciones, ya que el interés de la investigación está centrado en la expresión de la reflexividad. Consideraba necesario propiciar que los alumnos focalizaran un tema de reflexividad sobre prácticas de escritura académica para la discusión y la reflexión, y así tratar de lograr que escribieran sobre dicha temática, sin otras que los desviaran de la reflexión. Entonces tomé la decisión de que los alumnos de la Universidad Intercultural de Chiapas interactuaran con nosotros en una discusión y reflexión sobre las experiencias de redacción de los jóvenes en la licenciatura.

Les explicamos que nosotros estábamos haciendo una investigación para conocer las prácticas y experiencias de escritura de los alumnos de distintas universidades, y les

\footnotetext{
${ }^{25}$ Siete alumnos manifestaron ser monolingües del español. Además del español, dos dijeron hablar el inglés, uno el tzeltal y el inglés y uno el tzotzil, los 40 restantes dijeron hablar el tzetzal. Considero que no existen monolingües del español, puesto que en la universidad aprenden desde el primer semestre las lenguas regionales, en este caso, tzotzil y tzeltal.
} 
comentamos algunas de nuestras propias experiencias, por ejemplo, cuestiones que se nos facilitaban, dificultaban, las maneras en que resolvíamos cuestiones diversas, lo que sentíamos y nos representaba escribir, y que entre nosotros habíamos compartido nuestras propias experiencias de escritura en la universidad y cómo eso nos había ayudado. Además, les platicamos nuestra experiencia con los alumnos de Oaxaca, quienes participaron en una actividad en la que cada alumno hizo el papel de juez e hizo comentarios y sugerencias al texto de su compañero, y que después cada alumno recibiría su propio texto, comentado por el juez, y tomaría en cuenta las observaciones para hacer una segunda versión editada y mejorada. Les explicamos que de esta manera reflexionamos con los alumnos de Oaxaca sobre las prácticas de escritura y así, de alguna manera, buscábamos apoyarnos para mejorar la escritura.

Les insistimos en que nosotros deseábamos compartir nuestras experiencias personales y, en esta ocasión, las de otros alumnos, con la idea de mejorar a partir de la reflexión. También les dijimos que, a partir de nuestra experiencia, creíamos que cuando un alumno asume el papel de juez y hace observaciones y sugerencias a un compañero ayuda a que éste pueda reflexionar sobre su escritura con la idea de mejorar, y que el juez mismo también puede tomar ideas para mejorar su propio texto. Entonces retomamos la experiencia de Tehuantepec, Oaxaca, y les dijimos que les presentaríamos un ejemplo de cómo un juez apoya a su compañero con comentarios sobre su escritura, para que después éste escribiera una segunda versión de su texto con la idea de mejorar su escritura.

Con el propósito de propiciar la discusión, seleccioné un texto en el que el autor tendría que hacer una segunda versión después de leer los comentarios del juez, con la idea de mejorar su escritura, sin embargo, el autor no hizo esta segunda versión de su texto, y en su lugar reacciona ante las observaciones del juez haciendo una serie de promesas para mejorar la escritura. En la transcripción de los textos seleccionados respeto totalmente la escritura de los alumnos sin hacer modificación alguna, precisamente para propiciar la discusión, solamente en este reporte no sigo la línea gráfica por cuestiones de espacio. A continuación presento las sugerencias y comentarios del juez y la segunda versión del autor, en este caso, conformado por las promesas. Para evitar confusiones, en adelante me referiré a ellos como juez oaxaqueño y autor oaxaqueño. 


\begin{tabular}{|c|c|}
\hline $\begin{array}{c}\text { Sugerencias y comentarios } \\
\text { del juez oaxaqueño }\end{array}$ & $\begin{array}{l}\text { Texto del autor oaxaqueño, } \\
\text { tras la lectura de los comentarios }\end{array}$ \\
\hline $\begin{array}{l}\text { 1. Poner atención con los acentos } \\
\text { 2. Continuar con el parrafo. } \\
\text { 3. No repetir varias veces las palabras. } \\
\text { 4. No repetir los conectores varias veces } \\
\text { "conectores: la coma, la letra 'y'." } \\
\text { 5. Tener la paciencia de escribir o hacer la } \\
\text { letra de molde } \\
\text { 6. El punto se ocupa para separar el párrafo } \\
\text { o bien para continuar con el parrafo. } \\
\text { 7. Ser congruente con las escrituras } \\
\text { 8. Ponerle sangria a tu escritura } \\
\text { 9. Tener letra lejible } \\
\text { 10. Tener pensado lo que quieras escribir } \\
\text { 11.Ten tus pensamientos dentro del salón } \\
\text { de clases, deja un lado tus otras cosas. }\end{array}$ & $\begin{array}{l}\text { Ahora me prometo a mejorar mi escritura es cierto } \\
\text { lo que dijo mi compañero la escritura no logre } \\
\text { escribir la letra legible y también me falto poner las } \\
\text { comas, punto, sangría, separar parrafos debo de } \\
\text { mejorar la escritura y tambien debo de pensar antes } \\
\text { de escribir lo que debo de pensar de los x salones } \\
\text { porque se me dificulta captura algunas palabras o } \\
\text { aveces no capto las palabras que el maestro esta } \\
\text { explicando o a veces me quedo pensando como } \\
\text { debo de escribir en un deporte de la lectura. o } \\
\text { tambien debo de participar porque cuando estoy } \\
\text { exponiendo un tema es donde me gana los nervios y } \\
\text { es donde se me olvida las cosas que debo de hablar } \\
\text { por esa razón es donde no puedo lograr a terminar } \\
\text { de exponer el tema. }\end{array}$ \\
\hline
\end{tabular}

En el diseño de la interacción decidí no presentar la primera versión escrita por el autor oaxaqueño porque, tal como expuse en la sección anterior, aborda temas ajenos a la escritura académica y deseaba evitar distractores, la idea era centrarnos en los comentarios realizados por el juez oaxaqueño sobre el desempeño escrito en ambiente académico y la reacción del autor oaxaqueño. De hecho, ningún alumno de la UNICH preguntó o hizo referencia a la primera versión de este autor. Considero que esto facilitó y resolvió el asunto de la focalización en la temática de reflexividad sobre el desempeño de la escritura académica. Los alumnos que asistieron a la clase provienen de alguna de las siguientes licenciaturas.

Lengua y cultura
Desarrollo sustentable
Comunicación intercultural
Turismo alternativo
Grupos (por orden de aplicación del ejercicio)
5to semestre textos 01 al 19 en Oxchuc
1er semestre $\quad$ textos 20 al 33 en San Cristóbal de las Casas
5to semestre textos 34 al 51 en San Cristóbal de las Casas
51 alumnos de nivel licenciatura que participaron en la clase de lengua regional
Lenguas indígenas de los alumnos: tzeltal (predominante) y tzotzil ${ }^{26}$

\footnotetext{
${ }^{26}$ Todos los alumnos hablaban el español. Siete alumnos manifestaron ser monolingües del español. Además del español, dos dijeron hablar el inglés, uno el tzeltal y el inglés y uno el tzotzil, los 40 restantes dijeron hablar el tzetzal. Considero que no existen monolingües del español, puesto que en la Universidad aprenden desde el primer semestre las lenguas
} 
Inicialmente contemplé tres sesiones, sin embargo, no fue posible realizar la tercera, en la que los alumnos editarían la segunda versión, debido a un paro, movilización y marcha estudiantil por la destitución del rector. Ante esta problemática, consideré que no debería eliminar ninguna de las actividades preparadas, por lo que reduje todas las interacciones en grupos, por ejemplo, para comentar los textos del juez y el autor oaxaqueños. Sabía que no habría tiempo suficiente para la edición en la segunda versión. De cualquier manera, al final de la segunda sesión les solicité que hicieran los cambios pertinentes para mejorar sus textos, sin embargo, el tiempo no fue suficiente y algunos lograron reescribir su texto, otros apenas comenzaron y no acabaron y otros nunca comenzaron esta parte. Ante la premura muchos simplemente copiaron su texto inicial. Por ello, esta última parte, a pesar de que muestra datos relevantes, no la contemplo en el análisis, por las condiciones improvisadas debido al paro estudiantil ${ }^{27}$.

\section{Sesión 1 (una hora)}

1). Tal como expuse anteriormente, nos presentamos, comentamos nuestra investigación y nuestro interés por conocer y compartir sobre nuestras experiencias y las de otros alumnos en la redacción académica. Les platicamos nuestra experiencia con los alumnos de Tehuantepec Oaxaca, sobre la revisión y edición de sus textos al asumir el papel de autores y jueces. Destacamos que considerábamos que al asumir el rol de jueces podemos reflexionar sobre las prácticas de escritura, ayudar al compañero y tomar ideas para mejorar el texto propio.

2). Les proporcionamos copias de los textos. Compartimos y leímos grupalmente los textos del autor y juez oaxaqueños en voz alta, les permitimos releer los textos con calma. Con el propósito de generar la discusión los invitamos a reflexionar sobre los comentarios del juez, y sobre la reacción del autor oaxaqueño al escribir una segunda versión conformada por promesas, en lugar de la edición de su texto inicial. Propiciamos una breve discusión oral en equipos y al final de manera grupal sobre esta temática.

regionales, en este caso, tzotzil y tzeltal.

${ }^{27}$ En esta fase de elicitación me apoyaron Agustín Domínguez y Juan Carlos Rosas, de la maestría en Humanidades de la UAM Iztapalapa. 
3). Inmediatamente invitamos a los alumnos a que escribieran comentarios sobre los textos leídos, sobre lo escrito por el autor y el juez oaxaqueños, y que, además, también nos compartieran por escrito sus propias experiencias sobre la escritura académica, por ejemplo, lo que viven y sienten, lo que se les facilita, y lo que hacen para resolver aquello que se les complica en la redacción. A continuación presento las instrucciones en la hoja que les proporcionamos para escribir.

\section{Instrucciones}

Te invitamos a que comentes las reflexiones del estudiante en el texto que acabas de leer, sobre lo que sucede cuando escribe en la universidad y, así como él lo hace, tú también reflexiona por escrito sobre tus propias experiencias de escritura en ambientes escolares, tus habilidades, los aspectos que se te facilitan y dificultan, la manera en que vives la experiencia de redacción y lo que significa para ti, especialmente cuando tienes que tomar decisiones para intentar expresarte con claridad y proponer soluciones para redactar mejores textos escolares. Comparte tu experiencia y escribe un texto que, principalmente, te ayude a tu propia reflexión para mejorar tu escritura, y además, inspire a otros a este tipo de reflexiones.

4). Interacción guiada. Lluvia de ideas sobre las características que los alumnos consideran que debe cumplir un texto en un ambiente académico.

Una vez que terminaron de escribir, hicimos una interacción guiada basada en una lluvia de ideas en el pizarrón. Les pedimos que nos mencionaran las características que consideraban que debe tener un texto para ser claro y bien redactado, que se entienda y funcione en un ambiente académico. Los alumnos expresaron sus ideas y, sin hacer comentarios, las escribimos en una lista en el pizarrón. Ver Anexo 2. Aquí no propiciamos la discusión, simplemente, motivamos a que se expresaran y anotamos aquellos puntos que nos decían. El propósito de esta interacción era focalizar la atención en el tema de la escritura académica, preparando así el trabajo que realizarían inmediatamente en su rol de jueces.

5). Asumir el papel de jueces. Hacer una lista sobre las características de la escritura del compañero

Solicitamos que intercambiaran sus textos con algún compañero del grupo. Los invitamos a tomar el papel de jueces para iniciar la actividad de hacer comentarios y sugerencias por escrito a su compañero para ayudarlo a que mejorara su texto. Les indicamos que leyeran el texto de su compañero con mucha atención y cuidado. 
Inmediatamente les solicitamos que, así como hicimos un listado en el pizarrón sobre las características de un texto en ambiente académico, que ahora escribieran en una hoja que les proporcionamos (detrás de una guía de apoyo que utilizaríamos la siguiente sesión) una lista de aquellos aspectos que consideraban que su compañero debería mejorar. Insistimos en que por el momento simplemente mencionaran los aspectos contemplados, sin desarrollarlos, tal como habíamos hecho la lista en el pizarrón durante la lluvia de ideas. El propósito de esta última actividad era tener preparada una lista a manera de plan sobre los puntos que, tal vez, podrían abordar en la siguiente sesión, cuando se darían a la tarea de escribir el texto a su compañero. Inicialmente esta actividad estaba diseñada al comienzo de la siguiente sesión, pero la incluí en la primera por la reducción del tiempo, ante la cancelación de la última sesión debido al paro estudiantil que mencioné anteriormente.

\section{Sesión 2 (una hora)}

1). Guía de apoyo sugerida.

Continuamos trabajando de manera grupal ahora que todos asumieron el rol de jueces. Proporcionamos en una hoja la guía de apoyo. Les comentamos que en la sección 1 de esta guía nosotros les compartimos los aspectos que, en un ejercicio similar de revisión de textos, un grupo de estudiantes de licenciatura de la UAM Iztapalapa consideró relevantes para un texto académico. Les dijimos que habíamos platicado anteriormente sobre estos puntos y que estábamos de acuerdo en estos aspectos, y, también, que considerábamos que esta información les podría servir en caso de que desearan utilizarla ${ }^{28}$. Leímos de manera grupal esta sección sin detenernos a hacer comentarios, nunca les dijimos que tenían que basarse en esta lista, simplemente mencionamos que les podría servir lo que nosotros pensábamos, además, de la lluvia de ideas y del listado que ellos habían escrito sobre los aspectos de la escritura de sus compañeros. A continuación presento la información de esta sección de la guía de apoyo.

\section{Sección 1}

\footnotetext{
${ }^{28}$ Anteriormente empleamos esta parte de la guía en un primer ejercicio a manera de sondeo realizado con los alumnos de lingüística del Profesor Héctor Muñoz Cruz, en la materia de enseñanza de la lengua materna en la UAM Iztapalapa. En conjunto con el Dr. Muñoz Cruz realizamos el diseño y lo aplicamos con sus alumnos. En esa ocasión, los alumnos tendrían que revisar un texto de reflexión sobre las propuestas de temáticas y autores seleccionados como parte de su evaluación.
} 


\section{ASPECTOS RELEVANTES SOBRE LA ESCRITURA}

a) Procurar que el texto tenga armonía, que esté organizado en su estructura, en las concordancias entre pronombres, género, número y referencia, y que esté gramaticalmente bien armado.

b) Intentar que el texto sea claro y fácil de entender. Aquello que vas a explicar o plantear, debe coincidir con lo que escribes en el desarrollo a lo largo del texto; por lo tanto, no ser incongruentes.

c) Reflejar una intención, informar, responder a la situación, ser aceptable, eficaz, eficiente, propiedad.

La idea era que la guía y la interacción tuvieran un impacto en la selección de las temáticas abordadas por los alumnos al hacer comentarios. De este modo, en esta fase de elicitación el énfasis estaba puesto en reflexiones relacionadas con los principios constitutivos de textualidad, principalmente de coherencia y cohesión, tal como contemplan Beugrande \& Dressler (1997). Mediante este tipo de interacción, trataba de compartirles a los alumnos experiencias escolares que los motivaran a la reflexión. Contemplé está sección a partir de la aplicación y adaptación del ejercicio realizado con alumnos de la UAM Iztapalapa. En esa ocasión les presentamos lo que considerábamos sobre aspectos de coherencia y cohesión, sin realizar una explicación de estos puntos, y además, tomé información a partir del listado de la lluvia de ideas que generaron esos alumnos de la UAMI.

En general, en la lluvia de ideas realizada en Oxchuc y en San Cristóbal de las Casas, los alumnos contemplaron la mayoría de estos mismos aspectos, los únicos que no aparecieron fueron el ser eficaz, eficiente y la propiedad. En esta sección de la guía traté de focalizar la atención en los principios constitutivos de textualidad, principalmente, de coherencia y cohesión, tal como contemplan Beugrande \& Dressler (1997). En breve mostraré, en la otra parte de la guía la focalización sobre los otros aspectos, principalmente, los contextuales y de identidad sobre lo que les significa y representa a los alumnos participar en este ejercicio.

Inmediatamente, les leímos en la sección 2 de la guía una propuesta de esquema de apoyo para los jueces que les podría servir a todos para organizar la estructura del texto y que podrían emplear, si así lo deseaban, para escribir los comentarios para sus compañeros. Les pedimos que tomaran en cuenta estos aspectos y les dimos tiempo para reflexionar. 


\section{Sección 2}

¿A quién escribirás tu texto?

¿Qué deseas demostrar, expresar o comentar en torno a la reflexión sobre la escritura de tu compañero?

¿Cómo organizarás tus ideas?

Ideas principales que desarrollarás en tu texto: Enlístalas en orden de importancia para ti.

Aspectos de reflexión y sugerencias sobre la escritura de mi compañero.

Conclusión o cierre.

El propósito era centrar el interés en la temática de reflexividad y que los alumnos comentaran sobre la escritura de su compañero y que, además, hicieran sugerencias, por ello incluyo en la guía aquello que desean comentar sobre la escritura del compañero y las sugerencias que le pueden hacer. Por otra parte, la guía no incluye una manera en que deben organizar la estructura del texto, ya que no pretendía imponer un modelo a seguir, simplemente, contemplo la reflexión sobre la manera en que cada quien pensaba organizar su texto en la pregunta: “¿Cómo organizarás tus ideas?”.

2). Escribir las observaciones y sugerencias al compañero para mejorar su redacción.

Una vez que los jueces hicieron la lista de aspectos observados en los textos del compañero y que revisaron la guía, les pedimos que tomaran en cuenta estos aspectos y que apoyaran a su compañero, que le escribieran un texto a manera de carta en el que le hicieran observaciones, críticas y, además, sugerencias para que mejorara su texto. Con el propósito de evitar confusiones y dificultades sobre el género textual, les solicitamos que el texto fuera "a manera de carta", de forma tal que se dirigieran directamente a su compañero, puesto que en la fase de sondeos algunos alumnos escribían dirigiéndose al profesor y otros hacían descripciones del texto donde el autor nunca estaba contemplado. De hecho, pude percatarme de que el tipo de representación del destinatario y de los interlocutores constituye, al igual que el posicionamiento de enunciación del autor, un elemento fundamental que pone de manifiesto diversas facetas de intencionalidad y reflexividad. Proporcionamos las hojas con las siguientes instrucciones y todos se dieron a la tarea de escribir.

Has recibido el escrito de uno de tus compañeros. Revísalo con atención y cuidado y redacta un texto a tu compañero en el que le hagas observaciones y comentarios sobre 
su manera de escribir y los aspectos que debe tomar en cuenta para modificar y mejorar su escrito en una segunda versión.

Al terminar les pedimos a los jueces que devolvieran el texto a los autores, y les permitimos a éstos que leyeran con cuidado las sugerencias y observaciones recibidas.

3). Interacción, retroalimentación: El juez comenta oralmente lo que escribió

Con el propósito de establecer una interacción más cercana, les pedimos a los jueces que les hicieran comentarios de manera oral a sus compañeros sobre aquello que les escribieron y que intercambiaran impresiones y puntos de vista. Asimismo les comentamos que podían aclarar dudas al autor y, en su caso, ampliar la información.

4). El autor reflexiona sobre su propio texto y escribe lo que piensa sobre los comentarios y observaciones recibidas.

En este momento motivamos a los estudiantes a que reflexionaran sobre la experiencia de revisión y edición así como sobre su opinión de los comentarios del juez. En este momento no propiciamos la interacción oral, simplemente les solicitamos que consideraran los siguientes aspectos de la última parte de la guía:

\section{Sección 3}

a) ¿Cómo describo y evalúo mi texto? ¿Por qué? ¿Qué se me facilita y dificulta?

b) ¿Qué opino de lo que escribió el juez sobre mi texto? ¿Estoy de acuerdo? ¿Por qué?

c) ¿Qué aspectos influyen en que yo escriba de esta manera?

d) Lo que experimento y significa para mí redactar y revisar mi propio texto y el de otro en la universidad.

e) Sobre cómo planearé y organizaré mi texto para mejorarlo, lo que modificaré, ¿cómo y por qué?

El propósito de esta actividad era abordar otras temáticas de reflexividad distintas al aspecto formal, anteriormente contemplado. De esta manera el alumno puede contemplar, por ejemplo, los aspectos personales, contextuales, la valoración sobre su desempeño, lo que se le facilita o dificulta en ambiente académico, la interacción y los aspectos que influyen en la práctica de escritura académica. Además, los alumnos pueden manifestar lo que representa y les significa la interacción y el ejercicio desarrollado, destacando aspectos de la construcción de conocimiento e identidad.

En virtud de que el punto de interés era la reflexividad sobre el desempeño, les 
pedimos a los autores que escribieran únicamente lo que pensaban sobre los comentarios y sugerencias que les hizo el juez, les indicamos que escribieran esta reflexión en la parte posterior de la guía.

5). Hacer la segunda versión.

Los alumnos no tuvieron el tiempo suficiente para redactar la segunda versión, por la eliminación de la tercera sesión ante las situaciones inesperadas por el paro estudiantil y la manifestación, que anteriormente expliqué. Sin embargo, con el afán de no eliminar ninguna actividad del diseño, dejé un tiempo reducido al final de la segunda sesión (aproximadamente 15 minutos). A pesar de que en las segundas versiones redactadas podemos apreciar datos importantes sobre las decisiones para la edición textual, no contemplo estos datos para el estudio, puesto que no existieron condiciones de tiempo. De hecho la gran mayoría se limitó a copiar la primera versión y otros no terminaron.

\subsection{Sobre los alcances y limitaciones del diseño de la interacción para la elicitación.}

En general el diseño de elicitación aplicado en la Universidad Intercultural de Chiapas fue el resultado de una serie de toma de decisiones a partir de las experiencias vividas en los sondeos previos realizados en la Universidad Autónoma Metropolitana Iztapalapa y la Universidad Pedagógica Nacional en Ixtepec y Tehuantepec, además, de las consideraciones sobre las temáticas abordadas que propiciaran que los alumnos manifestaran aspectos de reflexividad sobre el desempeño propio y el del compañero en el marco de la interacción desarrollada en ambiente académico. El reto era lograr una interacción en la que los alumnos no se desviaran del tema de la escritura académica y el desempeño, tal como sucedió en los sondeos de la UPN en Oaxaca, para ello en el diseño de la elicitación contemplé el énfasis, por una parte, en los aspectos constitutivos formales de coherencia y cohesión y, por otra parte, en los aspectos regulativos sobre el desempeño que involucran las diversas cuestiones de práctica contextual, tal como apuntan Beugrande \& Dressler (1997) en su propuesta de textualidad. Además, en el diseño contemplo la reflexión sobre lo que significa y representa para los alumnos este ejercicio de escritura en 
ambiente académico, lo cual implica la construcción de conocimiento e identidad, tal como apunta Ivanič (1998).

El reto era hacer una propuesta que evitara la conducción guiada y normativa sobre el asunto del desempeño, la idea era no hacer que los alumnos se basaran en modelos preestablecidos impuestos para la reflexión, por otra parte tampoco podía dejar una interacción libre y abierta de manera tal que los alumnos escribieran sobre cualquier tema relacionado, el punto de interés era la escritura académica. En el diseño realizado en la Universidad Intercultural de Chiapas contemplé fundamentalmente que los alumnos interactuaran y reflexionaran a partir de ejemplos de experiencias de escritura académica, primero sobre los ejemplos de otros, del autor y juez oaxaqueños y los ejemplos del ejercicio aplicado con alumnos de la UAM Iztapalapa sobre expectativas de lo que consideraban que debe tener un texto para funcionar en ambiente académico, mismos que presentamos en la guía de apoyo.

Consideré que iniciar la interacción con una reflexión sobre el desempeño y las ideas de otras personas, en este caso, alumnos de otras universidades, facilitaría tomar distancia al opinar sobre el desempeño de otro y valorar sus consideraciones respecto a lo que toman en cuenta acerca de un texto académico. Después, la interacción ya no era de los ejemplos de otros, ajenos a la UNICH, sino la idea de compartir las experiencias sobre el desempeño propio para proceder a reflexionar y opinar, como juez, respecto a la escritura del compañero, y finalmente, opinar, como autor sobre las opiniones recibidas. Es decir, el paso de la toma de distancia al opinar sobre otros hasta llegar a opinar acerca del desempeño propio fue un proceso gradual en el que consideré la propuesta de motivar y compartir entre todos con la idea de ayudar y mejorar. Esperaba que los alumnos plasmaran muestras de escritura representativa y evidencias ejemplares de las temáticas de interés a partir de las distintas ideas abordadas en la interacción. Era necesario contemplar aspectos temáticos de reflexividad amplia sobre la práctica de escritura académica, es decir, considerar el aspecto estructural, formal de cohesión y coherencia, y, además, los distintos, aspectos contextuales, personales, interactivos y de construcción de conocimiento e identidad.

La idea de hacer una interacción a partir de compartir experiencias de otros 
alumnos, en este caso de la UPN Oaxaca y UAMI podría verse, tal vez, como la aplicación de modelos ajenos e impuestos a seguir. Intenté evitar este riesgo en la medida en que insistimos en un diseño de interacción en el que fomentamos la idea de compartir estas experiencias y las nuestras, e intentar que los alumnos de UNICH expresaran las suyas, principalmente, en la lluvia de ideas sobre lo que ellos consideraban que debe tener un texto en ambiente académico. Es decir, los ejemplos de otras experiencias de otros alumnos, de UPN y UAMI, fueron elementos disparadores para que los alumnos se animaran a expresar sus propias ideas, propuestas y experiencias. De esta manera contemplé evitar el riesgo de que los ejemplos proporcionados y la guía de apoyo se convirtieran en modelos impuestos para la expresión escrita de los alumnos de UNICH. Sin embargo, esto no garantiza que algunos alumnos hayan tomado estos ejemplos como modelos normativos a seguir, de hecho, este tipo de decisiones también forman parte de la intencionalidad y la reflexividad.

En el diseño de la interacción y las temáticas abordadas en la guía tomé en cuenta aquellos aspectos que deseaba enfatizar para centrar la atención en reflexiones sobre experiencias de escritura académica. De esta manera, los puntos de interés eran las actividades y temáticas relacionadas con los estándares de textualidad propuestos por Beugrande \& Dressler (1997), así como cuestiones contextuales sobre las prácticas de escritura en el ambiente universitario. Además de tratar de favorecer la motivación para la manifestación escrita de evidencias de intencionalidad y reflexividad, la guía tenía también el propósito de que los alumnos no se dispersaran y evitar desvíos temáticos en sus comentarios, tal como sucedió, por ejemplo, en la UPN Ixtepec cuando al discutir una lectura sobre un tema no centrado en la escritura académica, y ante una instrucción libre y abierta, los alumnos manifestaron evidencias, principalmente, implícitas de reflexividad sobre temáticas diversas, pero ajenas al desempeño de la escritura en la universidad.

Un punto novedoso fundamental en esta propuesta de elicitación en busca de elementos diversos de reflexividad era obtener los datos de manera escrita, y, no, exclusivamente, mediante la técnica de la entrevista oral, privilegiada en diversas propuestas metodológicas. Considero que en una propuesta del estudio de la textualidad es fundamental dar prioridad al dato escrito, con el propósito de tener elementos para el estudio de las relaciones diversas en el marco de la unidad textual. De hecho, contemplé 
que las entrevistas serían un aspecto complementario para ampliar las dinámicas diseñadas para la interacción sobre los puntos de lo que los alumnos expresaron respecto a la experiencia vivida, principalmente con lo abordado en la parte final de la guía. Por las condiciones de eliminación de la última sesión, desafortunadamente, no logramos hacer la actividad de las entrevistas, tan solo realizamos algunas hacia el final de la sesión en el patio y de manera improvisada. Debido a esta situación no contemplo los datos de esas entrevistas en el análisis.

La propuesta de diseño de elicitación aplicada en la UNICH, indudablemente, tiene algunas limitaciones y es susceptible de mejoría. Por ejemplo, en la fase de opinar sobre lo que el juez escribió, la instrucción fue tan abierta que lo expresado por los alumnos se centró fundamentalmente en las posturas de estar de acuerdo o en desacuerdo con o sin reservas. De tal manera que considero que en este punto la gran mayoría de los alumnos no manifestaron elementos de reflexividad como en los otros aspectos. También considero que la guía puede reducirse en el formato, y la actividad de la lluvia de ideas en determinados grupos puede adaptarse a distintas necesidades, por ejemplo, hacer el trabajo en equipos y que un representante escriba en el pizarrón, con el propósito de reducir la posibilidad de dar lugar a discusiones que desvíen el tema.

De manera general, la propuesta de conformación de un modelo de elicitación a partir de la evaluación, modificación y adaptación del tipo de materiales e interacciones, conforme a las situaciones presentadas en cada universidad, nos permite establecer criterios de aplicación general, evaluados y experimentados en cada sesión. De esta manera, podemos tomar decisiones fundamentales, por ejemplo, sobre el control de aspectos temáticos y materiales, así como el tipo y modo de interacción que favorezca la expresión escrita y la reflexión sobre el desempeño. Así tratamos de evitar la dispersión y los desvíos temáticos, focalizando la atención mediante la guía de apoyo y las interacciones orales de retroalimentación para motivar la escritura. En general, la interacción y la guía tuvieron un impacto para centrar la atención y la reflexión en las temáticas de desempeño con énfasis en los estándares de textualidad, fundamentalmente en recursos de textualización formales sobre coherencia, cohesión, pertinencia y eficacia, así como cuestiones contextuales sobre el uso y la construcción de identidad en las prácticas escritas. Por el momento este es un 
diseño fundamental que aporta elementos para una metodología de elicitación en busca de evidencias de reflexividad sobre el desempeño y la interacción en las prácticas de escritura académica.

\subsection{Criterios metodológicos para la identificación de los textos y la transcripción}

Una vez finalizada la fase de elicitación comencé el trabajo de identificación, clasificación, selección, caracterización y transcripción de ejemplos representativos. Contemplo dos tipos de folios o juegos de textos, por una parte, el texto del autor acompañado de las observaciones del alumno que comentó su escrito (folio autor y juez que revisó su texto), y, por otra parte, los textos en que un mismo alumno asumió primero el rol de autor y luego el de juez (folio autor y texto al que éste hace comentarios como juez). Estas dos identificaciones de los roles de autor y juez son fundamentales para la construcción del corpus de trabajo para dar seguimiento a los comentarios de los alumnos y a la manera en que asumen los roles, así como los tipos de reflexividad en cada caso.

\subsubsection{Criterios de identificación: folios}

Utilizo la siguiente nomenclatura para nombrar los textos en los folios autor y juez que revisó el texto:

tri (texto reflexión indígena): texto reflexividad alumno bilingüe indígena.

tsi (texto sapir whorf): texto Sapir-Whorf, Ixtepec

trt (texto reporte): texto reporte de lectura, Tehuantepec.

Sc (San Cristóbal de las Casas): Plantel San Cristóbal de las Casas de la UNICH

o (Oxchuc): Plantel Oxchuc de la UNICH

h (hombre)

m (mujer)

número: el número del texto, tal como fueron entregados cronológicamente.

j (juez)

Por ejemplo, el folio trisch47j corresponde al texto de un alumno bilingüe indígena de San Cristóbal de las Casas asignado con el número 47, quien asume el rol de juez. El 
folio triom07, corresponde al texto de una alumna bilingüe indígena de Oxchuc asignada con el número 07, quien asume el rol de autora.

Con el propósito de dar seguimiento al papel asumido por cada alumno, primero como autor y luego como juez, contemplo la identificación mediante folios de autor y texto al que éste hace comentarios como juez, para ello empleo una identificación mediante paréntesis para ubicar al autor al que un alumno en su papel de juez hizo sugerencias y comentarios. En cada caso, en la nomenclatura que propongo, el número en paréntesis indica el texto del compañero al que hizo observaciones y sugerencias cada alumno al asumir el rol de juez, por ejemplo, t9(12) indica que el autor 9 al asumir el papel de juez revisó el texto del alumno 12. De esta manera es posible ubicar la escritura de un mismo alumno como autor y como juez y caracterizar su escritura y reflexividad manifestada al asumir cada rol. Además, podemos establecer cruces entre los datos y las categorías de análisis, principalmente, sobre cómo se modifican, por ejemplo, la actitud, los comentarios, las temáticas y los niveles de reflexividad en un mismo individuo durante la interacción.

\subsubsection{Criterios de transcripción textual}

Un paso ineludible, previo al comienzo del análisis, es la transcripción de la escritura original. Este proceso implica una tarea compleja, ya que es necesario tomar decisiones sobre la materia gráfica. Los textos tienen tachaduras, letras sobrepuestas, grafías poco legibles, separaciones ambiguas entre palabras, etc. Se requiere transcribir respetando las grafías y las segmentaciones tal y como las escribió el alumno, y por ello es necesario comparar y contrastar cualitativamente los rasgos de las letras y segmentaciones en todo el texto.

En la transcripción de los textos seleccionados para el análisis respeto las líneas gráficas y la escritura, sin hacer modificaciones ni correcciones de ortografía, segmentación o acentuación. Sin embargo, en este trabajo, por motivos de espacio, no sigo la línea gráfica ni las segmentaciones al final de reglón, sólo contemplo el cambio de párrafo, sin indicar el número del mismo, debido a que el interés de esta investigación está centrado en la temática de reflexividad y no en la estructura interna textual. No pretendo establecer el 
criterio de párrafo como unidad de análisis ni de caracterización intratextual. En determinados textos no es posible establecer el criterio de párrafo, por ejemplo, bajo los criterios temáticos o de distribución gráfica intratextual, puesto que existen textos que no presentan separación de bloques de líneas gráficas o bien otros tienen diversos bloques, unos conformados por renglones. Para evitar entrar en esta polémica discusión sobre la caracterización de la noción de párrafo, en estos textos contemplo simplemente la línea o bloque de líneas gráficas separadas por un mayor espacio interlineal.

A continuación presento algunos de los criterios de transcripción que empleo:

[...] [...] Corchetes para indicar fragmentos al interior de un párrafo. Ejemplo

[...] cuando los maestros nos dejan de tarea que hagamos algún resumen. a la hora de llebarlo acabo, no se con que palabra debo empezar y explicar lo que entendi del texto eso es lo que seme dificulta, bueno \# también seme dificulta colocar los acentos, las comas, y que mi resumen este bién redactado [...] (triscm $45 \mathrm{p})$

Tachaduras y encimaduras para corregir la escritura. Ejemplo

Por mi parte considero que no es mi lengua natal sino que es nuestra segunda lengua por tal razon esas dificultades de la ortografía [...] (trsiscm41)

\# para indicar tachaduras y trazos no legibles. Ejemplo.

En mi caso se me dificultan poner acentos ¥o en dónde llevan acentos las palabras aunque sabiendo las reglas de las palabras graves, esdrújulas y sobre esdrújulas pues aún así se me presentan dudas, al igual que saber de las letras que llevan Xlas palabras que se escuchan igual pero se escriben diferente, en fin son algunas cuestiones, ya que la escritura de esta lengua es diferente a la escritura de la lengua originaria porque estas son más notorias. [...](trsiscm36)

Los problemas de escritura y redacción en los estudiantes, siempre ha existido y existira, ya que desde la educación básica tanto alumnos como profesores no tienen la inciativa de fomentar una cultura de lectura y menos de escritura. Hay muchos factores que implican que los $\# x x$ estudiantes tengan este problema. [...] (triscm45p)

Letra en superscript. Anotaciones y agregados al texto por encima de la línea gráfica. Ejemplos

Para ayudarle al $/^{\text {los }}$ compañero de oaxaca, ${ }^{o}$ en diferentes ciudades y pueblos creo que debe observar primero los párrafos de un texto [...] (trisch47p) 
En el siguiente ejemplo, además de la anotación agregada por encima de la línea gráfica, apreciamos tachaduras para corregir.

Hola! que tal compañera y amiga juana Maria no tengo mucho que decir ya que para mi ${ }^{\mathrm{me}}$ dificulta emucho por eæscrito, pero lo que quiero decirte es que la verdad tienes una buena vición y te das cuenta que es te dificultan para escribir un texto, y tus criticas estan muy bién pero me gustaria que nos apoyarasras para pode mejorar mi redacción. (triom07)

En los casos en que hago la transcripción de textos completos o bien pasajes al inicio o final del texto incluyo los siguientes criterios.

[np] Número de párrafo - línea o bloque de líneas gráficas separadas por espacio

[i] inicio del texto

[f] final del texto

\subsection{Decisiones sobre la restricción de la muestra para la construcción del corpus}

Durante la fase de elicitación siempre se presentan situaciones, unas predecibles otras complejas y otras más totalmente inesperadas que es necesario contemplar para la toma de decisiones sobre los datos que son fundamentales, relevantes $\mathrm{y}$, principalmente, que son el centro de interés de la investigación. De hecho, no todos los datos y textos obtenidos en la muestra en la fase de elicitación serán tomados en consideración para la clasificación y el análisis, es decir, para la construcción de los datos o el corpus pertinente para la investigación. Así, el corpus es una construcción razonada a partir de las decisiones tomadas en la elicitación y también sobre los aspectos surgidos en el desarrollo de la misma.

En esta investigación, en la primera fase de la construcción del corpus, tomé la determinación de hacer una restricción de la muestra en aquellos casos en que por diversos aspectos la interacción no pudo desarrollarse de manera normal, fundamentalmente en la última fase de elicitación en la Universidad Intercultural de Chiapas. Así, tomé la decisión de no contemplar en el análisis las muestras de la redacción de las segundas versiones de los autores, puesto que no existieron las condiciones de tiempo, debido a la eliminación de 
la última sesión de trabajo por el paro estudiantil que anteriormente comenté. A pesar de que en estos textos apreciamos aspectos de interés dignos de analizarse, tal vez en otro momento, en esta ocasión no los contemplo por la falta de sistematicidad, la parcialidad de la información y por la problemática de no tener los elementos completos para un análisis integral con los demás datos del corpus conformado. También eliminé todos aquellos textos en los que no fue posible completar el folio entre autor y juez, ya sea porque en la segunda sesión uno de ellos no se presentó o bien llegó muy tarde a la sesión, de manera que no fue posible su incorporación plena al trabajo.

\subsection{Caracterización general de los textos}

Es posible hacer una caracterización de múltiples aspectos de la muestra, incluyendo, por ejemplo, aspectos formales gráficos de caligrafía, ortografía, segmentación léxica, acentuación, estructuración interna, bloques temáticos o párrafos, así como el uso de la lengua, por ejemplo, el léxico empleado, la semántica, la estructuración gramatical, las dificultades manifiestas en la coherencia y la cohesión, así como ejemplos evidentes de falta de dominio de la lengua española escrita de algunos de estos alumnos indígenas. Además, podemos caracterizar el manejo de recursos del lenguaje de los alumnos para intentar expresarse en un contexto académico. En los textos encontramos gran variedad de situaciones contrastantes sobre todos estos aspectos, por ejemplo, textos que presentan múltiples problemáticas de redacción y uso léxico, y, por otra parte, textos con un dominio pleno de la lengua en la gramática, la ortografía y en general la coherencia y cohesión. En general hacer una caracterización de todos los aspectos de los textos de la muestra es un reto importante de análisis descriptivo que escapa a los objetivos de esta investigación, en otro trabajo podré hacer esto, puesto que existen datos importantes y asuntos que contemplar sobre este tipo de caracterizaciones en el manejo de recursos de escritura. Pero en esta investigación centro mi atención en una caracterización de aspectos relacionados con las tomas de decisiones de textualización por parte de los autores, los comentarios sobre el desempeño y las manifestaciones o evidencias de reflexividad sobre la escritura. 


\subsubsection{Sobre los comentarios como autores, jueces y decisiones de edición}

En los textos podemos apreciar determinados tipos de reflexión de los alumnos al asumir el rol de autores sobre el tema de la lectura proporcionada, en relación al tema del desempeño escrito de alumnos universitarios, en esta ocasión, el autor y el juez oaxaqueños, y, por otra parte, sobre experiencias relacionadas con el desempeño personal. En la tabla 3 podemos ver los criterios que contemplé para caracterizar el tipo de reflexión manifestada por los autores en sus escritos.

Tabla 3. Tipos de reflexión sobre el tema de la lectura y el desempeño (primera versión)

\begin{tabular}{|l|}
\hline Tipos de reflexión del autor en versión inicial \\
\hline Comentario general \\
\hline Comentarios prescriptivos \\
\hline $\begin{array}{l}\text { Comenta la lectura sin compartir } \\
\text { reflexión sobre sus experiencias }\end{array}$ \\
\hline Reflexión personal sin comentar la lectura \\
\hline $\begin{array}{l}\text { Comenta lectura y comparte reflexión } \\
\text { sobre sus experiencias }\end{array}$ \\
\hline
\end{tabular}

Además tomo en consideración una caracterización general de los textos correspondientes a las distintas universidades contempladas en las fases de elicitación. Para ello tomo en cuenta los comentarios y sugerencias de los jueces y las decisiones de edición en la segunda versión redactada por los alumnos. Ver Anexos 3 y 4 (Fase de elicitación 4: Universidad Intercultural de Chiapas), Anexos 8 y 9 (Fase de elicitación 2: Universidad Pedagógica Nacional plantel Ixtepec) y Anexos 11 y 12 (Fase de elicitación 3: Universidad Pedagógica Nacional Plantel Tehuantepec).

El trabajo metodológico de hacer una caracterización general de todos los textos conforme a los criterios de comentarios y sugerencias de los jueces y decisiones de edición en la segunda versión me permite establecer una propuesta de categorías que puedo aplicar con todos los textos con un énfasis en las prácticas concretas de redacción realizadas por los estudiantes. La metodología de caracterización a partir de decisiones de textualización 
me permite hacer una propuesta que puedo aplicar en los distintos textos de la muestra, tomando siempre en consideración que las categorías provienen directamente de los textos.

A continuación presento como ejemplo metodológico de esta propuesta, la aplicación de los criterios aplicados en la caracterización general de los textos obtenidos en la fase de elicitación 4. En primer nivel los jueces dan relevancia al nivel gráfico de las palabras: caligrafía (35), la puntuación (30), la ortografía (28) y la acentuación (27), no tachar, ser limpio (8) y cuidar la segmentación de palabras (4). En segundo nivel contemplan aspectos de cohesión y selección léxica, consideran que el compañero no repita palabras y que cuide el vocabulario empleado (22), escribir con claridad gramatical (12), cuidar el uso de conectores y elementos de transición léxicos y de puntuación (6) y un alumno contempla el posicionamiento del autor ante el texto. En tercer lugar consideran el manejo de contenidos: ser coherente, que reflexione antes de escribir, que aborde el tema, que lea primero (23) e incorporar información para enriquecer el texto (9). En cuarto lugar aparecen las valoraciones, evaluaciones y aportación de información por parte del juez: los elogios a la escritura del autor (20), las justificaciones de los errores, el tipo de escritura del autor y expresiones de aliento para mejorar (6) y motivaciones para mejorar sin observaciones concretas (3). En quinto lugar consideran la estructura interna y contemplan la organización y adecuado uso de párrafos (11). En el sexto lugar hacen observaciones sobre la planeación y la revisión: que el compañero planee, reflexione, organice, revise y corrija su propio texto (4) y que tome apuntes, que ponga atención (1). Ver en el Anexo 3 el seguimiento de estos aspectos.

Considero que la relevancia en primer lugar al aspecto formal gráfico (132 ocurrencias en total) se debe a una larga tradición escolar que contempla la cuestión gráfica como más relevante que, por ejemplo, el manejo de contenidos, la cohesión, la estructuración y la selección léxica. Además, me parece que esta atención prioritaria al aspecto gráfico se debe a que los jueces asumen que el compañero bilingüe indígena debe cuidar, por ejemplo, la ortografía y la acentuación del español en contexto académico, que en muchos casos es la segunda lengua de los alumnos y algunos aún no la dominan. De esta manera, los jueces dejan en un siguiente plano los recursos de cohesión y selección léxica (41) y el manejo de los contenidos para lograr la coherencia y la incorporación de 
información (32), que son los recursos constitutivos sobre la conformación de herramientas de redacción básica.

Por otra parte, destaca que los jueces dan mayor importancia a cuidar los comentarios ante los autores, por ejemplo, al expresar, elogios (20) y a justificar los errores (6) que a hacer observaciones y sugerencias sobre la estructuración, el uso de párrafos, la planeación y la revisión del texto. Esta situación pone de manifiesto que un número importante de jueces (29) se previene de la posible reacción del autor, que no están acostumbrados a este tipo de práctica y lo que les representa, significa e implica un tipo de construcción de relaciones de identidad complejas en ambiente académico. Además, el hecho de que los jueces contemplen el aspecto gráfico, la cohesión y el manejo de contenidos, por encima de la estructuración y el manejo de párrafos, es una evidencia de que, al hacer observaciones y sugerencias, los jueces se preocupan más por la claridad en la expresión escrita en español y el tema abordado, que en los aspectos formales de formato textual en la construcción de unidades temáticas en párrafos. Esto refleja que consideran relevante el poderse comunicar con claridad antes que la estructuración textual. En el sexto lugar, los jueces que toman en cuenta la planeación y revisión manifiestan un tipo de reflexividad sobre la redacción como un proceso y lo transmiten al autor como la necesidad de reflexionar, organizar y planear el escrito como práctica fundamental de la escritura.

Anteriormente comenté que no contemplo como parte del corpus de análisis la edición del texto en las segundas versiones en la última fase de elicitación, debido a las condiciones inadecuadas de tiempo, al compactar las actividades en las sesiones programadas. La mayoría de alumnos simplemente elimina información, reduce el texto, parafrasea algunos pasajes o copia casi toda su versión inicial y otros ni siquiera completan o hacen el ejercicio. Aquí simplemente hago mención de algunos elementos de reflexividad en la toma de decisiones. Estos datos no aparecerán en los siguientes capítulos de este trabajo, sin embargo considero importante hacer la caracterización general de los textos.

En la reelaboración del texto con la idea de mejorarlo en la segunda versión, los autores ponen de manifiesto evidencias de reflexividad, mediante la intencionalidad expresada en las decisiones sobre el manejo de recursos diversos de textualización. El primer aspecto al que dan relevancia corresponde a los contenidos, con el siguiente número 
de ocurrencias o apariciones en los textos: la reducción y eliminación de información en el texto (27), el parafraseo de pasajes de la primera versión (24), copia de toda o la mayor parte de la primera versión (15), versión final totalmente distinta (12), incorporación de información (8) y comentario (3).

El predominio de la eliminación de información, el parafraseo y la copia, refleja la reflexividad sobre decisiones relacionadas con la valoración de la pertinencia de los aspectos abordados sobre el tema en cuestión. Además, en estas decisiones influye el que no tuvieron el tiempo suficiente para la redacción de esta segunda versión. Resulta fundamental contemplar, cuando es posible, la intencionalidad y la reflexividad manifestada en los textos de autores que determinan no hacer ningún cambio y copiar íntegramente la primera versión, principalmente, cuando están en desacuerdo con lo expresado por el juez o bien aquellos que reciben sugerencias y comentarios, mismos que aceptan y que, sin embargo, al final hacen copias totales o parciales.

Considero que en el parafraseo los alumnos muestran un tipo de reflexividad e intencionalidad relacionada con la pertinencia y adecuación del lenguaje en términos formales y contextuales. Esta práctica implica una valoración y autorregulación sobre el desempeño en la selección de recursos para la búsqueda y determinación de opciones diversas para poder modificar su propia expresión con otras palabras, mismas que deben valorar y evaluar en distintos aspectos de textualización en la edición del texto. Este tipo de valoraciones también se aprecia cuando el alumno decide hacer una versión totalmente distinta o al incorporar nueva información. Únicamente en 3 casos aparece la incorporación de comentarios en la segunda versión, lo que refleja, indudablemente, que los alumnos, en su mayoría, no contemplaron valoraciones para ampliar o modificar los comentarios de la primera versión. Esta situación se debe fundamentalmente a que las primeras versiones están conformadas por comentarios correspondientes a distintos tipos de reflexividad.

$\mathrm{Al}$ igual que los jueces, los autores dan relevancia de segundo lugar a la cohesión y selección léxica en la elaboración de la segunda versión. El número de apariciones en los textos es el siguiente: procura mejorar selecciones léxicas (12), incorpora conectores o elementos de transición textual entre ideas y párrafos (2), modifica aspectos gramaticales (2). Este tipo de decisiones manifiesta la intencionalidad y reflexividad sobre el desempeño 
de los alumnos en los roles asumidos de jueces y autores. El interés está centrado en decisiones sobre la adecuación y la pertinencia del lenguaje y de la estructuración para dar claridad a lo expresado, por ejemplo, al parafrasear la primera versión y al decidir el vocabulario pertinente en ambiente académico. Además, los alumnos se ven en la necesidad de valorar y regular su expresión en relación a la estructuración textual, al emplear determinados conectores y elementos de transición textual, y decidir sobre el manejo de recursos para resolver problemáticas enfrentadas sobre el uso de la gramática del español y expresarse con propiedad en ambiente académico.

Los autores recibieron los comentarios de los jueces con la idea de mejorar su texto en una segunda versión, sin embargo, al igual que apreciamos en la lectura proporcionada sobre el autor oaxaqueño, 15 alumnos deciden reaccionar ante los comentarios recibidos y, en lugar de modificar su texto, incorporan información o reflexiones sobre los comentarios recibidos. Esta situación corresponde al tercer lugar sobre las decisiones de textualización. A pesar de que estos alumnos se desvían de la actividad esperada, es decir, la reelaboración del texto a partir de la versión inicial, la valoración de los comentarios recibidos, la reacción y la reflexión sobre los mismos, es relevante estudiar en estos textos el tipo de reflexividad e intencionalidad manifestada cuando el alumno decide hacer reflexiones sobre su escritura o bien sobre lo manifestado por el juez. Asimismo, es relevante contemplar las decisiones que toma al hacer caso omiso de lo que dice el juez, por ejemplo, modificar totalmente su texto o bien hacer copia íntegra de la versión inicial. En cualquiera de estas situaciones la toma de decisión implica valoraciones de textualización y, principalmente, la construcción de elementos de identidad contextual sobre lo que implica reelaborar su texto.

Llama la atención que ante la relevancia en primer nivel de los jueces sobre el nivel gráfico de las palabras con 132 apariciones de comentarios u observaciones, en las tomas de decisión para la edición, los autores contemplen este aspecto en cuarto nivel con el siguiente número de apariciones en los textos: modificar puntuación, ortografía, acentuación (8), mejorar caligrafía (7). En una primera apreciación contrasta el hecho de que mayoritariamente los alumnos como jueces den relevancia de primer lugar a estos aspectos gráficos, y que al asumir el papel de autores que corrigen su propio texto se olviden de la importancia que dieron, por ejemplo, a la ortografía y acentuación de su 
compañero, y que en sus propias decisiones de textualización estos aspectos pasen a los últimos lugares. El punto es que en términos de valorar el desempeño escrito, puede resultar más fácil opinar y evaluar la escritura del compañero que la propia, en relación a lo que consideramos prioritario, en este caso, la ortografía al asumir el rol de juez.

Existe concordancia entre la consideración de los jueces y los autores sobre la estructura interna y el uso de párrafos; en ambos casos se encuentran por debajo de la cohesión y selección léxica, los contenidos, el aspecto gráfico de las palabras y las reacciones expresadas por los jueces y los autores. Como decisiones de edición, los autores contemplan esta estructuración y manejo de párrafos en 5to lugar con 8 apariciones en los textos, y un caso de manejo de párrafo como unidades de transición temática. Los autores contemplan la prioridad sobre la claridad en la cohesión, la coherencia y los aspectos gráficos por encima de la forma de estructuración de unidad textual. Considero que esta situación se debe a que los alumnos se encuentran en un proceso gradual de construcción de conocimientos sobre la estructuración de unidades textuales que involucran el uso del párrafo o bloques temáticos. Ver el seguimiento de decisiones de edición en el Anexo 4.

Una vez que he realizado la caracterización general de los textos, en los siguientes capítulos haré una propuesta metodológica de construcción de categorías de análisis temáticas, y sobre el tipo y nivel de la reflexividad en los textos. Así contemplo estudiar las evidencias de reflexividad cuando los alumnos se expresan sobre el tema del desempeño de la escritura en ambiente académico.

\subsection{Consideraciones sobre la aplicación de los criterios metodológicos de la propuesta de elicitación y caracterización textual.}

El aporte fundamental de la propuesta de construcción del diseño de elicitación a lo largo de las sesiones de trabajo con alumnos de las distintas universidades es la creación, valoración y adaptación de los materiales y el tipo de interacción, por ejemplo, la guía, el tipo de interacción y la retroalimentación. En general, el enfoque de esta propuesta metodológica de prácticas de interacción y caracterización parte de la idea de que cualquier 
diseño para las sesiones de elicitación tiene que ser valorado conforme a las realidades presentadas en cada sesión y contexto en la educación superior. No podemos plantear modelos generales de diseño y decisiones de elicitación para aplicar en cualquier entorno, es necesario contemplar y modificar las interacciones para favorecer el trabajo.

Por otra parte, si bien no es posible establecer este tipo de generalizaciones para imponer modelos de interacción para las sesiones de elicitación, a partir de este trabajo de investigación logré establecer situaciones y decisiones para la conformación del diseño de elicitación que me permiten proponer criterios encaminados a una propuesta, en construcción, de un modelo de elicitación para propiciar la manifestación de determinado aspecto de interés, en este caso, las evidencias de intencionalidad y reflexividad.

En esta propuesta considero, en primer punto, que lograr la elicitación de evidencias de intencionalidad y reflexividad no es algo fácil, ya que los alumnos de manera espontánea y por escrito no manifiestan este tipo de discusiones y reflexiones, tal como vimos en los textos de la UPN, principalmente en Ixtepec, donde los alumnos manifestaron diversas cuestiones de reflexividad relacionadas, pero ajenas al desempeño escrito en ambiente académico. Por ello, en la propuesta considero fundamental crear instrumentos e interacciones para la elicitación que nos ayuden a focalizar o centrar la temática abordada, y en concreto, en los aspectos u objetos de estudio de interés, por ejemplo, los estándares de textualidad, la interacción, las prácticas, la conformación de identidad, las experiencias de revisión y edición, así como la retroalimentación. En cada caso el investigador tiene que decidir los puntos de interés para investigar y tomar en consideración que cualquier decisión metodológica, por ejemplo, la interacción con una guía, no será una cuestión neutra en la práctica, puesto que tendrá impactos en la manifestación escrita de los alumnos. Anteriormente he planteado que, en la medida de lo posible, debemos evitar las imposiciones de modelos normativos o esquemas rígidos para que los alumnos escriban, asimismo, debemos evitar una visión descalificadora sobre el desempeño y no conducir, manipular o regular la expresión de los alumnos. Sin embargo, es necesario reconocer que el diseño y la aplicación de cualquier material, instrumento o guía de apoyo, siempre tendrá una tendencia o enfoque. Por ejemplo, en esta investigación, el interés por la manifestación de comentarios sobre cuestiones relacionadas con estándares de textualidad y aspectos 
contextuales sobre las prácticas está presente en el diseño de la guía y, evidentemente, en los textos obtenidos. Es decir, en la propuesta de diseño metodológico de elicitación considero un control de la interacción para centrar, principalmente, la temática abordada, y en esta situación tratar de propiciar la expresión de diversas reflexiones y puntos de vista, en este caso, sobre el desempeño académico escrito en la universidad.

Por otra parte, la experiencia vivida con los alumnos nos lleva a hacer una propuesta de elicitación en la que debemos dar prioridad y favorecer la manifestación de las reflexiones por escrito y que toda interacción oral, por ejemplo de retroalimentación, debe estar diseñada para propiciar la expresión escrita. Esta situación requiere un trabajo metodológico de diseño de interacción, puesto que, recordemos, no es sencillo lograr que los alumnos manifiesten evidencias de reflexividad sobre el desempeño escrito. En general, predominan las investigaciones en las que se emplean metodologías de elicitación basadas en la entrevista oral y la transcripción de las mismas, sin embargo, en el contexto del estudio de la textualidad, la caracterización, clasificación, y creación de categorías de análisis sobre el desempeño en el manejo de recursos de textualización requiere, por obvias razones, de manejar datos y muestras de escrituras académicas en los distintos tipos de textos. Considero que la entrevista oral es una valiosa herramienta para aportar datos e información que complementa y enriquece la investigación, pero que no es en sí misma la materia prima en el marco de los estudios de la textualidad.

Por otra parte, en esta investigación propongo criterios generales para la caracterización textual desde la perspectiva del objeto estudio de interés, por ello considero fundamental tomar decisiones para tener el primer acercamiento a los textos desde la mirada del estudio de las decisiones de redacción y edición, los comentarios de los autores y jueces y las decisiones de textualización en la práctica de revisión y edición de textos. Es relevante contemplar una mirada panorámica de estos aspectos porque sobre ellos deseamos destacar las evidencias de intencionalidad y reflexividad. Además, los criterios de identificación de los textos de los autores y jueces, la transcripción textual y la restricción de la muestra para conformar el corpus de trabajo son fundamentales en la metodología de trabajo de la investigación para iniciar la propuesta de categorías y criterios de clasificación textual. 
Por el momento este es un diseño fundamental que aporta elementos para una metodología de elicitación, caracterización de los textos y conformación del corpus en busca de evidencias de reflexividad sobre el desempeño y la intencionalidad en las prácticas de escritura académica. 


\section{Capítulo IV}

\section{Criterios metodológicos para la clasificación de los textos}

\subsection{Pertinencia de crear criterios metodológicos de clasificación textual}

Una vez realizada la caracterización general de los textos es fundamental la toma de decisiones con el fin de tener un primer acercamiento y criterios de clasificación textual. De esta manera podemos ubicar grupos de textos que clasificamos conforme a características encontradas en la escritura de los alumnos. En una perspectiva con énfasis en el estudio de la textualidad, la clasificación debe llevarse a cabo a partir de criterios o categorías provenientes de los textos. De esta manera debemos evitar crear categorías y clasificaciones que resultan ajenas a los textos obtenidos en la fase de elicitación, por ejemplo, a partir de la escritura de expertos, de la estilística o la retórica. Este tipo de modelos impuestos para la clasificación no responden a la realidad correspondiente al desempeño de los alumnos.

Podemos ubicar e identificar fragmentos y textos completos en los que predominan, por ejemplo, determinadas características formales y de contenido que nos pueden servir para crear categorías de análisis. En los textos de las muestras de esta investigación un criterio metodológico que facilitó un primer acercamiento al análisis fue la clasificación conforme al género textual o tipo de texto, la temática abordada y, en las siguientes fases de elicitación, el tipo de comentarios y sugerencias. Tomé esta decisión metodológica porque, a partir de la primera caracterización general de los textos, pude percatarme de la presencia mayoritaria estos aspectos, como resultado, principalmente, de las características de los materiales empleados, el diseño y el desarrollo de la interacción y las prácticas de escrituras realizadas en cada una de las fases de elicitación. Así, en los textos correspondientes a los estudiantes de las universidades contempladas los primeros criterios de clasificación que tomé en cuenta fueron el tipo de texto o género textual y el tema (criterio de clasificación 
textual1: UPN Ixtepec), los contenidos de la clase y el género textual (criterio de clasificación textual 2: UPN Tehuantepec) y el tipo de comentario y de reflexividad manifestada, y, por otra parte, la temática en torno a una discusión de escritura académica (criterio de clasificación 3: UNICH).

Estos primeros criterios y categorías de clasificación son el punto de partida para una mirada a estos textos que me permitió posteriormente proponer otras categorías para identificar evidencias de intencionalidad y reflexividad y, también, para proponer cambios metodológicos en las fases de elicitación encaminados a favorecer que los alumnos expresaran, por ejemplo, determinados tipos de textos, comentarios y temáticas centradas en la escritura académica.

Como criterio general de la propuesta metodológica es necesario tomar en consideración que, principalmente, como resultado del diseño de elicitación, así como de las situaciones contextuales, apreciamos textos con determinadas características que podemos anticipar y, por otra parte, podemos encontrar textos que tienen ciertos aspectos que no estaban contemplados y que en algunas ocasiones nos pueden servir como criterios de clasificación y para la toma de decisiones para modificar el diseño de elicitación. Por ejemplo, la identificación del género textual y de la temática fue fundamental porque me permitió modificar el diseño inicial de manera tal que hiciera que los alumnos se centraran en la temática de escritura académica y que escribieran exclusivamente comentarios y sugerencias sobre el desempeño escrito.

En todos los casos es necesario tomar las decisiones para establecer las categorías de clasificación que faciliten el trabajo para el estudio de los elementos de la textualidad, y, principalmente, para tratar de identificar aquellos aspectos que deseamos focalizar como objeto de investigación. Los criterios de clasificación textual pueden corresponder a puntos de interés u objetos de nuestra investigación, y, en otras ocasiones, son herramientas metodológicas que nos ayudan a apreciar y manejar los datos para identificar el objeto de interés o investigación. En esta investigación los primeros criterios de clasificación me sirvieron para proponer otras categorías centradas en aspectos y temáticas de reflexividad sobre el desempeño académico. 
En este y los siguientes capítulos deseo mostrar y comentar las decisiones que tomé para el establecimiento de criterios y categorías como procedimiento metodológico para un primer acercamiento general al estudio y posterior clasificación de los textos de los alumnos de las universidades contempladas. Además hago valoraciones y reflexiones sobre estas decisiones metodológicas en el marco de las discusiones teóricas que he presentado en esta investigación y aprovecho la ejemplificación de los criterios metodológicos para presentar, de manera panorámica, evidencias ejemplares de textos representativos de las universidades en donde implementé la fase de elicitación. Debido a que las interacciones realizadas para la obtención de los textos fueron, en general, accidentadas y se presentaron imprevistos, además de que no existen elementos suficientes para hacer seguimientos o estudios de caso, no hago ningún tipo de trabajo de análisis de los textos, simplemente presento una visión panorámica de textos que muestran evidencias de distintos tipos de intencionalidad y reflexividad. Las consideraciones teóricas y metodológicas en la fase de elicitación y clasificación textual que aquí he presentado, pueden servir para hacer trabajos diversos de análisis de muestras de escritura académica.

\subsection{Primeros criterios de clasificación: el género textual y el tema abordado en la interacción y el instrumento empleado}

Recordemos que en la fase de elicitación 2: UPN Ixtepec los alumnos leyeron un texto del relativismo lingüístico relacionado con la Hipótesis Sapir-Whorf, sobre la discusión de que la gramática de la lengua determina el pensamiento de los hablantes. Los estudiantes escribieron una versión inicial, los jueces hicieron comentarios y los autores escribieron la versión final corregida a partir de los comentarios recibidos. Esperaba que los autores tomaran una postura o punto de vista sobre la discusión del relativismo linguiístico presentado en la Hipótesis de Sapir-Whorf, y que lo asumieran en el comentario, de manera tal que escribieran con intencionalidad argumentativa. Sin embargo, como podemos

apreciar en la tabla 4, en su mayoría los autores escribieron textos expositivos en las versiones inicial y final en los que simplemente exponen, parafrasean o copian el contenido de la lectura o bien exponen un tema relacionado, pero ajeno al contenido concreto del 
texto leído. En algunas de estas exposiciones los alumnos se enfrentan a dificultades en la comprensión de la lectura del texto y esto los lleva a tener problemáticas en el proceso de textualización, en distintos aspectos.

En estos textos fue escasa la manifestación de evidencias de reflexividad sobre el desempeño de la escritura académica, predomina la manifestación de intencionalidad y, además, existen manifestaciones implícitas de reflexividad a partir del tipo de decisiones de textualización de los autores una vez que revisaron los comentarios de los jueces. En general, la mayoría de alumnos se desvía del tema de la lectura proporcionada y escriben textos expositivos. El predominio de manifestaciones de intencionalidad y escasas manifestaciones de reflexividad en estos textos se debe, en gran medida, a que la lectura resultó complicada, al abordar un asunto de reflexión sobre la lengua y el pensamiento, pero no se centra en el desempeño lingüístico. No realizamos una interacción y reflexión grupal sobre la escritura académica para guiar la discusión en esta temática. Además, hicimos una instrucción muy abierta que impide enfatizar un tema en concreto al pedirles a los alumnos que escribieran sus puntos de vista en un comentario crítico.

Tabla 4. Clasificación de las versiones de los autores conforme al género textual

\begin{tabular}{|c|c|c|c|}
\hline Género textual & $\begin{array}{c}\text { En versión } \\
\text { inicial y final }\end{array}$ & $\begin{array}{c}\text { Combinado comentario } \\
\text { versión inicial y } \\
\text { expositivo versión final }\end{array}$ & $\begin{array}{c}\text { Combinado expositivo versión } \\
\text { inicial y comentario versión final }\end{array}$ \\
\hline Textos expositivos & 17 & - & - \\
\hline Comentarios & 5 & - & 2 \\
\hline $\begin{array}{c}\text { Textos con } \\
\text { parte expositiva } \\
\text { y comentario }\end{array}$ & 0 & 2 & - \\
\hline
\end{tabular}

Mediante esta clasificación de los textos obtenidos en la fase de elicitación 2 podemos percatarnos, por ejemplo, de algunos elementos de reflexividad en las observaciones de los jueces, fundamentalmente, al sugerir a los autores de textos expositivos que escribieran comentarios sobre la lectura. Este tipo de manejo de los géneros textuales me llevó a tomar la decisión de hacer la distinción de categorías sobre textos expositivos y comentarios, puesto que me ayudaba a tomar en consideración aspectos de reflexividad y estándares de textualidad. Por ejemplo, considero la intencionalidad y la 
aceptabilidad, es decir, determinar aquellas evidencias sobre lo que el alumno intenta expresar desde su repertorio de conocimientos y habilidades. También considero las valoraciones de aceptabilidad que pudiera plantear el juez que revisa y hace sugerencias sobre el texto, quien puede contemplar criterios regulativos de eficacia, efectividad y propiedad. Podemos ver que existe dificultad o falta de costumbre para distinguir y redactar comentarios y exposiciones en la escritura académica, en este caso, hacer un comentario sobre el tema de la lectura. En el siguiente ejemplo vemos esta situación.

Yo le entendí al texto que una persona habla y expresa sus sentimientos de acuerdo a su manera de como percibe el mundo que le rodea. Y de que nosotros, como otros seres vivos tenemos diferentes habilidades, y cada una tiene su manera de reconocer e interpretar. (tsih19)

En general los jueces se percatan de las dificultades de los compañeros al solicitarles, por ejemplo, que hagan comentarios, que aborden el tema y que proporcionen información aplicada a un contexto académico, de esta manera en las sugerencias destacan los estándares de informatividad, efectividad y la pertinencia textual del escrito en ambiente académico, tal como vemos a continuación.

Compañero joel. Es muy interesante tu opinion pero sí quisiera saber tu modo de pensar sobre este tema y no copiar todo. como esta ¡que le entendiste tú Joel! (tsih08juez)

Sobre la reflexividad relacionada con el manejo del género textual, en el caso de los escritos cuya primera versión es un comentario y la segunda es un texto expositivo, por ejemplo, en el texto tsim06j, el juez considera que es necesario contemplar la totalidad de la lectura sobre la Hipótesis Sapir-Whorf.

-Compañera Se debe abarcar todo el texto.

-Cuando uno platica con el autor no debemos perder el punto clave. (tsim06j)

En este ejemplo el juez contempla cuestiones relacionadas con la informatividad y la cognitividad en el marco de la escritura en contexto académico, que en este caso tienen impacto en que el autor escriba una segunda versión en la que cambia el tipo de texto. Es posible que al considerar el comentario del juez la alumna decida contemplar el contenido de la lectura y exponerlo, y al hacerlo deje de lado el comentario que antes había realizado. Así hace un cambio de género textual debido a un elemento de reflexividad sobre el 
contenido y el tema de la lectura realizada. El criterio metodológico de clasificación relacionado con el género textual nos permite ubicar elementos de intencionalidad cuando la alumna trata de explicar el tema abordado. En este ejemplo no existen evidencias explícitas de reflexividad, predomina la intencionalidad manifestada en torno a cuestiones de informatividad y cognitividad.

En los textos donde los alumnos escriben primero una versión expositiva y después un comentario, parece que los comentarios puntuales de los jueces sobre la necesidad de que el autor exprese sus puntos de vista, influyen en el cambio al comentario en la versión final. Revisemos las observaciones de estos jueces.

-Por lo que note, no te diste el tiempo de leer el texto, no te preocupes a la mayoría nos paso. "no es cierto"

-Pienso que debes ser un poquito mas crítico con tígo. (tsih07j)

Tu hipótesis whorfiana que tu escribiste no habla de que lengua. compañero que tu concides con el científico por que tienen las mismas ideas de acuerdo al tema.

falto una explicación mas clara como se relaciona en la sociedad. (tsih20j)

En este último ejemplo, parece que el juez hace ironía sobre la coincidencia entre el científico y su compañero, puesto que éste se limita a exponer el contenido. El juez contempla cuestiones relacionadas con cognitividad, informatividad y propiedad, pues considera el conocimiento de divulgación sobre la lectura, que su compañero escriba con propiedad en ambiente académico, que asuma una postura propia para comentar sobre la información y que no repita la información del texto leído. Así, en este punto el juez manifiesta una intencionalidad que refleja reflexividad sobre recursos de textualización en una práctica académica.

En otros textos los autores manifiestan evidencias de intencionalidad que involucran la comprensión del texto, el aspecto cognitivo y el manejo de recursos formales de textualización. Vemos en el siguiente ejemplo que la alumna trata de recuperar aspectos de la lectura con sus propias palabras y proporcionar ejemplos sobre su entorno. A pesar de que no logra abordar el tema de la lectura, la intencionalidad manifestada refleja estándares de informatividad relacionados con el tema de manera significativa sobre conocimientos y 
usos concretos de la lengua en su entorno y, también, destaca el intento por escribir un comentario centrado en el tema, como vemos a continuación.

Es que la hipótesis dice que toda lengua tiene Gramaticales es la manera que se escribe y otra como se pronuncia, en mi lengua se pronuncia, distinto comparando con las 2 derivadas de la lengua huave, y lo entendemos de distinta maneras pero hay palabras que significan iguales y otras distintas, en cada individuo tiene una lengua materna desde que nace lo aprende. (tsim15vf)

Por otra parte, destaca, de manera fundamental, además del género textual (expositivo o comentario), la presencia de textos relacionados o sin relación con la lectura proporcionada, es decir, el texto de la Hipótesis Sapir-Whorf, tal como vemos en la tabla 5. Es relevante el reducido número de textos conformados por comentario relacionado con el tema en versiones inicial y final. El punto es que esta situación propicia que los jueces expresen comentarios reflexivos sobre el desempeño de los alumnos y que contemplen ideas relacionadas con los principios constitutivos, principalmente, de propiedad y pertinencia de un texto en ambiente académico. Así el criterio metodológico nos ayuda a focalizar aspectos de reflexividad en torno a la escritura.

Tabla 5 El género textual y la relación con el tema de la lectura

\begin{tabular}{|l|c|c|l|l|}
\hline & $\begin{array}{l}\text { Comentario } \\
\text { relacionado } \\
\text { con el tema }\end{array}$ & $\begin{array}{l}\text { Comentario sin } \\
\text { relación con el } \\
\text { tema }\end{array}$ & $\begin{array}{l}\text { Exposiciones } \\
\text { relacionadas } \\
\text { con el tema }\end{array}$ & $\begin{array}{l}\text { Exposiciones sin } \\
\text { relación con el tema }\end{array}$ \\
\hline Versión inicial & 4 & 3 & 7 & 12 \\
\hline Versión final & 2 & 5 & 9 & 10 \\
\hline
\end{tabular}

Veamos un ejemplo representativo de una decisión reflexiva de autorregulación del desempeño y valoración del comentario recibido por el juez. En el texto tsim17 la alumna cumple con el comentario relacionado con el tema y constituye un ejemplo representativo de mayor avance, conforme a los principios regulativos de aceptabilidad, efectividad e intencionalidad. En su versión final hace cambios que favorecen la incorporación de información y de sus puntos de vista, además se posiciona ante el texto con precisión para plantear sus puntos de vista. A continuación presento algunos pasajes de este texto. ${ }^{29}$

\footnotetext{
${ }^{29}$ Los pasajes que subrayo reflejan la intencionalidad de la alumna para enriquecer su texto y aportar elementos para completar información fundamental en la segunda versión.
} 
Está hipótesis establece que existe una cierta relación entre las categorias gramaticales del lenguaje, que una persona habla y la manera de como ve y conceptualiza el mundo.

Creo que las dos hipótesis fuerte y debil tienen algo de razón Ła que en la primera podriamos decir que es cierto que la lengua de una persona monolingüe, dependiendo de su lengua índigena o el español, existen palabras que tienen un significado diferente y por lo tanto una conceptualización diferente de ver y expresar el mundo.

[...] Estoy de acuerdo en que la lengua no determina la vision de lo que nos rodea si no que también la memoria es un factor importante para determinar el lenguaje. $(\mathrm{tsim} 17 \mathrm{vf})$

El juez no aporta sugerencias concretas sobre el desempeño de la alumna, simplemente hace valoraciones, por ejemplo, al considerar que el texto tiene "mucha relación con la lectura", y que "hay que respetar los puntos y los guiones", a pesar de que en el escrito la alumna no presenta estos problemas. Este ejemplo refleja que a veces las observaciones del juez no son tomadas en consideración para la edición de los textos que muestran un mayor avance, aceptabilidad, eficacia y propiedad. Veamos el texto completo en el Anexo 5.

Los criterios metodológicos de clasificación sobre el tema y el género textual me permitieron apreciar que existen casos en que la versión inicial tiene relación con la lectura proporcionada, y la versión final es un texto sin relación alguna con el tema. Cabe preguntarnos lo que sucedió en estos casos, en relación a las decisiones del autor y la posible influencia de los comentarios del juez. Por ejemplo, en el texto tsim12 la alumna escribió en la versión inicial un comentario breve en el que retomaba algunos elementos de la lectura. El juez no hace sugerencias, simplemente hace un comentario breve y contundente sobre el pensamiento del hablante:

El pensamiento hablante tiene un poder muy importante en la conceptualizacion por que memoriza y clasifica (tsim12j)

Considero que este comentario motivó a la alumna a intentar hacer una reflexión sobre las características del pensamiento. Entonces ella se desvió de la lectura realizada y de su propia primera versión. La reflexividad sobre el tema y la intencionalidad para mejorar su escritura se manifiestan en su intento por manejar conceptos, enfrenta 
dificultades en la textualización relacionadas con la cohesión en el uso de pronombres para hacer referencia al tema que intentaba abordar, por ejemplo, al plantear al inicio de su segunda versión que:

Es importante conceptualizen muy bién entonces ya que sin el nosotros no podríamos memorizar y clasificar nuestros pensamientos, para ser transmitido por medio de nuestro lenguaje, y así poder hablar y entender a los demas y viceversa [...] (tsim12vi)

En contraste con el ejemplo anterior, la alumna se deja llevar por un comentario del juez que no le favorece para mejorar su texto, de manera tal que no hace una reflexión sobre sus propios recursos, sino sobre una idea del juez, que intenta desarrollar. Estos dos últimos ejemplos muestran que las decisiones del autor para modificar su texto, se deben, en algunos casos, a la influencia del juez y en otros exclusivamente a la revisión y valoración de los recursos propios de escritura del autor. De esta manera la reflexividad se manifiesta de manera implícita en el tipo de decisiones de textualización. Ver el texto tsim12 en el Anexo 6.

Un ejemplo en el que el comentario del juez parece ser determinante para que el autor mejore su texto, aparece en tsih07, donde el juez le dice al autor que "no te diste el tiempo de leer el texto" y "que debes ser un poquito mas crítico con tígo". Ante este comentario el autor modifica el texto expositivo sin relación con el tema de la lectura y en la segunda versión escribe un comentario que intenta relacionar con el tema, aunque no lo logra. Además se posiciona incluyéndose en segunda persona del plural para expresar su punto de vista.

De acuerdo a la lectura que se estuvo analizando es muy importante que nosotros nos demos cuenta con que personas estamos hablando para darnos cuenta quienes son si son de la misma comunidad porque muchas veces pasa eso que cuando un monolingüe va a otro lugar $[\ldots]$ porque hay palabras que si coinciden pero sus significados no los mismos son diferentes, (tsih07vf)

Indudablemente, este ejemplo muestra evidencias de intencionalidad en el manejo de recursos para hacer el comentario, a pesar de no haber abordado el tema de la lectura. Predomina la intencionalidad y podemos establecer que sólo existe evidencia implícita de reflexividad que podemos considerar mediante las decisiones de textualización sobre el género textual. A pesar de que no existe una manifestación explícita de reflexividad, este 
tipo de decisiones sobre el tema y el género textual constituyen una evidencia de la influencia de los comentarios del juez y de los procesos de valoración, evaluación y regulación del desempeño propio al intentar modificar elementos de textualidad. Podemos ver el texto completo en el Anexo 7.

Un criterio metodológico fundamental que contemplé para caracterizar el tipo de reflexividad sobre el desempeño, corresponde al tema de las sugerencias de los jueces y las decisiones de textualización que llevaron a cabo los autores para editar su texto. Esta información me permite contemplar la manera en que estas consideraciones de los alumnos pueden o no impactar o influir en las decisiones de los autores para revisar y editar sus textos en la segunda versión. Además, en los Anexos 8 y 9 presento, respectivamente el tipo sugerencias de los jueces y las decisiones y modificaciones que realizaron los autores en la segunda versión. Así, es posible establecer correlaciones más precisas entre las sugerencias y las decisiones en la revisión y la edición.

En general los jueces se centran predominantemente en el manejo de información, ya sea relacionada o ajena al tema, en algunos casos hacen sugerencias y en otros simplemente aportan información o bien opiniones sin relación alguna. En la edición de los textos predominó la toma de decisiones relacionadas con el manejo y cambio de contenidos y la incorporación de información sobre el tema abordado, por ello los autores contemplan aspectos relacionados con la informatividad y la cognitividad. Podemos constatar que la mayoría de autores y jueces no contemplan el cambio del género expositivo al comentario. Predominan las evidencias de intencionalidad cuando los autores intentan de diversas maneras proporcionar información sobre el tema en un contexto académico. Sobre el estándar textual de informatividad, podemos establecer que los alumnos se ven en la necesidad de comprender, valorar y contemplar la pertinencia de la información del texto proporcionado y las observaciones planteadas por los jueces para decidir como emplear dicha información en su propio escrito en el género textual requerido en ambiente académico. Así los aspectos de cognitividad e informatividad involucran la interrelación de contenidos y elementos de textualidad, principalmente, en las decisiones de textualización para escribir sobre el tema en determinado género textual. Tan sólo apreciamos manifestaciones implícitas de reflexividad que podemos establecer a partir del manejo de 
recursos de escritura en las decisiones de textualización. Por ello, en las siguientes fases de elicitación era necesario propiciar interacciones que favorecieran la manifestación escrita explícita de evidencias de reflexividad.

En los textos de correspondientes a la fase de elicitación 3: UPN Tehuantepec destaca de manera predominante la distinción en el manejo del género textual en las versiones iniciales y en las finales editadas y corregidas. Un grupo de textos corresponde al comentario de actividades desarrolladas y lo aprendido en la clase y el otro grupo corresponde a la narración de actividades o la exposición de temas desarrollados. Recordemos que en esta ocasión los alumnos realizaron, en el rol de jueces, comentarios sobre un reporte de uno de sus compañeros acerca de un tema desarrollado en una clase previa. En esta sesión no pudimos conocer la actividad que realizó el profesor la clase anterior, por lo que no pudimos resolver una confusión sobre la tarea asignada, ya que los alumnos hacen referencia tanto a un reporte de lectura como a un reporte de clase. Además, vemos textos en que los alumnos también hacen referencia a un comentario crítico sobre lo aprendido en clase.

Los alumnos hacen comentarios relacionados con el género textual, debido a que el tema estaba centrado en el escrito que los alumnos habían realizado la clase previa. Esta propuesta de clasificación, presente en la tabla 6, me permitió ubicar elementos representativos sobre comentarios relacionados con el género textual, mismo que posteriormente me servirían como herramienta metodológica para destacar evidencias de intencionalidad y reflexividad.

Tabla 6. Clasificación de los textos conforme al género textual.

\begin{tabular}{|l|c|c|}
\hline Género textual & Versión inicial & Versión final \\
\hline $\begin{array}{l}\text { Narración de actividades } \\
\text { desarrolladas }\end{array}$ & 12 & 9 \\
\hline $\begin{array}{l}\text { Expone secuencia de temas } \\
\text { de la clase sin desarrollarlos }\end{array}$ & 14 & 4 \\
\hline $\begin{array}{l}\text { Esquema o listado de ideas } \\
\text { conceptos o definiciones }\end{array}$ & 4 & 6 \\
\hline $\begin{array}{l}\text { Expresa impresión personal al } \\
\text { narrar o exponer actividades o } \\
\text { temas de la clase. }\end{array}$ & 3 & 4 \\
\hline $\begin{array}{l}\text { Comentario de los temas y lo } \\
\text { aprendido }\end{array}$ & 3 & \\
\hline
\end{tabular}


En su mayoría, los alumnos hacen sus reportes, ya sea narrando las actividades o al exponer la secuencia de temas. El reducido número de textos conformados por comentarios de los temas y lo aprendido, pone de manifiesto la falta de hábito para la redacción del comentario crítico. Algunos jueces hacen observaciones sobre la narración de actividades de la clase, la necesidad de contemplar el aprendizaje y el punto de vista personal. El siguiente ejemplo representativo y los textos conformados por comentarios de los temas y lo aprendido, son evidencias de que el profesor solicitó un reporte con un desarrollo y comentario crítico sobre lo aprendido en clase.

Hola compañero de lo que observe en tu texto que realizastes considero que te falta desarrollar un poco mas el texto que pidio el maestro ya que también le hace falta un inicio, desarrollo y una conclusión por lo que a la forma que el maestro pidio el trabajo considero que no fue así ya que tu lo que hicistes fue escribir las conceptos de cada palabra que vimos, ya que yo como le entendi fue que describiéramos lo que aprendimos y vimos durante la clase por lo que creo que devistes aber hecho es un texto más amplio o no tanto pero describir lo que entendistes, $[\ldots](\operatorname{trth} 25 \mathrm{j})$

Este ejemplo es representativo de la reflexividad relacionada con estándares constitutivos sobre la propiedad y la pertinencia de un texto en ambiente académico en relación al contenido y al escrito que solicitó el maestro. El alumno considera elementos de contenidos y estructuración textual al hacer valoraciones y evaluaciones del texto a partir de sus criterios sobre los requerimientos de propiedad relacionados con su conocimiento sobre las características del género textual, es decir, escribir una introducción, desarrollo y conclusión. Además, hace una valoración de la pertinencia del texto en un ambiente académico y por ello sugiere que modifique cuestiones de cognitividad y del manejo del lenguaje, destacando la necesidad de que escriba lo aprendido en clase.

En el siguiente ejemplo representativo podemos apreciar la manera en que los jueces se percatan de la necesidad de que los autores modifiquen la estructura textual para evitar la narración de actividades y centrarse en la temática de aprendizaje. A pesar de las sugerencias el autor mantiene la misma estructura de narración de actividades.

[...] Dentro del texto se debe hablar sobre el tema 
Ideas principales para que la persona que lea el texto sepa sobre el contenido del tema ya que en el suyo se observa una narración de manera generalizada de las actividades que se realizaron.

Anotar lo que aprendió durante la sesión

Punto de vista personal, es importante para saber si realmente se comprendió el tema. $(\operatorname{trtm} 28 \mathrm{j})$

\subsection{Clasificación conforme al criterio del tipo de comentario y reflexividad}

A partir de la revisión de los textos pude percatarme de las características de los comentarios que realizan los alumnos al asumir los roles de autor y de juez. Al caracterizar los tipos de comentarios podemos identificar distintas manifestaciones y facetas de intencionalidad y reflexividad. De esta manera tomé la decisión metodológica de proponer criterios de clasificación textual conforme al tipo de comentario y de reflexividad sobre el desempeño escrito. Esta decisión metodológica me permite proponer otras categorías y criterios de clasificación que me ayudan destacar más evidencias y elementos de intencionalidad y reflexividad. A continuación presento esta propuesta metodológica.

En los textos correspondientes a las fases de elicitación 2 y 3 predominan las manifestaciones de intencionalidad $\mathrm{y}$, además, existen manifestaciones implícitas de reflexividad a partir del tipo de decisiones de comentarios de los jueces sobre el género textual, el contenido y las decisiones textualización de los autores una vez que revisaron los comentarios de los jueces. No existen evidencias de reflexividad sobre creencias o representaciones relacionadas con el desempeño de la escritura académica, los jueces se centran en comentarios relacionados con estándares constitutivos de coherencia, cohesión, informatividad y pertinencia, relacionados con el tipo de comentarios, el género textual y la información. Así podemos establecer un tipo de intencionalidad reflexiva en los comentarios y las decisiones de textualización. De esta manera, en estos textos este tipo de reflexividad forma parte de la intencionalidad, y tan solo podemos percatarnos de la manifestación implícita de reflexividad en el conjunto de decisiones de textualización.

Sobre el tipo de comentarios en los textos correspondientes a las fases de elicitación 3: UPN Ixtpec y 4: UNICH, en esta ocasión contemplé como criterio 
metodológico de clasificación, el tipo de reflexividad sobre aspectos de textualización en los comentarios que hacen los alumnos, al asumir el papel de jueces para comentar o hacer sugerencias a sus compañeros. Propongo un tipo de reflexividad que denomino "parcial" sobre la actividad desarrollada en la que el juez se limita a comentar de manera expositiva, normativa o prescriptiva, o bien sólo hace sugerencias, sin comentar sobre la escritura del compañero. También considero un tipo de reflexividad con mayor énfasis en la textualidad que denomino "compuesta" sobre la actividad desarrollada en la que los jueces hacen comentarios y sugerencias a su compañero.

Existe un predominio de un tipo de reflexividad incipiente basada en comentar de manera prescriptiva o expositiva, principalmente, a partir de creencias y representaciones sobre aquello que consideran lo adecuado en la escritura, sin hacer ningún comentario ni sugerencia al compañero para ayudarlo a mejorar su texto. Sin embargo, destaca la existencia de textos en que los jueces manifiestan reflexividad sobre aspectos de textualización a partir de sugerencias y comentarios mediante ejemplos concretos sobre la escritura del compañero, y, por otra parte, la presencia de jueces que hacen referencias implícitas al modo de escritura. Esta situación refleja un tipo de intencionalidad en la valoración del texto del compañero a partir de distintas facetas de reflexividad.

Además, tomo en consideración el hecho de que el juez haga referencia explícita a recursos de textualización, con ejemplos concretos de la escritura de su compañero, o bien simplemente con referencias implícitas o sin hacer referencia alguna. Considero un tipo de reflexividad con mayor énfasis en la textualidad donde los alumnos hacen comentarios y sugerencias con referencias explícitas o concretas sobre ejemplos de la escritura de su compañero.

En la tabla 7 podemos apreciar el predominio de un tipo de reflexividad basada en comentar de manera prescriptiva o expositiva en los textos correspondientes a la fase de elicitación 3: UPN Tehuantepec. Sin embargo, destaca el hecho de que aquellos jueces que manifiestan reflexividad a partir de sugerencias y comentarios lo hagan mediante ejemplos concretos sobre la escritura del compañero, y, por otra parte, la presencia de jueces que hacen referencias implícitas al modo de escritura, y otros que sugieren y comentan a partir de referencias concretas con ejemplos. Esta situación refleja un tipo de intencionalidad 
relevante de los alumnos al valorar el texto del compañero. Considero que esta información me permite contemplar la manera en que esta intervención escrita puede o no impactar en las decisiones de revisión y edición del texto.

Tabla 7 Tipos de reflexividad en los comentarios de los jueces

\begin{tabular}{|l|c|c|c|}
\hline $\begin{array}{l}\text { Tipo de reflexividad } \\
\text { de los jueces }\end{array}$ & $\begin{array}{l}\text { Sin referencia } \\
\text { a recursos } \\
\text { de textualización }\end{array}$ & $\begin{array}{l}\text { Referencia } \\
\text { a recursos } \\
\text { de textualización }\end{array}$ & $\begin{array}{l}\text { Referencia } \\
\text { explícita } \\
\text { con ejemplos }\end{array}$ \\
\hline Reflexividad parcial & & & 4 \\
\hline $\begin{array}{l}\text { Solamente comenta } \\
\text { (modo expositivo o prescriptivo) }\end{array}$ & 7 & 4 & 2 \\
\hline Solamente sugiere & - & & 9 \\
\hline Reflexividad compuesta & & 3 & 9 \\
\hline Comenta y sugiere & - & & \\
\hline
\end{tabular}

En el texto trth09, por ejemplo, el autor intenta resolver el empleo de la estructura básica gramatical del español y la concordancia, al inicio logra dar solución a estos aspectos, sin embargo, posteriormente vuelve a tener estas dificultades en otros pasajes. Manifiesta una intencionalidad crítica en el manejo reflexivo de los recursos de redacción, aún cuando no logra resolver de manera global las dificultades. A pesar de las problemáticas afrontadas de cohesión, el juez comenta que "la escritura esta muy bien". trth09vi versión inicial.

La sociología fundó August comte en el siglo XIX La antropología son semejanzas y diferencia del hombre. [...]

Una paradigma habla sobre el estímulo y el estimulo refleja una respuesta [...] Nacionalidad es aquellos personas que representan a un Estado, en donde ellos tienen sus propios derechos y obligaciones.

Segunda versión:

A mediados del Siglo XIX el señor August Comte fundó la sociología.

La diferencia y semejanzas que tienen el hombre se basa por medio de la Antropología. $[\ldots]$

[...] para mi el conocimiento innato es todo persona que aprende desde sus primeros pasos (nacimientos). [...]

La paradigma tiene dos grandes aspectos para mejorar a los alumnos, [...]

Grupo étnico es el conjunto de personas que están regido en un mismo gobierno, que cada grupo étnico tiene un sólo idioma y sus propios tradiciones diferentes. (trth09vf)

Este ejemplo es representativo de los textos en que, a pesar de las dificultades en el desempeño, el alumno manifiesta un tipo de reflexividad implícita en el tipo de decisiones 
de textualización, que reflejan la intencionalidad para mejorar el texto, aunque no logre resolver dificultades. Además, a pesar de la valoración sobre el comentario del juez, que le dice que su escritura está "muy bien", el autor toma la decisión de hacer cambios para mejorar su expresión escrita. Veamos el texto trth09 en el Anexo 10.

En los textos de Tehuantepec también tomé la decisión de considerar como parte de los criterios de clasificación el tipo de sugerencias y comentarios de los jueces. Ver Anexo 11. Me pude percatar del interés predominante de los jueces por la incorporación de la información de la clase, lo cual refleja que al asumir el papel de jueces, los alumnos contemplan la información por encima del comentario sobre lo aprendido. Los datos muestran que los alumnos consideran que el expresarse con sus propias palabras, dar puntos de vista e impresiones personales o intentar ser coherentes, son prácticas asociadas a la instrucción de hacer un "reporte de clase", en el que, tal vez, consideran que comentan de manera crítica lo aprendido. De esta manera se conjuntan los criterios de reflexividad con los estándares de informatividad, propiedad y pertinencia de un tipo de texto en ambiente académico, es decir, la incorporación de información de la clase o bien el comentario sobre lo aprendido.

Sobre el tipo de modificaciones en la segunda versión destaca la prioridad en el manejo de la información de la clase, ya sea, copiando, incorporando, eliminando o parafraseando contenidos. Ver Anexo 12

Por otra parte, la reflexividad producida por el comentario de los jueces y el impacto en los autores se aprecia en los casos donde, en lugar de escribir una segunda versión de su escrito, a partir de las sugerencias recibidas, el autor hace una reflexión y valoración sobre aquello que le comentó y sugirió el juez. Veamos en trtm16j las sugerencias con referencia explícita al texto con ejemplos.

1. Poner atención con los acentos 2. Continuar con el parrafo 3. No repetir varias veces las palabras 34 . No repetir los conectores varias veces No conectores: la coma, la letra "y." 5. Tener la paciencia de escribir o hacer la letra de molde 6. El punto se ocupa para separar parrafo o bien para continuar con el parrafo. 7. Ser congruente con las escrituras 8. Ponerle sangria a tu escritura 9. Tener letra lejible. 10. Tener pensado lo que quieras escribir. 11. Ten tus pensamientos dentro del salón de clases, deja un lado tus otras cosas. (trtm16j)

A continuación lo que escribió el autor después de leer las sugerencias del juez. 
Ahora me prometo a mejorar mi escritura es cierto lo que me dijo mi compañero la escritura no logre escribir la lectura legible y también me falto poner las comas, punto, sangría, separar parrafos debo de mejorar la escritura y tambien debo de pensar antes de escribir lo que debo de pensar de los x salones por que me dificulta captura algunas palabras o aveces no capto las palabras que el maestro esta explicando o aveces me quedo pensando como debo de escribir en un deporte de la lectura. o tambien debo de participar porque cuando estoy exponiendo un tema es donde me gana los nervios y es donde se me olvida las cosas que debo de hablar por esa razón es donde no puedo lograr a terminar de exponer el tema.

Esta reflexión va más allá de los procesos de redacción, puesto que el alumno incluye una valoración sobre aspectos que se le dificultan: captar la atención y las palabras, así como los problemas antes de comenzar a escribir el reporte de lectura y para la exposición de un tema. El alumno manifiesta reflexividad integral sobre el desempeño de textualización en el manejo de recursos de redacción y, además, lo que impacta, implica y representa sobre lo contextual y la construcción de identidad y conocimiento en el desarrollo de habilidades lingüísticas y académicas. Este ejemplo es una evidencia escrita de preocupación e inseguridad sobre la actuación, al grado de que el alumno hace la promesa de mejorar, olvidándose por completo de que tenía que redactar la segunda versión de su escrito.

En los textos obtenidos en la fase de elicitación 3 contemplé las decisiones metodológicas de clasificación textual en los comentarios de los jueces y la segunda versión, debido a la falta de información sobre el texto redactado en la clase previa. Nosotros no estuvimos presentes en esa clase y el profesor no nos proporcionó información suficiente, además, la instrucción dada sobre el reporte de lectura causó confusión. Ante todas estas situaciones complejas es imposible hacer un proceso de análisis de los datos, sin embargo, considero que esta caracterización metodológica de clasificación aporta información relevante sobre la reflexividad en ambiente académico.

Por otra parte, la sesión de elicitación 1: UAM Iztapalapa, nos dejó grandes enseñanzas para no cometer descuidos en el control del diseño de interacción con los alumnos, puesto que, ante la complejidad de dar seguimiento a las actividades, no logramos establecer folios en los que pudiéramos identificar la correspondencia entre autores y jueces, además, los alumnos tendrían que hacer comentarios escritos en casa y 
posteriormente, interactuar con los compañeros. En general, no logramos controlar todas las variables y resultó una fase de elicitación que nos dejó muchas experiencias que pusimos en práctica para mejorar el diseño, principalmente, en las sesiones desarrolladas posteriormente en la Universidad Intercultural de Chiapas. Indudablemente, el aprendizaje fundamental era que el diseño tenía que controlarse en la interacción y, que para los intereses de la investigación, todas las actividades tendrían que hacerse en el aula.

En esta ocasión presento dos ejemplos representativos de revisión y edición de los textos en las dos versiones. No apreciamos manifestaciones explícitas de reflexividad sobre el desempeño, sin embargo, podemos apreciar en los comentarios de los jueces y en las decisiones de edición algunas evidencias de reflexividad implícita correspondientes a un tipo de reflexividad compuesta basada en comentarios y sugerencias de los jueces sobre recursos de textualización.

Presento una descripción de un par de textos de los alumnos del curso de Introducción al lenguaje. Recordemos que el trabajo consistió en elaborar un ensayo que correspondiera a uno de los siguientes temas: "El Cratilo", "El origen del lenguaje", "Las lenguas minoritarias" y "El hibridismo lingüístico". Posteriormente, el texto fue procesado digitalmente por otro alumno (juez), el cual añadiría sus sugerencias y comentarios con base en un cuestionario que se le proporcionó; esto con el fin de mejorar la primera versión. Finalmente, los alumnos, apoyados con un cuadro de instrucción, así como con las sugerencias de los jueces, escribieron sus versiones definitivas. La finalidad de este apartado es ver un seguimiento de los cambios que hubo en los textos, sin dejar de considerar las opiniones de los jueces. Una vez más, en este caso no hago análisis por las condiciones accidentadas de la fase de elicitación, simplemente presento estos ejemplos representativos de los cambios en las versiones.

En esta ocasión empleo una clasificación de recursos lingüísticos, que incluye el posicionamiento de enunciación y las transiciones temáticas.

Ejemplo: texto 05-versiones autor: vpartida

El siguiente texto manifiesta algunas variantes entre la primera y la última versión. Utilizo paréntesis para hacer comentarios.

Primera versión: 
En el texto "El origen del lenguaje" de Dortier se (posicionamiento impersonal) enlistan varias teorías que intentan responder la pregunta acerca de la primera manifestación del lenguaje en la historia del hombre. Sin embargo (punteo adversativo), sólo tres hipótesis han podido sobrevivir a las críticas y al nacimiento de otras teorías. Una de estas hipótesis fue la formulada por Etienne Condillac sobre el uso de gestos y ademanes. Esta teoría está fuertemente sustentada en los estudios que se hicieron sobre los indígenas de América del Norte [...]

Versión final:

En el texto "El origen del lenguaje" de Dortier se enlistan varias teorías que intentan responder la interrogante acerca de la primera manifestación del lenguaje en la historia del hombre. El autor nos explica que a lo largo del tiempo ha habido distintas teorías fuertemente sustentadas y apoyadas por diversos grupos sociales. Sin embargo (punteo adversativo), sólo tres hipótesis han podido sobrevivir a las críticas y al nacimiento de otras teorías (no hay cierre de párrafo con punto final)

Una de estas hipótesis fue la formulada por Etienne Condillac sobre el uso de gestos y ademanes; ésta estaba fuertemente sustentada en los estudios que se hicieron sobre los indígenas de América del Norte que vivieron antes y durante las expediciones inglesas. $[\ldots]$

En estos dos párrafos vemos que el autor intenta mejorar el texto de la primera versión. El posicionamiento es el mismo y presenta las teorías de un autor. Vemos que, en general, las versiones son similares. Divide su texto en dos párrafos y hace un cambio léxico de sustantivo (la pregunta $\rightarrow$ la interrogante). Por otro lado, tuvo la intención de organizar mejor la estructura, la cohesión. Hace una inmediata referencia intertextual al autor para organizar la manera de introducir el tema; esto es, cita a Dortier. Luego, el autor cambia de párrafo y lo que era la parte final del primer párrafo, en la versión final es parte de otro. Un cambio mínimo en este segundo párrafo es el cambio de tiempo verbal (está $\rightarrow$ estaba). El autor hace cambios mínimos, que fueron sugeridos por el juez.

Para cada hipótesis mencionada, el autor hace cambio de párrafo; esto muestra evidencia por considerar el texto como expositivo, en el cual las ideas se van distribuyendo según estén relacionadas entre sí.

Uno de los cambios realizados se debió a las sugerencias que hizo el juez. La primera versión fue escrita con sólo dos párrafos; por lo cual el juez manifestó lo siguiente:

“[...] hubiera deseado que el autor no hubiera hecho párrafos tan grandes. El uso del punto y aparte para separar ideas diferentes le habría venido muy bien al texto". 
Este comentario es importante porque reflejó comprensión acerca de las ‘definiciones' que hicimos sobre coherencia y cohesión. Otra de las sugerencias del juez fue hacer menos uso de puntos y seguido, ya que los considera como interrupciones de las ideas. Sugiere utilizar "más conjunciones o frases de enlace, de modo que el texto tenga más cadencia".

Además el juez plantea que el autor alcanza de manera "destacable" el objetivo sobre la discusión de la aparición del lenguaje. Sin embargo, considera que "faltó ahondar un poco más en estos temas y dar sus comentarios personales, puesto que la pregunta requería de esto". Considera, que el autor se expresa "de manera ordenada y coherente".

Indudablemente, los comentarios del juez, así como la lluvia de ideas, la elaboración del esquema de apoyo y la guía proporcionada fueron elementos fundamentales para la edición del escrito, misma que produjo la organización en bloques temáticos en párrafos. El autor contempla la presentación de las tres teorías como parte del enmarque y de las ideas principales en su plan para la redacción, tal como vemos a continuación:

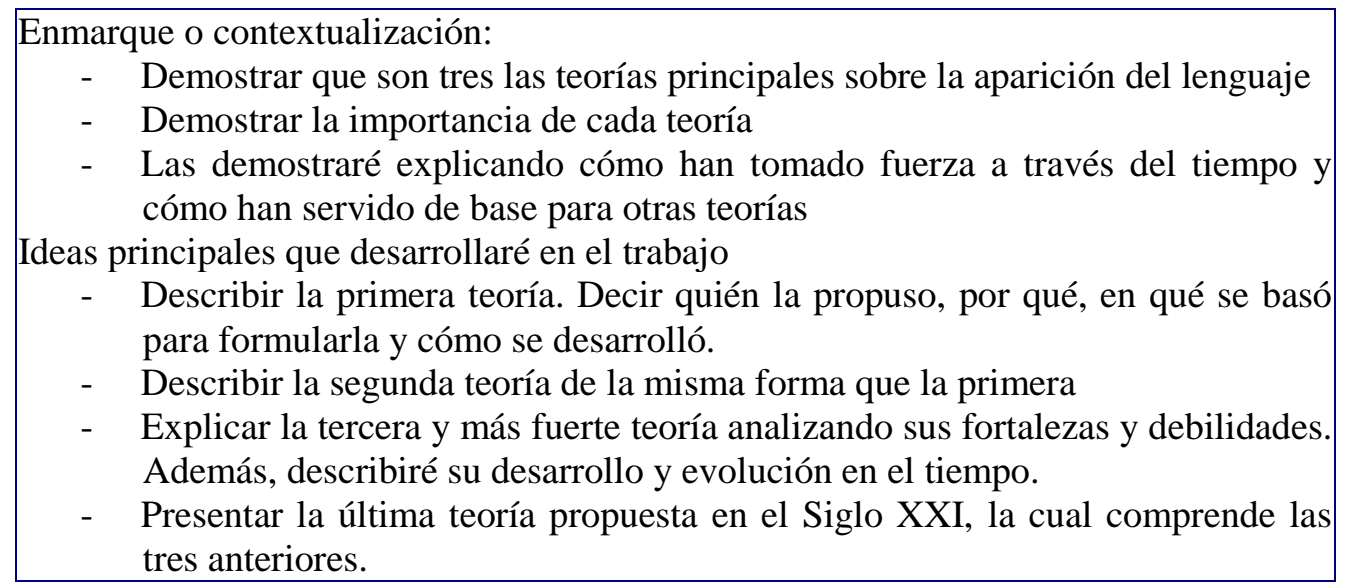

Otro punto relevante es que el alumno incorpora un apartado de punto de vista a manera de cierre o conclusión, mismo que el autor contempla en el esquema como conclusión:

Conclusión: Cada una de las tres principales teorías tenían razón en ciertos aspectos. Gracias a eso pudieron ser unidas en una gran teoría cuya fuerza se sustentaba de los argumentos que cada una de las tres primeras hipótesis ofrecía. 
La reorganización textual, a partir de los comentarios del juez y de la elaboración del esquema para organizar el texto final, propicia la reflexividad en este punto sobre la estructuración, con base en criterios temáticos concretos que le permiten al alumno mejorar la presentación de las ideas en la versión final. Recordemos que el juez le recomendó plasmar más su punto de vista y no ser tan expositivo, sin embargo, el autor se mantiene en el tono expositivo a lo largo del texto, pero agrega un cierre donde reflexiona sobre la importancia de las teorías, aunque con un distanciamiento en el posicionamiento de enunciación. Este cierre es el resultado de decisiones de edición en la construcción de procesos reflexivos de textualización, que contemplan los distintos aspectos involucrados en el ejercicio: la interacción en el aula, las instrucciones, los comentarios expresados, lo registrado en el pizarrón, el esquema previo a la redacción final, los comentarios de los jueces, la redacción, la revisión y la edición a partir de un proceso dinámico de revisión textual en el aula.

En este caso el juez considera de antemano los puntos que propusimos en la guía de esquema para organizar el texto, contemplando que el autor logró una adecuada organización.

¿Qué opinas de la organización del texto que revisaste?

Está bien organizado pues el autor del texto comienza escribiendo su idea principal y lo que opina del hibridismo; luego, presenta cada una de las ideas que lo llevaron a tener esa postura y las desarrolla a lo largo del texto por medio de párrafos diferentes. Sólo faltó, quizá, desarrollar un poco el final o agregar un párrafo retomando la idea de la última oración del texto.

Ejemplo: texto 08

En la transcripción del texto 08 sobre la lectura de Dotier, el juez aporta observaciones de manera digital (que aquí transcribo en letras superíndice) y señala con color azul el fragmento correspondiente y con amarillo el error de acentuación. (Utilizo subrayados para indicarlos). Agrega aquello que considera relevante "para complementar", más como información extra de apoyo que como aporte para incorporar al texto. Después, sobre la cohesión considera la necesidad de evitar repetir la información y contempla la propuesta crítica de "destacar las diferencias" 
Emergentista: Bien, sólo para complementar, estás no pueden tener una pre-programación dado que las relaciones cambiantes dependen de las mismas variaciones ambientales. Esta teoría no es muy clara para mí y lo que entiendo es que a base de un factor externo es posible el surgimiento del lenguaje.

En todas las tres teorías antes mencionadas se pueden establecer claras diferencias entre ellas, en la primera que es la teoría del innatismo nos dice que nosotros como seres humanos, nuestro cerebro se encuentra programado para hablar; mientras que la teoría del constructivismo habla sobre la autoorganización, a mí parecer creo que es en el desarrollo de la persona el punto clave de esta teoría; y por último la teoría emergentista habla acerca de factores externos. Creo que no es necesario reescribir las teorías, pero sí mostrar sus diferencias. Cada una de las teorías es clara y tienen puntos de vista diferentes, cada uno de ellos respetables porque nos dan a conocer distintos modos del origen del habla.

En el comentario como sugerencia para mejorar el texto, el autor considera que es necesario emplear palabras que le den seriedad al texto, asimismo destaca en color los problemas de acentuación.

[...] el caso del faraón Psa... Psámetico, en la historia de Herooto . que preocupado por saber como el hombre empezó a hablar, dio la orden de encerrar criar a dos niños, sin que nadie hablara con ellos ni que escucharan nada, [...] después de dos años los niños pronunciaron la palabra "becos" que significaban pan, La cual era una palabra frigia .ésta es solo una teoría, pero existen otras como la de la torre de Babel que se dice que los hombres la empezarón a construir para llegar

Este juez contempla que las aclaraciones sobre vocabulario y la selección de algunas palabras son elementos de seriedad, sin embargo considera que el texto está bien organizado en cuanto a la estructuración y el manejo de conceptos.

Está muy bien organizado, las teorías e ideas están distribuidas de forma entendible. [Los conceptos] se desarrollan de forma correcta, ya que lleva consigo la explicación de cada uno de los conceptos.

El recurso de clasificación en los textos obtenidos en la fase de elicitación 1 fue la ubicación de recursos de lenguaje en pasajes de los textos, debido a que la muestra era muy reducida, por la imposibilidad de recuperar todas las versiones y, en su caso, establecer los folios correspondientes. Esta situación me llevo a contemplar la necesidad de prestar especial atención a los detalles metodológicos operativos para evitar el descontrol en la conformación de las parejas y los folios correspondientes con los nombres de los estudiantes tanto en la función de juez y autor, así como tomar decisiones para descartar aquellos casos en que los jueces no hicieron o no completaron la actividad. Este tipo de detalles en la aplicación del diseño de elicitación son fundamentales en la metodología.

Podemos establecer que el manejo de la guía, las instrucciones del examen y la 
interacción centrada en la reflexión de aspectos constitutivos de cohesión y coherencia en la práctica de revisión y edición fueron fundamentales en el tipo de aspectos considerados por los autores y los jueces sobre aspectos de textualización. Los alumnos contemplan, de manera principal, los aspectos de textualización formal, establecen relación entre lo cognitivo, la informatividad, la propiedad, la aceptabilidad y, principalmente, la coherencia y la cohesión. Destaca el interés manifestado por la propiedad y el manejo de la informatividad necesaria para la redacción de un texto en contexto académico, en este caso el examen de su asignatura. En los roles de autores y jueces los alumnos se percatan de la necesidad de cuidar el tipo de lenguaje en sus selecciones léxicas que consideran apropiadas al abordar los conceptos de las lecturas seleccionadas.

Esta experiencia de elicitación nos aporta evidencias de la manera en que el diseño de instrumentos e interacciones, principalmente en la guía de apoyo y el esquema sugerido, son elementos que nos permiten proporcionar información que propicia la reflexión sobre aspectos relacionados con el desempeño escrito. Estos elementos disparadores de la reflexión pueden manifestarse en la escritura, cuando el alumno tiene elementos para evaluar y regular su propio desempeño e intencionalidad en la expresión escrita. De esta manera fue posible centrar la temática de reflexión en temas de escritura académica. Además, en el diseño de la interacción en esta fase de elicitación, los alumnos aportan y discuten sus propias reflexiones sobre experiencias de escritura académica, por ejemplo, en la lluvia de ideas. Esta experiencia de elicitación y caracterización de la escritura en una interacción en ambiente académico me sirvió para incorporar otros elementos para propiciar la manifestación de evidencias de intencionalidad y reflexividad, por ejemplo, en la retroalimentación y la manifestación escrita de las reacciones de los autores sobre los comentarios.

En la siguiente fase de elicitación 4: UNICH San Cristóbal de las Casas y Oxchuc estas consideraciones me permitieron utilizar un conjunto mayor de herramientas metodológicas y teóricas para crear categorías de clasificación, así pongo en práctica los recursos, instrumentos e interacciones que forman parte del diseño elaborado a lo largo de las sesiones previas de elicitación. En esta fase de elicitación también incorporo consideraciones teóricas y de clasificación desde la perspectiva del tipo de comentario y de 
la evidencia de reflexividad.

Anteriormente, consideré que la intencionalidad y la reflexividad son conocimientos que conforman las propias concepciones, ideas y actitudes. Son construcciones que cada individuo conforma a lo largo de su trayectoria y diversos desempeños, por ello evidencias de la reflexividad o parcialidades de ella pueden llegar a quedar plasmadas en los distintos comentarios, ante una interacción que favorezca la expresión de temas que cada quien considera relevantes. Nunca podremos garantizar que un individuo exprese todos los elementos de su reflexividad, pero podemos diseñar modelos de elicitación que favorezcan este tipo de manifestaciones escritas.

Además, propuse que la conformación de la reflexividad es un proceso multifacético, al tiempo que también se da la construcción de conocimiento e identidad. El individuo constantemente modifica el objeto de reflexión. En algunos momentos el individuo manifiesta determinada faceta de reflexividad, y posteriormente puede retomar, regresar o retroalimentarse de sus propias creencias y de diversos tipos de reflexividad, para conformar sus concepciones. En esto radica el aspecto cíclico y recursivo de la construcción de la reflexividad.

Propongo como categorías de clasificación textual para apreciar evidencias de la reflexividad el tipo de comentarios de los autores y los jueces. Inicialmente agrupo los textos en que los alumnos hacen comentarios generales, caracterizados por no expresar comentarios del texto que les proporcionamos, sobre el desempeño de los alumnos oaxaqueños, y por no compartir experiencias sobre el desempeño personal. En general Estos textos se caracterizan por la representación del autor en el texto mediante el posicionamiento de enunciación con distanciamiento, mediante el manejo de la $1^{\mathrm{a}}$ persona del plural (nosotros), así para expresar generalidades estos alumnos se representan junto con otros en el texto. En este rubro están también los comentarios prescriptivos con posicionamiento de enunciación directo o inclusivo, evidentemente porque al hacer prescripciones sobre los otros, el autor se representa en $1^{\mathrm{a}}$ persona singular (yo) o bien representándose inclusivamente junto con otros. Este grupo corresponde a los textos que no reflejan la reflexividad sobre el desempeño de la escritura académica o bien que abordan el tema de manera periférica con desvíos temáticos; esto no quiere decir que no presenten otro 
tipo de reflexividades, sin embargo, éstas no son el motivo de esta investigación

Para realizar la clasificación de los textos obtenidos en la fase de elicitación 4: UNICH, hago la propuesta metodológica de crear categorías sobre el tipo de comentario y reflexividad. Así, podemos apreciar un tipo de reflexividad parcial sobre el desempeño personal o el de otros. Existe evidencia de intencionalidad y reflexividad en la expresión de comentarios centrados en la temática de la escritura académica donde el autor: a) comenta la lectura sobre el autor y el juez oaxaqueños, sin compartir reflexión sobre sus propias experiencias o bien b) hace una reflexión personal sobre su desempeño, sin comentar la lectura del autor y el juez oaxaqueño.

Como criterio metodológico de clasificación propongo que ambos casos corresponden a una reflexividad parcial sobre el desempeño personal o el de otros en relación a la actividad desarrollada, en tanto que abordan una de las temáticas, ya sea la manera personal de escribir o bien los comentarios sobre la escritura de los alumnos oaxaqueños. Sin embargo, el segundo caso corresponde a un una manifestación de reflexividad de autoevaluación, puesto que al abordar la reflexión personal, el alumno hace una valoración de su manera de escribir. De hecho, considero que resulta más difícil opinar sobre el desempeño propio que sobre el de otros. Propongo la categoría de reflexividad parcial porque los alumnos manifiestan una de las temáticas contempladas en el ejercicio, y por ello sustentan sus comentarios sobre el texto leído o bien sobre sus experiencias personales de distintas maneras, ya sea mediante inferencias o intuiciones o de manera específica y con ejemplos concretos. Estas manifestaciones de reflexividad, en la mayoría de los casos, se modifican cuando los alumnos asumen el rol de jueces y cuando comentan sobre las opiniones recibidas.

En los textos donde apreciamos un tipo de reflexividad compuesta sobre el desempeño personal y el de otros, la evidencia de intencionalidad y reflexividad incluye los comentarios sobre la temática de la escritura académica donde el autor: a) comenta la lectura y comparte la reflexión sobre sus experiencias, con posicionamiento directo en primera persona del singular (yo) o bien b) comenta la lectura y comparte la reflexión sobre experiencias con posicionamiento directo en primera persona del plural (nosotros). 
En ambos casos las evidencias de reflexividad corresponden a una intencionalidad de hacer una autovaloración del desempeño y, por otra parte, el comentario de los textos del autor y el juez oaxaqueños, que en todo momento se centra en la temática propuesta en la interacción, sin desvíos a otros aspectos ajenos. En ambos casos el posicionamiento de enunciación de manera directa en $1^{\mathrm{a}}$ persona singular e inclusiva en $1^{\mathrm{a}}$ persona plural, refleja la intencionalidad de manifestar evidencias de reflexividad de manera más directa y personal y con toma de conciencia sobre el tema propuesto. En estos casos, en contraste con la reflexividad parcial, el modo inclusivo en $1^{\mathrm{a}}$ persona del plural, hace que el nivel de reflexión sirva para apoyar y dar fuerza a los comentarios, puesto que el alumno contempla su propia valoración y la hace extensiva a los demás, incluyéndolos en la temática de interés.

Considero el tipo de posicionamiento de enunciación o representación del autor en el texto y la referencia al tema de manera implícita o explícita, con o sin ejemplos concretos sobre la lectura, además de la reflexión sobre la escritura propia y los comentarios del juez. En general, considero que cuando un alumno hace referencia explícita, con ejemplos, sobre el tema de la lectura de los alumnos oaxaqueños o sobre su propio desempeño, tiene mayores posibilidades de mostrar más elementos de reflexividad en casos concretos sobre el tema. En este tipo de facetas de pensamiento reflexivo el alumno puede manifestar reflexividad crítica, consciente e introspectiva sobre sus propias creencias, intuiciones y conocimientos relacionados con el tema del desempeño en escritura académica.

Sobre el asunto teórico de la referencia al objeto de comentario, y por ende, de reflexividad recordemos que Recanati (1979 y 2004) contempla que focalizar el objeto de reflexión y construir el significado como un proceso gradual, implica que en la enunciación dicho objeto tiene una dualidad unas veces de opacidad y otras de transparencia, es decir, en unas ocasiones el individuo logra apreciarlo y hacer referencia explicita, y otras ocasiones simplemente no logra focalizar el objeto. Además, Perry (2001) destaca la referencia como mecanismo de regulación y valoración en la conformación de los diversos tipos de reflexividad, así el establecimiento de relaciones de referencia hacia el objeto de reflexión o aspectos del mismo es un proceso en distintas fases de apropiación de conocimiento y significado. Sobre el punto contemplo que al hacer referencia explícita con 
ejemplos concretos sobre el tema y el desempeño en la escritura, el alumno manifiesta una reflexividad con un mayor número de elementos, que en algunas ocasiones puede reflejar toma de conciencia y un ejercicio de introspección.

En la tabla 8 podemos observar el tipo de comentarios que permiten ubicar evidencias de distintos tipos de reflexividad al solicitarles a los alumnos, por una parte, que comentaran sobre la escritura del autor y juez oaxaqueños, y, por otra parte, que compartieran sus propias experiencias de redacción.

\section{Tabla 8. Tipos de reflexión sobre el tema de la lectura y el desempeño}

\begin{tabular}{|c|c|c|c|}
\hline $\begin{array}{l}\text { Tipos de reflexión del autor } \\
\text { en versión inicial }\end{array}$ & $\begin{array}{l}\text { Sin referencia alguna } \\
\text { al tema o desempeño }\end{array}$ & $\begin{array}{l}\text { Hace referencia no } \\
\text { explícita al tema o } \\
\text { desempeño }\end{array}$ & $\begin{array}{l}\text { Referencia } \\
\text { explícita } \\
\text { con ejemplos }\end{array}$ \\
\hline Comentarios generales y prescriptivos & 9 & 3 & 0 \\
\hline REFLEXIVIDAD PARCIAL & & & \\
\hline $\begin{array}{l}\text { Comenta la lectura sin compartir } \\
\text { reflexión sobre sus experiencias }\end{array}$ & 0 & 2 & 1 \\
\hline $\begin{array}{l}\text { Reflexión personal sin comentar } \\
\text { la lectura }\end{array}$ & 2 & 3 & 2 \\
\hline REFLEVIDAD COMPUESTA & & & \\
\hline $\begin{array}{l}\text { Comenta lectura y comparte reflexión } \\
\text { sobre sus experiencias } \\
\text { posicionamiento directo }\end{array}$ & 3 & 11 & 15 \\
\hline
\end{tabular}

El predominio del posicionamiento inclusivo ( $1^{\mathrm{a}}$ pers. plural: nosotros) al hacer prescripciones a los interlocutores o exponer ideas relacionadas, sin hacer referencia alguna al tema o al desempeño propio o del compañero, implica un distanciamiento en la representación del autor ante el texto, precisamente porque los autores no se representan a sí mismos asumiendo su voz textual para opinar generalidades y tomar actitudes normativas y prescriptivas ante los interlocutores. Este es un recurso de textualización para tomar distancia sobre lo que implica el decidir no reflexionar sobre el desempeño de otros, pero principalmente sobre el desempeño propio.

En los ejemplos que a continuación presento los alumnos comentan generalidades sin tratar el asunto de la lectura ni comentar sobre el desempeño personal, de manera distanciada al incluirse con otros en 1a persona del plural. En el siguiente texto la alumna aborda temáticas relacionadas con la escritura, sin contemplar el tema del desempeño personal ni el comentario sobre el texto de los alumnos oaxaqueños. 
[...] Por mi parte considero que no es mi lengua natal sino que es nuestra segunda lengua por tal razon dificultades de la ortografía, nos hace dificil escribir un texto tal como debe de ser por lo tanto también algunos de nosotros como estudiantes no nos gusta leer; porque es una buena corrección de escritura si lees; además vas conociendo nuevas en cuando vas leendo conoces nuevos conceptos y te das cuenta de como se respetan los acentos, punto, coma etc. [...] (trsiscm41)

La alumna contempla distintos aspectos relacionados, principalmente, con el estándar de construcción de identidad, correspondiente al principio de prácticas y usos. Existe reflexividad sobre identidad, relacionada con una actitud de justificar los errores y la ausencia de gusto por la lectura debido a que el español no es la lengua nativa. Esta situación está relacionada además con los estándares de dominios de uso de la lengua, así como con los repertorios de uso, en este caso la escritura académica. Considero que la reflexión lleva a la alumna a construir criterios de identidad al pasar de una justificación al reconocimiento de la necesidad del gusto por la lectura para mejorar aspectos relacionados con los estándares constitutivos de cohesión.

En el siguiente ejemplo la alumna, de manera prescriptiva, manifiesta reflexividad sobre los estándares constitutivos de coherencia y cohesión.

[i] Lo que yo pienso de está reflexión que nos da Ernesto Hernández Rodríguez, cuando nosotros hagamos una reflexión o escribimos es necesario que sea claro y preciso también tiene que se coherente para pode entender de que se trata a ese texto. Por otra parte tiene que llevar en cada texto a los conectores para que tenga claridad de lo que estamos hablando. [...] (trsicm24)

Por otra parte, en la tabla 8 apreciamos un tipo de reflexividad parcial sobre la actividad desarrollada donde, por ejemplo, el alumno puede representarse inclusivamente (en $1^{\mathrm{a}}$ pers. plural) en determinados pasajes, pero toma la decisión de representarse de manera directa para tomar postura al hacer comentarios, en unos casos sobre la experiencia de los alumnos de Oaxaca y, principalmente, sobre sus propias experiencias. Aquí aparecen evidencias de sustento a un tipo de reflexividad expresada mediante la referencia explícita con ejemplos, ya sea de la lectura o de pasajes de la escritura propia. En este rubro predomina la reflexión personal, desde quienes opinan sobre sí mismos sin hacer referencia alguna a aspectos de su desempeño hasta quienes hacen referencia explícita con ejemplos personales concretos. En todos estos casos lo importante es caracterizar la intencionalidad 
en la reflexión sobre el desempeño, independientemente del tipo de reflexividad. Sobre este punto, considero que aquellos alumnos que, sin comentar la lectura, hacen una reflexión personal sobre su escritura, con ejemplos concretos, manifiestan mayor número de elementos que conforman una reflexividad parcial sobre la actividad desarrollada, precisamente porque me parece que resulta más difícil comentar aspectos sobre el desempeño de uno mismo, que valorar y evaluar la escritura de otros. A continuación presento un ejemplo de reflexión sobre el desempeño del alumno de Oaxaca y uno en que el alumno comparte experiencias sobre su propio desempeño.

[i] Para ayudarle al/os ${ }^{\text {los }}$ compañero de oaxaca, ${ }^{\text {o en diferentes ciudades y pueblos }}$ creo que debe observar primero los párrafos de un texto escrito en lenguas originarias de cómo está estructurado, ya que el compañero ya observo, pues entonces lo podia escribirlo así tal como está, pero en diferentes textos al que desea elegirlo yasea articulo, textos breves etc. $[\ldots]($ trisch $47 p)$

En términos de la clasificación con criterios teóricos a partir de los estándares de textualidad, este alumno, principalmente, enfatiza los principios constitutivos de cohesión al comentar sobre la estructuración, asimismo aborda la temática de la propiedad, reflejada en la problemática para expresarse sobre las prácticas y usos en el manejo del género textual.

En el siguiente ejemplo predomina la reflexión relacionada con estándares constitutivos de aceptabilidad y propiedad, al comentar que el autor no le toma importancia al texto, así como el estándar de cohesión al contemplar la estructuración y el léxico.

[i] Siguiendo con el concepto del compañero en la escritura es la realidad, en muchas ocaciones en situacióne mía hay veces que no le tomo importancia al escribir un texto, sino lo escribo como se me venga en la mente no tengo paciencia en mejorar mi ortografía, y lo que más me dificulta al escribir es repetar todos los signos, como, la coma, el acento etc. tambien me dificulta al expresarme por repetir las mismas palabras, hay veces no encontro el significado o como debo de mencionarlo el termino de una palabra, y también al escribir una palabra me dificulta hay veces con que letra empiezo minuscula o mayuscula. [...] (trioh17)

Al comentar aquello que se le dificulta refleja una discusión sobre estándares de identidad que incluyen cuando reconoce que "no le tomo importancia al escribir un texto", el asunto de la paciencia, así como la intencionalidad en la búsqueda de estrategias para "no repetir las mismas palabras", como algo que se le dificulta. 
En la tabla 8 podemos observar las manifestaciones de reflexividad compuesta sobre la actividad desarrollada para comentar la lectura y compartir experiencias sobre el desempeño, predomina la decisión de posicionarse de manera directa y, por otra parte, un posicionamiento inclusivo en $1^{\mathrm{a}}$ persona del plural.

Aquí es necesario hacer una valoración sobre el posicionamiento inclusivo en primera persona del plural como elemento de la reflexividad, ya que éste puede reflejar cierto grado de distanciamiento, precisamente por incluir a otros ante el tema de reflexionar sobre el desempeño propio, tal como vemos en el siguiente ejemplo donde el alumno comienza a compartir sus experiencias de manera directa, pero no continúa así y prefiere reconocer sus dificultades de manera inclusiva.

[...] Cinceramente, en mi opinión personal, e pasado por esas cituaciones en que se nos dificulta ${ }^{\text {de }}$ realizar un texto, o la falta de compresión en la lectura, o que no le damos coherencia a la redacion, o no sabemos como escribir la idea o ampliar el texto.[f] (triom06)

El caso contrario sucede cuando el alumno emplea un posicionamiento inclusivo en $1^{\mathrm{a}}$ persona del plural y hace una transición a la representación personal directa que le permite enfatizar los comentarios que comparte, principalmente, sobre su propio desempeño. De esta manera incluye a los interlocutores en sus inquietudes, y además asume su voz textual al tratar el asunto de su desempeño como parte de la construcción de identidad, tal como vemos en el siguiente ejemplo.

[i] Pues yo pienso que para estar en una universidad debemos de mejorar, todos los aspectos de cómo escribir y por que no, también él del habla puesto que estamos educados hacer personas con una buena coherencia en lo queremos dar a entender a la hora de escribir.

Eso sería mi punto de vista.

Como experiencia puedo contar que si también me a pasado algo asi porque nadie es perfecto y de un modo $u$ otro tenemos errores mi experiencia seria que en una clase me pidieron que se redactara una lectura, la cual estaban leyendo y mi sorpresa fue que tuve una serie de faltas ortográficas y eso pues de un modo no me quedó algo claro ya que no quería fallar en eso, por que me sentía capaz de hacerlo bién y eso es todo.

Pues mi conclusió sería que hay que ser algo mejor cada día. [f] (trisch29)

El asunto de las oscilaciones en la representación del alumno en el texto corresponde a un criterio teórico aplicado aquí para la clasificación textual. Mediante el 
posicionamiento directo o inclusivo, refleja actitudes y reflexividad sobre la construcción textual y de identidad. A pesar de ser una cuestión relevante en la muestra, solamente un alumno, en su rol de juez, manifiesta explícitamente el distanciamiento en el posicionamiento de enunciación al mencionar sobre su compañero que "cuando redacta se refiere a otra persona". (trisch49j).

En general, podemos apreciar una mayoría de alumnos que manifiesta reflexividad compuesta con posicionamiento de representación directa para comentar sobre los alumnos de Oaxaca y sobre su propio desempeño, con referencias sobre el tema, ya sea de manera no explicita o explícita. Los alumnos reflejan la intencionalidad de asumir comentarios críticos sobre sí mismos, representándose ante el texto para comentar la lectura y compartir experiencias.

A continuación presento un ejemplo de reflexividad compuesta sobre la actividad desarrollada con posicionamiento directo, con ejemplos concretos de reflexión sobre el texto del autor oaxaqueño y sobre el desempeño propio. Apreciamos en sus comentarios los estándares constitutivos de cohesión, con énfasis en la acentuación, además cuestiona la propiedad y la informatividad, al considerar el contenido relacionado con una promesa y la necesidad de "ocuparnos de eso". De esta manera también pone de manifiesto una actitud que refleja la conformación de la identidad en ambiente académico. Destaca la seguridad para posicionarse de manera directa, para tratar el asunto de su desempeño propio.

[i] Con respecto a la reflexión que hace el compañero sobre su escritura que empieza por una promesa, pues que no solamente debe de prometerse sino operar por mejorar sus fallas asi como se dice "No solo hay que preocuparse sino hay que ocuparnos de eso".

El comentario que hace el alumno a su compañero, esta bien para mí ya que le sugiere poner los acentos, no hacer repeticiones y entre otras pero también que ponga los acentos, así como de la palabra "párrafo" pues es una palabra esdrújula...al igual que en otros puntos para cada línea.

En mi caso se me dificultan poner acentos o en dónde llevan acentos las palabras aunque sabiendo las reglas de las palabras graves, esdrújulas y sobreesdrújulas pues aún así se me presentan algunas dudas, al igual que saber de las letras que llevan łlazs palabras que se escuchan igual pero se escriben diferente, en fin son algunas cuestiones, ya que la escritura de esta lengua es diferente a la escritura de la lengua originaria porque estas son más notorias. [...] (trsicm36)

A continuación presento un ejemplo de reflexividad sobre experiencias y evidencias 
concretas relacionadas con estándares constitutivos de cohesión y coherencia. El alumno reconoce sus dificultades con posicionamiento directo. Además menciona el texto sobre el desempeño de los alumnos de Oaxaca como referente para hacer su reflexión. Refleja la construcción de identidad al manifestar que cree que dichas dificultades están relacionadas con el hecho de ser bilingüe, situación relacionada con las prácticas y los repertorios lingüísticos, y además, con el manejo de estrategias en el desempeño en la práctica de escritura académica.

[i] Los comentarios que nos hacen llegar a conocer los alumnos de la universidad de Oaxaca, son muy importantes para los estudiantes de diferentes niveles academicos; ya que la mayor parte de nosotros nos llega a dificultar mucho de la escritura, sobre todo de las ortografía, caligrafia entre todo loque lleva al elavorar un texto.

Cuando se lee un texto, como alumno al estar frente al grupo de compañeros y profesores, nos ponen nerviosos ya que siempre tenemos en la mentalidad de echarlo todo a perder por los nervios.

De manera personal durante los años como estudiante siempre he tenido la dificultad de escribir textos, ya que la mayor parte me falta en corregir la ortografía y repito muchas palabras Conocidas como las muletias, y la caligrafía. Tambíen cuando estoy escribiendo de algun tema tratado se me olvidan las cosas en que poner en mi texto en otras de las razones, creo que por ser bilingüe ya que en mi pueblo como jovenes siempre nos comunicamos en la lengua materna, más no nos expresamos mucho en la segundo lengua (Español) por eso que al redactar un texto, no se nos viene ídeas para anexar en los textos que se escriben [...] (trioh15)

Por otra parte, resulta fundamental en la metodología de acercamiento a los textos hacer una clasificación de la reflexividad y la intencionalidad de los jueces al comentar y hacer sugerencias, además de contemplar los temas que abordan y el tipo de comentarios, en términos de los distintos aspectos involucrados en la escritura académica. Tomar el papel de juez para comentar y hacer sugerencias implica asumir una postura y una actitud ante la tarea designada, de esta manera, el juez construye identidad en la práctica académica.

Veamos ahora las tendencias sobre reflexividad textual de los jueces en la tabla 9. Tomé la decisión metodológica de clasificación textual correspondiente al tipo de comentario y reflexividad. Esta manera de clasificar los textos me permite contemplar en un primer momento a aquellos jueces que no comentan y no sugieren nada sobre el desempeño académico, basándose en recomendaciones generales, además, un tipo de 
reflexividad parcial, de quienes sólo elogian, comentan o sugieren y una reflexividad compuesta, de aquellos que comentan el desempeño del compañero y también hacen sugerencias. También considero el tipo de reflexividad de quienes no hacen referencia a recursos de textualización, quienes hacen referencia sin ejemplos de escritura y los que hacen referencia explícita con ejemplos concretos de la escritura.

La tabla 9 (UNICH) refleja que los jueces manifiestan un mayor número de elementos de reflexividad textual, puesto que destaca el hecho de que sólo un juez no comenta y no sugiere nada, centrándose en recomendaciones generales, y en el caso de la reflexividad parcial sobre la actividad desarrollada, que un solo juez se limite a elogiar la escritura sin ninguna referencia a recursos de textualización.

Tabla 9. Tipo de reflexividad del juez

\begin{tabular}{|l|c|l|l|}
\hline $\begin{array}{l}\text { Tipo de comentarios } \\
\text { y sugerencias del juez }\end{array}$ & $\begin{array}{l}\text { Sin referencia } \\
\text { a recursos } \\
\text { de textualización }\end{array}$ & $\begin{array}{l}\text { Referencia } \\
\text { a recursos } \\
\text { de textualización }\end{array}$ & $\begin{array}{l}\text { Referencia } \\
\text { explícita } \\
\text { con ejemplos }\end{array}$ \\
\hline $\begin{array}{l}\text { Recomendaciones generales, } \\
\text { no comenta y no sugiere }\end{array}$ & 1 & 0 & 0 \\
\hline REFLEXIVIDAD PARCIAL & & & 0 \\
\hline Solamente elogia la escritura & 1 & 0 & 1 \\
\hline Solamente comenta & 1 & 5 & 0 \\
\hline Solamente sugiere & 0 & 5 & 14 \\
\hline REFLEVIDAD COMPUESTA & & & 22 \\
\hline Comenta y sugiere & 1 & & \\
\hline
\end{tabular}

En el siguiente ejemplo el alumno hace recomendaciones generales sobre estándares relacionados con prácticas y usos, sobre estrategias sugeridas, pero no hay comentarios concretos ni sugerencias.

[i]Querido compañero le hago estas anotaciones para que puedas mejorar la escritura, lo que debes tomar en cuenta es que pongas mucha concentración para una buena redacción, todos tenemos la capacidad de hacerlo, la cuestión es tener paciencia y tratar de desarrollar las ideas en una buena redacción, no te distraigas en el momento de estar escribiendo, mis buenos deceos para ti, espero tengas en cuenta mi opinión. [f] (trioh02j)

En el siguiente pasaje la juez, antes de hacer observaciones sobre su compañera, hace una valoración sobre sus propias dificultades, y entonces elogia el desempeño de su compañera. Considero que en este ejemplo se manifiesta una actitud correspondiente a la 
construcción de identidad en el marco del desempeño en ambiente académico, al reconocer dificultades personales, elogiar y pedir apoyo a la compañera para mejorar.

[i] Hola! que tal compañera y amiga juana Maria no tengo mucho que decir ya que para mi ${ }^{\text {me }}$ dificulta emucho por e*scrito, pero lo que quiero decirte es que la verdad tienes una buena vición y te das cuenta que es te dificultan para escribir un texto, y tus criticas estan muy bién pero me gustaria que nos apoyarasras para pode mejorar mi redacción. [f] (triom07)

En los casos de aquellos que sólo comentan, podemos percatarnos del modo prescriptivo y expositivo en lo descriptivo para dirigirse a su compañero, tal vez por la falta de costumbre para hacerle sugerencias a un compañero sobre su desempeño escrito. A continuación presento un ejemplo de comentario expositivo y otro prescriptivo, en ambos casos predominan estándares constitutivos de cohesión, en general aspectos formales y prescripciones sobre estrategias como la lectura y la legibilidad.

[i] Observo en el texto que el escrito no tiene una coherencia, muchos errores ortograficos, falta de signos, puntos, simbolos entre otros. Pero todo se puede corregir empezando primero de leer muchos libros [...] trsich40

[i] Mira compañero las palabras no se pueden rayotar y hay que dar acentos las palabras donde llevan, sino lo das se cambian totalmente sus significados las palabras y hay que ver como separarlos parrafos que haces en tu texto.

También escribirlo bien las palabras que menciones en tu escritura. [f] (trioh10)

El siguiente ejemplo es representativo de los jueces que solamente hacen sugerencias a los autores, además de las cuestiones formales, el juez manifiesta el manejo de estrategias y actitudes al proponerle que trate de expresarse hasta donde pueda.

[i] ¡Oye! Compañero; cuando redactes checa bien la escritura si esta correctamente o le falta algún acento, coma, etc, $y$, procura escribir bien las letras si va respectivamente con esas palabras.

Trata de expresarte hasta donde puedas y que tengas una mente imaginatoria para que así redactes mucho, өy al mismo tiempo te servira y será un beneficio para ti. ¡Gracias! [f] (trioh17)

Sobre el criterio de clasificación conforme al tipo de reflexividad compuesta sobre la actividad desarrollada, tenemos a una mayoría de jueces que de manera directa se dirigen al compañero para comentar y hacer sugerencias, así consideran una valoración del manejo de recursos escritos y asuntos contextuales vinculados, y una reflexión sobre los mismos para aportar ideas que permitan mejorar el texto, sin desviarse a otros temas o 
generalidades sin relación con el asunto tratado.

Parece que en su mayoría los alumnos no están acostumbrados a comentar los textos haciendo referencia explícita con ejemplos concretos de la escritura del compañero, o tal vez deciden no hacerlo, por lo que implica valorar y evaluar el desempeño del otro y las posibles reacciones o actitudes por la falta de costumbre. De esta manera se pone de manifiesto el criterio teórico de la construcción de identidad sobre lo que les significa y representa este tipo de actividad en la universidad.

En los textos correspondientes a la reflexividad parcial sobre la actividad desarrollada vemos ejemplos concretos de la escritura del alumno, en su mayoría predomina tan solo la referencia a recursos de textualización. En el rubro de reflexividad compuesta sobre la actividad desarrollada también apreciamos este tipo de predominio, sin embargo, considero notable la decisión de los jueces que hacen comentarios y sugerencias al compañero con ejemplos concretos, tal como apreciamos en las observaciones relacionadas con estándares constitutivos formales sobre la caligrafía en el siguiente texto.

[i] Creo que los aspectos que debes tomar encuenta es: que debes escribir con letras lejibles que se puedan entender como por ejemplo la " $y$ ", " $t$ " y la "m" porque costaba distinguir que era lo que decia, como también los signos de puntuación, pero igual no en todo estubo mal porque se podía expresar bien y casi no repetia palabras. A y una sugerencia es de que lea para poder corregir las faltas ortografías...

Otro detalle que me acabo de dar cuenta es de que la letra "v" la hace como la "u" y lógicamente así no se puede entender bien el texto porque le da otro sentido, o que también no separa bien las palabras y cuesta entender lo que quiere decir.

Debe echarle ganas con la lectura que le ayudara a tener buena escritura. [f] (trisch29)

El juez muestra, además, el criterio de clasificación conforme a los estándares de aceptabilidad y el contextual de construcción de significados al plantearle que "no se puede entender bien el texto o le da otro sentido", así continúa con las sugerencias relacionadas con estándares de prácticas y usos sobre estrategias generales para mejorar, al plantear, por ejemplo, que debe "echarle ganas con la lectura que le ayudara tener buena escritura."

En este ejemplo vemos con claridad el criterio teórico sobre la representación textual como recurso para la clasificación textual. Apreciamos el distanciamiento en el posicionamiento de enunciación del juez para dirigirse a su compañera, puesto que inicia de manera directa en $2^{a}$ persona del plural (tú), por ejemplo al comentarle "que debes tomar 
encuenta es: que debes escribir con letras legibles". Sin embargo, después parece que hace un texto expositivo dirigido a otro interlocutor puesto que se refiere a su compañera en $3^{\mathrm{a}}$ persona al escribir, por ejemplo, que "no en todo estubo mal porque se podía expresar bien y casi no repetia palabras. A y una sugerencia es de que lea para poder corregir las faltas ortografías". Considero que en esta transición el juez refleja una intencionalidad expresiva de evaluar como si estuviera dirigiéndose a otro interlocutor, porque no tiene la costumbre de comentar de manera directa al compañero, lo cual refleja reflexividad sobre la construcción de identidad y el impacto sobre las prácticas de escritura académica.

Una vez presentados los criterios de clasificación conforme al género textual, el tema abordado en los materiales presentados y en la interacción, así como el tipo de comentario y de reflexividad parcial y compuesta, tenemos elementos para proponer una metodología centrada en la caracterización de recursos de textualización, a partir de evidencias de textualidad presentes en los escritos de los alumnos debido al desempeño y al impacto de las decisiones metodológicas e instrumentos implementados en la fase de elicitación. Al proponer las categorías de caracterización y clasificación podemos tener elementos para crear otro tipo de categorías que nos permiten destacar elementos de intencionalidad y manifestaciones multifacéticas de reflexividad. En este caso estos elementos están presentes, por ejemplo, en el posicionamiento de enunciación del autor en el texto, en la representación de interlocutores, así como en la referencia explícita o implícita a ejemplos de recursos de textualización presentes en los textos.

Considero que el criterio del tipo o género textual es una categoría fundamental presente en todos los textos y que sirve como punto de partida en todos los casos para identificar y caracterizar las evidencias de reflexividad, principalmente, al proponer el tipo de comentarios y de reflexividad parcial y compuesta. Asimismo, pude percatarme de la necesidad de controlar las temáticas abordadas en los instrumentos manejados en la fase de elicitación. De esta manera, contemplo en la propuesta la necesidad de centrar los temas en torno a discusiones relacionadas exclusivamente con cuestiones de escritura académica. De esta manera pude contemplar que el diseño de elicitación en los textos obtenidos en las fases de elicitación 2 y 3 determinó, en gran medida, que los autores y los jueces comentaran y reflexionaran sobre temas ajenos al desempeño escrito en ambiente 
académico. En ambos casos los alumnos hacen comentarios y sugerencias relacionadas con la informatividad, la temática de la lectura o la actividad presentada, el género textual y los estándares textuales de cohesión y coherencia. Por ello propuse categorías de clasificación sobre estos aspectos para identificar elementos de intencionalidad y reflexividad. De esta manera encontré que predomina en estos textos la manifestación de intencionalidad sobre el manejo de recursos textuales, y, por otra parte, evidencias incipientes e implícitas de reflexividad manifestadas en el tipo de comentarios de los autores y en las decisiones de textualización para editar los textos.

Destaca que el hecho de que la reflexividad compuesta de los jueces, basada en comentarios y sugerencias sobre el desempeño, refleje un mayor número de elementos de reflexividad que incluye el comentario, la sugerencia y, principalmente, la referencia a elementos de textualidad. Esta realidad nos puede llevar a proponer que en el nivel superior los alumnos bilingües indígenas tienen conocimientos sobre recursos de textualidad relacionados, principalmente, con estándares constitutivos de coherencia, cohesión e informatividad que les permiten comentar el texto de otro, pero requieren desarrollar la práctica y las habilidades para aplicarlos en su propio desempeño. De esta manera, existe un nivel de reflexividad crítico al nivel de evaluación como juez, mismo que se manifiesta en el desempeño propio con problemáticas en distintos tipos de intencionalidad. En este punto lo que importa no es caracterizar el nivel de desempeño, lo relevante es estudiar el tipo de intencionalidad y de reflexividad sobre los recursos de textualización.

Por otra parte, podemos establecer que las manifestaciones de reflexividad con ejemplos concretos sobre elementos de textualidad y en los que el autor se representa de manera directa, constituyen ejemplos representativos de un tipo de reflexividad multifacética con mayores elementos de evaluación y regulación sobre el desempeño propio. Estos alumnos comentan de manera crítica al considerar diversas cuestiones del desempeño de otros y, principalmente, el desempeño personal, tomando en consideración su posicionamiento personal ante los interlocutores o lectores potenciales y al abordar, de manera concreta con ejemplos de la textualidad, los aspectos de reflexividad sobre temáticas de escrituras académicas. En conjunto es posible apreciar estos elementos de intencionalidad y de reflexividad al trabajar de manera sistemática con la metodología de 
criterios de caracterización y clasificación textual al construir categorías que nos permitan el acercamiento a diversos elementos de la textualidad durante la investigación.

\subsection{Clasificación conforme al criterio de temáticas de reflexividad}

Hasta este momento he realizado una propuesta de elaboración de criterios de clasificación de los textos mediante la conformación de categorías a partir de aquellos elementos que nos proporcionan los textos y que nos pueden ser útiles para apreciar las evidencias de reflexividad y en general los objetos de nuestro estudio que deseamos focalizar. Además de contemplar categorías de clasificación conforme a criterios teóricos abordados en este trabajo y sobre el tipo de comentario y de reflexividad, considero el criterio de las temáticas relacionadas con la escritura académica, abordadas por los alumnos en los textos, precisamente porque éstas pueden relacionarse con las distintas modalidades de reflexividad y con los principios teóricos de los estándares de textualidad.

Inicialmente realicé una adaptación del modelo de Beugrande \& Dressler (1997) para proponer la caracterización de cuatro tipos de estándares de textualidad: constitutivos, regulativos, contextuales y de uso y práctica, además tomo en cuenta los distintos tipos de comentarios correspondientes a la clasificación metodológica propuesta, conformada por los tipos de reflexividad textual presentes en comentarios generales y reflexividad parcial y compuesta sobre la actividad desarrollada.

En esta sección considero la caracterización de las temáticas manifestadas en los comentarios presentes en los textos, ya que existen temáticas abordadas por los alumnos, que son susceptibles de reflejar, en algunos casos, evidencias de reflexividad textual. De esta manera es posible proponer algunos criterios de clasificación temática e interpretaciones sobre los contenidos reflexivos.

El criterio metodológico de clasificación a partir de las temáticas de reflexividad abordadas nos permite contemplar los aspectos de textualización sobre los cuales los

autores y los jueces reflexionan, incluyendo no solamente los aspectos formales y de cohesión textual, sino también, por ejemplo, cuestiones contextuales, personales, culturales 
y las que permiten construir significados e identidad sobre lo que implica y representa la escritura académica, las experiencias, las reacciones u opiniones sobre los comentarios del juez y la práctica cooperativa de revisión y edición de textos. En el diseño de la lectura proporcionada y la interacción, procuramos propiciar la reflexividad sobre esta variedad de aspectos en torno a las experiencias de escritura y factores relacionados.

En general podemos apreciar el predominio de temáticas de reflexividad relacionadas con aspectos del desempeño en el manejo de la conformación de los recursos formales y las concepciones sobre aspectos contextual sobre la escritura en ambiente académico, existe un predominio pleno sobre recursos formales para los jueces. Sobre este punto, rescato la propuesta de Hyland (2005), quien considera, en su estudio de reflexividad metadiscursiva de la construcción textual, la interrelación sobre las temáticas de recursos formales y contextuales como una cuestión regulativa en la construcción del texto. Además, en la muestra aparecen las temáticas sobre la identidad y el uso de la gramática y el desempeño.

\subsubsection{Clasificación de las temáticas predominantes en los textos}

En las dos sesiones de la fase de elicitación 4: UNICH tomé en consideración en la práctica desarrollada en el aula, actividades que pudieran favorecer la manifestación de comentarios sobre temáticas relacionadas con aspectos constitutivos de textualización en el plano de la cohesión y la coherencia y, por otra parte, temáticas sobre diversos aspectos relacionados con las prácticas de escritura académica. En la tabla 10 presento la clasificación temática predominante de cada texto. Evidentemente en un texto el autor puede abordar diversos temas, en este caso, la caracterización corresponde a las temáticas centrales o predominantes.

Tabla. 10 Temáticas de la reflexividad observadas en los textos

\begin{tabular}{|l|c|c|c|}
\hline Temáticas de la reflexividad (en los 51 textos) & Autor & Juez & Total \\
\hline Sobre los recursos formales de escritura & 27 & 50 & 77 \\
\hline Contextual sobre escritura en ambiente académico & 25 & 3 & 28 \\
\hline Identidad impacto y significado de escribir & 12 & 0 & 12 \\
\hline Sobre la gramática y lengua de instrucción & 12 & 4 & 16 \\
\hline
\end{tabular}


La temática mayoritaria de reflexividad corresponde a los recursos de escritura o constitutivos de un texto, fundamentalmente, la coherencia y la cohesión. Los jueces dan prioridad a estas cuestiones formales de redacción, tal vez, al considerar con mayor peso el planteamiento de que comentaran sobre aspectos de la experiencia de la escritura de los alumnos de Oaxaca y que apoyaran a su compañero para que mejorara su escrito. Asimismo en la lluvia de ideas solicitamos que contemplaran aquellos aspectos que consideraban relevantes para la experiencia de redacción académica y lo que requiere un texto para responder satisfactoriamente a las necesidades académicas en la universidad.

Revisemos el texto trsiscm36, en el que la alumna toma en cuenta el comentario sobre la escritura de los alumnos oaxaqueños, comparte sus propias dificultades y, además, pone a discusión el tema de la distinción sobre la escritura del español y la lengua indígena.

[...] El comentario que hace el alumno a su compañero, esta bien para mí ya que le sugiere poner los acentos, no hacer repeticiones y entre otras pero también que ponga los acentos, así como de la palabra "párrafo" pues es una palabra esdrújula... al igual que en otros puntos para cada línea.

En mi caso se me dificultan poner acentos *o en dónde llevan acentos las palabras aunque sabiendo las reglas de las palabras graves, esdrújulas y sobre esdrújulas pues aún así se me presentan dudas, al igual que saber de las letras que llevan *las palabras que se escuchan igual pero se escriben diferente, en fin son algunas cuestiones, ya que la escritura de esta lengua es diferente a la escritura de la lengua originaria porque estas son más notorias. [f] (trsiscm36)

En el caso de la reflexividad de los jueces, los aspectos constitutivos textuales, formales, de coherencia, cohesión, ortografía y puntuación, son considerados como prioritarios, muy por encima del tema abordado o de cuestiones contextuales o personales sobre la experiencia de redacción. Ejemplos.

[...] tienes algunos detalles como: mezclar singular y plural, a veces cambias de género cuando en realidad no va con eso, te falta poner algunos signos de puntuación, tales como la coma y el acénto, unas que otras le falta coherencia a lo que quieres decir, pero bueno a cualquiera le puede pasar. [...] (triom03juez)

[...] utiliza los conectores que van acorde a tus ideas o línea de ideas, ya que muchos repetimos los conectores o sino empleamos uno que no enlaza de manera adecuada las oraciones. [...]

Ten muy encuenta tus ideas principales para darle cuerpo a tu texto y no enredar esas 
ideas, además de que debemos utilizar los signos de puntuación en ella parte correcta, es decir, en la parte de la oración que debe llevar para a zasí darse a entender mejor. [f] (triscm35juez)

[i] Compañero he notado que tus letras son ilegibles, tus ideas deben ser claros y precisos, a lo que te refieres. También coloca debidamente los acentos gramaticales para que tu texto se entienda, no te confundas con letras mayúsculas y minúsculas.

Tienes problemas cuando inicias el siguiente párrafo, ya que las reglas de acentuacion indican que debes iniciar con letra mayúscula. [...] (trisch44pjuez)

La temática de reflexividad contextual sobre recursos de redacción en ambientes académicos se manifiesta cuando los alumnos reflexionan sobre las prácticas de escritura en las circunstancias concretas de lo que experimentan en la vida universitaria, por ejemplo, las problemáticas enfrentadas, la resolución de dificultades, los miedos a compartir, comentar y revisar, la intencionalidad comunicativa, los usos de los géneros textuales, el entorno social, cultural e institucional, las expectativas y todo aquello que el contexto escolar implica en el desempeño y la interacción para la comunicación. Considero que estas diversidades temáticas reflejan un tipo de reflexividad fundamental sobre la redacción, ya que aportan otro tipo de criterios que no se centran exclusivamente en los recursos formales, y que indudablemente son parte del proceso de la textualización integral.

Sobre la temática contextual, observamos el contraste entre autores y jueces. El hecho de que para los autores exista una diferencia mínima en el número de ocurrencias sobre las temáticas de recursos de escritura y, por otra parte, lo contextual en ambiente académico, refleja que, en general, para los alumnos es relevante el conjunto de factores contextuales involucrados en sus prácticas de redacción. Esto implica las prácticas concretas de comunicación e interacción en la universidad, por ejemplo, al escribir los trabajos, en los exámenes y en el manejo de géneros textuales en circunstancias determinadas. En los siguientes ejemplos podemos apreciar la interrelación entre las temáticas contextuales, la construcción de identidad y el impacto y significado de escribir en ambiente académico.

[...] como humanos cometemos cualquier error que tanto compañeros o maestros no critique al alumno que aún está mal de la ortografía o que también nos dificulta hablar el español, en vez de eso que nos ayuda a mejorar, Tambien sabemos que un error ay que verlo como una experiencia de lo que cometemos y que no se para nosotros como 
una burla, sobre todo contar con el apollo de los maestros "que entre compañeros nos apollemos para mejorar la escritura y que no exista la critica." [f] (triom11)

[i] Los problemas de escritura y redacción en los estudiantes, siempre ha existido y existira, ya que desde la educación básica tanto alumnos como profesores no tienen la inciativa de fomentar una cultura de lectura y menos de escritura. Hay muchos factores que implican que los $\# x x$ estudiantes tengan este problema, por lo mismo de que las metodologías de enseñanza de la lengua castellana en comunidades Originarias no estan contextualizadas de acuerdo a las necesidades de alumnos. [...] (triscm45p)

De esta manera, la intencionalidad manifestada por los alumnos en la textualización puede incorporar, de manera integral, la relación entre recursos formales y las variables de la experiencia del contexto académico vivido en la universidad. Cuando los alumnos contemplan estas distintas temáticas, en su mayoría, reflejan un tipo de reflexividad compuesta sobre la actividad desarrollada, y, en algunos casos, también corresponde a alumnos que resuelven problemáticas diversas de textualización. En este punto debemos tomar en cuenta que los textos conformados por comentarios con un mayor número de elementos correspondientes a un tipo de reflexividad compuesta, no tienen por qué necesariamente estar relacionados con determinado nivel de desempeño de textualización. Existen, por ejemplo, textos un con mayor número de elementos de crítica y evidencias de reflexividad sobre la escritura académica que, sin embargo, manifiestan diversos tipos de intencionalidad de los alumnos para reorganizar la escritura, pero éstos no logran resolver dificultades diversas en el desempeño. Indudablemente existe mayor evidencia de valoración, regulación y evaluación en los casos en que los alumnos reconocen sus dificultades, tal como apreciamos en el siguiente ejemplo.

[...] cuando los maestros nos dejan de tarea que hagamos algún resumen. a la hora de llebarlo acabo, no se con que palabra debo empezar y explicar lo que entendi del texto eso es lo que seme dificulta, bueno ¥ también seme dificulta colocar los acentos, las comas, y que mi resumen este bién redactado[...] (triscm45)

Las temáticas de reflexividad sobre la identidad, que incluyen lo que les representa y significa a los alumnos escribir y, por otra parte, sobre la gramática y el uso de la lengua de instrucción en la universidad, considero que ponen de manifiesto textos con un mayor número de elementos de reflexividad, principalmente, cuando incorporan, además, evidencias de reflexividad sobre recursos formales y situaciones contextuales sobre la 
escritura académica. Destaca, en el caso de los jueces, que no existan ocurrencias sobre la categoría de identidad, así como de lo que les representa y significa escribir en la universidad, precisamente por el énfasis en recursos constitutivos textuales. Sólo aparecen 4 ocurrencias de reflexión sobre la gramática y el uso de la lengua de instrucción para hacer comentarios y sugerencias. En estos textos el tipo de reflexividad de los jueces refleja un mayor número de elementos, porque contemplan no sólo sugerencias y comentarios sobre el desempeño del compañero, sino también sobre el funcionamiento y las propiedades de la lengua escrita en la universidad. Es decir, la intencionalidad y la reflexión se manifiestan en temáticas diversas en el comentario sobre las concepciones de las propiedades de la lengua escrita, relacionadas con las sugerencias del desempeño del compañero. Veamos ejemplos sobre la identidad y lo que les representa y significa a los alumnos escribir en ambiente académico.

[...] Es importante el respeto a como se escribe y a cómo se habla, ya que es parte de nuestras raíces por lo que no nos sentimos avergozados y nos gusta como hablamos y nos gusta ser indígenas. [...] (trsiscm42)

[...] Para mi tener buena redacción significa mucho porque así puedo expresar mejor mis ideas sin temor de que el maestro no entienda lo que estoy tratando de decir. [...] (trsiscm45p)

[...] me parece que algunos de nosotros tenemos esta discapacidad, por decirlo asi, de no saber lograr escrivir bien. o expresarnos bien en nuestra escritura, pues al igual tengo mis dificultades de escribir, de redactar y sobre todo tener esa dificultad es como no ser cápaz de hacer algo [...] también ctenemos esa dificultad de participar dentro del salon, pero por ese razon nosotros mismos no tenemos la capacidad de vencer el miedo que nos tiene atados. igracias! [f] (trisch49)

El caso de la reflexividad sobre la gramática y el uso de la lengua de instrucción tiene como factor fundamental que los alumnos son bilingües indígenas, que están escribiendo en español, y que, algunos de ellos, expresan por escrito experiencias de dificultad, y las maneras en que intentan resolver problemáticas de textualización para emplear la gramática del español y el desempeño en ambiente académico. También apreciamos reflexiones sobre las gramáticas de las lenguas indígenas. En general, la temática sobre la gramática y el uso de la lengua de instrucción está relacionada con los aspectos contextuales, de identidad y lo que representa y significa la escritura. En los siguientes ejemplos podemos apreciar esta interrelación de aspectos temáticos. 
[...] A mi se me dificulta mi materia Tseltal, ya que no aprendí a hablarlo y sólo lo entiendo, me cuesta ver donde va la glotal (') (uk) la escritura de esto, la congruencia de lo que escribo, si voy con la misma narración; como la escritura en tseltal es un poco diferente al castellano, no puedo pensar fácilmente en palabras y comprende el texto que leemos

Es muy práctico la lectura del castellano pues ayuda a observar los escritos, es decir, vemos donde lleva el acento, la coma, dos puntos, punto y coma, etc. [...] (trsich50)

[...] Y otra de las cosas es que no escribas como un mensaje de celular ya que esto es

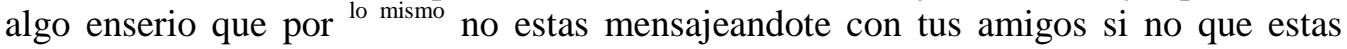
plasmando lo que piensa.

Checa bien lo que has escrito y veras que estas escribiendo como un celular por lo que antotaste " $\mathrm{x}$ " $\mathrm{y}$ eso no se ocupa en este tipo de redacciones. (triom05juez)

LA NOCIÓN DEL ALUMNO ES NO PODER DAR COEHERENCIA A TEXTOS EN DONDE DICHO TEXTO CONTEMPLA PALABRAS ELEVADAS, ES DECIR, LA SITUACIÓN QUE MANIFIESTA UNA PALABRA ELEVADA PODRÍA DAR MUCHO MÁS DE LO ESPERADO YA QUE SU FUNCIÓN PUEDE SER EXTENSA. EN PARTE LA COHERENCIA ES IMPORTANTE PARA ASI PODER ENTENDER LO QUE PUEDE EXPRESAR UN TEXTO.

EN CIERTA MANERA LA LENGUA INDIGENA PODRIA NO USAR TERMINOS

EN EL QUE PUEDAN DAR SIGNIFICADOS COMUNES O BIEN SIGNIFICAR MUCHO, PUES A MANERA QUE LA LENGUA SOLAMENTE PUEDEN TRADUCIRSE UNAS CUANTAS PALABRAS. (trioh09)

\subsection{Enfoque integral en los criterios de clasificación textual}

En este capítulo he realizado una propuesta de clasificación textual que contempla criterios teóricos y metodológicos para la caracterización de los textos en la búsqueda de identificar y destacar evidencias de intencionalidad y reflexividad desde una perspectiva del estudio de la textualidad en textos redactados en interacciones en ambiente académico. La esencia del enfoque de la propuesta es la integración de criterios teóricos y metodológicos aplicados tanto a la fase de elicitación, así como a la creación de criterios de clasificación textual. El aporte en este capítulo es realizar una propuesta para aplicar e integrar los conceptos de reflexividad, intencionalidad y textualización desde la perspectiva de la aplicación teórica y metodológica de la textualidad, y con estas herramientas crear criterios y categorías para aplicar en las decisiones metodológicas de clasificación textual.

En las decisiones metodológicas de clasificación textual podemos apreciar elementos diversos relacionados con el planteamiento teórico de los conceptos de 
textualización, intencionalidad y reflexividad, así como los estándares de textualidad y los criterios de cognición, evaluación y regulación sobre el desempeño. Por otra parte, los primeros acercamientos metodológicos de clasificación basados en el género textual, el tema de la lectura proporcionada y el tipo de comentarios me permiten proponer otras categorías relacionadas con criterios teóricos que nos permiten identificar elementos de intencionalidad y reflexividad en los textos. Estas categorías incluyen elementos y herramientas teóricas correspondientes al estudio de la textualidad. Podemos destacar el posicionamiento de enunciación del autor ante el texto, la representación de interlocutores, el tipo de referencia implícita o explícita hacia los objetos de reflexividad y la propuesta de clasificación sobre las temáticas de reflexividad.

La aplicación de criterios teóricos y metodológicos en la clasificación nos permite tener una mirada panorámica sobre la diversidad de tipos de textos. El punto de partida es el establecimiento de los primeros criterios de clasificación y la posterior aplicación de categorías creadas exclusivamente a partir de los elementos presentes en los textos. De esta manera puedo clasificar los textos de manera integral a partir los criterios metodológicos establecidos, por ejemplo, el tipo de comentarios y la reflexividad parcial y compuesta. Asimismo, es necesario contemplar que los criterios teóricos aplicados se complementan con el tipo de decisiones metodológicas presentes en el tipo de interacción y los materiales empleados en cada fase de elicitación. Así, un criterio teórico contemplado, por ejemplo, la representación textual del autor y de los interlocutores solamente cobra relevancia si tomamos en cuenta la manera en que la interacción en el diseño de elicitación influye, determina, o llega a favorecer la presencia de un criterio de textualidad.

El manejo integral de los criterios teóricos y metodológicos nos permite tomar decisiones metodológicas para destacar las posibles manifestaciones de intencionalidad y reflexividad. Así sucedió con la propuesta de clasificación de las distintas temáticas de reflexividad a partir de lo manifestado por los alumnos en el texto. Pude percatarme de que además de la temática presente en los instrumentos empleados en las fases de elicitación, los alumnos abordan distintas temáticas predominantes, mismas que se centran en cuestiones de desempeño escrito en la universidad cuando en la interacción proponemos la reflexión y discusión sobre la escritura académica. 
Al concebir una propuesta de clasificación textual a partir de las temáticas predominantes de reflexividad evidentemente tomé en consideración comentarios relacionados con la propuesta teórica de los estándares de textualidad de Beugrande \& Dressler (1997). Relaciono estos estándares con los criterios teóricos anteriormente presentados, principalmente, los tipos de comentarios parcial y compuestos y la representación textual del autor y los interlocutores, para caracterizar, por ejemplo, evidencias de reflexividad implícita basadas en creencias generales donde predomina la intencionalidad o bien evidencias con un mayor número de elementos de reflexividad.

En la propuesta de clasificación de la temática de reflexividad contemplo la consideración teórica de la intencionalidad desde la perspectiva del estándar de textualidad de Beugrande \& Dressler (1997) en el desempeño al emplear recursos de textualización. También tomo en cuenta las manifestaciones de la manera en que el autor de un texto no siempre expresa o logra expresar su pensamiento intencional, ya sea porque deliberadamente así lo desea o bien porque al enfrentarse a dificultades de textualización su escrito resulta ambiguo o no corresponde a lo que el alumno manifiesta que trató de expresar, tal como proponen Copi \& Burges-Jackson (1996) y Beuchot (2002). En este trabajo el centro de interés es estudiar este tipo de intencionalidad manifestada en los comentarios que reflejan reflexividad sobre la escritura. En estos comentarios cobra relevancia el criterio de las temáticas de reflexividad al abordar determinadas cuestiones relacionadas con distintas concepciones y experiencias de la escritura en la universidad.

La relación entre tipo y temática de reflexividad presenta múltiples facetas debido a que un mismo alumno puede abordar diversas temáticas de interés en distintos momentos e interacciones en los roles asumidos como autor y juez. En este punto también es importante considerar que las múltiples posibilidades y oscilaciones de reflexividad temática son el reflejo de diversos aspectos contextuales y personales, así como del tipo de decisiones metodológicas para la interacción en la fase de elicitación. En esta investigación estas manifestaciones de reflexividad temática forman parte de un enfoque integral en el proceso completo de clasificación textual que aquí he presentado. En el siguiente capítulo haré un seguimiento de las distintas manifestaciones reflexividad de cada alumno como autor y luego como juez. 


\section{Capítulo V}

\section{Reflexividad del alumno como autor y luego como juez}

\subsection{Tipo de reflexividad como autor y luego como juez}

Hasta este momento he presentado los criterios de clasificación textual a partir de los aspectos relacionados con los tipos y temáticas de reflexividad correspondientes a las parejas de autor y juez en cada caso, sin hacer un seguimiento puntal de la manera en que cada alumno se expresó, primero como autor y luego como juez, y, principalmente, los posibles cambios y actitudes manifestadas al asumir estos distintos roles.

En este capítulo contemplo un tipo de clasificación de los textos obtenidos en la fase de elicitación 4: UNICH a partir de los cruces necesarios entre los datos correspondientes a cada folio, para ubicar los textos de cada alumno y verlos en sus roles como autor y juez. Además presento algunos ejemplos de este tipo de clasificación, también en las reacciones escritas del autor sobre los comentarios del juez. Este manejo de los datos facilita la caracterización, principalmente, de las posibles transiciones de los tipos de reflexividad y de las diversas temáticas.

Al conocer la manera en que un alumno manifiesta elementos de reflexividad en sus comentarios primero como autor y luego como juez, tenemos la posibilidad de estudiar aquellas evidencias de transiciones de tipo y temática de reflexividad. Así, podemos ver en los ejemplos concretos que la reflexividad de cada alumno puede variar en distintas modalidades y facetas conforme al rol asumido de autor o juez, al tipo de comentarios y a las temáticas abordadas. Por ejemplo, en algunos momentos el individuo manifiesta reflexividad incipiente e implícita y en otras situaciones expresa un mayor número de elementos de reflexividad sobre sus propias creencias y concepciones relacionadas con 
elementos de textualidad y desempeño en escritura académica. En otros casos un mismo alumno manifiesta el mismo tipo de reflexividad como autor y como juez, pero incorpora distintas temáticas y modalidades de intencionalidad y reflexividad. En cada faceta y manifestación de reflexividad el individuo se retroalimenta en una conformación constante del objeto de reflexión, al tiempo que también construye conocimiento e identidad. De esta manera el objeto de estudio es la construcción de reflexividad sobre la práctica de escritura académica en las diversas formas de intencionalidad manifestadas por el alumno. Por ejemplo, un autor puede asumir una postura crítica sobre su desempeño en una reflexividad compuesta sobre la actividad de escritura académica y contemplar aspectos temáticos contextuales diversos, y al asumir la postura de juez simplemente puede hacer comentarios generales, sin aportar sugerencias al compañero, y después asumir una actitud de justificación ante las observaciones recibidas por su compañero. En este caso lo importante es revisar el seguimiento de este conjunto de transiciones de intencionalidad y reflexividad.

En la muestra existen evidencias de distintas transiciones del tipo y tema de reflexividad. Además, podemos encontrar diversas transiciones en el posicionamiento de enunciación, ya sea de manera directa en $1^{a}$ persona de singular, en $1^{a}$ persona de plural inclusiva y con distanciamientos, en impersonal o de manera prescriptiva. En cada caso la toma de posicionamiento implica una actitud que refleja construcción de identidad, de interlocutores y de reflexividad. De hecho cuando un alumno comenta sobre su propio desempeño y lo hace incluyéndose con otros alumnos en $1^{\mathrm{a}}$ persona del plural (nosotros), como una problemática generalizada o con distanciamiento en impersonal, en realidad refleja una actitud reflexiva determinada en la decisión de no posicionarse o representarse como un actor en sí mismo, ya que requiere aparecer textualmente junto con otros al abordar una temática. En esta sección presento ejemplos de las transiciones sobre el tipo y el tema de reflexividad, así como del posicionamiento de enunciación, como elementos fundamentales de la intencionalidad comunicativa en estos textos.

En las tablas que presento a continuación apreciamos la clasificación a partir de la caracterización del tipo de reflexividad y de temática de cada alumno al asumir los roles de autor y de juez. En esta sección tomé la decisión metodológica de crear un código de nomenclatura para identificar en los folios los textos correspondientes a cada alumno en los 
papeles de autor y juez. En estas tablas, en cada caso el número en paréntesis indica el texto del compañero al que cada alumno, al asumir el rol de juez, hizo observaciones y sugerencias, por ejemplo, 9(12) indica que el autor 9 al asumir el papel de juez revisó el texto del alumno 12. Además, en esta sección eliminé los folios en los que los jueces no se presentaron en la segunda sesión para escribir las sugerencias y comentarios, evidentemente porque de esta manera no es posible hacer un seguimiento puntual de estos alumnos. Los folios eliminados son 44(51), 45(49), 46(48), 47(c3) y c3(50). Además, agregué 3 folios en que los jueces hicieron observaciones a textos que eliminé de la muestra y que no fueron contemplados en el corpus del análisis, pero en el seguimiento de cada alumno como autor y luego como juez era necesario contemplar la parte correspondiente a las observaciones para dar el seguimiento completo de cada alumno en sus dos roles. Denomino a estos textos agregados como los folios c1, c2 y c3.

\section{Tabla 11 Tipo de reflexividad del alumno primero como autor y luego como juez}

\begin{tabular}{|c|c|c|c|}
\hline Autor Juez & $\begin{array}{l}\text { Generalidades } \\
\text { juez }\end{array}$ & $\begin{array}{l}\text { Reflexividad } \\
\text { parcial: juez }\end{array}$ & $\begin{array}{l}\text { Reflexividad } \\
\text { compuesta: juez }\end{array}$ \\
\hline $\begin{array}{ll}\text { Comentarios } & \\
\text { generales } & \mathrm{y} \\
\text { prescriptivos } & \end{array}$ & 0 & $\begin{array}{c}3 \\
1(10),, 41(42), \mathrm{cl}(25)\end{array}$ & \begin{tabular}{|l}
\multicolumn{1}{|c}{10} \\
9(12), 11(9), 12(11), 23(24), \\
24(23), 31(22), 35(36), \\
$38(37), 42(41)$, c2(33) \\
\end{tabular} \\
\hline $\begin{array}{l}\text { Reflexividad } \\
\text { parcial }\end{array}$ & 0 & 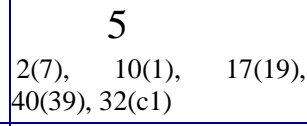 & $\begin{array}{c}4 \\
18(14), 25(32), 37(38), 34(43)\end{array}$ \\
\hline $\begin{array}{l}\text { Reflexividad } \\
\text { Compuesta }\end{array}$ & $\begin{array}{c}1 \\
6(2)\end{array}$ & 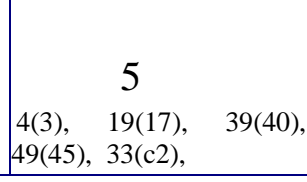 & \begin{tabular}{|c}
21 \\
$3(8), 5(4), 7(6), 8(5), 13(16), 14(18)$, \\
$15(13), 16(15), 20(28), 21(30), 22(31)$, \\
$26(27), 27(26), 28(29), 29(20), 30(21)$, \\
$36(35), 43(34), 48(46), 50(47), 51(44)$
\end{tabular} \\
\hline
\end{tabular}

En la tabla 11 podemos destacar la tendencia de los alumnos a mantenerse en un tipo de reflexividad compuesta, pasando, mayoritariamente, desde el tipo de comentarios generales y prescriptivos como autores a la reflexividad compuesta como jueces sobre la actividad desarrollada. Tan solo apreciamos 6 alumnos que manifiestan en sus escritos un regreso o retroalimentación desde una reflexividad compuesta a una parcial, o bien a comentarios generales. Así tenemos 5 alumnos que pasan de la reflexividad compuesta a la parcial, en tanto que solamente 1 alumno hace una transición de la reflexividad compuesta a comentarios generales. 
En el caso de la reflexividad parcial, ningún alumno pasa al tipo de comentarios generales, y 4 avanzan a una reflexividad compuesta. Estos datos reflejan el predominio de la transición de reflexividad compuesta sobre la actividad desarrollada al asumir el rol de juez. La transición mayor corresponde al paso de generalidades como autor a la reflexividad compuesta como jueces.

Sobre la transición de los alumnos que avanzan de generalidades a la reflexividad compuesta, alguien podría decirnos que este dato no representa gran mérito o manifestación crítica de intencionalidad, por el hecho de considerar que es más fácil tener una actitud crítica cuando comentamos sobre el desempeño de otra persona que sobre el desempeño de uno mismo. Considero que esta transición es relevante porque los alumnos incorporan en su comentario el tema abordado, mismo que no habían contemplado en la primera versión, además de la consideración y posible toma de conciencia sobre algunos elementos concretos relacionados con los principios de textualidad, que anteriormente propuse en la investigación. Además, este tipo de transición en la reflexividad pone de manifiesto la construcción de interlocutores y el posicionamiento de enunciación para contemplar las observaciones sobre el desempeño y también las sugerencias al compañero. Además, en cada caso debemos considerar las temáticas que contemplan los jueces, principalmente, sobre aspectos relacionados con los estándares constitutivos de textualidad.

Recordemos que en la creación de categorías de clasificación textual caractericé los tipos de reflexividad a partir de los criterios de la transición de generalidades ajenas al tema abordado, prescripciones, comentarios sobre el texto del autor y el juez oaxaqueños, sobre el desempeño propio, compartir experiencias, así como sugerencias y comentarios sobre escritura académica. Además contemplé el criterio de referencia a elementos de los textos, en algunos casos de manera implícita y otras con ejemplos concretos. Por ello, el seguimiento del tipo de reflexividad como autor y luego como juez es fundamental porque involucra criterios sobre la caracterización de comentarios de la textualidad.

Revisar los comentarios y la reflexividad de cada alumno en una clasificación como autor y luego como juez es fundamental. Además contemplo este mismo criterio sobre el tipo y temática de reflexividad, caracterizado en cada uno de los tres grupos que conforman la muestra, porque la interacción desarrollada en cada caso da lugar a ciertas tendencias 
sobre el tipo de transiciones. No pretendo hacer un estudio de las cuestiones que motivaron estos resultados en cada grupo, simplemente porque implica un conjunto de variables que escapan a los alcances de esta investigación.

Me parece importante tener un panorama general del seguimiento y apuntar algunos aspectos de las transiciones observadas y cuestiones generales que se presentaron en la interacción y que influyeron en los resultados, tanto del tipo de reflexividad como de las temáticas. A continuación presento en la tabla 12 la información sobre este seguimiento en cada uno de los grupos con los que trabajamos en la UNICH.

\section{Tabla 12: El tipo de reflexividad de cada alumno como autor y como juez}

\begin{tabular}{|c|c|c|}
\hline $\begin{array}{l}\text { Grupo 1: 5to semestre } \\
\text { Plantel Oxchuc } \\
1 \text { - 1(10) general a parcial. } \\
2 \text { - 2(7) parcial a parcial } \\
3 \text { - 3(8) compuesta a compuesta } \\
4 \text { - 4(3) compuesta a parcial } \\
5 \text { - 5(4) compuesta a compuesta } \\
6 \text { - 6(2) compuesta a general } \\
7 \text { - 7(6) compuesta a compuesta } \\
8 \text { - 8(5) compuesta a compuesta } \\
9 \text { - 9(f12) general a compuesta } \\
10-10(1) \text { parcial a parcial } \\
11 \text { - 11(9) general a compuesta } \\
12-12(11) \text { general a compuesta } \\
13 \text { - 13(16) compuesta a compuesta } \\
14 \text { - 14(18) compuesta a compuesta } \\
15 \text { - 15(13) compuesta a compuesta } \\
16 \text { - 16(15) compuesta a compuesta } \\
17-17(19) \text { parcial a parcial } \\
18 \text { - 18(14) parcial a compuesta } \\
19 \text { - 19(17) compuesta a parcial }\end{array}$ & $\begin{array}{l}\text { Grupo 2: 1er semestre } \\
\text { Plantel San Cristóbal de las Casas } \\
20 \text { - 20(28) compuesta a compuesta } \\
21 \text { - 21(30) compuesta a compuesta } \\
22 \text { - 22(31) compuesta a compuesta } \\
23 \text { - 23(24) general a compuesta } \\
24 \text { - 24(23) general a compuesta } \\
25 \text { - 25(32) parcial a compuesta } \\
26 \text { 26(27) compuesta a compuesta } \\
27 \text { - 27(26) compuesta a compuesta } \\
28 \text { 28(29) compuesta a compuesta } \\
29 \text { - 29(20) compuesta a compuesta } \\
30 \text { - 30(21) compuesta a compuesta } \\
31 \text { - 31(22) general a compuesta } \\
32 \text { - 32(c1) parcial a parcial } \\
33 \text { - 33(c2) compuesta a parcial } \\
\text { c1 - c1(25) general a parcial } \\
\text { c2 - c2(33) general a compuesta }\end{array}$ & $\begin{array}{l}\text { Grupo 3: 5to semestre } \\
\text { Plantel San Cristóbal de las Casas } \\
34 \text { - 34(43) general a parcial } \\
35 \text { - 35(36) general a compuesta } \\
36 \text { - 36(35) compuesta a compuesta } \\
37 \text { - 37(38) parcial a compuesta } \\
38 \text { - 38(37) general a parcial } \\
39 \text { - 39(40) compuesta a parcial } \\
40 \text { - 40(39) parcial a parcial } \\
41 \text { - 41(42) general a parcial } \\
42 \text { - 42(41) general a compuesta } \\
43 \text { - 43(34) compuesta a compuesta } \\
44 \text { - 44(51) compuesta a ausente } \\
45 \text { - 45(49) compuesta a ausente } \\
46 \text { - 46(48) general a ausente. } \\
47 \text { - 47(c3) parcial a ausente } \\
48 \text { - 48(46) compuesta a compuesta } \\
49 \text { - 49(45) compuesta a parcial } \\
50 \text { - 50(47) compuesta a compuesta } \\
51 \text { - 51(44) compuesta a compuesta } \\
\text { c3 - c3(50) compuesta a ausente }\end{array}$ \\
\hline
\end{tabular}

En general la clasificación textual en los tres grupos muestra que los alumnos tuvieron un desempeño similar, no existen desproporciones, casi vemos un balance en la distribución del nivel de quienes se mantienen en la reflexividad compuesta como autor y luego como juez: grupo 1: 8, grupo 2: 8 y grupo 3: 5, de la transición mayor, es decir, de quienes avanzan del nivel de generalidades a la de $2^{\circ}$ grado: (grupo 1: 3, grupo 2: 4 y grupo 5: 3). A pesar de que no es posible hacer un estudio sobre este tipo de información, ya que no contemplé esos aspectos porque escapan a los alcances de la investigación, considero que los alumnos se desempeñaron de esta manera debido a que asisten a cursos de lengua 
regional, y por ello me parece que presentaron disposición a la reflexión sobre el tema, y esto se refleja en datos similares en los tres grupos.

\subsection{Temática de reflexividad como autor y luego como juez}

Indudablemente es necesario hacer el mismo tipo de clasificación textual para las diversas temáticas de reflexividad abordadas por el alumno primero como autor y luego como juez. Considero que revisar las transiciones en las temáticas es un aspecto que nos permite caracterizar de manera más puntual la forma en que cada alumno aborda y asume los temas de interés fundamental en sus comentarios y en las evidencias de reflexividad, presentes en los textos. La temática de reflexividad nos permite contemplar los principios de textualidad que, de manera consciente o inconsciente, el alumno pone en juego para el manejo de recursos de textualización.

Anteriormente hice una caracterización general a partir de las temáticas predominantes en cada texto. Esta manera de revisar la reflexividad facilita el estudio de la relación entre la temática abordada y la manera en que el juez hace sus observaciones. Además es necesario hacer un seguimiento puntual de cada alumno, en el tipo de transiciones temáticas que realiza en la unidad textual completa como autor y como juez, es decir, las distintas temáticas que aborda, además de la temática general o predominante. Algunos autores se mantienen en el mismo tema y otros hacen distintas transiciones en el mismo texto o bien al cambiar al rol de juez.

Este seguimiento es relevante para estudiar los distintos tipos y complejidades de reflexividad. En gran medida, las transiciones temáticas se relacionan con los principios de textualidad que he propuesto a partir del modelo inspirado en Beugrande y Dressler (1997) y son las que determinan el tipo de reflexividad y el posicionamiento asumido por los alumnos. Propongo las categorías temáticas en relación con los estándares de textualidad que construyo a partir del modelo que he ampliado de Beugrande y Dressler (1997). Así contemplo en la tabla 13 las siguientes relaciones entre temáticas y estándares de textualidad a partir de los temas encontrados en los textos. 
Tabla 13: Propuesta de modelo integral de estándares de la textualidad.

\begin{tabular}{|l|l|}
\hline Temáticas de reflexividad en los textos & Principios de textualidad propuestos \\
\hline Recursos constitutivos de textualización & $\begin{array}{l}\text { Constitutivos: cohesión, coherencia, } \\
\text { informatividad, aceptabilidad e intencionalidad }\end{array}$ \\
\hline Identidad, impacto, significado de escribir. & $\begin{array}{l}\text { Regulativos: efectividad, propiedad, estrategias, } \\
\text { reflexividad sobre la textualidad }\end{array}$ \\
\hline Regulación contextual de la escritura & $\begin{array}{l}\text { Contextuales: intertextualidad, temporalidad, } \\
\text { situacionalidad, significados, trayectoria textual, } \\
\text { géneros }\end{array}$ \\
\hline $\begin{array}{l}\text {-Prácticas e interacción en torno a la escritura } \\
\text {-Sobre la escritura y gramática de la lengua de } \\
\text { instrucción }\end{array}$ & $\begin{array}{l}\text { Prácticas: repertorios, interacción, funciones, } \\
\text { interpretación, actores e interlocutores, identidad. }\end{array}$ \\
\hline
\end{tabular}

En la tabla 14 presento las temáticas abordadas por los alumnos. Los autores abordan el tema de la escritura y la gramática, pero no abordan este tema como jueces. En un mismo texto pueden aparecer distintas temáticas, además de las predominantes.

Tabla 14. Temáticas de reflexividad como autor y luego como juez.

\begin{tabular}{|c|c|c|c|c|}
\hline Autor & $\begin{array}{l}\text { Recursos constitutivos de } \\
\text { textualización: coherencia y cohesión }\end{array}$ & \begin{tabular}{|l|} 
Regulación \\
contextual de \\
la $\quad$ escritura \\
académica
\end{tabular} & $\begin{array}{l}\text { Prácticas } \\
\text { interacción en } \\
\text { torno a } \\
\text { escritura }\end{array}$ & $\begin{array}{l}\text { Identidad, } \\
\text { impacto, significado } \\
\text { de escribir }\end{array}$ \\
\hline $\begin{array}{l}\text { Recursos } \\
\text { constitutivos de } \\
\text { textualización: } \\
\text { coherencia y } \\
\text { cohesión }\end{array}$ & 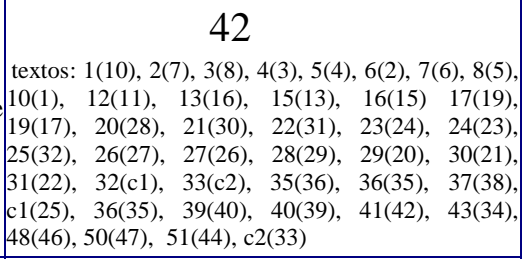 & $\begin{array}{cc}5 & \\
13(16), & 20(28) \\
11(25), & 37(38) \\
48(46) & \end{array}$ & $\begin{array}{l}5 \\
6(2) \quad 25(32), \\
30(21), \\
32(\mathrm{c} 1), \\
51(44)\end{array}$ & $\begin{array}{l}3 \\
7(6), \mathrm{c} 1(25), 51(44)\end{array}$ \\
\hline $\begin{array}{l}\text { Regulación } \\
\text { contextual de la } \\
\text { escritura } \\
\text { académica }\end{array}$ & \begin{tabular}{|l}
22 \\
textos: 3(8), 4(3), 5(4), 7(6), 8(5), 9(12), 11(9), \\
$14(18), 18(14), \quad 15(13), 19(17), 27(26), 29(20)$ \\
$35(36), 37(38), 38(37), 39(40), 41(42), 42(41)$ \\
$43(34), 49(45), \quad 51(44)$
\end{tabular} & $\begin{array}{c}3 \\
\text { textos: } \\
8(5), 18(14) \\
27(26)\end{array}$ & $\begin{array}{c}2 \\
18(14) \\
51(44)\end{array}$ & $\begin{array}{l}\quad 4 \\
4(3), \quad 7(6), \quad 38(37), \\
51(44),\end{array}$ \\
\hline $\begin{array}{l}\text { Identidad, } \\
\text { impacto, } \\
\text { significado } \\
\text { de escribir } \\
\end{array}$ & 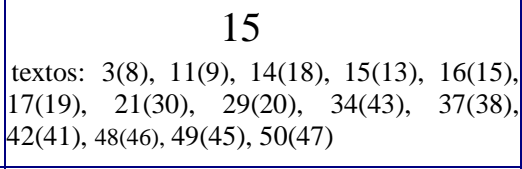 & $\begin{array}{c}1 \\
37(38)\end{array}$ & 0 & $\begin{array}{c}1 \\
37(38)\end{array}$ \\
\hline $\begin{array}{l}\text { Prácticas e } \\
\text { interacción } \\
\text { torno a } \\
\text { escritura }\end{array}$ & 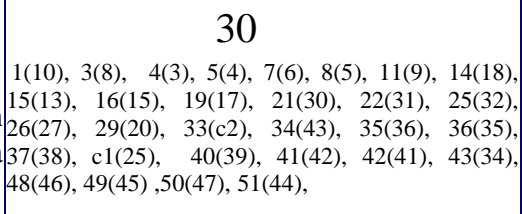 & \begin{tabular}{|l}
3 \\
$37(38)$ \\
$48(46)$
\end{tabular} & $\begin{array}{c}2 \\
25(32) \\
51(44)\end{array}$ & $\begin{array}{lll} & & \\
4(3), & 7(6), & \mathrm{c} 1(25), \\
38(37), & 51(44) & \end{array}$ \\
\hline 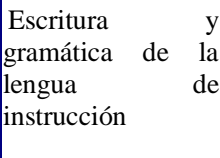 & 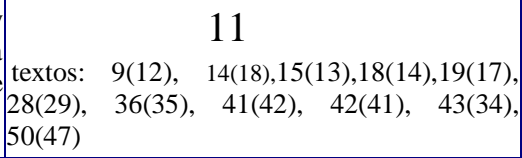 & $\begin{array}{l}1 \\
39(40),\end{array}$ & 0 & 0 \\
\hline
\end{tabular}

Jueces ausentes en: 44(51), 45(49), 46(48), 47(c3), c3(50) 
El predominio temático de recursos constitutivos de textualización, principalmente de coherencia y cohesión, como autor y luego como juez refleja el interés sobre el manejo de recursos textuales y la necesidad de que el texto sea aceptable e informe conforme a una intencionalidad que responda al ambiente académico, principalmente, en el caso de los jueces. Considero que esto se debe a que los autores tuvieron oportunidad de interactuar y comentar sobre temáticas distintas debido al diseño de la interacción en la práctica de elicitación. En esta ocasión tomé en consideración el tema del desempeño del autor y el juez oaxaqueños, aspectos contextuales, las prácticas y que los alumnos compartieran sobre sus experiencias en ambientes académicos. De esta manera, la segunda temática de relevancia abordada por los autores corresponde a las prácticas e interacción en torno a la escritura. El tema de las prácticas e interacción en torno a la escritura involucra la multiplicidad de usos en el marco de la realidad del bilingüismo y del contexto de la educación intercultural, por ejemplo, las caracterizaciones de los repertorios lingüísticos, las funciones y la construcción de identidad.

Sobre los datos relacionados con la regulación contextual de la escritura académica, considero que los alumnos contemplan aspectos relacionados con el desempeño en el marco de la realidad y los significados que construyen en la universidad y los relacionan con los aspectos regulativos sobre sus propias prácticas de escritura. De esta manera considero que las temáticas de regulación contextual de la escritura y las de identidad, impacto, y significado de escribir se relacionan estrechamente y corresponden a los estándares regulativos (efectividad, propiedad, estrategias y reflexividad) y contextuales (intertextualidad, temporalidad, situacionalidad, significados, trayectoria textual y géneros) respectivamente. En conjunto contemplo en estas dos temáticas, aspectos de regulación debido al contexto y a la construcción de identidad, pues reflejan elementos fundamentales relacionados con la intencionalidad y la reflexividad en la escritura académica.

La temática de escritura y gramática de la lengua de instrucción, indígena en contraposición con el español, con una mayoría de jueces que abordan recursos constitutivos de textualización, es manifestación de diversos tipos de reflexividad sobre conocimientos y conceptualizaciones sobre la manera en que los alumnos consideran que, 
por ejemplo, la gramática de la lengua indígena impacta en el desempeño escrito en la universidad, las actitudes hacia el español o bien las ventajas y desventajas de aspectos formales en una lengua y otra. En su mayoría estos alumnos expresaron justificaciones sobre su desempeño debido a la condición de tener al español como segunda lengua. La tabla 14 nos deja ver que esta temática de reflexividad (11 ocurrencias) es propia de estos autores, quienes como jueces predominantemente abordan aspectos constitutivos de textualización, sin embargo, ellos mismos no retoman esta temática de la escritura y gramática de la lengua de instrucción para hacer observaciones sobre el uso del español de sus compañeros en la práctica desarrollada en esta ocasión.

En general los datos de la tabla 14 nos dejan ver que, además del predominio de recursos constitutivos, los alumnos tienen diversos intereses, preocupaciones e inquietudes sobre el desempeño académico en la universidad. Una vez más considero que es difícil tener acceso a este tipo de evidencias de reflexividad y que el diseño de la interacción, con sus limitaciones y aspectos para mejorar, fue determinante para que los alumnos abordaran estas múltiples temáticas de reflexividad sobre la intencionalidad y el desempeño.

Así como anteriormente realicé la clasificación conforme al seguimiento sobre el tipo de reflexividad en cada grupo, ahora realizo este mismo tipo de clasificación sobre las transiciones temáticas. Tampoco aquí pretendo estudiar las cuestiones o motivaciones relacionadas con la interacción que dieron lugar a estos datos porque esta situación escapa a los intereses de esta investigación. En el Anexo 13 presento el detalle de esta información en los tres grupos en los que realicé la actividad.

El tipo de clasificación que propongo en esta sección me ha permitido contemplar que la aparición de diversas transiciones temáticas en un mismo texto refleja algunas manifestaciones de la intencionalidad y reflexividad. De esta forma distingo el tipo de reflexividad parcial y compuesta, correspondiente a la naturaleza de los comentarios y sugerencias, y, por otra parte, las manifestaciones de reflexividad debidas a las transiciones temáticas. Un texto puede reflejar amplia reflexividad temática y al mismo estar conformado por una reducida o incipiente reflexividad sobre la actividad desarrollada, principalmente cuando los alumnos comentan distintas temáticas, pero no hacen comentarios sobre el tema de la interacción, es decir, la escritura académica, el texto de los 
alumnos oaxaqueños y el desempeño propio. A continuación presento ejemplos representativos del seguimiento del tipo y tema de reflexividad e incluyo la revisión del posicionamiento de enunciación del autor para representarse ante el texto y la reacción del autor ante los comentarios recibidos sobre su texto.

\subsection{Elementos de reflexividad en las reacciones de los autores ante los comentarios recibidos}

Contemplar el criterio temático en la metodología de clasificación textual nos permite tomar en cuenta aspectos que considera el autor de los textos sobre los comentarios recibidos. Participar en un ejercicio de revisión y edición de textos de manera cooperativa, al asumir el papel de juez, hacer y recibir sugerencias, opinar sobre las observaciones del juez, reflexionar sobre la escritura propia y tomar decisiones para editar el texto, constituyen prácticas donde se ponen en juego distintas reacciones, tanto para quien revisa, comenta y sugiere, como para el autor que reflexiona sobre dichos comentarios y toma de decisiones. Por una parte, los jueces asumen distintas actitudes y, en general, parece que en la práctica escolar no tenemos muy desarrollado el hábito de hacer comentarios a un compañero, sin que no nos afecten las posibles actitudes, miedos y reacciones. De hecho, en los textos apreciamos, por ejemplo, situaciones en que el juez se previene de no incomodar al compañero con sus comentarios, lo cual indica un nivel de reflexividad sobre el comentario que se manifiesta de distintas maneras y estilos.

[i] Mira compañera te mando esta carta ya que para mi es importante que sepas lo que he visto de tu texto que me distes, espero que no te molesta pero es mejor que te dieras cuenta y no mentirte $[\ldots]$

Bueno sin mas por el momento espero no hacerte sentir mal y espero tu mejoramiento. [f] (triom04)

Además de la reflexividad sobre el tema leído, el comentario en torno al desempeño de los alumnos de Oaxaca, las experiencias personales de redacción que algunos compartieron, y sobre el escrito del compañero, consideré fundamental que los autores se expresaran por escrito sobre el tema de la opinión que les merece lo que comentó y sugirió el juez sobre su escrito. Por ello en la metodología de elicitación, que anteriormente 
presenté, contemplé una breve retroalimentación oral entre juez y autor, e inmediatamente que los autores expresaran por escrito sus reacciones sobre los comentarios del juez y sobre su propia escritura, con la intención de favorecer la toma de decisiones de textualización encaminadas a escribir una segunda versión mejorada. En la tabla 15 presento las reacciones u observaciones de los autores a lo que dice el juez, porque considero que la reflexividad sobre la intencionalidad y el desempeño que el autor hace de su propia escritura se manifiesta de manera más objetiva cuando éste reflexiona y opina sobre los comentarios recibidos. Así el autor toma una postura sobre su desempeño y manifiesta un nivel de reflexividad en el que evalúa y regula su escritura, en términos de la experiencia de comentar a otros, compartir experiencias, valorar su propio desempeño, tomar una postura crítica sobre los comentarios recibidos y autoevaluarse para emitir reflexiones sobre la opinión del juez.

Tabla 15 Reflexividad sobre los comentarios del juez

\begin{tabular}{|l|l|}
\hline $\begin{array}{l}\text { Observaciones de los autores a lo } \\
\text { que dice el juez }\end{array}$ & $\begin{array}{c}47 \text { de los } 51 \text { textos } \\
\text { ( } 44 \text { al } 47 \text { no se presentaron a la segunda sesión) }\end{array}$ \\
\hline Acepta & $\begin{array}{l}25 \text { (textos: } 01,02,03,08,09,10,11,14,17,18,20, \\
21,25,27,28,31,32,33,34,36,37,40,41,43,49)\end{array}$ \\
\hline $\begin{array}{l}\text { Acepta y reflexiona sobre } \\
\text { escritura }\end{array}$ & 9 (textos: 06, 12, 16, 19, 22, 26, 35, 38, 48) \\
\hline Acepta pero discrepa & 4 (textos: 04, 05, 15, 50) \\
\hline $\begin{array}{l}\text { Acepta y critica la escritura del } \\
\text { juez }\end{array}$ & 4 (textos: $13,29,39,42)$ \\
\hline Discrepa & 2 (textos: 07, 30) \\
\hline Discrepa y critica al juez & 3 (textos: 23, 24, 51) \\
\hline
\end{tabular}

Podemos establecer variantes temáticas de quienes aceptan o están de acuerdo con los comentarios del juez: por una parte aquellos que reflexionan sobre el comentario y lo relacionan directamente con su escritura de manera concreta, $y$, por otra parte, quienes aceptan comentarios de jueces, quienes opinan, por ejemplo, generalidades sobre el tema, ajenas a la escritura del autor, o que expresan prescripciones, valoraciones ambiguas o hipercorrecciones. De esta manera, estar de acuerdo con el juez no sólo indica una toma de postura sobre los recursos de textualización, sino también una reflexividad para evaluar el comentario sugerido y el desempeño propio. 
Considero que cuando los alumnos aceptan los comentarios y sugerencias hacen una valoración y evaluación de su propia intencionalidad para expresarse por escrito, puesto que el autor acepta, pero se vuelve crítico del comentario sobre su propio desempeño. Las reacciones de aceptación con discrepancia ponen en juego el balance reflexivo sobre la autorregulación y la valoración del desempeño propio, en relación solamente a determinados aspectos con los que concuerda con el juez. Además, al criticar la escritura del juez, el autor se desprende de la autorregulación para señalar y reflexionar sobre aspectos que considera "inadecuados o cuestionables" sobre la escritura del compañero, lo cual implica una postura sobre la construcción de identidad en la práctica cooperativa de escritura, al contemplar el desempeño propio y el de otros, situación que sucede también con quienes discrepan y critican al juez (2 de 47). Ejemplos:

Aceptación y crítica al juez: El juez comenta normativa y prescriptivamente, sin referencia alguna a recursos de textualización, a pesar de que el autor refleja intencionalidad por cuidar la cohesión, la coherencia y los recursos gráficos. Parece que el juez no contempla el intento del autor por expresarse con claridad, y, además, no apunta nada sobre problemáticas, por ejemplo, de ortografía y acentuación.

[i] Pues me doy cuenta que te faltan algunas palabras en tu escrito y también te falta poder expresarte un poco más para poderle entender a tu lectura hechale muchas ganas y beras que todo lo que te ando escribiendo es para que mejores tu escrito y tu lectura suerte en todo. [f] (triscm39juez)

Reacción ante los comentarios

[i $]^{*} \in$ Creo que tenemos los mismos problemas entonces quizás le falto mucho mi compañero para criticar sobre mi texto. ademas que tengo ese problema de escribir y expresar es lógico que por la falta de la leer. [f] (triscm39)

El autor reacciona criticando al juez y aceptando "ese problema”, del cual el juez no aportó aspectos concretos de apoyo. El autor en su primera versión comentó que sus "problemas sobre la escritura muchas de ella son: comprender, expresar, repetir palabra, conectores entre otras." La manifestación de reflexividad se aprecia en que esa aceptación es realmente un refuerzo de lo expresado en la primera versión y no una real aceptación al comentario del juez. 
Discrepa y critica al juez: El juez apunta el listado de aspectos que contempla en el escrito del autor, y no se presentó a la siguiente sesión y por ello no redactó el texto de sugerencia y comentario. Este pequeño listado fue suficiente para que el autor expresara la crítica al juez. El autor comenta aspectos de propiedad textual en ambiente académico para la entrega formal de trabajos y los demás puntos del listado.

-Faltó la sangría -letras chiquitas -faltó acento en realizó -conectores (trisch51juez)

Reacción ante los comentarios.

Estoy en desacuerdo, las sangrías se utilizan cuando redactas textos parar entregárselo a tu asesor o cualquier persona. Estos tipos de requisitos que me piden se utilizan a nivel posgrado, las letras pequeñas no importa; siempre y cuando sea entendible. Sobre los conectores no se a que te refieres. Me dices que me falta el acento en la letra que escribí realizó es un mínimo de error a comparación al tuyo. Gracias por corregirme y te sugiero que hagas lo mismo (trisch51)

Acepta pero discrepa: El juez apunta aspectos de caligrafía, a pesar de que la letra del autor es impecable y comenta que tiene un problema de redacción, puntuación y acentuación y, además, no comenta nada sobre la ortografía. Sin embargo, éste es uno de los textos con mayor avance en el desempeño en una redacción estructurada y clara, con un mínimo de fallas ortográficas, de acentuación, y de puntuación ${ }^{30}$. Es decir, el juez, hace comentarios alejados de la realidad del texto que leyó, y el autor reflexivamente se percata de esta evaluación y discrepa.

[i] Querido Amigo Edgar, te hago llegar este escrito, en la cual tienes *un problema sobre la redacción de algunos texto, te hace falta poner algunos acentos, califgrafia, y no marcar las letras. pero tambien tengas en cuenta los puntos, coma, para que el texto sea entendible la información.

Por último; te recomiendo, por los Acentos de cada concepto y tener buena caligrafía. [f] (trioh15juez)

Reacción ante los comentarios

[i] Lo que pienso de lo que escribio mi compañero, en elo que alifico del texto, es de que tiene la razón en corregir mi escritura ya que la mayor parte de lo me califico es lo que falta en mejorar pero hay algunas cosas que no muy me fayan al escribirlo por ejemplo al mencionar mi compañero que marco mucho mi letra simplemente solo es un

\footnotetext{
${ }^{30}$ El mínimo de dificultades que considero se aprecia al escribir: academicos, las ortografia, elavorar, moletias, algun, ídeas, y, por otra parte, en puntuación al introducir las frases de transición "en otras de las razones" y "por eso", sin embargo, esto no altera la cohesión, y no es representativo de errores sistemáticos, ya que emplea sin dificultad la puntación en otros conectores de transición. El juez fue estricto al plantear que tiene problemas de redacción.
} 
error al escribir. Pero le agradezco sobre su buena voluntad al enlistármelo en el texto. [f] (trioh15)

Acepta y reflexiona sobre su escritura: El autor acepta los comentarios del juez; además hace una reflexión crítica al destacar dificultades en ortografía, acentuación y la necesidad de emplear sangría en el párrafo. Agradece que el juez calificara su ortografía, a pesar de que nunca lo hizo.

[i] Compañero Fidel, te falta mucho la redacción de un texto con los signos de puntuación repetiste conectores y te faltó mucho la caligrafia, pero yo creo que tú lo entiendes o no tu letra y te digo que lo puedes mejorar enderzar y ordenar bien tus palabras.

Creo que te faltó concentración al escribir porque repetiste palabras, si usas palabras elevadas busca el sinónimo y trata de leer mucho. [f] (trioh16juez)

\section{Reacción ante los comentarios}

[i] De manera personal, creo que sí tengo malas ortografías, de no poner los acentos, signos de puntuacion; pero agradesco que mí compañero haya calificado la ortografía del texto. Tambien tratare de tener letra legible, poner los acentos en los conceptos y la manera de terminar una redacción, por ultimo, me falta poner la sangria de los párrafos y es buena la correccion. [f] (trioh16)

El autor acepta todo lo planteado por el juez, y, además, reconoce lo que realmente le parece difícil.

[i] La corrección a los puntos que hace mención mi compañero en donde debo de mejorar mi redacción, en algunos casos si puedo mejorarlo y poder corregir estos errores.

Lo que sí se me hace difícil es el ampliar màs mi redacción y usar otros conceptos, ya que el poco dominio de los conceptos utilizados en el castellano es lo que yo escribo y es lo que pienzo y redacto en este texto, mis ideas y las referencias que tengo con relación a la escritura. [f] (trisch48)

Discrepa: Anteriormente comenté que en el texto triom07 el juez simplemente elogia la escritura, sin aportar sugerencias ni comentarios. Entonces, la autora valora su desempeño y reflexivamente discrepa.

[i] En el punto número uno, en realidad lo que escribió mi compañero que tengo un buen análisis de texto, no es cierto, porque siempre se me dificulta, aveces no me expreso muy bien, no tengo letras legibles, tampoco entendibles aveces $€$ escribo de esa manera cuando me conviene hacerla y cuando no, pues siempre escribo como caiga; nunca checo mi Ortografía. [f] (triom07) 
Acepta: El autor acepta comentarios del juez sobre el uso de conectores y puntuación, a pesar de que en realidad en el texto, los conectores no presentan problemáticas que afecten la cohesión ni son repetitivos. El juez plantea refinar la puntuación, el autor dice que no sabe usarla. Este es un caso de reflexividad donde el autor acepta comentarios alejados de la realidad del texto y además el autor magnifica las observaciones, en una autoevaluación estricta, no acorde al desempeño.

Compañera tu escritura a mi parecer es buena, las únicas sugerencias que te daría es que no uses conectores en repetidas ocaciones, eso pienso le quita aveces el sentido al texto tambien pienso que debes indagar mas sobre el tema, como que repites en ocaciones las mismas ideas sobre todo lo demas pienso es bueno, solo quedaría refinar el uso de comas o puntos. (triscm43juez).

Yo creo que mi compañero que me juzgo, tiene mucha razon cuando dice que uso muchos conectores o conexiones ya que aveces los uso demasiado cuando no tengo claras mis ideas. En el uso de comas y puntos tiene razon en ocasiones los uso porque en realidad no se como utilizarlas jeje. [...]" (triscm43)

A partir de las categorías de clasificación y de los ejemplos, es posible establecer las ventajas de contemplar la práctica de interacción y retroalimentación para que los jueces comentaran oralmente aquello que escribieron al autor, y que éste inmediatamente escribiera lo que consideraba sobre su propia escritura y sobre los comentarios recibidos. De esta manera podemos apreciar distintas facetas de reflexividad de los alumnos sobre el desempeño escrito en ambiente académico. Las reacciones de los autores ante los comentarios recibidos reflejan manifestaciones de reflexividad relacionadas con la intencionalidad, diversas temáticas y estándares de textualidad, principalmente, aquello que a los alumnos les impacta y representa este tipo de prácticas de revisión y edición como parte de la construcción de identidad en la universidad.

\subsection{Caracterización integral del tipo y temática de reflexividad como autor y luego como juez}

Los criterios y categorías metodológicas de clasificación textual sobre el tipo y las temáticas de reflexividad son herramientas que en esta investigación me han permitido 
tener una aproximación y al estudio de los textos para destacar algunas evidencias de intencionalidad y reflexividad. Con el propósito de hacer una clasificación y aproximación al estudio de estos textos es fundamental hacer un trabajo metodológico de caracterización para interrelacionar los criterios y las categorías del tipo y temática de reflexividad de manera integral en los roles de autor, juez y en la reacción del autor ante los comentarios recibidos. Por lo anterior, en esta sección presento ejemplos representativos correspondientes a cada una de las categorías del tipo de comentario y de reflexividad, mismas que relaciono con las temáticas y los diversos elementos de reflexividad presentes en cada texto.

\subsubsection{Comentarios generales y prescriptivos a reflexividad parcial sobre la actividad desarrollada}

En el siguiente ejemplo la autora hace comentarios generales y no alude al tema de la escritura académica personal ni al texto proporcionado sobre el autor y el juez oaxaqueño. Aborda la cuestión de la dificultad de escribir en una segunda lengua, la aceptabilidad, además, menciona aspectos constitutivos y las prácticas y usos en ambiente académico.

$41 \mathrm{~m}$ (42): [i] Por mi parte considero porque no es mi lengua natal sino que es nuestra segunda lengua por tal razon ${ }^{\text {tenemos }}$ esas dificultades de la ortografia, nos hace dificl escribir un texto tal como debe de ser por lo tanto, también algunos de nosotros como estudiantes no nos gusta leer; porque es una buena corrección de escritura si lees; ademas vas conociendo nuevas cosas en cuando vas leendo conoces nuevos conceptos y te das cuenta de como se respetan los acentos, punto, coma etc.

mas cuando no le ponemos atención a nuestro texto que escribimos: porque hay momentos tambien que solo lo hacemos por hacer y tambien tengamos el interes de lo queremos escribir y al igual tenerlo claro la idea deseas anotarlo [f] (trsiscm41)

Podemos ver que la autora toma distanciamiento en el posicionamiento de enunciación al representarse en el texto, primero, al asumir de manera directa en $1^{\text {a }}$ persona del plural (yo) que tiene que expresarse en la segunda lengua, y considera, de manera inclusiva (nosotros), las dificultades que tiene al comentar, por ejemplo, sobre "esas dificultades de la ortografia nos hace dificil escribir un texto". Después enfatiza el distanciamiento al considerar mediante la $2^{\mathrm{a}}$ persona (tú genérico e inclusivo) que cuando 
"vas leendo conoces nuevos conceptos y te das cuenta de como se respetan los acentos". Finalmente cierra de manera inclusiva posicionándose en $1^{\mathrm{a}}$ persona del plural. Considero que esta manera de representación textual distanciada manifiesta una reflexividad básica, porque no contempla el desempeño ni experiencias personales.

Ahora como juez

[i] Compañera: Miranda

Miranda Escobar Rosario: Corrección de la escritura 29/09/2011 S.CL.C Chiapas

Compañera te recomiendo que hagas un poco legible tus letras porque estan muy chiquitas, tambien que tratas de hacer menos borrones cuando escribes textos y Respetar las letras que llevan puntos.

Letras legibles, respetar las letras que llevan puntos, Menos borrones.

Pues te recomiendo que leemos mucho porque no solo tu tienes esos errores [f]

La alumna hace una transición hacia comentarios de evidencia textual sin ejemplificar, fundamentalmente sobre sugerencias. En contraste con su propio texto como autor, al asumir el papel de juez utiliza la representación directa. El avance al tipo de reflexividad parcial sobre la actividad desarrollada se debe a que contempla la temática abordada y la referencia al desempeño de la escritura.

Posteriormente cuando la alumna recibe los comentarios sobre su propio texto, retoma el distanciamiento al reconocer sus dificultades, puesto que de manera inclusiva, en $1^{\text {a }}$ persona plural, asume que es "el mayor problema de todos".

Reacción ante los comentarios del juez

[i] Lo que pienzo lo que comento la compañera. De acuerdo porque me dificulta ordenar mis ideas: Pero creo que el mayor problema de todos es la falta de la lectura.

También el uso de las letras, puntuación, punto, coma. [f]

\subsubsection{Comentarios generales $y$ prescriptivos a reflexividad compuesta sobre la actividad desarrollada}

En el ejemplo que presentaré a continuación la autora refleja la mayor transición al pasar de un tipo de reflexividad alejado de la actividad desarrollada mediante prescripciones generales y señalamientos de las fallas encontradas en el texto, a una reflexividad compuesta como juez al incorporar observaciones y sugerencias en el texto que 
revisó.

Considero que la reflexividad presente en el texto como autora nos hace ver también una actitud tal vez de desinterés a la actividad, puesto que simplemente es breve y tajante en la crítica y no aborda las temáticas propuestas sobre comentar la escritura del juez y autor oaxaqueños ni compartir sus propias experiencias. Esta actitud es distinta al asumir el rol de juez, puesto que además de las observaciones y sugerencias, se posiciona directamente para dirigirse a su compañera y proporciona ejemplos concretos, en este caso, sobre caligrafía, y hace referencia a los espacios y a no confundir letras. Además contempla temáticas sobre la práctica, al recomendar estrategias para corregir la escritura. La reacción ante los comentarios recibidos es de reconocer que debe mejorar sus acentuaciones y la caligrafía. Esto refleja el avance a la reflexividad compuesta sobre la actividad desarrollada en su rol de juez y después al valorar su propio desempeño.

c2m (33) [i] Bueno que al compañero lo corrijan tambien porque mi parte mucho tiene ortografias ya que no so lo entiendo las palabra que dice que nos aportan.

Tambien se le dificultaron las acentuaciones los punto y las comas. [f] (c2m)

Ahora como juez

[i] Compañera te sugiero que no escribas juntas las palabras porque hay algunas que no entiendo. y además checa bien donde van las acentuaciones.

Te sugiero que cuando te expreses más explicate bien.

y que hagas bien tu escritura ya que no son muy entendibles tus letras además la $\mathrm{r}$ la realizas como si fuera 1 pero además checa bien en los espacios donde, apuntes tu texto cuando lo quieras escribir.

Además en tu escritura pones letras que no deben ir.

Cuando tengas tiempo puedes hacer una plana para poder corregir tu escritura y trata de escribir en hojas blancas, para qué tus letras se vayan en linea y no se vayan chueco. Son mis recomendaciones que te sugiero. [f]

\section{Reacción ante los comentarios recibidos}

[i] Lo qué pienso qué me comenta el juez.

Ló que pienso es que tienes la razón compañera ya que la s la hago como manuscrita pero tratare de mejorar, ademas también en las acentuaciones que tiene los textos que escriba y sere más clara en cuanto a veces la s se me dificulta. [f] 


\subsubsection{Reflexividad parcial a reflexividad parcial sobre la actividad desarrollada}

Recordemos que la reflexividad parcial en este trabajo corresponde a los textos donde los alumnos contemplan alguna de las temáticas propuestas en la interacción, es decir, el comentario sobre la lectura del autor y el juez oaxaqueños o bien comentar y compartir experiencias personales sobre la escritura académica. En el siguiente ejemplo el alumno muestra reflexividad con posicionamiento directo en $1^{\mathrm{a}}$ persona del plural para tratar distintas temáticas sobre su propio desempeño, destacando sus dificultades y actitudes, por ejemplo, al plantear que en ocasiones no le toma importancia a la escritura, contempla elementos constitutivos formales, de propiedad en el uso del vocabulario y de los significados. Únicamente le faltó hacer comentarios sobre el texto del autor y el juez oaxaqueños. El posicionamiento directo permite apreciar con mayor transparencia la intencionalidad comunicativa, al contemplar una visión y evaluación autocrítica de su propio desempeño. Posteriormente, como juez utiliza una vez más un posicionamiento directo para dirigirse al compañero y hacerle observaciones sobre estándares constitutivos relacionados fundamentalmente con la informatividad, la cohesión y la selección léxica. Finalmente, en el reconocimiento de sus dificultades ante los comentarios recibidos una vez más contempla de manera crítica y directa cuestiones de coherencia y cohesión. De esta forma mantiene el nivel de reflexividad parcial en ambos roles. Esto pone de manifiesto la recursividad de la reflexividad, puesto que hace una reflexión sobre sus propias concepciones relacionadas con su desempeño y el reconocimiento de dificultades, posicionándose de manera directa en $1^{a}$ persona del singular. Esta situación nos permite apreciar la valoración, la evaluación y la regulación como parte de un procedimiento en términos funcionales del razonamiento que refleja distintas facetas de intencionalidad y reflexividad manifestadas en los comentarios escritos.

17h (19h) [i] Siguiendo con el concepto del compañero en la escritura es la realidad, en muchas ocasiones en situacion mia hay veces no le tomo importancia al escribir un texto, sino lo escribo como se venga en la mente no tengo paciencia en mejorar mi 
ortografia, y lo que mas me dificulta al escribir es respetar todos los signos, como, la coma, el acento, etc. tambien me dificulta al expresarme por repetir las mismas palabras, hay veces no encontro el significado o como debo de mencionarlo el termino de una palabra me dificulta hay veces con que letra empiezo minuscula o mayuscula.

En mi conclusión me haré responsable de tomarle mucha importancia la escritura, siempre y cuando conocer al fondo donde debe ir todo los signos de puntuación. Y asi poda mejorar mi escritura y que sea entendible. (trioh19)

Ahora como juez

Que tal amigo solo te escribo para darte unos consejos sobre tu escritura, el texto que tu escribiste le fanlta un poco ${ }^{\text {mas }}$ de entendimiento, lo que haces tocas un tema y luego te brincas a la otra, y no hay que repetir varias veces las mismas palabras, espero no lo tomes a mal y tambien quiero que seas sincero tambien sobre mi escritura, no me queda mas que decirte que le pongamos mucho empeño a la escritura. hasta luego. [pf]

Reacción a los comentarios recibidos

\section{LO QUE PIENSO DE LO QUE MESCRIBIÓ MI COMPAÑERO.}

-pienso que realidad Me falta expresarme para redactar y no tener un tema fijo para hablar solamente de eso y que además me faltan los signos de puntuación en donde se cierra el texto, también de que repito muchas veces las mismas palabras.

\subsubsection{Reflexividad parcial a reflexividad compuesta sobre la actividad desarrollada}

En el siguiente ejemplo el alumno avanza en el tipo de reflexividad al incorporar como juez comentarios y sugerencias al compañero. En su rol de autor comenta el texto proporcionado sobre los alumnos oaxaqueños y contempla aspectos contextuales sobre "lo que se vive en las escuelas del país", la valoración sobre aspectos constitutivos formales, que contempla como evidencia de que el alumno oaxaqueño no domina el español escrito, así como la propiedad y la informatividad, al considerar que el texto no es claro por los cambios drásticos. En el plano de las prácticas académicas, destaca el apoyo del compañero sin burlarse, y plantea una valoración contextual de las prácticas y actitudes en su experiencia como alumno bilingüe indígena, así toma en consideración la construcción de identidad, en lo que le representa la interacción académica en una sociedad manipuladora. El alumno maneja una multiplicidad temática en su reflexividad, sin embargo no hace comentarios ni comparte experiencias concretas personales sobre su desempeño propio, se centra más en el nivel de la reflexividad contextual. 
Al asumir el rol de juez este alumno manifiesta reflexividad compuesta, al contemplar comentarios y sugerencias sobre cohesión y articulación textual mediante el uso de conectores, además, hace referencia a la necesidad de cumplir con la informatividad y la propiedad en ambiente académico, al sugerirle que indague sobre el tema para no ser repetitiva. De esta forma muestra también multiplicidad temática en su reflexividad.

$34 \mathrm{~h}(43 \mathrm{~m})$ [i] En mi opinión, la lectura es muy interesante porque muestra lo que se vive en las escuelas del pais, a primera instancia se nota que el compañero que redacto el escrito esta aun adoptando el español por la manera de su redacción, ya que cambia drasticamente de un momento a otro lo que esta diciendo, pero lo mas interesante es que el otro compañero le da algunos consejos de como hacer una redacción y no ace burla de la redacción del compañero al contrario le extiende la mano y el autor de la redacción al sentirse apoyado acepta la realidad que vive.

La lectura nos pone a pensar de como entre alumnos nos podemos ayudar pero lamentablemente es un valor que pocos lo tenemos en mi poca experiencia vivida en la universidad intercultural me he dado cuenta de que en vez de apoyar asemos caso omiso de la situación peor aun, tomamos una actitud no aceptable, porque burlamos al compañero y en vez de ayudarlo lo estamos perjudicando mas.

En mi vivencia como estudiante indigena si es bastante dificil tomar el control de lo que uno hace, por lo general somos manipulados por la sociedad y no tenemos otra alternativa mas que adaptarnos a ella. [puf] (trisch34)

Ahora como juez

Compañera tu escritura a mi parecer es bueno, las unicas sugerencias que te daria es que no uses conectores en repetidas ocaciones, eso pienso que le quita aveces el sentido al texto, tambien pienso que debes indagar mas sobre el tema, como que repites en ocasiones las mismas ideas sobre todo lo demas pienso es bueno, solo quedaria refinar el uso de comas o puntos.

\subsubsection{Reflexividad compuesta a generalidades sobre la actividad desarrollada}

A continuación presento un ejemplo de una alumna que muestra el paso de reflexividad compuesta a generalidades. Así podemos ver que en la reflexividad al asumir los roles de autor y juez, los alumnos muestran transiciones contrastantes que indudablemente están asociadas a múltiples aspectos, principalmente, la actitud ante la práctica de comentar el texto de otro. La alumna inicia su comentario del texto de los alumnos oaxaqueños reconociendo las dificultades con cierto distanciamiento. Se incluye junto con otros en un posicionamiento en $1^{\mathrm{a}}$ persona del plural, al decir que "se nos dificulta realizar un texto o no nos fijamos en la redacción" sobre aspectos constitutivos 
formales. Inmediatamente en su valoración del texto destaca la propiedad, la informatividad y el contexto, al destacar que de lo contrario "el texto no se entendería al momento de leer". En este punto, la reflexividad de comentarios sobre el texto contiene temáticas sobre el uso y las prácticas en la realidad contextual de los estándares de textualidad para que un texto funcione en ambiente académico.

La alumna refleja la intencionalidad por plasmar sus propias experiencias con un posicionamiento directo, sin embargo, oscila inmediatamente en su representación textual al retomar inmediatamente un posicionamiento distanciado, en el que se representa inclusivamente al considerar "esas cituaciones en que senos dificulta ${ }^{\text {de }}$ realizar un texto" y "que no le damos coherencia a la redacción, o no sabemos como escribir la idea". Este tipo de oscilación en el posicionamiento de enunciación responde a un tipo de reflexividad relacionado con la actitud sobre el reconocimiento de aspectos del desempeño propio y aquí cabe la posibilidad de que la alumna tome distanciamiento de manera consciente o inconsciente.

$\mathrm{Al}$ asumir el papel de juez vuelve a oscilar en el posicionamiento de enunciación, mostrando así una reflexividad temática relacionada con la manera en que se representa ante el texto al abordar determinados aspectos sobre el desempeño, ya que se dirige de manera directa hacia su compañero con comentarios generales, al recomendarle que trate de no cometer muchos errores, y que no se distraiga en el momento de estar escribiendo. Aquí toma un posicionamiento inclusivo para motivarlo al plantearle, sobre las sugerencias para mejorar, que "todos tenemos la capacidad de hacerlo".

En cada caso de representación textual la intencionalidad y la reflexividad quedan plasmadas en evidencias textuales relacionadas con la actitud. Además, el hecho de que en su rol de juez sólo mencione generalidades, sin contemplar sugerencias y comentarios sobre el desempeño del compañero, nos deja ver una transición de una reflexividad autocrítica sobre el desempeño a una reflexividad alejada de la práctica de escritura y desempeño, al centrarse en generalidades como juez. Así podemos ver que la reflexividad transita por diversas facetas conforme al rol asumido, a la temática y a la actitud reflexiva, por ejemplo, en la manera de representación textual del autor.

6m(02) En cierto Aspecto me pare_ce muy interesante, las reflexiones, en lo personal 
mes muy cierto lo que dice en el texto, ya que en momentos se nos dificulta realizar un texto, o no nos fijamos en la redación que palabras lleva acento, en donde va la coma o cuando es un punto y seguido. En todos los puntos que el estudiante realizo me parece que son los mas importantes que se deben tomar en cuenta para poder realizar una buena redacción, y comnocer los significados de cada palabra y los sinónimos para no repetir lo mismo en una escritura; al no utilizar estos puntos mencionados o las sugerencias que el alumno en listó, el texto no se entenderia al momento de leer.

Cinceramente, en mi opinion personal, e pasado por esas cituaciones en que senos dificulta ${ }^{\text {de }}$ realizar un texto, o la falta de compresión en la lectura o que no le damos coherencia a la redacción, o no sabemos como escribir la idea, o ampliar el texto. (triom06)

Ahora como juez

Querido compañero le hago estas anotaciones para que puedas mejorar la escritura; lo que debes tomar en cuenta es que pongas mucha concentración para una buena redacción, todos tenemos la capacidad de hacerlo, la cuestión es tener paciencia y tratar de desarrollar las ideas en una buena redacción, trata de no cometer muchos errores, no te distraigas en el momento de estar escribiendo; mis buenos deceso para ti; espero tengas en cuenta mi opinión.

Otra muestra de estas transiciones en el tipo y temática de reflexividad se aprecia cuando, ante los comentarios recibidos, el autor cambia su actitud al reconocer aspectos de su desempeño, pero ahora, en contraste con lo anterior, decide representarse de manera directa en $1^{\mathrm{a}}$ persona del singular, tal como vemos a continuación.

Reacción ante los comentarios recibidos.

Lo que pienso de lo que me escribió mi compañero.

Es cierto que lo que dijo mi compañera, ahora me doy cuenta que la verdad tengo una dificultad para escribir textos devido a aveces no comprendo lo que un texto me quiere decir.

Considero que aquí la intencionalidad experimentada y vivida en la interacción le permite tomar confianza y atreverse a reconocer sus dificultades de manera directa, por ejemplo, al plantear "que la verdad tengo una dificultad para escribir textos devido aveces no comprendo lo que un texto me quiere decir". Entonces, este ejemplo muestra evidencia de una transición de distintos tipos de reflexividad como autor y como juez en lo relativo al tipo de comentarios, pero refleja una variedad reflexiva en los dos roles, en lo relativo a las oscilaciones para representarse ante el texto al tratar determinada temática. Así el estudio de la reflexividad incluye distintas facetas y no solamente la naturaleza del comentario y el tema en cuestión. Este ejemplo nos permite ver las oscilaciones en las evidencias textuales, 
ya que la reflexividad puede cambiar continuamente en distintas facetas y modalidades en forma recursiva y cíclica.

\subsubsection{Reflexividad compuesta a parcial sobre la actividad desarrollada}

$\mathrm{Al}$ abordar las temáticas de las prácticas y usos académicos sobre recursos textuales constitutivos, de propiedad e informatividad, principalmente en el manejo del léxico y de la construcción de significados, en el siguiente ejemplo la alumna asume una postura autocrítica de manera directa, al reconocer dificultades concretas al compartir que siente que lo que dice no le encuentra sentido y suele repetir palabras. Además, contempla la construcción de recursos o estrategias alternativas o compensatorias para buscar soluciones, así muestra reflexividad sobre la regulación y valoración del desempeño, principalmente, en la revisión de su propio texto para corregir errores. Este tipo de reflexividad se centra en la regulación, en la revisión y la edición textual para corregir errores y "entregar el mejor trabajo", por lo que además, en la regulación contempla los estándares de aceptabilidad, efectividad, informatividad y propiedad en la búsqueda de construir estrategias para mejorar.

$4 \mathrm{~m}(3 \mathrm{~m})$ : Al momento de redactar un texto, muchas veces cuando se trata de un trabajo original, osea, creada por nosotros mismos, en lo personal se me dificulta buscarle coherencia a una frase e incluso a veces siento que lo que digo no le encuentro sentido y ocasionalmente suelo repetir palabras.

Cuando esto pasa, no me preocupa porque antes de entregar un trabajo releo para corregir estos errores y tratar de entregar el mejor trabajo que pueda hacer, claro que como toda persona puedo equivocarme pero con mis errores aprendo.

En cuanto a las observaciones y sugerencias que hace el alumno a su compañero, son muy buenas, ahunque también depende mucho el tipo de texto que se esté escribiendo. por ejemplo cuando hablaba de los acentos ya que con un acento que falte puede cambiar el significado total de una palabra.

Por eso es preciso leer y releer un trabajo o un texto para tener claro lo que uno quiera decir. (triom04)

Cuando comenta el texto de los alumnos oaxaqueños manifiesta reflexividad sobre las prácticas y usos al referirse al género o tipo de texto, sin embargo, no desarrolla esta idea, pero intenta hacerlo. Contempla la temática del manejo de acentos que cambian significados, y para cerrar, a manera de conclusión vuelve a retomar la idea de la revisión 
textual, que antes comentó, pero ahora con énfasis en comprenderse a uno mismo al "leer y releer un trabajo o un texto para tener claro lo que uno quiera decir”.

La alumna refleja intencionalidad al expresar ideas para apoyar su postura, por momentos no lo logra del todo, pero en una muestra de la intencionalidad vuelve a retomar y a enriquecer su propuesta de revisión, para comprenderse y corregirse en el plano de construcción de estrategias regulativas. Este es uno de los ejemplos de reflexividad introspectiva, pues incluye la autorregulación para construir estrategias y aborda el tema de la revisión textual en la entrega de trabajos, es decir, en las prácticas cotidianas más complejas de la universidad.

Posteriormente, al hacer observaciones sobre la escritura de su compañera, contempla la temática de la construcción de la identidad sobre lo que les representa y significa a los alumnos recibir comentarios y se previene sobre la posible reacción de su compañera. Reconoce aspectos favorables como la caligrafía y hace observaciones puntuales sobre el texto en el plano de estándares constitutivos formales de gramática y puntuación. Además, cuestiona la informatividad al nivel de la coherencia para poder comprender el texto. De esta forma la reflexividad es multifacética por diversos señalamientos tan puntuales, mismos que matiza al principio y al final, reiterándole a la compañera que desea que no se sienta ofendida, es decir, contempla las temáticas de actitud, identidad y el impacto de lo que representa a los alumnos recibir observaciones en ambiente académico.

\section{Ahora como juez}

Hola compañera, esperando que por los comentarios que te haré llegar a través de esta carta no te haga sentir mal ni ofendida sino todo lo contrario, espero que te haga reflexionar y se que algún día no muy lejano me lo agradecerás je je je. Para empezar debo reconocer que tienes bonitas letras, legible y que es entendible sobre todo, pero como a cualquiera también tienes algunos detalles tales como: mezclar palabras en singular con plural, a veces cambias de género cuando en realidad no va con eso, te falta poner algunos signos de puntuación tales como la coma y el acénto, unas que otras le falta coherencia a lo que quieres decir, pero bueno a cualquiera le puede pasar.

Me despido de ti, esperándo que mis comentarios no te ofendan, todo lo contrario, hago esto para ayudarte a detectar tus errores y así mismo ayudarte a que en un futuro seas una persona de bien.

tu amiga Ara

Por otra parte, esta misma alumna (Ara) discrepa ante los comentarios que recibió 
sobre su propio texto, principalmente porque la observación que recibe es contraria a lo que planteó en su propio texto, es decir, que ella revisa y relee sus textos, tal como apreciamos anteriormente en el ejemplo. Además recibe un cuestionamiento sobre la propiedad del uso del léxico en la sugerencia de que escriba con palabras conocidas, que las considere en determinado entorno para la comunicación y que evite la repetición. A continuación presento el comentario que recibió esta alumna (Ara) sobre su texto.

[...] Tu texto me parecio muy bueno pero procura escribir con palabras conocida: Y no lo que tu hablas con tus amigas, pude ver que repites varias palabras en tu texto, la mejor forma es que revises tus palabras si están escritas correctamente para que otras personas fuera de tu entorno puedan leer y entender lo que tu escribas.

Bueno sin mas por el momento espero que no hacerte sentir mal y espero tu mejoramiento.

Por ello reacciona a manera de defensa que ella no emplea palabras desconocidas, sin embargo decide no desarrollar el punto, y, simplemente, expresa sobre el comentario que es aceptable, reconoce la repetición de palabras, agradece los comentarios, como vemos a continuación.

Lo que pienso acerca del comentario de mi compañera

*En el primer punto, pienso que no son palabras desconocidas, pues a cualquiera lo puede escribir, pero bueno es aceptable.

* Gracias por esta segunda observación, hay ocasiones que no me doy cuenta al repetir las palabras y reconozco que esto es uno de mis detalles.

*Procuraré revisar los detalles que me sugiere la compañera.

Considero que en esta reacción existe evidencia de reflexividad sobre la autovaloración relacionada con el desempeño propio, que sin embargo no está manifestada en el texto. Simplemente me parece que la alumna decidió no expresar esta situación y, de manera tal vez contradictoria o diplomática, considera sobre el comentario que "bueno es aceptable.” No aborda la sugerencia de que revise su texto. La única evidencia expresada refleja su desacuerdo, de lo demás sólo podemos interpretar su posible molestia por la falta de evidencia textual, simplemente comentaré la evidencia escrita y nada más. Recordemos que la reflexividad y la intencionalidad son construcciones personales, y que un individuo en condiciones favorables puede llegar a manifestarlas, tal vez la alumna tenía otras consideraciones, sin embargo no tenemos acceso a estos puntos de reflexividad porque no 
quedaron plasmados en el texto.

\subsubsection{Reflexividad compuesta a reflexividad compuesta sobre la actividad desarrollada}

El siguiente ejemplo es tan solo una muestra de los distintos tipos y variedades de textos correspondientes a reflexividad compuesta en los roles de autor y de juez. En este caso contemplé simplemente un ejemplo que muestra variedad en el manejo temático, distintos estándares de textualidad y oscilaciones en el posicionamiento de enunciación, para ejemplificar la variedad en distintos tipos de reflexividad.

El autor hace observaciones que evidencian reflexividad compuesta, mediante referencias explicitas con ejemplos concretos sobre estándares constitutivos formales de textualización, la coherencia y el funcionamiento de la lengua en la distinción oral y escrita. Comparte de manera directa con posicionamiento en $1^{\mathrm{a}}$ persona del singular (yo) algunas de sus experiencias y estrategias de regulación para mejorar su desempeño, considera los usos y la prácticas en el contexto escolar. Menciona cuestiones sobre la propiedad y aceptabilidad al considerar información sobre el género textual de "tipo memorándum". Hace una crítica sobre el desempeño del autor oaxaqueño al no responder a la tarea académica solicitada, lo cual refleja reflexividad sobre las prácticas y el género textual en ambiente académico. Lo anterior corresponde a una reflexividad compuesta con elementos variados que incluyen lo temático y el posicionamiento de enunciación directo sobre experiencias personales. A continuación presento los comentarios que hace sobre el texto de los alumnos oaxaqueños y sus propias experiencias académicas.

De acuerdo a la lectura sobre el texto escrito por el alumno, pude observar que repite patrones como "también", "y" $\theta$ u "o", le falta generalizar sus acentos, no tiene congruencia en lo que trata de explicar con lo que escribió y escribe tal como habla.

Mis experiencias para mejorar mi escritura es que con base a la lectura he logrado mejorar las reglas de redacción o escritura; en lo que se me dificulta al momento de realizar una lectura, es la comprensión de las ideas principales y cuando trato de redactar un texto de tipo memorándum, me cuesta trabajo para poder comenzar a redactarlo de tal manera que siempre comienze con un tipo de saludo.

Nota.- El alumno que escribió el texto, hizo caso omiso de las observaciones hechas por parte de su compañero, lo que practicamente hizo, fue cambiar el texto por un sentimiento que precenció al momento de las observaciones. 30h(21m) 
Ahora al asumir el rol de juez, hace observaciones y sugerencias puntuales sobre los aspectos débiles de su compañera en la coherencia y cuestiones formales, sin embargo no hace sugerencias concretas sobre el texto y destaca la manera directa de dirigirse a su compañera. En sus sugerencias contempla una temática sobre estrategias para mejorar y ampliar el léxico, en la que incluye la lectura y el análisis de las palabras, y propone más estrategias para ampliar su léxico. Aborda la temática de propuesta de estrategias. Revisemos el texto.

Estimada compañera María, de acuerdo a tu escritura pude constatar que no tienes buena congruencia en tu redacción, te hace falta conocer aún más las reglas de acentuación.

Yo te sugiero que hagas de tu vida cotidiana la lectura, puedes leer artículos de tu interés para que no te sea aburrida y así te tome importancia el conocer palabras nuevas.

Tómate tu tiempo para analizar las palabras que escribirás, ya que esto conlleva a que tu texto lleve cierta congruencia.

Crea tu propio glosario de palabras que desconoscas, para que con base a estas fortalezcas tus conocimientos a la hora de redactar un texto. Nuevamente te recuerdo que la lectura es la mejor opción para que tus conocimientos en la lectura y redacción sean más complejos, aparte de que por supuesto de acuerdo a lo que leas te genera facilidad para crear ideas en tu vida diaria.

Podemos apreciar que este mismo alumno presenta una transición de una reflexividad compuesta a una reflexividad parcial para justificarse cuando reacciona ante los siguientes comentarios recibidos.

-Querido compañero Daniel, te recomiendo en primer lugar que escribas con letras legibles ya que aveces no se entiende lo que escribes en segundo lugar ponle acento a las palabras porque se puede mal interpretar tu texto y en tercer y ultimo lugar tu ortografia utiliza bien la s y c y distingue en qué palabra se debe y en que no se debe utilizar.

Pues felicitarte porque tienes una buena idea sobre los textos y....

Ante las observaciones se justifica y plantea que no tiene dificultades. De esta forma pone de manifiesto la construcción de identidad y lo que le representa y significa recibir sugerencias. Por otra parte, considero que curiosamente el alumno no presenta problemáticas de acentuación, ya que solamente deja de acentuar cuando escribe la palabra practicamente, pero recibe la observación de ponerle acento a las palabras. Ante esta 
observación, el alumno se justifica, tal como si hubiera cometido muchas fallas. Así exhibe inseguridad en una reflexividad sobre la valoración de su propio desempeño en la temática de regulación del manejo de recursos de escritura y sobre la construcción de identidad. Sobre los demás puntos se justifica innecesariamente porque sí presenta las problemáticas señaladas y pretende dejar en claro que realmente no tiene problemas. Así vemos las evidencias de reflexividad al participar en una interacción para recibir sugerencias.

Lo que pienso de lo que me comentó el juez

Los acentos faltantes que menciona mi compañero, me hicieron falta por motivos de rapidez al momento de escribir, pero en mi persona conozco cuando una pala va con acento ortográfico o no.

Y mi letra que tal parece no es legible, es por costumbre en escribir rápido y depende también mucho de la tinta.

En otro ejemplo de reflexividad compuesta como autor y como juez, el alumno comenta el texto de los alumnos de Oaxaca con un énfasis sobre el contexto académico de las problemáticas que vive en la universidad, representándose de manera inclusiva, al decir que es una dificultad de "la mayor parte de nosotros". Después asume un posicionamiento impersonal genérico al considerar lo que sucede cuando "se lee un texto". Esta es una manera distanciada de representarse en el texto para abordar las prácticas y el contexto de la interacción en ambiente académico, sin embargo, inmediatamente se representa de manera directa para reconocer sus dificultades al escribir textos, incluyendo la corrección textual.

Sobre la temática de sus prácticas y dificultades para organizar su texto, expresa su creencia de que esto se debe al impacto del uso de su lengua materna en la cotidianeidad, por encima del español. Manifiesta reflexividad temática contextual, las prácticas y la gramática de la lengua indígena en contraposición con el español. Mantiene su posicionamiento directo hasta el final cuando agradece el apoyo de sus maestros en la universidad.

15h(13h) Los comentarios que nos hacen llegar a conocer los alumnos de la universidad de Oaxaca, son muy importantes para los estudiantes de diferentes niveles academicos; ya que la mayor parte de nosotros nos llega a dificultar mucho de la escritura, sobre todo de las ortografia, caligrafia entre todo loque lleva al elavorar un texto.

Cuando se lee un texto, como alumno al estar frente al grupo de compañeros y 
profesores, nos ponen nerviosos ya que siempre tenemos en la mentalidad de echarlo todo a perder, por los nervios.

De manera personal durante los años como estudiante siempre he tenido la dificultad de escribir textos, ya que la mayor parte me falta en corregir la ortografía y repito muchas palabras conocidas como la moletias, y la caligrafía. También cuando estoy escribiendo de algun tema tratado se me olvidan las cosas en que poner en mi texto en otras de las razones, creo que por ser bilingüe ya que en mi pueblo como jóvenes siempre nos comunicamos más en la lengua materna, más no nos expresamos mucho en la segunda (Español) por eso que al redactar un texto, no se nos viene ídeas para anexar en los textos que se escriben.

Ya estando en la universidad agradezco a los maestros de lenguas que nos han apoyado mucho en la escritura y he tenido un avance con mi escritura.

Como juez, la reflexividad compuesta está presente en la distinción clara y precisa al plantear sugerencias y comentarios relacionados con estándares constitutivos formales y al hacer referencia a elementos del texto, aunque no presenta ejemplos de la escritura, tal como vemos a continuación.

En tu forma de escribir, tienes mucho para mejorar, no se te olvide poner acentos en las palabras que las necesitan, tampoco hay que cortar palabras o dejar en medías lo que estas escribiendo. Mejorar tu caligrafía y ortografía al escribir.

-Te sugiero, que al escribir concluyas las fraces para poder comenzar en otras frases de tu texto.

-Trata de no repetir muchas palabras al escribir.

-Usa punto y coma siempre cuando donde termina las palabras del texto.

-poner en orden tus ideas al escribir

Sobre la reacción ante los comentarios recibidos apreciamos un reconocimiento directo de dificultades, sin embargo deja ver que no tiene fallas en todo.

Lo que pienso de lo que escribió mi compañero, en e lo que califico del texto, es deque tiene la razón en corregir mi escritura ya que la mayor parte de lo que me califico es lo que falta en mejorar pero hay algunas cosas que no muy me fallan al escribirlo por ejemplo al mencionar mi compañero que marco mucho mi letra simplemente solo es un error al escribir. Pero le agradezco sobre su buena voluntad al enlistarmelo en el texto.

A lo largo de este capítulo he presentado el criterio de clasificación correspondiente a las evidencias reflexividad de cada alumno en sus roles de autor, juez y en su reacción ante los comentarios recibidos. Esta propuesta de metodología de clasificación textual me ha servido para destacar que además de los tipos de reflexividad relacionados con la clase de comentarios, existen otros casos de reflexividad relacionados con las posibilidades 
temáticas abordadas por los alumnos y con el tipo de posicionamiento de enunciación. Además, he podido contemplar los distintos tipos de transición de reflexividad al cambiar de roles y en las reacciones ante los comentarios recibidos. Además de hacer una caracterización integral de los criterios y categorías del tipo y temática de reflexividad en ejemplos representativos, es necesario tener una mirada de la conformación de la unidad textual con el propósito de contemplar el conjunto de relaciones inter e intratextuales y, de esta manera, considerar las herramientas teóricas y metodológicas correspondientes al enfoque de la textualidad en la caracterización de textos y folios completos obtenidos en las fases de elicitación desarrolladas en esta investigación.

\subsection{Visión integral en la unidad textual}

Una vez que he presentado los diversos criterios teóricos y metodológicos contemplados para la clasificación textual, considero que es necesario caracterizar de manera global algunos recursos de textualización que he presentado en este trabajo. Es necesario hacer la revisión de textos completos de los folios, para observar de manera integral la unidad textual en la redacción de los autores, los comentarios de los jueces y las reacciones de los autores. Anteriormente, presenté fragmentos representativos de reflexividad en los textos, además del seguimiento de la reflexividad de cada alumno, primero como autor y luego como juez.

Es necesario contemplar textos en su escritura original de la primera y segunda versiones y con los comentarios de los jueces. A continuación presento ejemplos que involucran distintos tipos de intencionalidad y reflexividad en los textos obtenidos en la fase de elicitación 4 UNICH. Aquí sólo presento de manera general, la información de los textos correspondientes al folio en cuestión y para una visión global podemos ver los ejemplos íntegros que aparecen digitalizados.

\section{Texto triom05}

La autora manifiesta una reflexividad crítica compuesta al hacer comentarios y compartir sus experiencias con cierto distanciamiento, principalmente, en 1a persona del plural e impersonal, por ejemplo, al decir que "como estudiantes a veces no tomamos en 
cuenta los puntos de acentuación" y que "cuando uno lee un artículo en la cual realiza un sintesis o resumen y no llega a una buena redacción por desconocimiento de significado de palabras". En su reflexión contempla aspectos constitutivos formales de herramientas de textualización, cuestiones contextuales sobre la escritura de los estudiantes y la selección léxica en ambiente académico, al cuestionar, por ejemplo, cuando el joven de Oaxaca escribe "x que para el significa por".

La alumna en su papel de juez comenta y sugiere sobre aspectos formales de escritura, se previene sobre la posible reacción de su compañera y que tome a mal sus comentarios. Considera sobre la selección léxica en un texto académico que su compañera no escriba como lo hace en el celular, al decirle que no escriba " $X$ " y eso no se ocupa en este tipo de redacciones", a pesar de que su compañera sólo estaba ejemplificando el uso inapropiado de este tipo de escritura. Ante esta situación, la autora acepta los comentarios sobre recursos formales, pero hace la aclaración sobre la confusión de la juez al plantear que "yo no escribo como mensajes de celular, yo creo que se confundio". Finalmente en la última versión la autora copia y parafrasea la mayor parte de su texto, y evita escribir la abreviación mencionada. 


\begin{abstract}
Nombre del alumno: Lola Areiy Gomez Santiz
Licenciatura Lengua y cultala semestre $5^{\circ}$ Lugar de origen oxchuc, chi apas Lenguas que hablas además del español Iseltal

Nombre del juez que revisa el texto Loordes Magalif perez Mondez

Instrucciones

Te invitamos a que comentes las réflexiones del estudiante en el texto que acabas de leer, sobre lo que sucede cuando escribe en la universidad y, asi como él lo hace, tú también reflexiona por escrito sobre tus propias experiencias de escritura en ambientes escolares, tus habilidades, los aspectos que se te facilitan y dificultan, la manera en que vives la experiencia de redacción y lo que significa para ti, especialmente cuando tienes que tomar decisiones para intentar expresarte con claridad y proponer soluciones para redactar mejores textos escolares. Comparte tu experiencia y escribe un texto que, principalmente, te ayude a tu propia reflexión para mejorar tu escritura, y además, inspire a otros a este tipo de reflexiones.
\end{abstract}

En esta reflexion dan buenas sugerencias, pero como estudiantes aveces ho tomamosen coenta.los Pontos de acentuacion yporllo nos lleva a tener mala redacion o simplemente no llega a tener coherencia.

Para no cometer errores es necesario inuestigar o leer mas articulos que nos facilite escribir sobre on tema determinado.

Repetimas patabias o fraces mas segoidos en ind redaccion por lo $m i s m o$ goe aveces no conocemos sinomimos de palabras.

Cuando uno lee on articulo en la cud realiza Un sintesis o resomeny no llega a una buena redaccion Por desconecimlento de significado de palabras. Es necesario traer siempre con uno mismo un dicclorario sinedio que facilite la redaccion de cualquier tetto.

En a texto leido en la cual el citudiante se compromete a mejoral, utiliza abreviatoras 0 Simplemente omite excribil toda la palabra como X que para el significa por.. A veces como jovenes tomamos una forma de excribir fuera de lo establerido para comonicarnas o para escribil textas por celdar. pero eso no debe de saliv para excribir textos para la escuela, creo que todo tiene so momento de

Lewado para otilizarlas, y saber conquicn dirigirlt. 


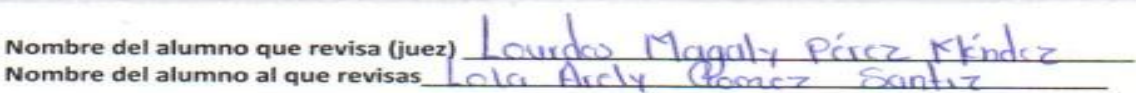

Has recibido el escrito de uno de tus compañeros. Revisalo con atención y cuidado y redacta un texto a tu compañero en el que le hagas observaciones y comentarios sobre su manera de escribir $\mathrm{y}$ los aspectos que debe tomar en cuenta para modificar y mejorar su escrito en una segunda versión.

Compañara Ardy Gomez Santiz; eopero que tomes a mal lo que opino de to escritura pero la verdad yo pienso que debou de excribir mucho mejor que tos letras sean entendibles: no como lo haces to que pareciera que escribes a la carrera que no os entienden muy bien lo que anotas.

Y otra de las cosas es que no escribas como un mesaje de celular ya que esto es algo enserioprino estas menogjeandote con two amigos si no que estas plasmando lo que piensa.

checa bien lo que has escrito y veras que estas excribiendo como un crlutar por lo que anotarte " $x$ " $y$ eso no se ocupa en este tipo de redacciones.

Nombre del juez: Lourdes Magaly perez Mendez

Nombre del alumno: Lola Arely Gomez Saintiz

- Letras legibles

- La ortografia, acentuación de las palabras.

- No escribir Como en los

Celurares

Lo gue pienso de lo que me comento mi compañero es que si tiene razon la que a veces excribo a las carreras no es por ello que no logro a tener una letra legible tambien seme pasa poner las acentoaciones, Pero yo no escribo como mensajes de celotar yo creo que se confundio yo decia por el texto de oaxaca la de un estodiante pero borna-yo creo que Por medio de estas palabras espero mejorar mis redacciones 4 escritora

\section{Texto trisch 37}

El autor manifiesta reflexividad parcial sobre la actividad desarrollada al compartir experiencias personales en ambiente académico con un posicionamiento directo. Sólo 
menciona la sinceridad del alumno de Oaxaca e inmediatamente comparte sus dificultades ortográficas. Considera aspectos contextuales sobre la dificultad de provenir de "lugares marginados" y el impacto en su desempeño, sobre el uso de la lengua en la universidad y sobre la normalización de la ortografía, como factores que le producen dificultades al entregar trabajos. Sobre la construcción de identidad y lo que le representa y significa escribir, destaca su negación a que otros revisen su escritura por el miedo a las burlas sobre su desempeño. No presenta ejemplos concretos, solo hace referencia a las dificultades. Finalmente retoma su valoración sobre la sinceridad al reconocer cuestiones sobre su desempeño. La alumna como juez sólo apunta el aspecto de la legibilidad, y la necesidad de que permita que otros compañeros revisen su texto. No hace referencia a recursos de textualización. El juez acepta y agrega que le falta escribir más y su dificultad con las mayúsculas.

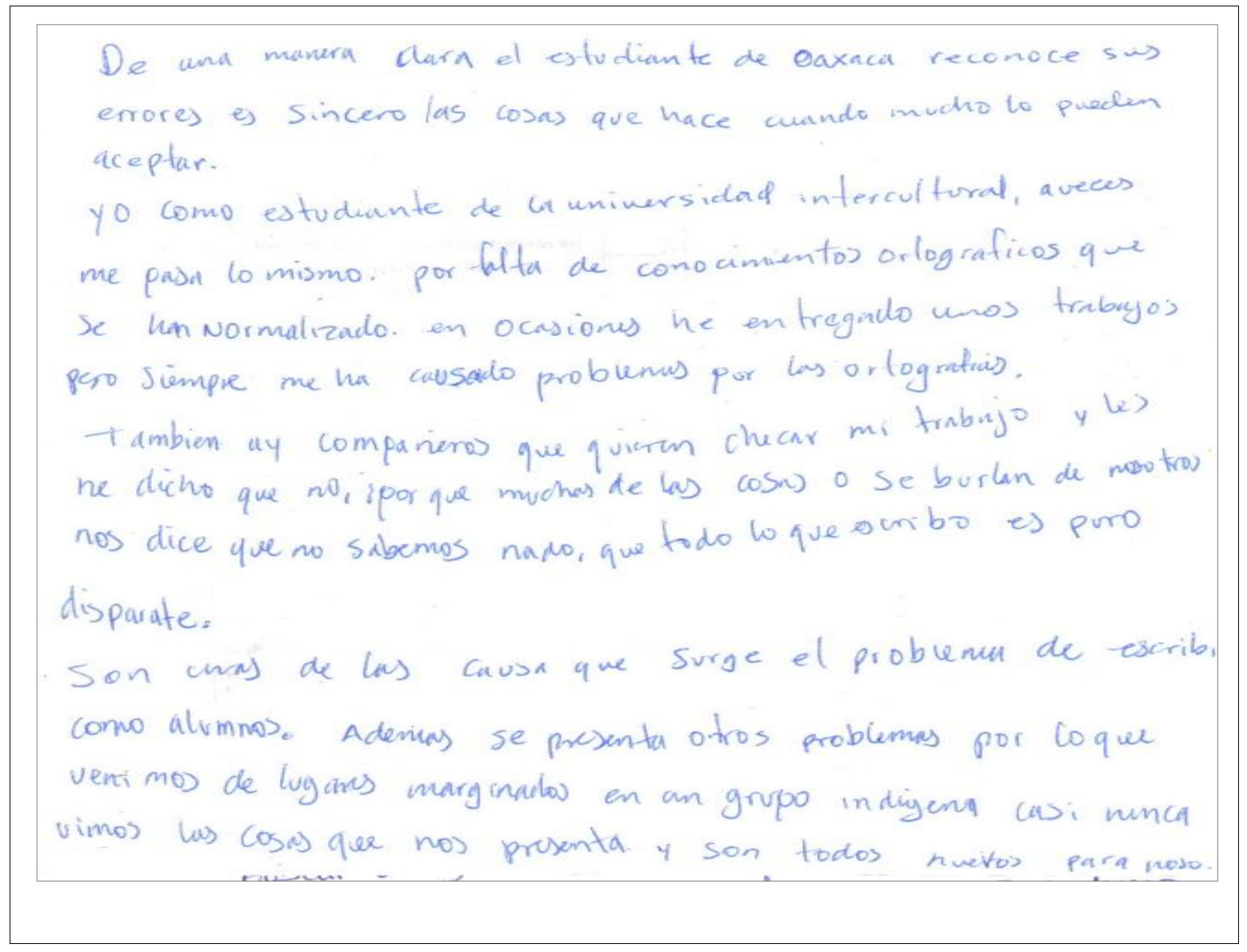


tros.

pro en este pequiño leotura me doy cuenta que es por el biend noboto mimes; oparamos que sea lay asos que actura con 4 verdal solo as podumos avansur por que ta sinceridnd es bida. My un devindto en mustro oxaitura.

Juez

Amigo estudiante las observaciones que hice en tu texto fue que en algunas de las escriturers que haces no se logra a leer.

In una part de texto mencionas que no quieres que otros cameañeros chequen o revisen tu trabajo que forque te da peno que se builen deti. La seguerencia, es mejor que alguin te diga los merrokes que tengas a qu lo tengas eara toda la vida.

182 
Juez: Harlene HeNdez SaniHez.

ALUMNO: HANUEL GOMEZ SANTIZ

observaciones: Algunas palabras no se euede leer. uso de mayusculas en medio de minusculas

lo que pienso lo que comento mi companem.

S. estoy de acuerdo porque aveces se me proa la mano de no escribir mas o ejcribir cor mayus culli en el medio.

en forlo ello agradesco tus consejos 10 pondro en pratica.

En las segundas versiones de los autores de los textos triom05 y trisch37, predominan la copia y el parafraseo de la primera versión. En el texto trisch37 el alumno cuida la caligrafía e incorpora párrafos como unidades temáticas. 


\section{trisch37}

De una manera clara el estudiante de oaxaca reconoce sus errores es sincero de las cosas que naze y lo hacep ta cuando muchos no los hacen.

yo como estudiante de La universidad Intercultoral en muchas de las veces me pasalo mismo.

por fatta de conocimientos de ortogratias que han normalizado.

En ocaaonesshe entregado trabayo y me ha carsado problemas por no escribir bien las palabras o es ta mal ejorito.

Tambien hay companeros que han querido checar mi trabajo y les he dicho queno, por ave muchouvery solo se burla de nosotros nos dice que es puro dípara. te o no sabemos nada en escribir.

son unos de mis problemas al escribir como alumno

como otro problema nos presenta que venimos de como nidades marginados y nos enfrentamos cosas nuevas nuncal visto, o no fueron aplicado en nuestro apren dizaje anterior

paro en este lectura me doy cuenta que es importa ser sincen Solo asi podemos avansar. 
triom05

En está reflexión dan buenas sugerencias, pero como estudlantes a veces no tomamos en cuenta los pontos de acentuación y por ello nos lleva a tener mala redacción 0 simplemente no lega a tener coherencia.

para no cometer errores es necesario investigaro leer mas àrticulos que nos facilite escribir sobre un tema determinado.

Repetimos palabras o fraces mas seguidos en una redaccion for 10 mismo gue aveces no conocemos sinonimos de palabras.

cuando uno lee un articulo en la cual realiza un Sintesis o resumin y no se alcanta una boena redacción For desconocer significado de palabras, para ello es necesario traer un diccionavio, para que al redactar nos facilite.

En el texto leido en la cual el estudiante se compro mete a mejorar, Jtiliza abreviatoras o simplemente omite escribir toda la palabra como a "por." A veces como Jovenes tomamos una forma de escribir fuera de 10 establecido para comoni carnos o para escribir texto for celular, pero eso no debe de salir para escribal textos asi para dirigirnor a la escuela, creo que todo trene su momento de Utilizar y saber a quien dirigirse.

185 


\section{Texto trisch25}

Este es un texto representativo de un autor que reestructura totalmente su texto; incorpora párrafos, cuida las selecciones léxicas y resuelve algunas dificultades de concordancia, ya que, por ejemplo, en la primera versión escribió que "El texto de nuestra compañera de Oaxaca ellos decían". Soluciona esta problemática mediante el uso del plural. Además, escribe "el punto y el coma", situación que intenta resolver mediante estrategias compensatorias con el uso del plural al escribir "los puntos y coma". A pesar de que no logra resolver la problemática, pone de manifiesto decisiones reflexivas sobre la concordancia y los artículos. Es un texto que ejemplifica la intencionalidad y la reflexividad sobre el desempeño en este tipo de toma de decisiones, puesto que trata de resolver de manera integral la gramática y el manejo de selecciones léxicas.

el texto de nucstra eotudiante do cexaca ellos decian que mejoremos nuestro forma de texto, pero ellos dice algunos estudiantes otilizan muchos o rekiten las mismas Nalabras el punto y el Coma.

En mi Opinión para proponer la falla de texto, utilizó do puntor a el cona.

es pedir anoyo a un pipfesor o entre otras Persona que tenga experciencia

bueno el textos do nuestros ostudiantes ostaban mal catructurado.

y nise entiende. 
Juez

Compañero, to escritura vo air mejorando, en el transcorso de to practica. A la ora de escribir no lo hagas tal como hablas para que la persona queen lea tu escrito pueda entender lo qua to quieres dar a entender. Tambien deberas evitar los manchones para dar formalidad a tos escritos.

Te oclaro componiero, que al darte estas sogerencias, pienso al mismo tiempo que me lo estor haciendo a mí mismo, por que yo tengo los mismos evrores que tambien tienes.

Lo que pienso del juez, creo que si tiene la razón ine falto algunos texto de redactarle Gasi no útilize punto y el coma. y no deje crparios y sanqrias.

187 
Versión final

El texto de los estudiantes de coxaca ellos e nos dán de conocer y respetar los puntos y coma y mejorar nucotro forma do escritura.

Tambien los estudiantes dan una Opinion a verca de las palabras que $x e$ repiten, ellos trataban de mejorar y no repotir las cosas.

El texto de compañeros de odraca estaban un poco desordenado y no tiene sentido, todo lo contrario ellos repitieron los puntos, y no estai bien estructurado

Wues yo tambien pucdo llegar a tenor ese problema, como ne dijo ol juez que tengo problemas de oitegratia.

Al final el autor se desvía de la edición del texto y reflexiona sobre su desempeño, al reconocer que puede tener los mismos problemas de ortografía que los alumnos de

188 
Oaxaca.

El juez no hizo ninguna sugerencia relacionada con los cambios que realizó el autor, sólo se limitó a decirle que evite escribir tal cual habla y que evite manchones, reconoce que él también tiene esos errores. El autor acepta los comentarios y agrega sus dificultades de puntuación y sangrías. Esto refleja que en las decisiones de textualización el alumno manifestó reflexividad, puesto que autorreguló su desempeño para organizar su texto y logró resolver algunas problemáticas.

\section{Conclusiones y reflexiones finales}

El aporte fundamental de esta investigación es proponer un acercamiento conceptual y metodológico sobre la escritura de alumnos de nivel superior en las prácticas de revisión y edición de sus escritos desde un enfoque de la textualidad. De esta manera destaco evidencias de intencionalidad y reflexividad a partir del trabajo de elicitación, clasificación textual y la conformación de criterios para un primer acercamiento a la interpretación de los textos. Elaborar una propuesta conceptual y teórica para concebir la textualidad, la intencionalidad y la reflexividad es un paso imprescindible para plantear un enfoque para la investigación. Asimismo en la investigación fue fundamental el establecimiento de relaciones entre el enfoque conceptual sobre la textualidad en el marco de las escrituras académicas y la propuesta metodológica de elicitación y de creación de criterios y categorías para la clasificación de los textos. Por ello, crear relaciones o ligas entre las consideraciones teóricas y metodológicas es el sustento para la propuesta de enfoque sobre las escrituras académicas al destacar algunas evidencias de intencionalidad y reflexividad en los textos.

En el caso de las consideraciones teóricas y conceptuales podemos destacar la manera en que éstas están contempladas en el enfoque de la propuesta metodológica de elicitación y clasificación textual. Por ejemplo, sobre la reformulación del concepto de textualización propuesto en la investigación, mismo que incluye diversos aspectos formales, de estructuración, así como cuestiones contextuales, usos y prácticas, considero 
en el diseño de la guía de apoyo secciones dedicadas a motivar que los alumnos manifiesten comentarios y reflexiones sobre este tipo de aspectos. Además, en las modificaciones del diseño de elicitación traté de incluir prácticas textuales académicas relacionadas con algunos de los estándares de textualidad de Beugrande y Dressler (1997) que los alumnos manifiestan en sus escritos, principalmente, aspectos constitutivos formales de cohesión y coherencia, la informatividad, la pertinencia y la propiedad.

Sobre la propuesta conceptual de la intencionalidad y la reflexividad, tomo en consideración, por ejemplo, el establecimiento de ligas con la metodología de clasificación textual al hacer una propuesta para caracterizar el tipo de comentarios de los autores y los jueces que me ayuda a crear categorías para clasificar distintas facetas y modalidades de evidencias de reflexividad en los textos. Contemplo el vínculo entre lo conceptual y lo metodológico al clasificar los textos conforme el tipo de comentarios sobre el desempeño propio y el de otros, así como de diversos elementos que considero característicos de la reflexividad, como la manera en que el autor se posiciona ante el texto y se refiere a elementos de textualización a partir de los escritos revisados.

La clasificación que propongo me permite destacar los textos en que existen comentarios relacionados con los estándares de textualidad de Beugrande y Dressler (1997), así como manifestaciones de evaluación, regulación, intencionalidad y tipos de reflexividad sobre el desempeño en las prácticas de revisión y edición. La consideración de la naturaleza del tipo de comentarios me permite apreciar evidencias textuales que me ayudan a identificar, por ejemplo, la reflexividad basada en creencias sobre el desempeño escrito, la no manifiesta pero presente de manera implícita en las decisiones de textualización. En algunos casos, podemos apreciar un tipo de comentarios con mayor número de elementos de reflexividad sobre el desempeño personal, o bien sobre las creencias relacionadas con el desempeño propio, fundamentalmente, en los textos obtenidos en la última fase de elicitación. Además, la propuesta metodológica de clasificación me permitió apreciar en los textos correspondientes a las primeras fases de elicitación, el predominio de la intencionalidad sobre la reflexividad, manifestada de manera implícita, principalmente, a partir del tipo de decisiones de textualización de los autores una vez que revisaron los comentarios de los jueces. Esta situación se debió en gran medida, a que en el 
diseño de dichas fases de elicitación aún no incorporaba los ajustes y las decisiones metodológicas que en la última fase favorecieron la manifestación de comentarios y temáticas con contendidos reflexivos sobre el desempeño de la escritura académica.

Podemos apreciar los aspectos conceptuales sobre las distintas facetas y modalidades de intencionalidad y reflexividad en las consideraciones metodológicas de clasificación que propongo en la investigación, principalmente, al caracterizar los comentarios en términos de reflexividad parcial y compuesta sobre la práctica textual académica desarrollada. Además incluyo los elementos conceptuales de textualidad que he planteado que son característicos de la reflexividad textual, por ejemplo, la representación textual del autor en el posicionamiento directo en $1^{\mathrm{a}}$ persona del singular (yo) o de manera inclusiva, así como los distanciamientos en la representación del autor o de los interlocutores al abordar determinadas temáticas sobre el desempeño escrito. Asimismo, destaco que la manifestación escrita de la intencionalidad puede corresponder a parcialidades o a ninguna parte de la intención mental y personal de cada individuo, por ejemplo, cuando el individuo intenta pero no logra plasmarla por escrito o bien lo hace de manera implícita o ambigua.

Esta manera de concebir la intencionalidad me sirve al proponer la clasificación metodológica de los tipos de comentarios de autores y jueces sobre el desempeño escrito cuando los alumnos valoran y evalúan los diversos tipos de intencionalidad presentes en los textos. En la metodología de elicitación diseñé actividades para que los alumnos se expresaran sobre la valoración y evaluación de la intencionalidad cuando en la práctica de escritura académica, en la última fase de elicitación, se retroalimentan y reaccionan por escrito sobre los comentarios recibidos por los jueces. De esta manera tomo en cuenta consideraciones conceptuales aplicadas en el diseño de elicitación para tratar de favorecer que los alumnos manifiesten evidencias de intencionalidad y reflexividad en las temáticas abordadas. Posteriormente, en el trabajo con los textos caracterizo el tipo de comentarios y evalúo los resultados obtenidos para tomar decisiones de modificación del diseño para la siguiente fase de elicitación y para crear categorías de clasificación textual. En general, en cada fase de elicitación podemos obtener evidencias textuales que nos permiten crear categorías para la clasificación textual como herramientas metodológicas que nos sirven 
para destacar los ejemplos en que apreciamos evidencias de intencionalidad y reflexividad. De hecho, en la última fase de elicitación aparece un mayor número de evidencias y elementos de reflexividad textual debido a que en el diseño apliqué las modificaciones y adaptaciones de la interacción y materiales con un centro de reflexión en escrituras académicas.

Sobre el impacto de la metodología desarrollada en la investigación, debemos contemplar que los resultados obtenidos corresponden, en gran medida, a la aplicación de las actividades de elicitación. Además, podemos destacar resultados que corresponden a evidencias que aparecen en los textos de todas las fases de elicitación, y por ello son muestras generales representativas de la escritura de alumnos de nivel superior en ambiente académico. En estos ejemplos representativos podemos encontrar la manifestación de estándares de coherencia, cohesión, informatividad, pertinencia y propiedad, así como los recursos de intencionalidad en la revisión, regulación, evaluación, representación textual del autor y los tipos de comentarios correspondientes a la propuesta de clasificación metodológica de reflexividad parcial y compuesta. De esta manera, además de las consideraciones teóricas y metodológicas la investigación aporta elementos de caracterización de algunos elementos representativos de la escritura académica de alumnos de nivel superior.

La metodología de clasificación empleada y el diseño de las fases de elicitación nos permitieron apreciar que en los textos de Ixtepec y Tehuantepec predominan la intencionalidad y un tipo de reflexividad implícita manifestada en el tipo de decisiones de textualización. En los textos de la UNICH, apreciamos, además de este tipo de textos, el predominio de otras modalidades y elementos de reflexividad sobre la escritura académica, principalmente, en la reflexividad compuesta. En la reflexividad crítica e introspectiva sobre las creencias propias o conocimientos predomina la toma de conciencia de diversas facetas de intencionalidad y de reflexividad, con referencias explícitas a elementos de textualidad, con representación directa de interlocutores para hacer referencia a los destinatarios de los textos, principalmente, en $2^{\mathrm{a}}$ persona singular (tú) al hacer comentarios al compañero. También predomina el posicionamiento de enunciación del autor de manera directa en $1^{a}$ persona del singular (yo) al reflexionar, principalmente, sobre su propio 
desempeño. Poder apreciar estos elementos es el resultado del trabajo conceptual y metodológico de elicitación y de creación de categorías de clasificación.

Al considerar las temáticas de reflexividad que abordan los estudiantes, he tomando en cuenta algunos criterios teóricos relacionados, por ejemplo, con los estándares de textualidad de Beugrande y Dressler (1997) y la conformación de identidad planteada por Ivanič (1998). Contemplé estos enfoques en el diseño de la guía en las fases de elicitación para que tuvieran un impacto como temáticas de reflexión en la práctica textual académica, desarrollada en el aula. Por ello, la guía y la práctica desarrollada influyen de manera determinante en el tipo de comentarios y temáticas de reflexividad. Estos criterios de clasificación conforme al tipo de comentarios centrados en el tema de escritura académica me llevaron a crear otras categorías que me permitieron identificar elementos de intencionalidad y de reflexividad. A partir de las evidencias encontradas en los textos, propuse la clasificación conforme a las siguientes temáticas de reflexividad: 1) estándares constitutivos formales, 2) contextual sobre escritura académica, 3) identidad, impacto y significado de escribir académicamente y 4) gramática y uso de la lengua de instrucción. Por lo anterior, en la investigación he considerado la creación de categorías de clasificación textual partir de algunos elementos conceptuales, de manera tal que podemos apreciar el establecimiento de ligas y relaciones entre lo conceptual y lo metodológico.

Al proponer que los estudiantes interactuaran y recibieran retroalimentación oral de los jueces y que plasmaran por escrito su reacción ante los comentarios recibidos, pude obtener evidencias de reflexividad escrita sobre el impacto de este tipo de actividades y de la manera en que los alumnos modifican su propia reflexividad como autor y como juez. La caracterización de cada alumno en su desempeño como autor y luego como juez es una propuesta metodológica que nos permite apreciar oscilaciones de intencionalidad y reflexividad conforme al rol asumido y la reacción ante los comentarios recibidos. Estas oscilaciones son evidencias de los aspectos teóricos que he presentado en este trabajo sobre la naturaleza multifacética, cíclica y recursiva de la reflexividad de cada individuo en distintos momentos. Estas manifestaciones de intencionalidad y reflexividad ponen de manifiesto la diversidad de conceptualizaciones sobre la valoración del desempeño personal y el de los compañeros, y los factores que el individuo, concibe, considera y puede llegar a 
manifestar como relevantes para la comunicación y para su desempeño académico.

En sí misma, en la propuesta conceptual aporta un enfoque sobre escrituras académicas a partir de una perspectiva de herramientas teóricas propias de la textualidad, tal como aparece en los trabajos de Adam (2005), Beugrande \& Dressler (1997), Hyland (2005) e Ivanič (1998). De esta manera realizo la caracterización de los escritos y los comentarios para destacar la reflexividad textual a partir de los estándares de textualidad, las reflexiones sobre las prácticas de textualización y la intencionalidad manifestada en los comentarios sobre la revisión y edición de los escritos. La creación de categorías de clasificación, análisis e interpretación de la intencionalidad y la reflexividad incorpora, además de los aspectos de la cognición, la evaluación, y la regulación, el conjunto de herramientas teóricas y metodológicas de la textualidad en el marco de la intratextualidad y la intertextualidad presente en la práctica de escritura académica y en la linguística textual

Además en la sección correspondiente a las temáticas abordadas por los estudiantes en tus textos, tomo en consideración el concepto de reflexividad como la construcción de significados y de identidad en la redacción académica y su relación con la reflexividad cultural y las dinámicas interculturales, principalmente, cuando los alumnos escriben sobre lo que les significa y representa la escritura en el ambiente académico, tal como apreciamos en los trabajos de Turner (2011) e Ivanič (1998).

En esta investigación aporto una propuesta sobre la conceptualización de la reflexividad sobre la textualización en la que destaco su manifestación consciente o inconsciente, implícita o explícita, generalmente, de parcialidades del pensamiento reflexivo. Considero que la reflexividad sobre la escritura es un proceso jerárquico, cíclico, multifacético y recursivo en distintos tipos de conceptualizaciones sobre la valoración de la escritura y del desempeño propio y el de otros. Contemplo los factores que el individuo, concibe, considera y puede llegar a manifestar como relevantes para la comunicación y para su desempeño académico. La reflexividad sobre las prácticas de escritura implica que los alumnos se expresen, en este caso por escrito, sobre la experiencia de textualización, los recursos empleados, las problemáticas enfrentadas, lo que les representa la escritura académica en términos del manejo de principios constitutivos y regulativos, así como lo que experimentan y les significa la revisión y edición de sus propios textos como parte de la 
construcción de identidad y de conocimiento. Este tipo de reflexividad incluye lo cognitivo, lo afectivo, la inseguridad, el prestigio, criterios sobre el desempeño lingüístico y las actitudes ante dificultades enfrentadas en la redacción.

Por otra parte, el diseño metodológico en las prácticas desarrolladas para obtener muestras representativas de escritura académica en cada una de las universidades, constituye un aporte metodológico en el enfoque de una propuesta de elaboración del diseño de las fases de elicitación. Al elaborar este diseño considero la necesidad de tomar en cuenta el impacto del conjunto de materiales e instrumentos empleados en la práctica de escritura académica en las fases de elicitación. De esta manera las manifestaciones escritas de los alumnos reflejan diversos aspectos que incluyen, por ejemplo, las prácticas, cuestiones personales, contextuales e institucionales, además de los aspectos producidos por las tomas de decisiones en el diseño de la fase de elicitación. Considero la manera en que la guía y las interacciones desarrolladas con los alumnos influyen en lo que éstos expresan por escrito y, en general, el desempeño en la práctica de revisión y edición. En algunos casos las consideraciones metodológicas contempladas en los instrumentos y la actividad de escritura académica propuesta en las fases de elcitación favorecen la manifestación de evidencias de intencionalidad y reflexividad. En otros momentos estas decisiones metodológicas requieren ser modificadas o eliminadas para mejorar el diseño. En otras ocasiones es necesario valorar situaciones no planeadas e imprevistas que pueden proporcionar datos y evidencias textuales que aportan elementos que podemos contemplar y, en su caso, incorporar en las siguientes fases de elicitación. De esta manera, en este trabajo la propuesta de fases elicitación está centrada en la valoración y constante evaluación del diseño de la práctica de escritura académica desarrollada, con el propósito de mejorarla y adaptarla a las realidades y necesidades del entorno y el tipo de alumnos con los que hacemos la práctica de elicitación.

Sobre las evaluaciones, modificaciones y adaptaciones del diseño de elicitación en las universidades contempladas en la investigación, puedo establecer criterios fundamentales de aplicación general como propuesta de criterios metodológicos de elicitación. También considero que algunos criterios deben adaptarse a cada realidad y contexto de alumnos e instituciones. Por ejemplo, considero que a partir de las experiencias 
de elicitación, puedo establecer que un criterio metodológico de aplicación general corresponde al diseño de practica de escritura académica a partir de instrumentos y actividades de interacción que favorezcan, en la medida de lo posible, la discusión centrada en la temática que deseamos destacar, en este caso, el desempeño de la escritura en ambiente académico. Además, el diseño de instrumentos de apoyo nos es de utilidad para evitar desvíos temáticos en las discusiones de reflexión y nos ayuda para tratar de anticipar y planear, en la medida de lo posible, los aspectos que pretendemos que los estudiantes expresen por escrito.

En esta ocasión el diseño, la evaluación y la modificación de la guía durante las fases de elicitación me permitió tomar decisiones a partir de revisar los textos obtenidos y determinar en qué medida el diseño de elicitación favoreció que los estudiantes escribieran sobre diversos aspectos de interés para el estudio, en este caso, las evidencias de intencionalidad y reflexividad. Cuando los textos obtenidos no presentaban este tipo de evidencias, entonces tomé otras decisiones para la modificación del diseño de actividades de la práctica de escritura académica. Por ejemplo, en las fases de elicitación desarrollamos las primeras prácticas a partir de un comentario sobre un tema relacionado con la lengua, la discusión sobre si la gramática de la lengua determina el pensamiento (UPN Ixtepec), sobre los comentarios de un reporte de clase (UPN Tehuantepec) y de recursos de redacción para editar un examen (UAMI). Salvo el sondeo realizado en la UAMI, la temática no estaba centrada en el tema de la reflexión sobre desempeño académico, y, a pesar de que les pedimos a los estudiantes que hicieran comentarios y sugerencias para revisar y editar los textos con la idea de mejorarlos en un segunda versión, la mayor parte de estudiantes abordaron temáticas distintas al desempeño de escritura académicas.

Además, en todas estas fases realizamos la mayor parte de la reflexión en interacciones orales con la idea de motivar la escritura. El problema que se nos presentó es que una vez que los alumnos reflexionaron de manera oral no presentaron la disposición de plasmar por escrito aquello que ya habían reflexionado de manera oral. En su mayoría, los alumnos prefieren expresarse de manera oral sobre temáticas relacionadas con el desempeño académico. Por lo anterior en el diseño final desarrollado en la UNICH tomé la decisión de desarrollar la práctica de escritura académica a partir de instrumentos y 
dinámicas centradas en la reflexión sobre el desempeño escrito de alumnos universitarios bilingües indígenas de otra universidad, así como a partir de reflexiones y comentarios sobre el desempeño personal. En el diseño incluí una lectura sobre evidencias de la escritura de alumnos de la UNP Tehuantepec, la lluvia de ideas, la guía de apoyo y las interacciones orales de retroalimentación entre autores y jueces. Además, enfaticé la prioridad de expresión de comentarios y reflexiones por escrito, de manera tal que la interacción oral solo era como actividad disparadora de discusión para propiciar la expresión escrita.

Por lo anterior, considero como criterios generales de aplicación metodológica de elicitación para obtener muestras de escritura académica, la necesidad de propiciar la manifestación escrita de comentarios, reflexiones y sugerencias sobre el desempeño escrito. En las prácticas de revisión y edición propongo el diseño de un modelo de elicitación centrado en la temática de escritura académica y cuidar que en las interacciones los alumnos no se desvíen del tema en cuestión. Además, es necesario planear actividades que den prioridad a la expresión escrita de los comentarios de los alumnos. De esta manera las interacciones orales de reflexión deben realizarse solamente para motivar la discusión, misma que debemos buscar que quede plasmada por escrito para poder tener elementos para estudiar los escritos en el marco de la textualidad y destacar las evidencias de intencionalidad y reflexividad. Considero que la evidencia oral sobre la reflexión relacionada con el desempeño escrito es relevante, sin embargo, es fundamental trabajar en una perspectiva metodológica a partir de los datos de la textualidad. Los datos orales grabados o en entrevista son fundamentales como complemento para enriquecer la información, pero no son el centro metodológico de esta investigación.

En este punto era necesario tener cuidado de no hacer una interacción dirigida, normativa y basada en modelos preestablecidos y conducidos que condicionaran los comentarios de los alumnos. Por otra parte, era fundamental cuidarnos de no dejar libre expresión con instrucciones tan abiertas que dieran lugar a la dispersión o que los alumnos abordaran temáticas relacionadas pero no centradas en el desempeño de los estudiantes en las prácticas de escritura académica. En este punto, la investigación permite poner a discusión la necesidad de mantener un equilibrio entre el diseño de elicitación controlado y 
la observación libre de aquello que los alumnos deseen manifestar. Pude percatarme de que en las interacciones era necesario hacer intervenciones para regular y dirigir la temática en momentos de dispersión. En particular las intervenciones previas al momento de escribir, para motivar y focalizar el tema de discusión eran fundamentales en determinados momentos para centrar el interés en el asunto del desempeño y la escritura académica.

Es posible ver que un mismo alumno puede tomar una actitud como autor, otra como juez y cambiar radicalmente en la reacción a los comentarios recibidos. Este tipo de oscilaciones del tipo, tema y faceta de la reflexividad en un mismo autor, nos permite constatar que la reflexividad se conforma como un proceso que se desarrolla en distintas facetas. Los alumnos se retroalimentan al manifestar diversos tipos y modalidades de reflexividad, y por momentos en esas oscilaciones el objeto de reflexividad se transparenta y otras veces es opaco, principalmente, cuando los alumnos resignifican sus actitudes y lo que les implica la escritura académica.

La parte correspondiente al seguimiento del tipo y temática de reflexividad de cada alumno primero como autor y luego como juez constituye un criterio metodológico que me permite ubicar con más precisión las transiciones del tipo y temática de reflexividad. Podemos ver el cambio de actitudes y concepciones de cada estudiante al comentar, por ejemplo, los textos de los alumnos de otra universidad, al compartir experiencias personales, hacer sugerencias y comentarios, reaccionar ante los comentarios recibidos y, en la medida de lo posible, tomar decisiones para editar el texto. El seguimiento también puede hacerse sobre las transiciones e incorporaciones temáticas y la manera de oscilar en las actitudes y el posicionamiento de enunciación. De esta manera podemos contemplar la multiplicidad contextual de aspectos que intervienen en las actitudes y la construcción de conocimiento e identidad presentes en la reflexividad.

En general la investigación me ayudó a establecer los límites y alcances para construir las consideraciones teóricas y metodológicas para las fases de elicitación y la creación de categorías para la clasificación textual, así como las situaciones complejas que debemos considerar para obtener muestras ejemplares de evidencias de reflexividad, por ejemplo, ante el surgimiento de situaciones inesperadas, por ejemplo, el paro estudiantil que me llevó a modificar el diseño de las actividades. El trabajo realizado nos deja ver la 
dificultad para hacer que los alumnos manifiesten en sus comentarios muestras de reflexividad sobre un tema en particular sin que existan, en la medida de lo posible, desviaciones que nos alejen de nuestro tema de estudio, en este caso la escritura académica.

Como perspectiva fundamental contemplo a partir de esta investigación la necesidad de continuar este trabajo mediante el diseño de situaciones de elicitación que me permitan lograr que los alumnos de nivel superior expresen los distintos tipos de reflexividad. Estos diseños metodológicos están pensados con un centro de interés mayor en las temáticas abordadas, aquello que expresan los jueces y las reacciones de quienes reciben comentarios. Además, es necesario contemplar las concepciones sobre la gramática en el ambiente académico y la construcción de identidad a partir de las decisiones de textualización que involucran el posicionamiento de enunciación y la reestructuración textual a partir del impacto producido por los comentarios de los jueces. Poder apreciar estos elementos es el resultado del trabajo conceptual en el marco del enfoque de la textualidad y el diseño metodológico de elicitación y de creación de categorías de clasificación textual. El siguiente paso es hacer propuestas para estudiar estos diversos aspectos y proponer criterios y categorías de análisis en otros estudios sobre las prácticas de escritura académica de alumnos de nivel superior.

\section{Referencias bibliográficas}

Adam, Jean-Michel (1990). Eléments de linguistique textuelle. Liege: Mardaga.

Adam, Jean-Michel (2005). La linguistique textuelle: Introduction á l'analyse textuelle des discours. Paris: Armand Colin.

Anscombre, G. E. M. (1965). The Intentionality of Sensation: a Grammatical Feature. En Butler, R. J. (ed.), Analytical Philosophy, B. Blackwell: Oxford. pp. 158-180.

Austin, John L. (1962). How to do things with words. Cambridge Massachusetts: Harvard University Press.

Bateson, Gregory (1972). Pasos hacia una ecología de la mente: Una aproximación 
revolucionaria a la autocomprensión del hombre. Buenos Aires: Ediciones Carlos Lohlé, 1976.

Beugrande, Robert de \& Wolfang Dressler (1997). Introducción a la lingüística del texto. Barcelona: Ariel Lingüística.

Béguelin, Marie-José (2002). Unidades de lengua y unidades de escritura. Evolución y modalidades de la segmentación gráfica. En Ferreiro, Emilia (comp). Relaciones de (in)dependencia entre oralidad y escritura. Barcelona: Gedisa. pp. 31-52.

Bernat, E. \& I. Gvozdenko (2005). Beliefs about language learning: Current knowledge, pedagogical implications and new research directions. En TESL-EJ Teaching English as a second or foreign language. vol. 9, núm 1. Disponible en: http://teslej.org/ej33/a1.html. Consulta realizada el 9 de noviembre de 2005.

Beuchot, Mauricio (2002). Perfiles esenciales de la hermenéutica. México: Universidad Nacional Autónoma de México.

Bilguer, Mirelle. (1995). Escribir mejor: la técnica de la redacción. En Teberosky, Ana y Liliana Tolchinsky. Más allá de la alfabetización: El conocimiento fonológico, la ortografía, la composición de textos, la notación matemática y el aprendizaje. Buenos Aires: Santillana. pp. 129-155.

Blanche- Benveniste, Claire. (1998). Estudios lingüísticos sobre la relación entre oralidad y escritura. Barcelona: Gedisa.

Brentano, F. (1960). The Distinction between Mental and Physical Phenomena. En Chisholm, M. (ed.), Realism and The Background of Phenomenology. Ohio: Ridgeview. p. 4-6.

Brice Heath, Shirley (1983). Ways with words: language, life, and work in communities and classrooms. New York: Cambridge University Press, 2009.

Brice Heath, Shirley \& Brian V. Street with Molly Mills (2008). Ethnography: Approaches to language and literacy. New York: Teachers College Press.

Camps, Ana (1990), Modelos del proceso de redacción: algunas implicaciones para la enseñanza. En Infancia y aprendizaje, núm. 49. pp. 3-19.

Camps, Ana (1992). Algunas observaciones sobre la capacidad de revisión de los adolescentes. En Infancia y aprendizaje. núm. 58. pp. 65-81. 
Camps, Ana (1995). Aprender a escribir textos argumentativos: características dialógicas de la argumentación escrita. En Comunicación, lenguaje y educación. núm. 25, pp. 5164.

Camps, Ana \& Marta Milian (2000). Del texto intentado al texto escrito: formulación oral y reformulaciones del texto en el proceso de redacción en grupo. Lengua, discurso, texto. En I Simposio Internacional de Análisis del Discurso. Universidad Complutense (Madrid) / Universidad París XXII. Madrid 20-22 abril 1998. pp. 27512765.

Camps Melgar, David (2009). Advanced EFL student's revision practices through their writing process. En Cater, Awena, Theresa Lillis \& Sue Parkin. Why writing matters: Issues of access and identity in writing research and pedagogy. Philadelphia: John Benjamins Publishing Company. pp. 129-149.

Carlino, Paula (2004). El proceso de escritura académica: cuatro dificultades de la enseñanza académica. En Educere Investigación arbitrada. año 8. núm 26. pp. 321327.

Carlino, Paula, (2006). Prácticas y representaciones de la escritura en la universidad: los casos de Australia, Canadá, EE.UU. y Argentina. En Proyecto de Investigación Plurianual 2005-2006, PIP 5178, Leer y escribir en la universidad: perspectivas de alumnos y docentes en asignaturas de las ciencias sociales. Disponible en www.saece.org.ar/docs/congreso1/Carlino.doc. Consulta realizada el 10 de diciembre de 2012.

Cifuentes, Bárbara (1998). Letras sobre voces: Multilingüismo a través de la historia. México: Ciesas-INI.

Copi, Irving M. \& Keith Burges-Jackson (1996). Informal logic. New Jersey: Prentice Hall.

Cotterall, S (1995). Readiness for autonomy: investigating learner beliefs. En Davies, N., Dickinson, L. \& A. Wenden (eds.) System. Special Issue: Autonomy, self-direction and self access in language teaching and learning: The history of an idea. Sweden: Pergamon.

Dellerman, Peter; Pierre Coirier \& Merchand Eveluyne (1996). Planning and expertise in argumentative composition. En Rijlaarsdam, Gert; Huub van Bergh; Couzijn, Michael (eds.). Theories, models and methodology in writing research. Ámsterdam: Ámsterdam University Press. pp. 182-195.

Dennett, Daniel C. (1991). Consciousness explained. Back Bay Books: Washington D.C. 
Dennett, Daniel (1996). Kinds of minds. Toward an understanding of consciousness, New York: Basic Books, Perseus Books Group.

Derrida, Jacques, (1967). L`ecriture et la différence. Paris: Èditions du Seuil

Desinano, Norma B. (2009). Los universitarios y la escritura académica. Rosario: Homo sapiens Ediciones.

Eco, Umberto (1979). Lector in fabula: la cooperación interactiva en el texto narrativo. Barcelona: Lumen.

Ferraris, Maurizio (1998). Historia de la hermenéutica. México: Siglo XXI, 2002.

Flower, L. \& J.R. Hayes (1980). Writing as a problem solving. En Visible Language. vol.14, núm 4, pp. 388-399.

Flower, L. \& J.R. Hayes (1981). A cognitive process theory of writing. En College composition and communication. núm 32. pp. 365-387.

Fragoso Peralta, Gilberto (2007). Los problemas del estudiante universitario con la redacción. En Revista Educación y Desarrollo, núm. 7. pp. 69-76

Gadamer, Hans-Georg (1973). Verdad y método Vols. I y II. Salamanca: Ed. Sígueme. 1998.

Galaburri, María Laura (2000). Una experiencia de revisión de textos o cómo recuperar el tesoro de la cueva de Alí Babá. En Lectura y vida. vol. 21. núm. 3.

García Elskamp, Rafaela (1986). Intención e intencionalidad: estudio comparativo. En Anales de filosofía. Depósito digital institucional de la Universidad de Murcia. vol. 4 pp. 147- 156. Disponible en http://digitum.um.es/xmlui/handle/10201/11500. Consultado el 12 de noviembre de 2012.

Gardner, D \& L. Miller (1999). Learners' and teachers' beliefs and attitudes about language learning. En Establishing self-access: From theory to practice. United Kingdom: Cambridge University Press.

Groult, N., \& V. Mercau (1999). Estudio exploratorio de las representaciones acerca del aprendizaje de lenguas extranjeras. En Foro de enseñanza e Investigación en Lenguas y Culturas Extranjeras en la Universidad Autónoma Metropolitana. México. Universidad Autónoma Metropolitana. pp. 1-9. 
Halliday, M.A.K. (1978). Language as a social semiotic: The social interpretation of language and meaning. London: Edward Arnold

Halliday, Michael y Rugaiya Hasan (1976). Cohesion in English. London: Longman

Heidegger, Martin (1988). Ontology: The hermeneutics of facticity. Indiana: Indiana University Press.

Hernández Rodríguez, Ernesto (2003). La redacción de textos con intencionalidad argumentativa de alumnos de bachillerato. Tesis de Maestría en Ciencias con Especialidad en Investigaciones Educativas. Centro de Investigación y de Estudios Avanzados del I.P.N. Asesora Dra. Emilia Ferreiro

Hernández Rodríguez, Ernesto (2010). Recursos y resolución de problemáticas de textualización en la redacción con intencionalidad argumentativa de alumnos de bachillerato. Signos lingüísticos, Universidad Autónoma Metropolitana Iztapalapa, vol. 6, núm. 11, pp. 113-125. Disponible en

http://www.neppi.org/projetos/tellus detalhes.php?id=365. Consulta realizada el 17 de noviembre de 2012.

Hernández Rodríguez, Ernesto (2011). Prácticas de revisión y edición de textos de alumnos bilingües indígenas de licenciatura en Oaxaca: la reflexividad y la intencionalidad en la redacción de comentarios. Revista Tellus. Campo Grande MS. Brasil. año 11. núm. 21. pp. 71- 96. Disponible en http://www.neppi.org/projetos/tellus_detalhes.php?id=365. Consulta realizada el 22 de noviembre de 2012.

Hernández Rodríguez, Ernesto (2012). Impacto de la reflexividad en la revisión y edición cooperativa de textos de alumnos universitarios bilingües indígenas en Tehuantepec, Oaxaca, México. Tercer Milenio. Escuela de Periodismo de la Universidad Católica del Norte de Chile. año 17. núm. 24. pp. 36-46. Disponible en http://www.periodismoucn.cl/tercermilenio/2012/12/impacto-de-la-reflexividad-en-lareision-y-edicion-cooperativa-de-textos-de-alumnos-universitarios-bilingues-indigenas-entehuantepec-oaxaca-mexico/. Consulta realizada el 10 de enero de 2013.

Hyland, Ken (2005). Metadiscourse: exploring interaction in writing. London: Continuum.

Horwitz, E. (1987). Surveying student's beliefs about language learning. En Wenden, A. \& J. Rubin (eds.) Learner strategies in language learning. United Kingdom: PrenticeHall. pp. 119-129.

Husserl, Edumund (1901). Investigaciones lógicas 1. Versión española de Manuel G. Morene y José Gaos Madrid: Alianza Editorial. 1999. 
Husserl, Edmund (1913). Ideas relativas a una fenomenología pura y una filosofía fenomenológica, traducción de José GAOS, Fondo de Cultura Económica: México, 1997.

Ivanič, Roz. (1998). Writing and identity: The discoursal construction of identity in academic writing. Philadelphia: John Benjamins Publishing Company.

Johns, Ann M. (1997). Text, role and context. New York: Cambridge University Press.

Lea, Mary (1999). Academic literacies and learning in higher education: constructing knowledge through texts and experience. En Jones, Carys, Joan Turner \& Brian Street (eds). Students writing in the university: cultural and epistemological issues. Philadelphia: John Benjamins Publishing Company, pp. 103-124.

Lea, Mary \& Brian V. Street (1998). Student writing in higher education: An academic literacies approach”. En Studies in Higher Education. vol. 23. núm. 2, pp. 157 - 172.

Lillis, Theresa M. (2001). Student writing: Access, regulation, desire. London: Routledge.

Manrique Castañeda, Leonardo (1988). Atlas cultural de México: Lingüística. México: SEP-INAH-Planeta.

McIntyre, Ronald \& David Woodruff Smith (1989). Theory of intentionality. En Mohanty, J.N. \& William McKenna (eds). Husserl's Phenomenology: A Textbook. Washington, D.C.: Center for Advanced Research in Phenomenology and University Press of America. Disponible en http://consc.net/neh/papers/smith2.pdf.. Consulta realizada el 27 de noviembre de 2012.

Muñoz Cruz, Héctor (2010). Reflexividad sociolingüística de hablantes de lenguas indígenas: concepciones y cambio. México: Universidad Autónoma Metropolitana Iztapalapa Ediciones del Lirio.

Muñoz Cruz, Héctor (2009) Proyecto Conacyt 99274. Dominio lingüístico y académico de estudiantes bilingües indígenas en algunas universidades de México: habilidades comunicativas y académicas, reflexividad sociolingüística y políticas interculturales del lenguaje. Mexico: Universidad Autónoma Metropolitana Iztapalapa.

Nikitiina, L \& F. Furuoka (2006). Re-examining Horwitz's beliefs about language learning inventory (BALLI) in the Malaysian context. En Electronic Journal of Foreign Language Teaching. vol. 3, núm 2. Singapore: Centre for Language Studies, National University of Singapore. 
Paredes Martín, María del Carmen (2007). Teorías de la intencionalidad. Madrid: Síntesis.

Oxford, Rebeca. (1990). Language learning strategies: what every teacher should know. USA: Heinle \& Heinle Publisher.

Patiño Garzón, Lucelli (2006). La escritura académica en la formación del docente universitario. En Revista Educación y Pedagogía, Universidad de Antioquía. Facultad de Educación. vol. 18. núm. 46. pp. 125-133.

Perelman, Flora (2001). Textos argumentativos: su producción en el aula. En Lectura y vida, vol. 22. núm 2. pp. 32-48.

Perry, John (2001). Reference and reflexivity. Standford: Centre for the study of language and information.

Peirce, Charles Sanders (1868). Cuestiones acerca de ciertas facultades atribuidas al hombre. Journal of speculative philosophy 2.103 - 104. En Houser Nathan \& Christian Kloesel (1992). Charles Sanders Peirce: Obra filosófica reunida Tomo I (1867 - 1893). México: Fondo de Cultura Económica.

Recanati, Francoise (1979). La transparencia y la enunciación: Introducción a la pragmática. Buenos Aires: Hachette.

Recanati, Francoise (2004). Literal meaning. Cambridge: Cambridge University Press.

Ricoeur, Paul. (2003). El conflicto de las interpretaciones: ensayos de hermenéutica. México: Fondo de Cultura Económica.

Ribas Seix, Teresa (2001). La regulación del proceso de composición escrita en grupo: análisis de la utilización de pautas de revisión. En Camps, Anna (coord.). El aula como espacio de investigación y reflexión. Barcelona: Editorial Graó. pp. 51-67.

Rorty, Richard (1991). Objectivity, relativism and truth. Philosophical Papers 1. Cambridge: Cambridge University Press.

Rubio, Mariela y Valeria Arias (2002). Una secuencia didáctica para la enseñanza de la argumentación escrita en el Tercer Ciclo. En Lectura y vida. vol. 23. núm. 4. pp. 3441.

Saussure, Ferdinand de (1916). Cours de linguistique générale. edition critique preparé par Tulio de Mauro (1965). París: Payot, 1972. 
Scott, Mary (1999). Agency and subjectivity in student writing. En Jones, Carys, Joan Turner \& Brian Street (eds). En Students writing in the university: cultural and epistemological issues. Philadelphia: John Benjamins Publishing Company. pp. 171192.

Searle, John (1969). Actos de habla. Barcelona: Planteta-De Agostini. 1994.

Serrano de Moreno, María Stella; Yolimar Duque de Duque \& Alix Madrid de Forero. Prácticas de escritura académica en la universidad: ¿Reproducir o transformar. En Educere Investigación arbitrada. año 16. núm 53. pp. 93-108.

Street, Brian V. (2009) The future of 'social literacies'. En Baynham, Mike \& Mastin Prinsloo (eds.). The future of literacy studies. Hampshire. Palgrave Macmillan.

Street, Brian V. (2009b). "Hidden" Features of Academic Paper Writing. En Working papers in educational linguistics. vol. 24. núm 1. pp. 1-17.

Turner, Joan (2011). Language in the academy: cultural and intercultural dynamics. Bristol: British Library Cataloguing in Publishing Data.

Wenden, A. (1986). Helping language learners think about learning. En Rossner, R (ed.). En ELT Journal. An international journal for teachers of English to speakers of other languages. vol. 40. núm. 1. pp. 161-175.

Wittgenstein, Ludwig (1953). Philosophical investigations. edición de Anscombre, G.E.M. $\&$ Rush Rees. Oxford: Blackwell. Disponible en http://new.pensamientopenal.com.ar/21122009/filosofia04.pdf. Consulta realizada el 2 de diciembre de 2012.

Whorf, Benjamin Lee (1964). Language, thought and reality. New York: The MIT Press.

Zammuner, Vanda Lucia (1991). Children writing of argumentative texts: Effects of indirect instruction. En European Journal of Psychology of Education. vol. 6, núm. 2. pp. 243-256.

Zavala, Virginia (2009). “¿Quién está diciendo eso?” Literacidad académica, identidad y poder en la educación superior. En Kalman, Judith \& Brian Street (coords.). Lectura, escritura y matemáticas como prácticas sociales: diálogos con América latina. México: Siglo XXI-CREFAL. pp. 348-363. 


\section{Anexos}

\section{Anexo 1}

\section{Hipótesis de Sapir-Whorf}

La hipótesis de Sapir-Whorf establece que existe una cierta relación entre las categorías gramaticales del lenguaje que una persona habla y la forma en que la persona entiende y conceptualiza el mundo. También se conoce a esta hipótesis como PRL (Principio —o hipótesis - de Relatividad Lingüística). Podemos distinguir una formulación fuerte y una más débil del siguiente modo:

* Hipótesis whorfiana fuerte: La lengua de un hablante monolingüe determina completamente la forma en que éste conceptualiza, memoriza y clasifica la «realidad» que lo rodea (esto se da a nivel fundamentalmente semántico, aunque también influye en la manera de asumir los procesos de transformación y los estados de las cosas expresados por las acciones verbales). Es decir la lengua determina fuertemente el pensamiento del hablante.

* Hipótesis whorfiana débil: La lengua de un hablante tiene cierta influencia en la forma que éste conceptualiza y memoriza la «realidad», fundamentalmente a nivel semántico. Esto significaría que a igualdad de todo lo demás pueden existir diferencias estadísticas significativas en la forma que dos hablantes de diferentes lenguas resuelven o enfocan ciertos problemas.

La hipótesis de Sapir-Whorf ha sido uno de los principales temas dentro de las discusiones en torno al relativismo lingüístico.

Anexo 2

\section{Lluvia de ideas en el grupo de Oxchuc (5to semestre textos 01 al 19)}

\begin{tabular}{|l|l|}
\hline Reflexión & Pueda interpretar \\
Ortografía - escritura comprensible fija y clara & Relacionar ideas \\
Texto coherente, que se entienda & Jugar - no ser repetitivo \\
-ideas principales. - saber ubicarlas & Cuidar el orden \\
-Puntos importantes & Resumir lo importante \\
-Entrender párrafos & Tener presente un plan de lo que escribo \\
& Organizar léxico \\
\hline
\end{tabular}

Lluvia de ideas en el grupo de San Cristóbal de las Casas

(1er semestre textos 20 al 33)

\begin{tabular}{|l|l|l|}
\hline Cómo empiezo & Escribir como en el celular & -El texto debe tener coherencia \\
-Cómo usar coma, punto & Cómo terminar y redactar & -Uso diccionario de sinónimos para no \\
-La ortografía & repetir palabras \\
-La caligrafía & Tensar en lo que quiero decir & -Los signos de puntuación \\
-Usar ideas elevadas & & \\
\hline
\end{tabular}

Lluvia de ideas en el grupo de San Cristóbal de las Casas (5to semestre textos 34 al 51)

Hábito de la lectura

Evitar repeticiones de patrones

Ser coherente

Buscar significado de palabras desconocidas

Saber utilizar puntos y comas
Mencionar palabras relacionadas con el lenguaje del habla

Acentuaciones

Evitar abreviaturas incorrectas

No escribir como hablamos

Separar frases de manera concreta

Uso correcto de mayúsculas 
Anexo 3

Sobre el tipo de sugerencias y comentarios de los jueces.

\begin{tabular}{|c|c|}
\hline Sugerencias u opiniones del juez al autor & Número de textos en que aparece \\
\hline $\begin{array}{l}\text { NIVEL DE CONTENIDOS Y COMENTARIOS } \\
\text { Sugiere que incorpore información para enriquecer el texto }\end{array}$ & 9 (textos: $24,25,26,28,31,32,39,43,48)$ \\
\hline $\begin{array}{l}\text { Sugiere que sea coherente, que reflexione antes } \\
\text { de escribir, que aborde el tema, que lea primero }\end{array}$ & $\begin{array}{l}23 \text { (textos: } 01,02,03,09,13,18,19,20,21,23,24,26,27 \\
31,33,34,36,40,41,43,44,46,48)\end{array}$ \\
\hline $\begin{array}{l}\text { NIVEL GRÁFICO DE LAS PALABRAS } \\
\text { Sugiere mejorar la ortografía }\end{array}$ & $\begin{array}{l}28(01,04,05,06,09,11,12,13,17,20,22,23,25,27,28 \\
29,30,31,32,33,34,37,40,41,44,46,48,49)\end{array}$ \\
\hline Sugiere mejorar caligrafía & $\begin{array}{l}35 \text { (textos: } 02,03,05,06,07,09,10,11,12.13,14,15,16 \\
18,20,22,26,27,28,29,30,31,32,33,34,35,36,37,38 \\
42,44,45,46,47,51)\end{array}$ \\
\hline Sugiere mejorar la puntuación & $\begin{array}{l}30 \text { (textos: } 01,03,06,08,09,11,13,15,16,17,19,20,21 \\
22,24,26,27,28,29,32,34,35,36,40,41,42,43,45,49 \\
50 .\end{array}$ \\
\hline Sugiere no tachar, remarcar, ser limpio & 8 (textos: $10,18,25,28,38,42,45,46)$ \\
\hline Sugiere mejorar acentuación & $\begin{array}{l}27 \text { (textos: } 01,03,06,08,10,11,13,15,17,20,21,22,24, \\
26,27,28,29,30,31,33,44,46,42,47,49,50,51)\end{array}$ \\
\hline Segmentación de palabras & 4 (textos: $06,13,29,33$ ) \\
\hline \multicolumn{2}{|l|}{ NIVEL DE ESTRUCTURA INTERNA Y PÁRRAFOS } \\
\hline $\begin{array}{l}\text { Sugiere mejorar la estructura, organización, } \\
\text { adecuado uso de párrafos }\end{array}$ & 11 (textos: $10,11,16,31,35,41,43,44,45,49,51$ ) \\
\hline $\begin{array}{l}\text { NIVEL: COHESIÓN Y SELECCIÓN LÉXICA } \\
\text { Sugiere que no repita palabras, cuidar la selección léxica }\end{array}$ & $\begin{array}{l}22 \text { (textos: } 04,05,06,07,08,09,13,14,16,19,21,23,26 \\
31,35,36,39,40,41,43,47,50)\end{array}$ \\
\hline $\begin{array}{l}\text { Sugiere cuidar el uso de conectores y elementos } \\
\text { de transición léxicos y puntuación }\end{array}$ & 6 (textos: $06,16,28,35,43,51$ ) \\
\hline Sugiere escribir con cohesión (claridad, gramática) & 12 (textos: $03,08,13,20,24,25,29,35,38,41,44,47$ ) \\
\hline $\begin{array}{l}\text { NIVEL: PLANEACIÓN Y REVISIÓN } \\
\text { Sugiere que planee, reflexione, organice, revise } \\
\text { y corrija su propio texto }\end{array}$ & 4 (textos: $08,14,23,37,44)$ \\
\hline Sugiere que tome apuntes, que ponga atención & 1 (texto: 44$)$ \\
\hline \multicolumn{2}{|l|}{$\begin{array}{l}\text { NIVEL: EL JUEZ OPINA, EVALÚA } \\
\text { Y APORTA INFORMACIÓN }\end{array}$} \\
\hline $\begin{array}{l}\text { Justifica los errores, el tipo de escritura del autor, } \\
\text { expresión de aliento para mejorar }\end{array}$ & 6 (textos: $03,14,16,25,28,34)$ \\
\hline Elogia la redacción & $\begin{array}{l}20 \text { (textos: 03, 04, 07, 09, 11, 14, 18, 20, 21, 24, 27, 29, 30, } \\
31,32,34,35,36,43,45)\end{array}$ \\
\hline Motiva para mejorar pero no hace observaciones concretas & 3 (textos: $02,07,40$ ) \\
\hline Posicionamiento del autor & 1 (texto: 49 ) \\
\hline
\end{tabular}




\section{Anexo 4}

Decisiones de edición

\begin{tabular}{|c|c|}
\hline $\begin{array}{l}\begin{array}{l}\text { Sobre el tipo de decisiones para modificar la segunda } \\
\text { versión }\end{array} \\
\end{array}$ & Número de texto en que aparece \\
\hline $\begin{array}{l}\text { CONTENIDOS } \\
\text { Elimina información o reduce el texto }\end{array}$ & $\begin{array}{l}27 \text { (textos: } 04,06,07,08,09,10,11,12,13,14,15,16,17,18 \\
19,22,34,35,38,39,40,41,42,43,48,50,51)\end{array}$ \\
\hline Parafrasea pasajes de su primera versión & $\begin{array}{l}24 \text { (textos: } 03,04,06,08,10,11,13,14,17,18,19,22,24,25 \text {, } \\
26,27,28,36,37,38,41,42,43,50)\end{array}$ \\
\hline Copia toda o la mayor parte de la primera versión & $\begin{array}{l}15 \text { (textos: } 04,05,20,21,23,24,26,27,28,29,30,32,33, \\
34,51)\end{array}$ \\
\hline $\begin{array}{l}\text { Modifica completamente la información } \\
\text { (versión distinta) }\end{array}$ & 12 (textos: $09,11,12,15,16,25,31,35,39,41,48,49$ ) \\
\hline Incorpora información sobre el tema & 8 (textos: $09,19,25,31,35,39,41,50$ ) \\
\hline Incorpora comentario sobre el tema & 3 (textos: $09,39,48$ ) \\
\hline $\begin{array}{l}\text { COHESIÓN Y SELECCIÓN LÉXICA } \\
\text { Procura mejorar sus selecciones léxicas }\end{array}$ & 12 (textos: 03, 04, 05,06, 08, 13, 17, 21, 24, 25, 30, 36) \\
\hline $\begin{array}{l}\text { Incorpora conectores o elementos de transición textual entre } \\
\text { ideas y párrafos }\end{array}$ & 2 (textos: 03,36$)$ \\
\hline Modifica aspectos gramaticales & 2 (textos: 37,38 ) \\
\hline $\begin{array}{l}\text { REACCIÓN ANTE LOS COMENTARIOS } \\
\text { Responde al juez, incorpora información o reflexión sobre } \\
\text { comentarios recibidos }\end{array}$ & 9 (textos: $01,02,11,12,16,25,31,49,50)$ \\
\hline Hace caso omiso de las sugerencias & 6 (textos: $09,20,23,29,33,40$ ) \\
\hline $\begin{array}{l}\text { NIVEL GRÁFICO DE LAS PALABRAS } \\
\text { Modifica puntuación, ortografía, acentuación }\end{array}$ & 8 (textos: $20,21,26,27,29,34,36,37$ ) \\
\hline Mejora caligrafía & 7 (textos $03,05,14,16,33,37,38)$ \\
\hline $\begin{array}{l}\text { ESTRUCTURA INTERNA PÁRRAFOS } \\
\text { Modifica estructura, organización }\end{array}$ & 7 (textos: $07,10,12,15,28,37,51)$ \\
\hline Usa párrafos como unidades de bloques temáticos & 1 (texto 37) \\
\hline
\end{tabular}




\section{Anexo 5}

Texto tsim 17 completo

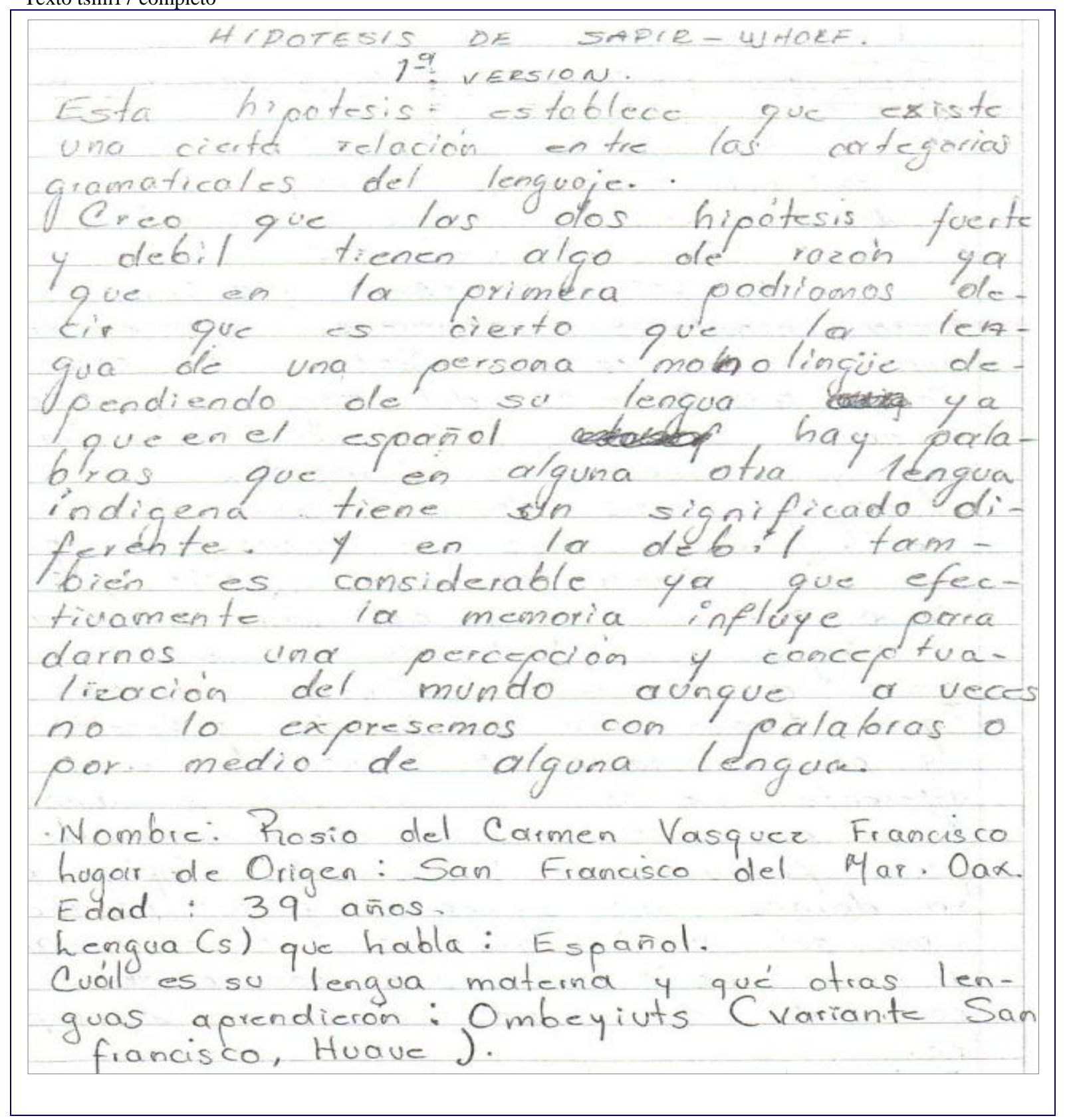




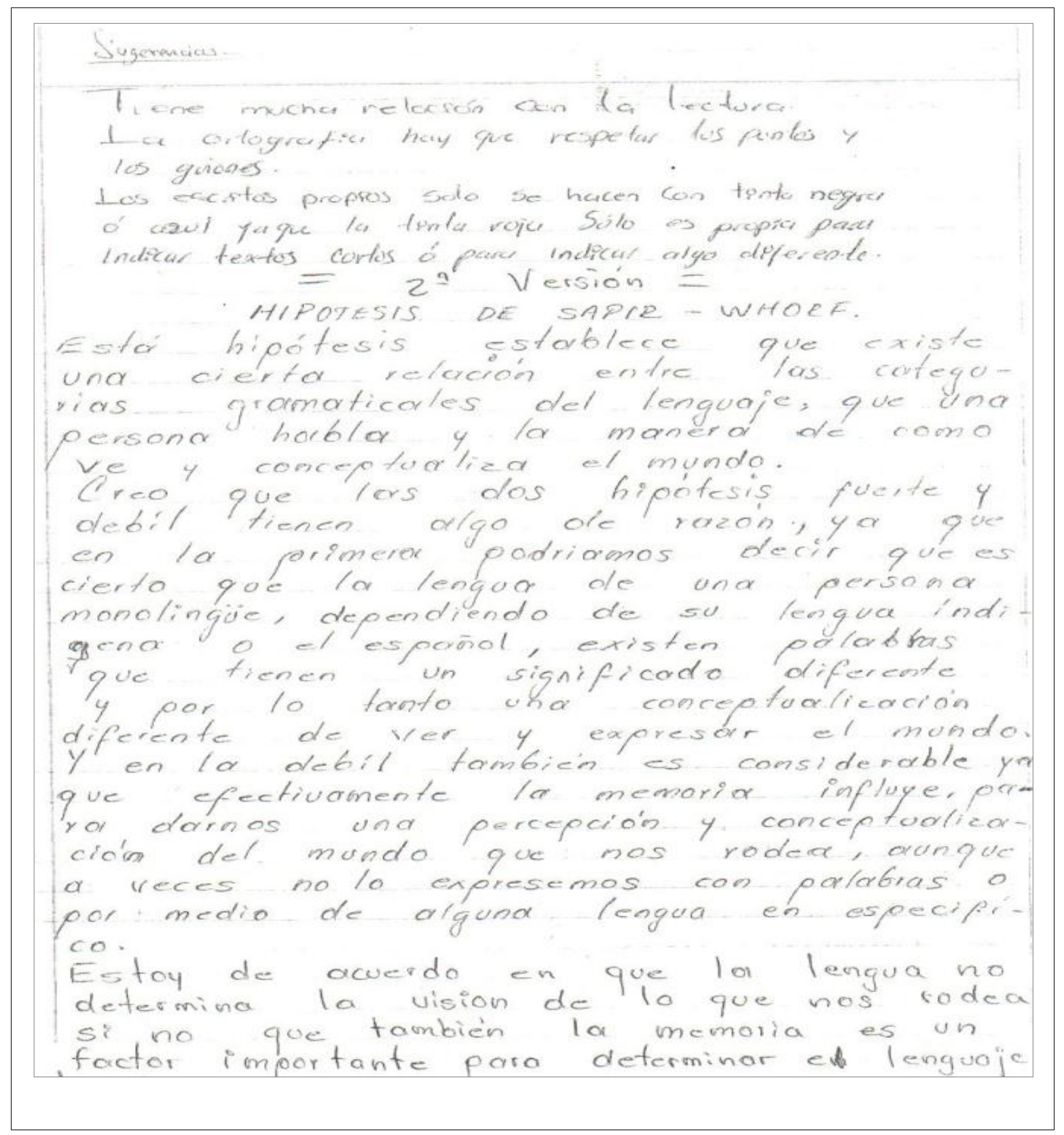


Anexo 6

$\neq f^{\prime}-$ versión $\neq$

Qq-Abrit-2oll.

Mas que nada en este pequerio texto nos habla del lenguaje alogoe yo le entende, se refiere qoe nosolros conceptualizamos questro entono mediante nuestro lenguaje.

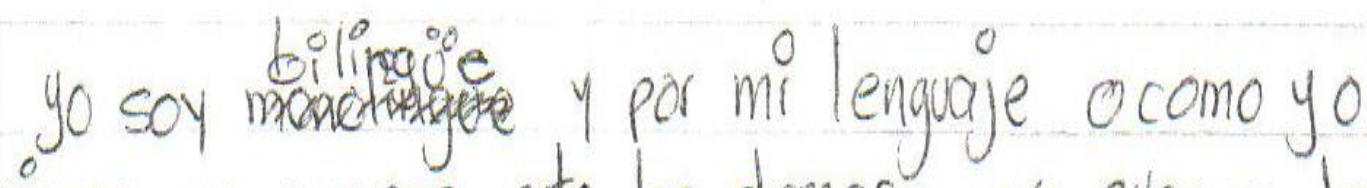
pienso me expieso ante los demas pero aveces tengo un paco de dificultad pa que quizas no conceptualizo moy bién.

Li2

212 


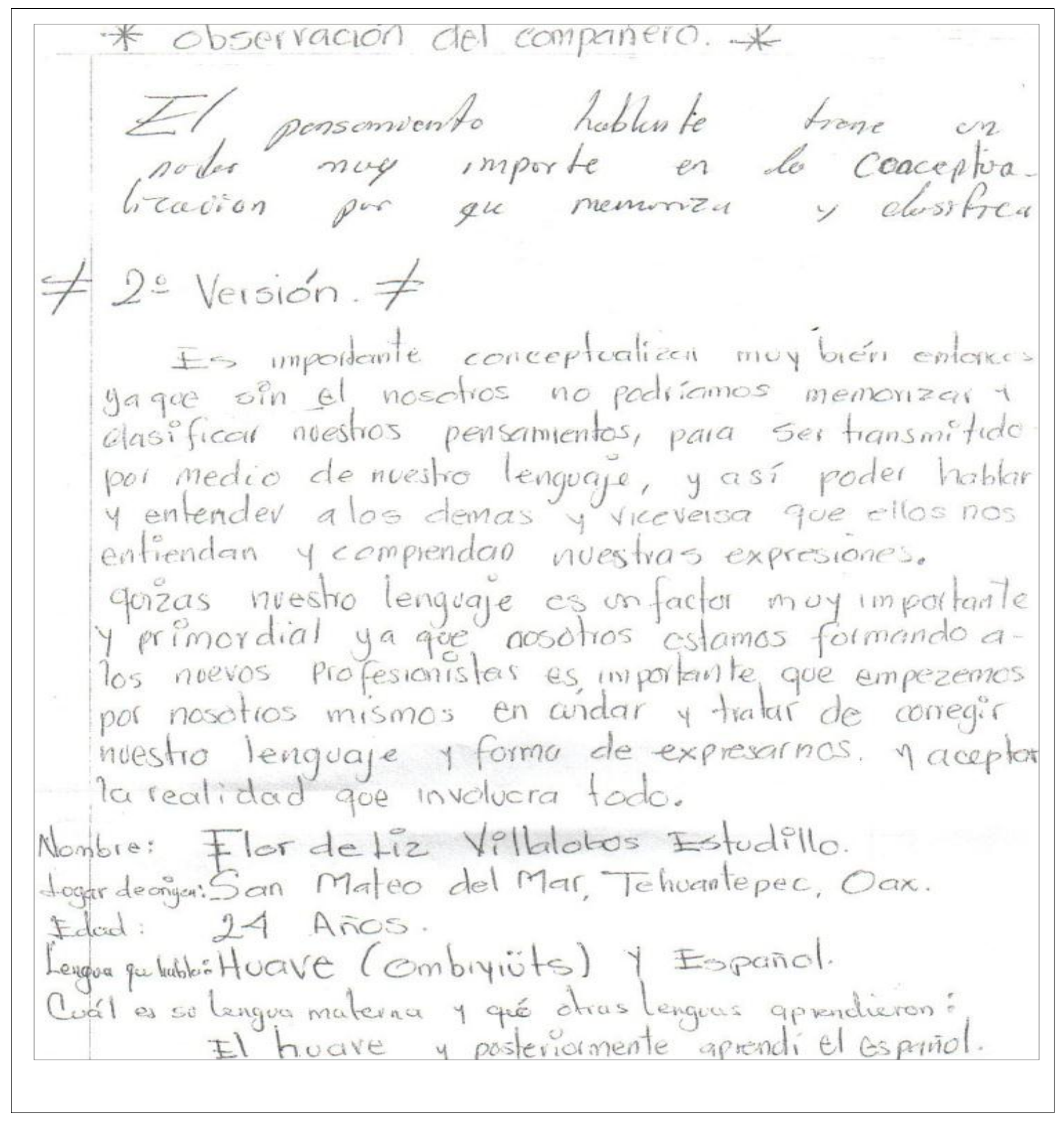


Anexo 7

Texto tsih07 completo

Victor Hugo Diaz Gutiérrez

Como nos habla la lectura sobre lo que es un monolingue, un monolingue es el que sabe 0 siente lo que esta en su enterno porque 10 vive y, se desenvuetue con ella.

Muchas veces nos pasa eso porque como individuos siempre esperamos que hable el otro para darnos cuenta quien es y que lengua habla

por ejemplo sies mixe o no, o si es rapoteco ono ya con esa platica se un uno adaptando con otras ideas

Juez

Por lo que note no te diste el tiempo de leer el textb, no te preocupes a la mayoría nos paso. "no es cierto" Prenso que debes ser un poguito $\mathrm{ma}_{2}$ arifico con tigo.

214 
De acuerdo a la latura que se estuvo analizando es muy importante que nosotros nos demos cuenta con que personas estamos hablando para darnos cuenta quienes son si son de la misma comunidad porque muchas veces pasa eso que cuando un monolingüe va a otro lugar $y$ se encuentra con uno que no habla la misma lengua por eso es muy importante ver donde andamos quienes somos con que nos identificamos y también. como manejamos nuestra lengua que terminos usamos, porque hay palabras que si coinciden pero sus significados no los mismos son diferentes, a to mejor si hay palabras que coinciden pero son palabras que cambian nadamas del sonido porque si son de la misma region peco de diferentes comunidades

* Nombre: Víctor Hugo Díaz Gutiérrez

* Lugar de origen: Santa María Tlahuitoltepec Mixe.

* Edad: 22 años

* Lenqua (s)o que habla: Mixe, Español. * Cual es su lengua Materna y que otras lenguas 
Anexo 8

Sobre el tipo de sugerencias y comentarios de los jueces. (Ixtepec)

\begin{tabular}{|l|c|}
\hline Sugerencias u opiniones del juez al autor & $\begin{array}{l}\text { Apariciones en 22 textos } \\
\text { (En } 4 \text { de los 26 textos no aparecen } \\
\text { comentarios del juez) }\end{array}$ \\
\hline Sugiere sobre la cohesión & 5 (textos:04,17, 18, 21 y 23) \\
\hline Sugiere que explique con sus propias palabras, expresar su opinión. & 5 (textos: 05, 08, 14,19 y 20) \\
\hline $\begin{array}{l}\text { Sugiere que el autor proporcione información de la lectura, que aborde el } \\
\text { tema, que sea coherente, que lea primero }\end{array}$ & 9 (textos: 04, 06,07,13,14,15, \\
\hline Sugiere que incorpore información para enriquecer el texto & 2 (textos: 13 y 19) \\
\hline $\begin{array}{l}\text { Expresa punto de vista sobre la lectura, el tema o las ideas del autor, pero } \\
\text { no sugiere }\end{array}$ & 5 (textos: 01, 09, 10, 25, 26) \\
\hline Aporta información sobre el tema pero no sugiere nada & 5 \\
\hline Aporta información ajena al tema & $3 \quad$ (textos:02, 10, 16) \\
\hline Elogia la redacción & 4 \\
\hline Señala lo que no pudo hacer el autor & 2,21 y 23) \\
\hline
\end{tabular}

\section{Anexo 9}

Tabla 5 Tipo de modificaciones en la segunda versión

Sobre el tipo de decisiones para modificar la segunda|Apariciones en los 22 textos versión

\begin{tabular}{|l|cc|}
\hline No realiza cambios significativos & 6 & (textos:01, 02, 04, 05, 09, 17) \\
\hline Cambia género textual & 4 & (textos: 07, 20 y 06,16) \\
\hline Cambia contenido de 1a versión inicial & 6 & (textos: 12, 16, 19, 20, 25, 26) \\
\hline Incorpora información & 5 & (textos: 13, 14, 19, 21 y 23) \\
\hline Elimina información & 3 & (textos: 08, 15 y 18) \\
\hline $\begin{array}{l}\text { Se apropia o se influye de las ideas } \\
\text { del juez y las sigue en su escrito }\end{array}$ & 3 & (textos: 10, 12, 25) \\
\hline Segunda versión es totalmente distinta & 5 & (textos: 16, 19, 20, 25, 26) \\
\hline Modifica puntuación, ortografía & 2 & (textos: 17, 21) \\
\hline Responde al comentario del juez & 2 & (textos 01, 07) \\
\hline
\end{tabular}




\section{Anexo 10}

Texto trth09vi completo trth09vi página 1

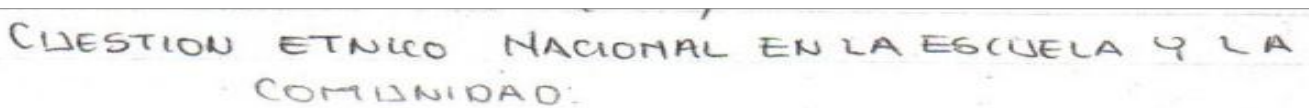

ima sociología fundó August comte en el siglo $x$ ix

La Antropología son semejama y diferencio del hombue.

Conocimiento innato es aquella persona que aprende desde sw nacimiento.

Conocimiento nato es aquella persona que aprende día a día en su entorno.

Los premios y castigos pueden ser de dosmaneras que pueden ser "positivos" ' "Negativos". en ese aspecto enfoca a la paradigma. ina paradigmaa habla sobre el estimulo enfoca ona respuesta

El estado se dibide er Y sobierno.

Taylor diso que el "salvajisping se enfoca a la aparición del tu fuego, en cuestión/d l la familia.

El estado de Oaxaca 4ieng/570 municipios, 30 distritos 4 /6 gropos étficos.

GRUPO ÉTNICO es el conjunto be personos que estáb regido en un mísmo gobierno, que cada grupo étnico tiene on solo idioma y sos tradiciones difirentes.

Nacionalidad es aquellos personas que representon a on Estado, en donde ellos fienen sos propios derechos y obligaciones. 
Versión final (trth09) página1

A mediados del siglo $x \times x$ el señor August comte fundó la sociología.

La diferencia y semejanzas que tienen el hombre

se basa por medio de la Antropología.

La palabra constructivista entiendo que nosotros mísmos debemos de construir nuestros propios conocimientos. para mi el conocimiento innato es todo persona que aprende desde sus primeros pasos (nacimientos). conocimiento nato es toda persona que aprende día con día en la vida diaria.

ta paradigma tiene dos grandes aspectos para mejorar a los alumnos, en cuanto a los premios y castigos puedenser positivos a negativos.

El estado sedivide en territorio, población y gobiern?

Taylor dijo que el Saluajismo se enfoca a la aparición del fuego, en cuestión de la familia.

El estado de Oaxaca cuentacon 570 municipios, 30 distritos y 16 grupos étnicos.

Grupo étnico es el conjunto de personas que están regido en un mismo gobiemo, que cada grupo étnico tiene un sólo idioma y sus propios tradiciones diferentes. 
trth09vi página 2

Etnia: aquellos personas que conservan sus vascis a

costumbres en donde comparten sus nucionalidades como mexicanos, sus territorios, culturas, razas y tradiciones.

Todo grupos étnicos tienen elementos en las que caracterizan como identidad, costumbre, lengua, Vestimen. ta, tervitorio o religión.

los grupos étnicos siempre se organizan mediante usos y costumbres.

Sócrates murió en el año 369 a.c. "Y fue conside. rado como "encontra de la religión".

219 
Versión final (trth09) página 2

Nacionalidad es aquellos personas que representan unestado, endonte tienen at derebhos i oblicacione: Etniai son aquellos personas que conservan sus usos y costumbres, al mismo tiempo comparten sus nacionalida. des como mexicanos, sus territorios, culturas, razas y tradiciones.

Todo grupo étnico tienen elementos en las que carac. terizan como identidad, costumbre, lenzua, vestimenta territorio y religión.

Los grupos étnicos siemore se organizan mediante usos y costumbres.

según recuerdo que socrates murió en el año 369 antes de cristo $y$ sócrates está encontra de la religión.

220 


\section{Anexo 11}

Sobre el tipo de sugerencias y comentarios de los jueces.

\begin{tabular}{|c|c|}
\hline Sugerencias u opiniones del juez al autor & Número de textos en que aparece \\
\hline \begin{tabular}{|l} 
NIVEL DE CONTENIDOS Y COMENTARIOS \\
Sugiere que incorpore información para enriquecer el texto
\end{tabular} & $\begin{array}{l}21 \text { (textos: } 01,02,05,06,07,08,09,10,11,12,13, \\
17,18,19,25,27,28,29,32,34,35)\end{array}$ \\
\hline $\begin{array}{l}\text { Sugiere que sea coherente, que reflexione antes de } \\
\text { escribir, que aborde el tema, que lea primero }\end{array}$ & $\begin{array}{l}13 \text { (textos: } 10,12,14,15,16,18,20,22,24,27,28, \\
30,36)\end{array}$ \\
\hline $\begin{array}{l}\text { Sugiere que explique con sus propias palabras, } \\
\text { expresar su opinión, crítica }\end{array}$ & $\begin{array}{l}12 \text { (textos: } 03,04,05,08,09,14,17,25,26,28,30 \\
32\end{array}$ \\
\hline $\begin{array}{l}\text { Sugiere que escriba lo que aprendió, lo significativo } \\
\text { de la clase, que haga propuestas }\end{array}$ & 8 (textos: $03,04,08,11,14,25,26,28$ ) \\
\hline Sugiere que sea concreto, que aporte lo significativo & 6 (textos: 01, 03, 07,08, 11, 32) \\
\hline $\begin{array}{l}\text { NIVEL GRÁFICO DE LAS PALABRAS } \\
\text { Sugiere mejorar la ortografía }\end{array}$ & 11 (textos: $02,07,14,18,20,21,22,23,28,32,34$ ) \\
\hline Sugiere mejorar caligrafía & 11 (textos: $03,04,16,18,19,22,23,24,29,33,34$ \\
\hline Sugiere mejorar la puntuación & $\begin{array}{l}10 \text { (textos: } 02,03,04,08,09,14,16 \\
20,21,24)\end{array}$ \\
\hline Sugiere no tachar, remarcar, ser limpio & 4 (textos: $07,21,22,23$ ) \\
\hline Sugiere mejorar acentuación & 2 (textos: 04,16$)$ \\
\hline \multicolumn{2}{|l|}{ NIVEL ESTRUCTURA INTERNA Y PÁRRAFOS } \\
\hline $\begin{array}{l}\text { Sugiere mejorar la estructura, organización, } \\
\text { adecuado uso de párrafos }\end{array}$ & 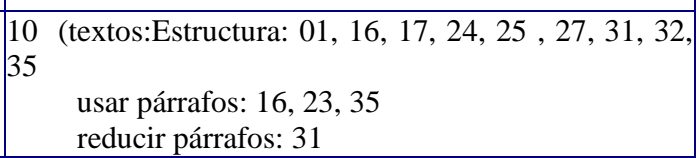 \\
\hline $\begin{array}{l}\text { NIVEL: COHESIÓN Y SELECCIÓN LÉXICA } \\
\text { Sugiere que no repita palabras, cuidar la selección léxica }\end{array}$ & 7 (textos: $06,16,18,23,31,35,36)$ \\
\hline $\begin{array}{l}\text { Sugiere cuidar el uso de conectores y elementos } \\
\text { de transición léxicos y puntuación }\end{array}$ & 6 (textos: $16,18,23,31,35,36)$ \\
\hline Sugiere escribir con cohesión (claridad, gramática) & 6 (textos: $06,12,15,22,23,36)$ \\
\hline $\begin{array}{l}\text { NIVEL: PLANEACIÓN Y REVISIÓN } \\
\text { Sugiere que planee, reflexione, organice, revise } \\
\text { y corrija su propio texto }\end{array}$ & 7 (textos: $03,06,13,14,16,27,30)$ \\
\hline Sugiere que tome apuntes, que ponga atención & 5 (textos: $05,10,13,16,21)$ \\
\hline $\begin{array}{l}\text { NIVEL: EL JUEZ OPINA, EVALÚA } \\
\text { Y APORTA INFORMACIÓN } \\
\text { Señala lo que no pudo hacer el autor } \\
\end{array}$ & 6 (textos: $12,13,19,30,34,35)$ \\
\hline $\begin{array}{l}\text { Justifica los errores, el tipo de escritura del autor, } \\
\text { expresión de aliento para mejorar }\end{array}$ & 5 (textos: $4,22,25,30,33$ ) \\
\hline Elogia la redacción & $4($ textos $01,09,19,21)$ \\
\hline $\begin{array}{l}\text { Aporta información o explica al autor } \\
\text { sobre el tema o sobre la sugerencia }\end{array}$ & 3 (textos: $13,16,17$ ) \\
\hline
\end{tabular}




\section{Anexo 12}

Tipo de modificaciones en la segunda versión

\begin{tabular}{|c|c|}
\hline Sobre el tipo de decisiones para modificar la segunda versión & Apariciones en los 36 textos \\
\hline $\begin{array}{l}\text { NIVEL: CONTENIDOS Y COMENTARIOS } \\
\text { Incorpora información sobre la clase }\end{array}$ & $\begin{array}{l}15 \text { (textos: } 01,05,09,13,14,17,18,20,27,28,29,24, \\
32,33,34)\end{array}$ \\
\hline Elimina información o reduce el texto & $\begin{array}{l}14 \text { (textos: } 01,03,04,05,07,08,12,15,17,21,24,25, \\
26,30)\end{array}$ \\
\hline Copia la mayor parte de la primera versión & $\begin{array}{l}13 \text { (textos: } 01,03,04,05,11,13,18,21,22,24,28,31 \\
34 \text { ) }\end{array}$ \\
\hline Parafrasea pasajes de su primera versión & $12($ textos $09,12,14,15,19,20,25,26,27,29,32,33)$ \\
\hline $\begin{array}{l}\text { Modifica completamente la información } \\
\text { (versión totalmente distinta) }\end{array}$ & 6 (textos: $08,15,16,23,26,30)$ \\
\hline Incorpora comentario sobre lo aprendido & 4 (textos: $02,09,10,20)$ \\
\hline $\begin{array}{l}\text { NIVEL: ESTRUCTURA INTERNA PÁRRAFOS } \\
\text { Modifica estructura, organización }\end{array}$ & 11 (textos: $02,12,14,15,17,19,20,25,26,27,30$ ) \\
\hline Emplea párrafos como unidades de bloques temáticos & 9 (textos.: $02,03,06,15,19,20,27,33,35$ ) \\
\hline Mejora la estructura, organización & 7 (textos: $02,15,17,19,20,27,35$ ) \\
\hline $\begin{array}{l}\text { NIVEL: COHESIÓN Y SELECCIÓN LÉXICA } \\
\text { Procura mejorar sus selecciones léxicas }\end{array}$ & 8 (textos :07, 09, 12, 15, 17, 21, 33, 36) \\
\hline $\begin{array}{l}\text { Incorpora conectores o elementos de } \\
\text { transición textual entre ideas y párrafos }\end{array}$ & 5 (textos: $02,06,17,26,33$ ) \\
\hline Corrige problemas gramaticales & 4 (textos: $07,09,12,15$ ) \\
\hline $\begin{array}{l}\text { NIVEL GRÁFICO DE LAS PALABRAS } \\
\text { Mejora caligrafía }\end{array}$ & 6 (textos: $19,21,22,29,33,34)$ \\
\hline Mejora puntuación, ortografía & 3 (textos: $15,19,21)$ \\
\hline \begin{tabular}{|l|} 
REACCIÓN ANTE LOS COMENTARIOS \\
Responde al comentario del juez \\
\end{tabular} & 4 (textos: $11,16,19,23)$ \\
\hline Hace cambios que no sugirió el juez y que mejoran su texto & $\begin{array}{l}13 \text { (textos: } 02,06,07,09,11,12,15,17,20,26,27,30, \\
33 \text { ) }\end{array}$ \\
\hline
\end{tabular}




\section{Anexo 13}

Transiciones temáticas primero como autor y luego como juez Nomenclatura empleada

rf: Recursos formales: constitutivos de textualización (coherencia y cohesión)

contextual: Regulación contextual de la escritura académica Identidad: Identidad, impacto, significado de escribir pi: Prácticas e interacción en torno a la escritura gram ind vs esp: Escritura y gramática indígena versus español

\section{Grupo 1: Oxchuc}

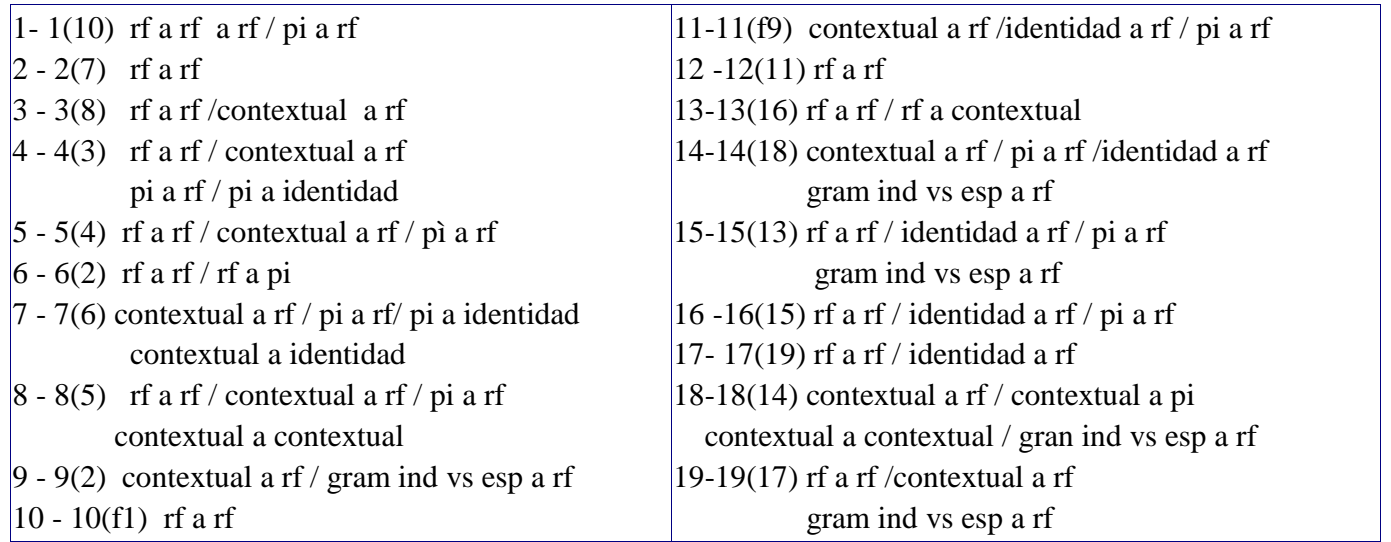

El seguimiento como autor y luego como juez en este grupo nos permite apreciar que en el total de ocurrencias aquí no predomina la temática de los recursos constitutivos, principalmente, los formales. Las ocurrencias de autores que inician con recursos constitutivos y la regulación contextual es el mismo (14 en cada caso), y destacan las transiciones a las temáticas de identidad, impacto, significado de escribir, las prácticas e interacción en torno a la escritura y 5 de las 12 apariciones temáticas sobre la gramática indígena en contraposición con el uso del español. Considero que esa variedad temática corresponde, en general, a un tipo de reflexividad de mayor complejidad, puesto que al poner en consideración distintos aspectos sobre la escritura académica, los alumnos manifiestan evidencias diversas de aspectos reflexivos.

\section{Grupo 2: San Cristóbal de las Casas}

\begin{tabular}{|c|c|}
\hline $\begin{array}{l}\text { 20- 20(28) rf a rf / rf a contextual } \\
\text { 21- 21(30) rf a rf / identidad a rf / pi vs esp a rf } \\
\text { 22- 22(31) rf a rf / pi a rf } \\
\text { 23- 23(24) rf arf } \\
\text { 24-24(23) rf a rf } \\
\text { 25- 25(32) rf a rf /rf a pi/ pi a rf /pi a pi } \\
\text { 26- 26(27) rf a rf / pi a rf } \\
\text { 27- 27(26) rf a rf / contextual a rf }\end{array}$ & $\begin{array}{l}28-28(29) \mathrm{rf} \text { a rf / gran ind vs esp a rf } \\
29-29(20) \mathrm{rf} \text { a rf / contextual a rf } \\
30-30(21) \mathrm{rf} \text { a rf / rf a pi } \\
31-31(22) \mathrm{rf} \text { a rf } \\
32-32(\mathrm{c} 1) \mathrm{rf} \text { a rf / rf a pi } \\
33-33(\mathrm{c} 2) \mathrm{rf} \text { a rf / pi a rf } \\
\text { c1- c1(25) rf a rf / rf a contextual } \\
\quad \text { pi a contextual / pi a identidad } \\
\text { c2 -c2(33) rf a rf }\end{array}$ \\
\hline
\end{tabular}

En contraste con el grupo anterior, en este caso es notable el predominio de la temática sobre aspectos constitutivos, principalmente formales, primero como autor y luego como juez. En todos los casos en que existen transiciones los alumnos vuelven a tomar esta misma temática en algún momento dado. 
Grupo 3: San Cristóbal de las Casas

34 -34(43) identidad a rf /pi a rf

35-35(36) rf a rf / pi a rf / contextual a rf $36-36(35)$ pi a rf / rf a rf / gram ind vs esp a rf

37-37(38) $\mathrm{rf}$ a rf /rf a contextual/contextual a rf identidad a rf / pi a rf / identidad a contextual identidad a identidad / pi a contextual

38- 38(37) pi a identidad / contextual a identidad contextual a rf

39- 39(40) $\mathrm{rf}$ a rf /contextual a rf /

gram ind vs esp a rf

40 - 40(39) rf a rf / pi a rf

41-41(42) $\mathrm{rf}$ a rf / pi a rf / gram ind vs esp a rf contextual a rf

$42-42(41)$ identidad a rf / pi a rf gram ind vs esp a rf / contextual a rf

\begin{tabular}{|l|}
43 -43(34) rf a rf /contextual a rf / pi a rf \\
gram ind vs esp a rf \\
$44-44(51)$ contextual a juez / ausente. Cancelado \\
\hline $45-45(49)$ contextual a juez / ausente. Cancelado \\
$46-46(48)$ contextual a juez / ausente. Cancelado \\
\hline $47-47(\mathrm{c} 3)$ gramática ind vs esp / a juez ausente. \\
Cancelado \\
48 - 48(46) rf a rf / pi a rf / rf a contextual / \\
pi a contextual / identidad a rf \\
$49-49(45)$ identidad a rf / pi a rf / contextual a rf \\
50 -50(47) rf a rf / identidad a rf / pi a rf \\
gram ind vs esp a rf \\
$51-51(44)$ rf a rf / rf a pi / rf a identidad \\
contextual a rf / contextual a pi / pi a identidad \\
contextual a identidad / pi a rf \\
c3 -c3(50) contextual a juez ausente. Cancelado.
\end{tabular}

En este grupo tampoco existe un predominio temático de los aspectos constitutivos, principalmente, de los formales en el seguimiento de las temáticas. En el grupo existen diversas transiciones temáticas en las que destacan las temáticas de identidad, impacto, significado de escribir y la regulación contextual de la escritura. 